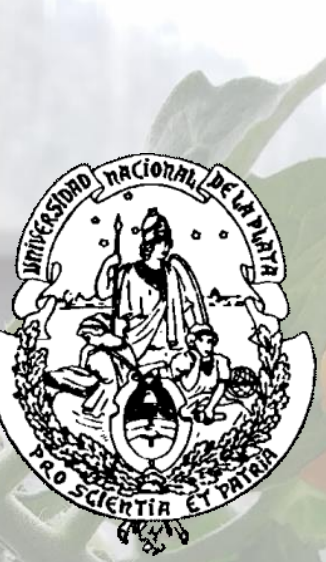

UNIVERSIDAD NACIONAL DE LA PLATA

Facultad de Ciencias Naturales y Museo

\title{
Participación del ácido ascórbico en la maduración de frutos de tomate
}

\section{Tesis presentada para optar al título de}

Doctor en Ciencias Naturales

Licenciado en Biología Matias Leonel Alegre

\section{Directores:}

Dr. Carlos Guillermo Bartoli

Dr. Gustavo Esteban Gergoff Grozeff 
El presente trabajo de tesis, para optar al grado de Doctor en Ciencias Naturales, fue realizado en el Instituto de Fisiología Vegetal de La Plata (INFIVE) CONICET- UNLP, bajo la dirección del Dr. Carlos Guillermo Bártoli y el Dr. Gustavo Esteban Gergoff Grozeff.

La Plata, Buenos Aires, 2020 
Dedico esta tesis

a mi abuela Ita

a mis padres, Leonel y Silvana

y a mis hermanos Cristian, Diego y Antonela. 


\section{AGRADECIMIENTOS}

Al Consejo Nacional de Investigaciones Científicas y Técnicas (CONICET) por el financiamiento para realizar esta tesis. El desarrollo soberano de un país depende de la inversión en ciencia y tecnología.

A la Universidad pública y gratuita, por permitirme acceder a una educación de grado y posgrado de excelente calidad.

A mis directores Carlos Bartoli y Gustavo Gergoff Grozeff, que con su experiencia y profesionalismo supieron guiarme en la realización de esta tesis.

A mi compañera de la vida Alejandra. Por ser la primera en leer y criticar, con mucho amor y objetividad científica, cada renglón de esta tesis. Por su paciencia y apoyo incondicional durante la escritura de esta tesis, en aquella temporada del aislamiento compartido.

A mi familia, Mamá, Papá, Abuela, Anto, Diego y Cristian por su esfuerzo para que yo pueda estudiar durante mis años de Facultad, por apoyarme siempre desde allá y darme aliento para continuar.

A mí amigo Seba por abrirme las puertas de su casa cuando lo necesité y por estar siempre apoyando en todas.

A los compañeros becaries e investigadores del Laboratorio $C$ por el trabajo, las ideas y los mates compartidos. Especialmente a Charlotte Steelheart y a Inti Ganganelli por su ayuda en la mesada, en el invernáculo y por los buenos momentos compartidos en cursos y congresos.

A los compañeros becaries e investigadores del Laboratorio de postcosecha de frutas y hortalizas por permitirme usar varios de sus equipos y por brindarme un montón de ayuda, protocolos y responder mil preguntas siempre con la mejor predisposición.

Al Dr. Hernan Rosli y la Dra. Marina Pombo por su asesoramiento en cuestiones de biología molecular.

Al Dr. Eduardo Tambussi por su asesoramiento en cuanto a las mediciones de fotosíntesis y funcionamiento del IRGA.

A la Dra. María Lujan Maydup por facilitarme la cámara infrarroja y ayudarme a realizar las mediciones de temperatura foliar.

A los compañeros CPA Santiago Martínez, Mauro Bartolozzi y José Vera Bahima por su gran ayuda con el trabajo pesado de muestreo y mantenimiento de los ensayos. Gracias también a Mariela Bayardo por enseñarme las técnicas para realizar los análisis de expresión génica.

Al equipo de pesca del INFIVE, Diego Fanello, Santiago Martínez y Mauro Perini, por esas gloriosas salidas de pesca. Un método infalible para acomodar las ideas después de largos días de trabajo en el laboratorio.

Gracias también a todos y cada uno de los integrantes del INFIVE. Siempre dispuestos a dar una mano y hacer del instituto un lugar tan agradable para trabajar, sentí eso el primer día y lo sigo sintiendo luego de 5 años. 


\section{INDICE}

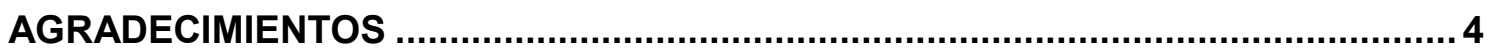

INDICE

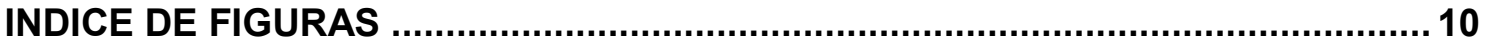

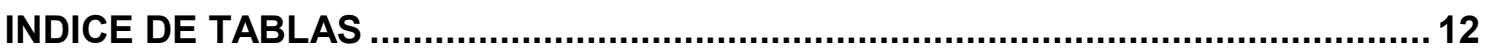

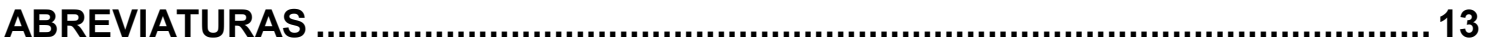

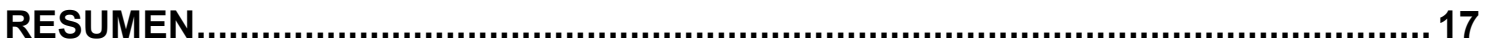

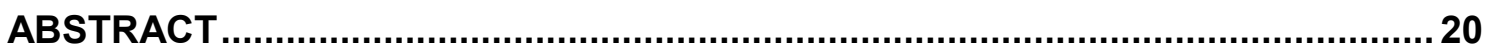

INTRODUCCIÓN GENERAL............................................................................ 23

Importancia del tomate como fuente de vitamina C .........................................24

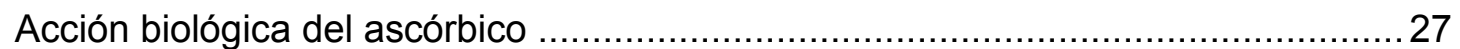

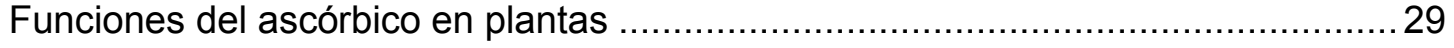

La síntesis de ácido ascórbico en plantas ................................................... 32

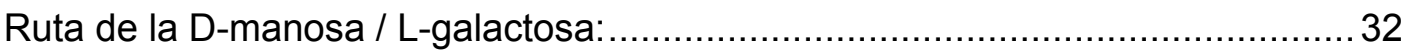

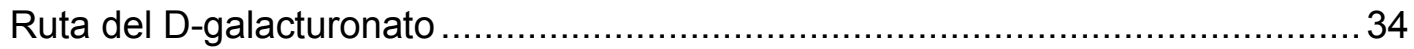

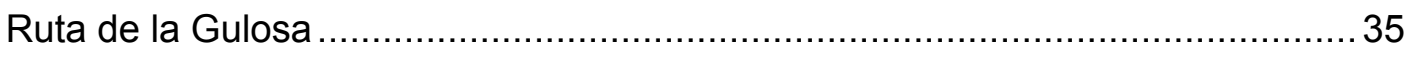

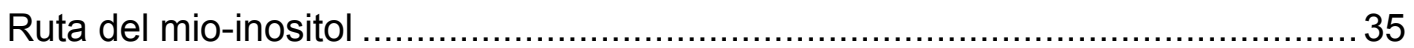

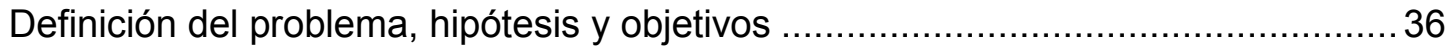

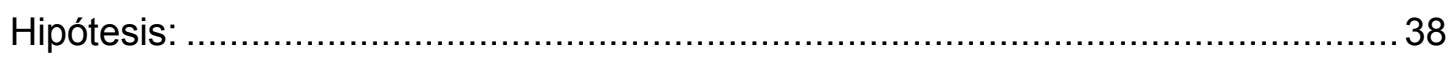

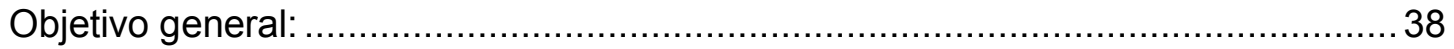

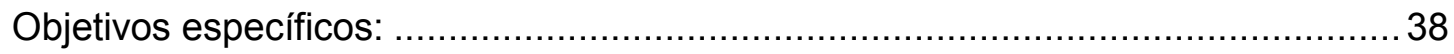

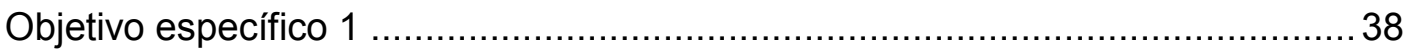

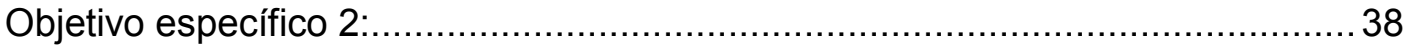

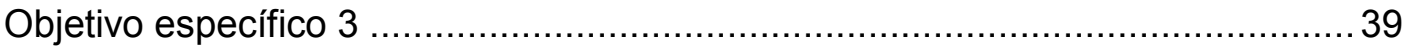

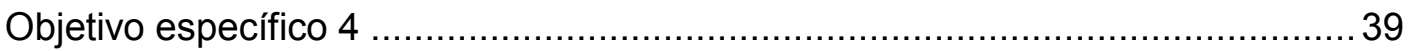

CAPÍTULO I

Caracterización de plantas de tomate mutantes deficientes en GDP-L-galactosa fosforilasa: Fenología y parámetros de crecimiento......................................... 41

1.1 Introducción: 


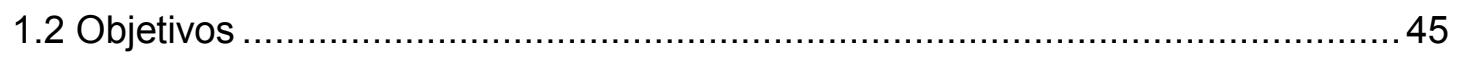

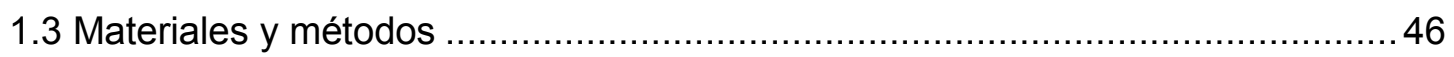

1.3.1 Material vegetal: Características genéticas de los mutantes slggp1 .....46

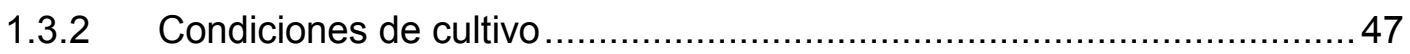

1.3.3 Determinación de los contenidos de ácido ascórbico y dehidroascórbico 50

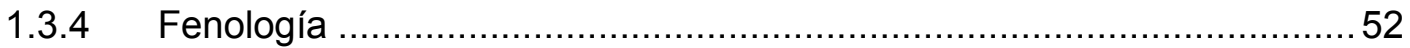

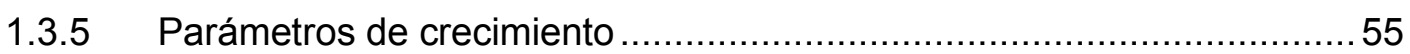

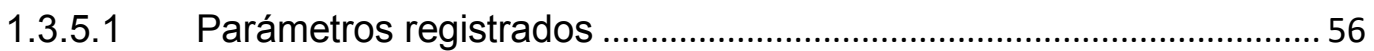

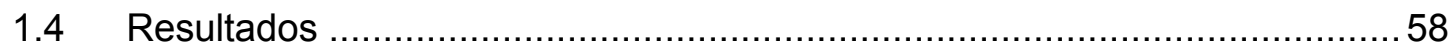

1.4.1 Contenido de ácido ascórbico en hojas, raíz, flores y frutos en distintos

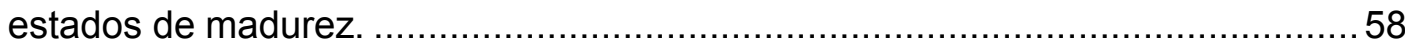

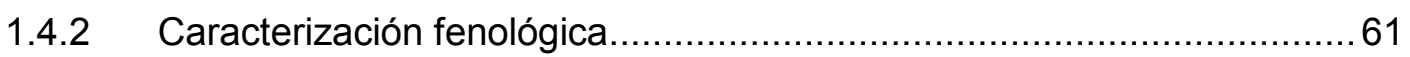

1.4.3 Parámetros de crecimiento durante el desarrollo ................................63

1.4.3.1 Peso de los distintos órganos y área foliar ....................................... 63

1.4.3.2 Productividad de mutantes deficientes en GDP-L-Galactosa fosforilasa 68

1.5 Discusión

\section{CAPÍTULO II}

"Efectos de la deficiencia en GDP-L-galactosa fosforilasa y la deficiencia de

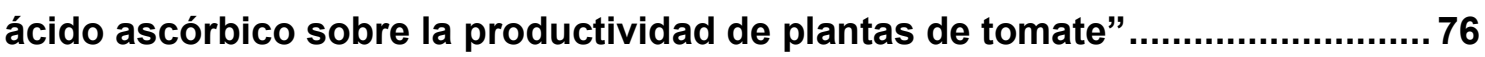

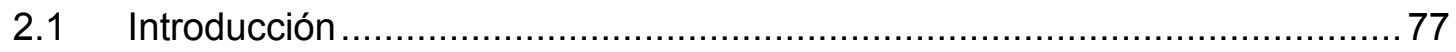

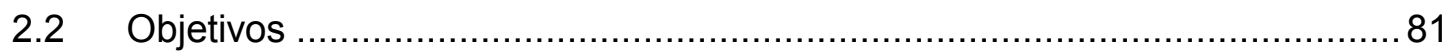

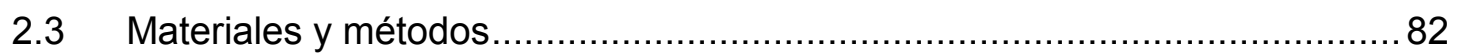

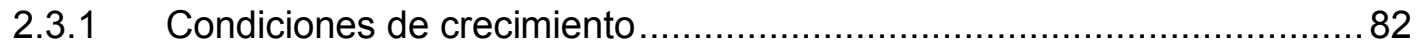

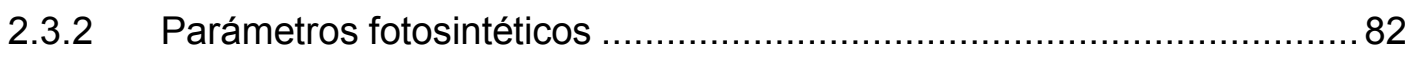

2.3.3 Diseño experimental ensayo fuente destino ….................................. 84

2.3.4 Ensayo de restitución de los niveles de ascórbico .............................. 86

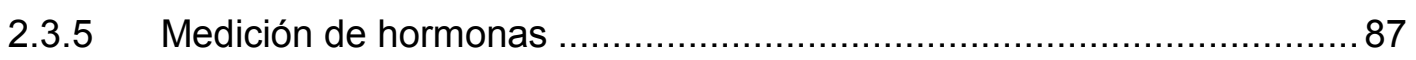

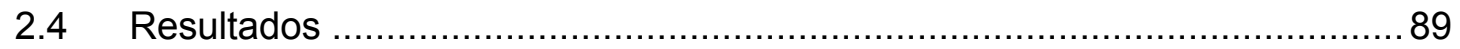

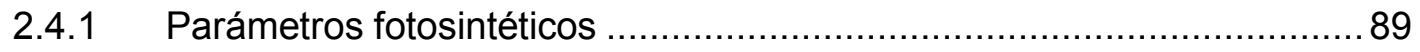


2.4.2 Efecto de la manipulación de las relaciones fuente-destino en el

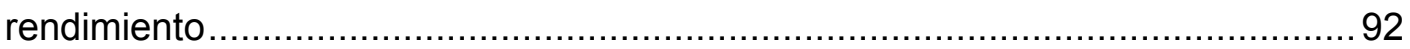

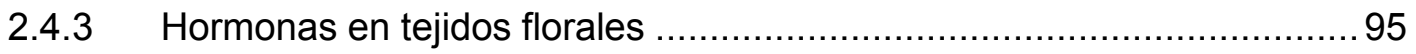

2.4.4 Restitución de los niveles de ácido ascórbico .......................................96

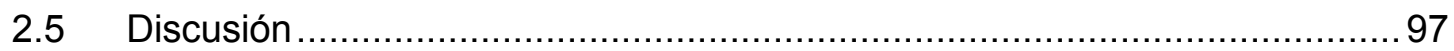

\section{CAPÍTULO III}

"Efecto de la deficiencia en GDP-L-galactosa fosforilasa en la maduración en planta y postcosecha de frutos de tomate." ..................................................... 103

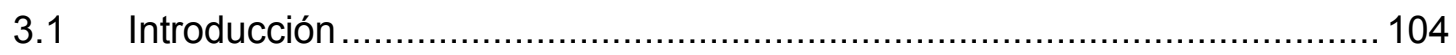

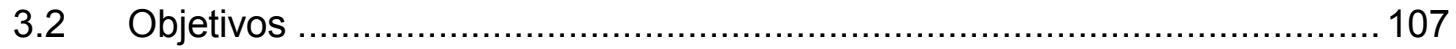

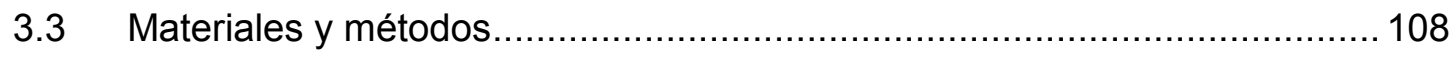

3.3.1 Cuantificación del color superficial ................................................. 108

3.3.2 Determinación de la actividad respiratoria ........................................ 109

3.3.3 Determinación de la tasa de producción de etileno............................110

3.3.4 Determinación de la firmeza .......................................................... 110

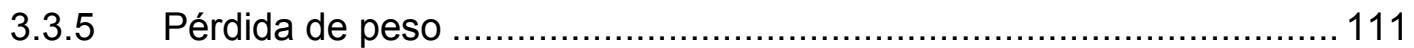

3.3.6 Determinación de sólidos solubles totales ..................................... 111

3.3.7 Ph y acidez total titulable ......................................................... 112

3.3.8 Determinación de azúcares ..................................................... 112

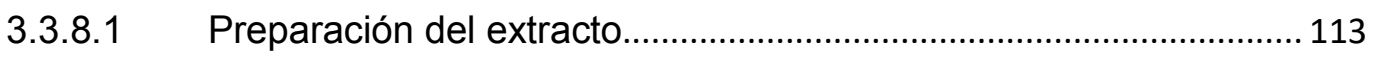

3.3.8.2 Determinación de azúcares totales ............................................... 113

3.3.8.3 Determinación de azúcares reductores ........................................... 113

3.3.9 Ensayo de almacenamiento postcosecha de tomates en estado verde maduro 114

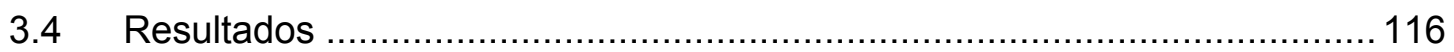

3.4.1 Maduración en planta de frutos deficientes en GPP-L-Galactosa

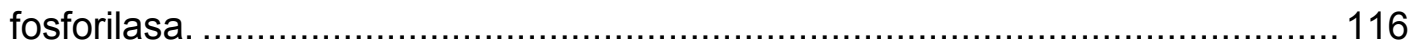

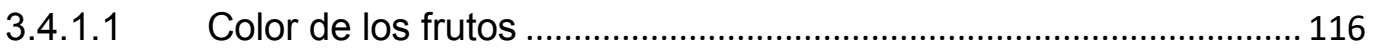

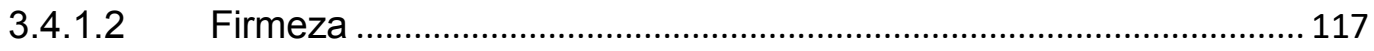

3.4.1.3 Producción de etileno en frutos..................................................... 117

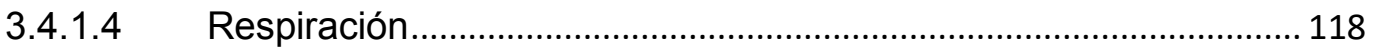


3.4.1.5 Parámetros clásicos de maduración

3.4.1.6 Azúcares reductores y totales

3.4.2 Maduración postcosecha de frutos deficientes en GPP-L-Galactosa fosforilasa.

3.4.2.1 Cambio de color a lo largo del almacenamiento .............................. 121

3.4.2.2 Cambio de la firmeza a lo largo del almacenamiento...................... 123

3.4.2.3 Porcentaje de pérdida de peso a lo largo del almacenamiento ..... 125

3.4.2.4 Cambio en el contenido de sólidos solubles a lo largo del almacenamiento

\section{CAPÍTULO IV}

Expresión de genes de enzimas clave en la vía de síntesis de ácido ascórbico y de receptores de etileno en plantas deficientes en GDP-L-galactosa fosforilasa 1

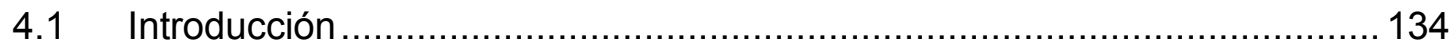

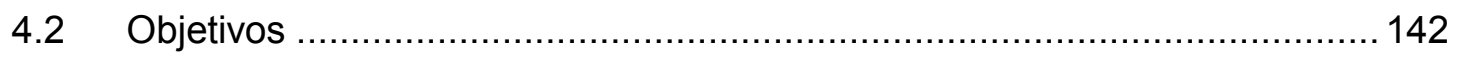

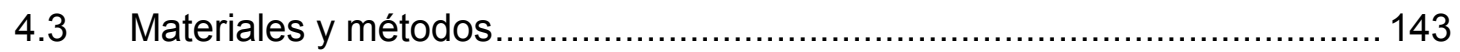

4.3.1 Extracción de RNA de hojas ...................................................... 143

4.3.2 Extracción de RNA de frutos................................................... 145

4.3.4 Síntesis de ADNc .................................................................. 146

4.3.5 Análisis de expresión de genes por RT-qPCR .............................. 147

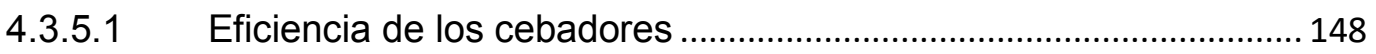

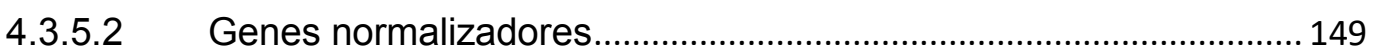

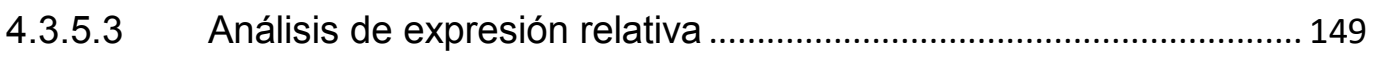

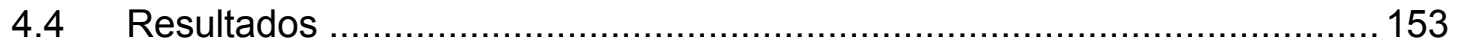

4.4.1 Expresión génica relativa en hojas ............................................... 153

4.4.1.1 Expresión relativa de genes que codifican enzimas de la vía de síntesis de ascórbico en hoja.

4.4.1.2 Expresión relativa de genes que codifican enzimas de la vía de síntesis y degradación de componentes de pared celular en hoja.

4.4.1.3 Expresión relativa de genes que codifican enzimas de las rutas del reciclado del ácido ascórbico en hoja.

4.4.1.4 Expresión relativa de genes que codifican receptores de etileno en hoja. 
4.4.2 Expresión génica relativa en frutos

4.4.2.1 Expresión de genes que codifican enzimas de la vía de síntesis de ácido ascórbico en frutos.

4.4.2.2 Expresión de enzimas que participan en vías de síntesis y degradación de pectinas .

4.4.2.3 Expresión génica relativa de enzimas que participan del reciclado del ácido ascórbico...

4.4.2.4 Expresión génica relativa de receptores de etileno en frutos......... 166

4.5 Discusión 168

\section{Capítulo V}

Conclusiones generales y perspectivas a futuro 176

Conclusiones generales 177

Perspectivas futuras. 179

Referencias 180 


\section{INDICE DE FIGURAS}

\section{INTRODUCCIÓN}

Figura 1-Ciclo ascorbato-glutatión 29

Figura 2-Rutas de biosíntesis de ácido ascórbico en plantas superiores.

\section{CAPÍTULO I}

Figura 1.1-Secuencia correspondiente al gen SIGGP1 silvestre (Solyc06g073320) .... 47

Figura 1.2-Secuencia proteica de la enzima GDP-L-galactosa fosforilasa..................... 47

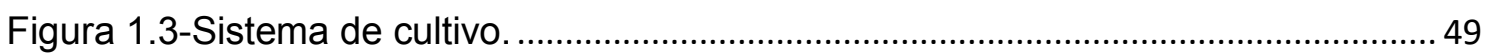

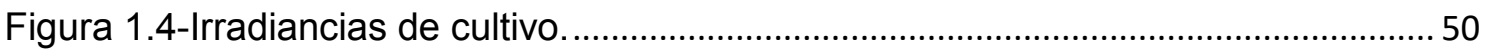

Figura 1.5-Temperatura y humedad relativa de cultivo.................................................. 50

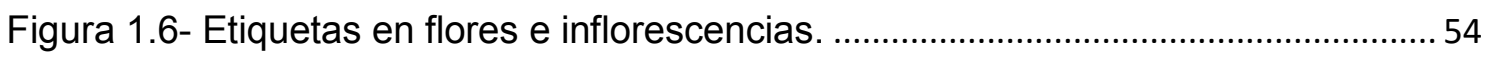

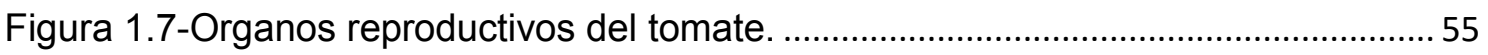

Figura 1.8-Estados fenológicos elegidos para la realización de muestreos y estudio del

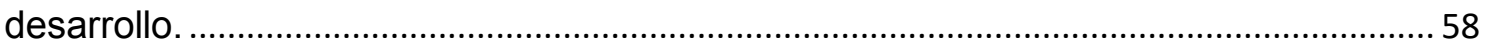

Figura 1.9-Contenido de ácido ascórbico en distintos órganos de mutantes slggp1

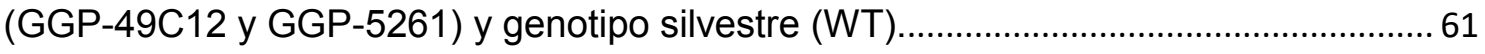

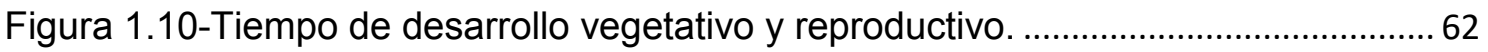
Figura 1.11-Tiempo en días requerido por cada genotipo para pasar de un estado de

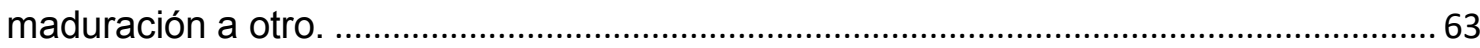

Figura 1.12 Peso fresco total y peso fresco vegetativo a lo largo del desarrollo............64 64

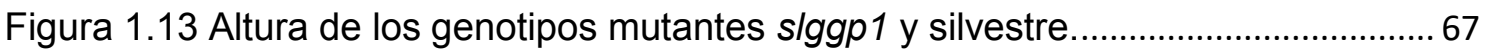

Figura 1.14-Distribución de la cantidad de frutos en cada estado de maduración.........69

\section{CAPITULO II}

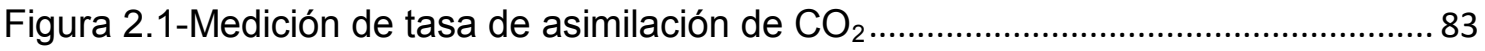

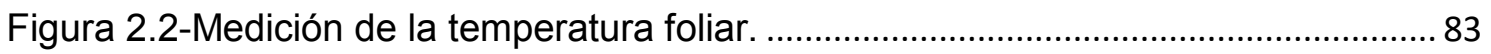

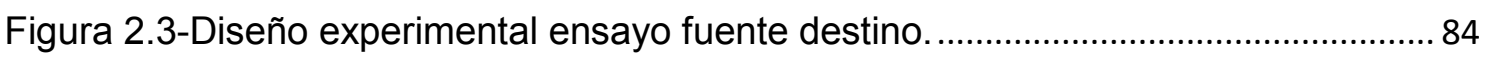

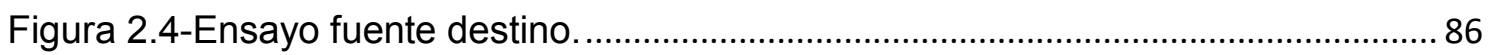

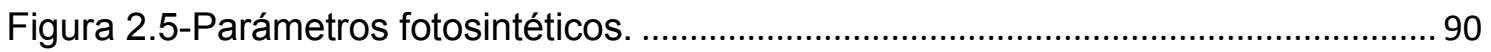

Figura 2.6-Mediciónes de fluorescencia modulada de la clorofila................................... 91

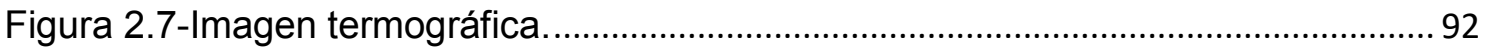

Figura 2.8-Análisis de componentes principales para parámetros de desarrollo en tomate.

\section{CAPITULO III}

Figura 3. 1-Rango de color correspondiente al estadio de maduración. 108

Figura 3. 2-Representación esquemática de la variación del ángulo de matiz o tono ( $\left.{ }^{\circ} \mathrm{HUE}\right)$.

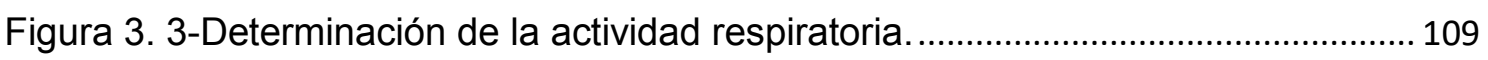

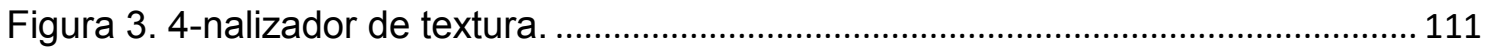

Figura 3. 5-Frutos en estadio VM utilizados en el ensayo de maduración en almacenamiento postcosecha. 
Figura 3. 6-Representación esquemática del tratamiento con 1-metilciclopropeno (1MCP).

Figura 3. 7-Representación esquemática de los muestreos realizados durante el periodo de almacenamiento postcosecha.

Figura 3. 8-Angulo de HUE

Figura 3. 9-Firmeza de los frutos madurados en planta. .................................................. 117

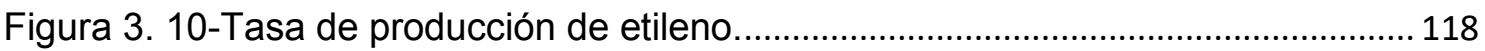

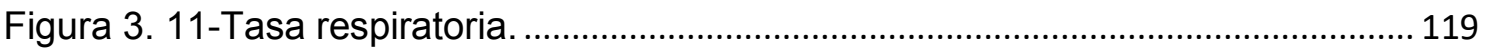

Figura 3. 12-Contenido de azúcares totales y reductores en frutos madurados en

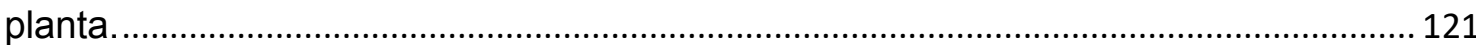

Figura 3. 13-Ángulo de HUE de frutos en almacenamiento postcosecha....................... 122

Figura 3. 14-Firmeza de frutos madurados en almacenamiento postcosecha.............. 123

Figura 3. 15-Ablandamiento durante el almacenamiento postcosecha.......................... 124

Figura 3. 16-Porcentaje de pérdida de peso en almacenamiento postcosecha. .......... 126

Figura 3. 17-Contenido de sólidos solubles en frutos madurados en almacenamiento postcosecha.

\section{CAPITULO 4}

Figura 4. 1-Rutas metabólicas y enzimas evaluadas mediante expresión génica. ..... 152

Figura 4. 2-Análisis de la expresión de los genes SIGMP, SIGME, SIGGP1, SIGGP2,

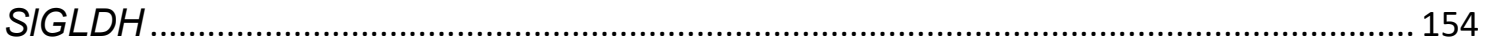

Figura 4. 3-Análisis de la expresión de los genes SIGMD, SIAKR …............................. 155

Figura 4. 4-Análisis de la expresión de los genes SIMDHAR1, SIMDHAR3.................. 156

Figura 4. 5-Análisis de la expresión de los genes SIETR2 y SIETR3 ............................. 157

Figura 4. 6-Análisis de la expresión de los genes SIGMP, SIGME ............................... 159

Figura 4. 7-Análisis de la expresión de los genes SIGGP1, SIGGP2, SIGLDH........... 161

Figura 4. 8-Análisis de la expresión de los genes SIGMD, SIAKR ................................. 163

Figura 4. 9-Análisis de la expresión de los genes SIMDHAR1, SIMDHAR3 y SIDHAR1.

Figura 4. 10-Análisis de la expresión de los genes SIETR2, SIETR3. 167 


\section{INDICE DE TABLAS}

\section{CAPÍTULO I}

Tabla 1. 1 Parámetros de crecimiento de los genotipos mutantes slggp1 y silvestre ... 66

Tabla 1. 2-Productividad de los genotipos mutantes slggp1 y silvestre. .68

\section{CAPITULO II}

Tabla 2. 1-Ensayo fuente-destino. 94

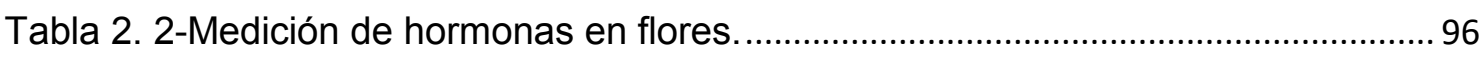

Tabla 2. 3-Ensayo de suplementación exógena con ácido ascórbico .................................96

\section{CAPÍTULO III}

Tabla 3. 1-Parámetros de maduración.

Tabla 3. 2-Tasa de ablandamiento.

\section{CAPÍTULO 4}

Tabla 4. 1-Cebadores utilizados en el análisis de expresión génica tanto en hoja como en fruto de tomate. 151 


\section{ABREVIATURAS}

\begin{tabular}{|c|c|}
\hline A & adenina \\
\hline ABA & ácido abscísico. \\
\hline ACC & 1-aminociclopropano-1-carboxilato \\
\hline ADN & ácido desoxiribonucleico \\
\hline ADNc & ácido desoxiribonucleico complementario \\
\hline ADN-T & ADN de transeferencia \\
\hline AKR4B & aldo-ceto reductasa \\
\hline AKRs & aldo-ceto reductasas \\
\hline ALO & L-gulono-1,4-lactona oxidasa \\
\hline$A_{\max }$ & asimilación máxima \\
\hline ANOVA & análisis de la varianza \\
\hline APX & Ascorato peroxidasa \\
\hline ARN & ácido ribonucleico. \\
\hline $\mathrm{ARNi}$ & ARN de interferencia \\
\hline ARNm & ácido ribonucleico mensajero \\
\hline AsA & ácido ascórbico \\
\hline ATG & codón de inicio \\
\hline ATP & adenosin trifosfato \\
\hline ATT & acidez total titulable \\
\hline $\mathrm{BRCH}$ & escala fenológica. Biologische Bundesanstalt, Bundessortenamt y \\
\hline ВВСН & CHemische \\
\hline C & citosina \\
\hline $\mathrm{CP} 1$ & componente principal 1 \\
\hline $\mathrm{CP} 2$ & componente principal 2 \\
\hline CTR1 & receptor de etileno. Del inglés "Constitutive triple response" \\
\hline cyt1 & mutantes de Arabidopsis deficientes en GDP-D-manosa pirofosforilasa \\
\hline DEPC & pirocarbonato de dietilo \\
\hline $\mathrm{DHA}$ & ácido dehidroascorbico \\
\hline DHAR & dehidro ascorbato reductasa. \\
\hline DPS & días posteriores a la siembra \\
\hline DTT & ditritiotreitol \\
\hline EIL & factor de transcripción. Del inglés "ethylene insensitive 3-like" \\
\hline EIN $1 / 2 / 3$ & factor de transcripción. Del inglés "Ethylene insensitive" \\
\hline EMS & etil metil sulfonato. \\
\hline ETR & tasa de transporte electrónico \\
\hline
\end{tabular}




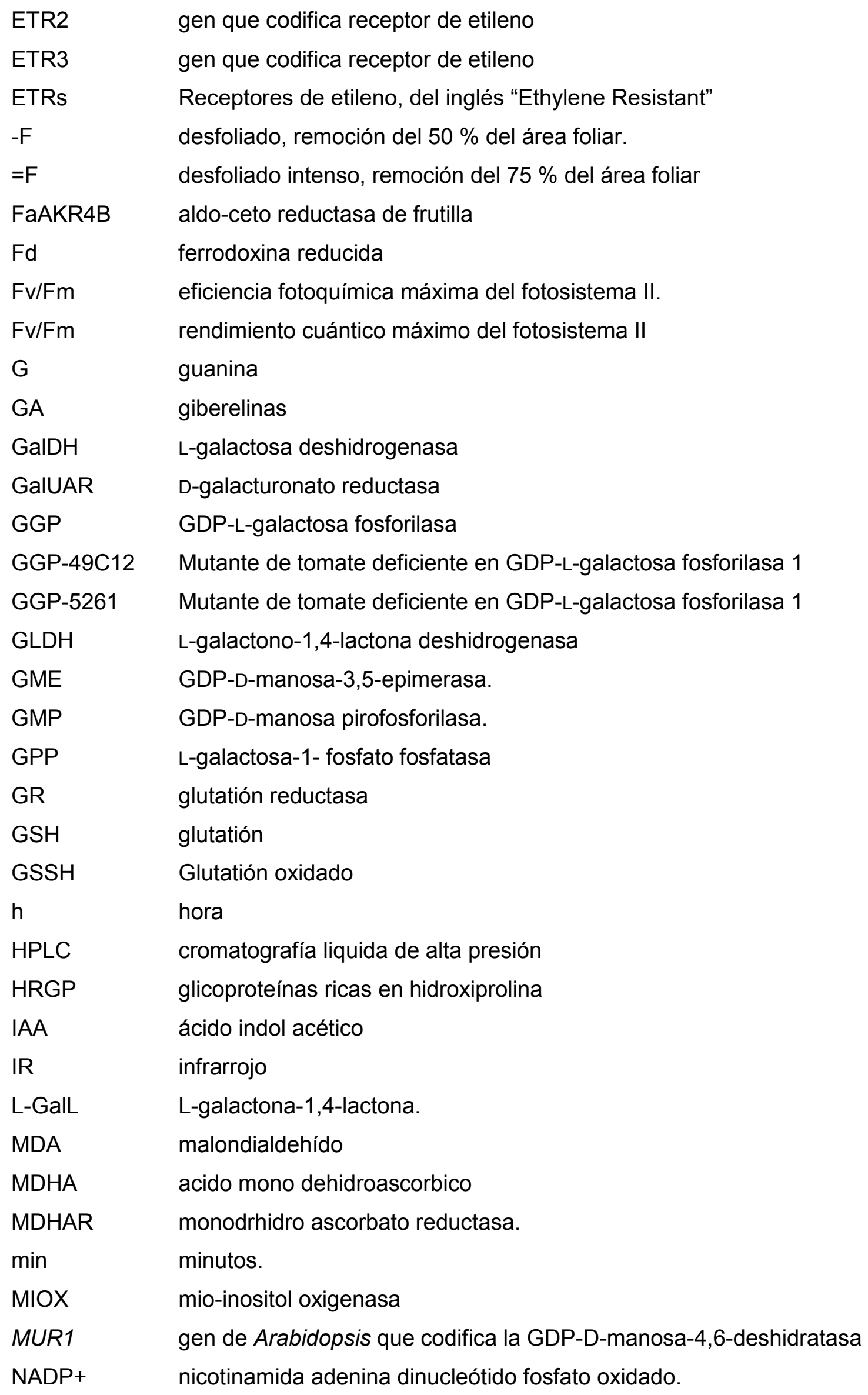




\begin{tabular}{|c|c|}
\hline $\mathrm{NADPH}$ & nicotinamida adenina dinucleótido fosfato reducido. \\
\hline NPQ & quenching no fotoquímico \\
\hline $\mathrm{O} 2$ & oxigeno \\
\hline O2•- & oxigeno singulete \\
\hline$P$ & pintón \\
\hline PF & peso fresco \\
\hline PF & peso fresco \\
\hline PGI & fosfoglucosa isomerasa. \\
\hline PMI & fosfomanosa isomerasa. \\
\hline PMM & fosfomanomutasa. \\
\hline$P n$ & tasa fotosintética neta \\
\hline$P_{\text {pot }}$ & fotosíntesis potencial \\
\hline PS & peso seco \\
\hline PSII & fotosistema II \\
\hline $\mathrm{R}$ & rojo \\
\hline ROS & especies reactivas del oxígeno \\
\hline RuBisCO & ribulosa-1,5-bis-fosfato-carboxilasa-oxigenasa \\
\hline Seg & segundos \\
\hline SIAKR & gen de tomate que codifica la enzima Aldo-ceto reductasa de tomate \\
\hline SIETR1-6 & genes de tomate que codifican receptores de etileno en tomate \\
\hline SIGALDH & $\begin{array}{l}\text { gen de tomate que codifica la enzima L-galactona-1,4-lactona } \\
\text { deshidrogenasa }\end{array}$ \\
\hline SIGGP1 & gen de tomate que codifica la isoenzima GDP-L-galactosa fosforilasa 1. \\
\hline slggp1 & $\begin{array}{l}\text { mutantes GGP-5261 y GGP-49C12 deficientes en GDP-L-galactosa } \\
\text { fosforilasa } 1\end{array}$ \\
\hline SIGGP1 & gen de tomate que codifica la enzima GDP-L-galactosa fosforilasa 1 \\
\hline SIGGP2 & gen de tomate que codifica la isoenzima GDP-L-galactosa fosforilasa 1. \\
\hline SIGGP2 & gen de tomate que codifica la enzima GDP-L-galactosa fosforilasa 2 \\
\hline SIGMD & gen de tomate que codifica la enzima GDP-D-manosa-4,6-deshidratasa \\
\hline SIGME & gen de tomate que codifica la enzima GDP-D-manosa-3',5'-epimerasa \\
\hline SIGMP & gen de tomate que codifica la enzima GDP-D-manosa pirofosforilasa \\
\hline SIMDHAR & gen de tomate que codifica la enzima monodehidro ascorbato reductasa \\
\hline SST & sólidos solubles totales \\
\hline $\mathrm{T}$ & timina \\
\hline TFA & trifluoracetico \\
\hline TGA & codón de terminación \\
\hline
\end{tabular}




\begin{tabular}{|c|c|}
\hline TILLING & Targeting Induced Local Lesions IN Genomes \\
\hline uORF & fragmento de lectura abierto. \\
\hline uORF & $\begin{array}{l}\text { marco abierto de lectura en la región aguas arriba del gen del inglés } \\
\text { "upstrem Open Reading frame" }\end{array}$ \\
\hline UTR 5' & región no traducida hacia el extremo 5'. Del inglés "untranslated región" \\
\hline UV & ultravioleta \\
\hline VI & verde inmaduro \\
\hline VM & verde maduro \\
\hline vtc & $\begin{array}{l}\text { mutante de Arabidopsis deficiente en ácido ascórbico (vitamin C } \\
\text { deficient). }\end{array}$ \\
\hline vtc 2 & mutante de Arabidopsis deficiente en GDP-L-galactosa fosforilasa 1. \\
\hline vtc1-1 & mutante de Arabidopsis deficiente en GDP-D-manosa pirofosforilasa \\
\hline vtc1-2 & mutante de Arabidopsis deficiente en GDP-D-manosa pirofosforilasa \\
\hline VTC2 & $\begin{array}{l}\text { gen de Arabidopsis que codifica la isoenzima GDP-L-galactosa } \\
\text { fosforilasa } 1 .\end{array}$ \\
\hline vtc2-1 & mutante de Arabidopsis deficiente en GDP-L-galactosa fosforilasa 1. \\
\hline vtc2-vtc5 & $\begin{array}{l}\text { doble mutante de Arabidopsis deficiente en las dos isenzimas GDP-L- } \\
\text { galactosa fosforilasa }\end{array}$ \\
\hline VTC5 & $\begin{array}{l}\text { gen de Arabidopsis thaliana que codifica la isoenzima GDP-L-galactosa } \\
\text { fosforilasa } 2 \text {. }\end{array}$ \\
\hline vtc5 & $\begin{array}{l}\text { mutante de Arabidopsis deficiente en la isoenzima GDP-L-galactosa } \\
\text { fosforilasa } 2 .\end{array}$ \\
\hline$W T$ & genotipo silvestre \\
\hline (C) & control, cuatro inflorescencias por planta sin desfrutado. \\
\hline $1 \mathrm{~F}$ & 1 fruto por inflorescencia y 4 inflorescencias por planta. \\
\hline $2 \mathrm{~F}$ & 2 frutos por inflorescencia y 4 inflorescencias por planta. \\
\hline 1-MCP & 1-metilciclopropeno \\
\hline
\end{tabular}




\section{RESUMEN}

El ácido ascórbico es un compuesto muy abundante en las plantas. Las funciones de este metabolito son muy diversas y se puede destacar su función como antioxidante, su participación en la optimización de la fotosíntesis, como así también en procesos de crecimiento y división celular. También cumple un papel importante como cofactor de enzimas dioxigenasas que participan de la síntesis de polisacáridos y de la síntesis de hormonas como giberelinas, etileno y ácido abscísico.

La principal vía de síntesis de ácido ascórbico en plantas es la ruta de la galactosa o ruta de Smirnoff-Wheeler. En esta ruta, la enzima GDP-L-galactosa fosforilasa es la primera enzima exclusivamente implicada en la síntesis de ácido ascórbico y un punto clave de regulación en la síntesis de este metabolito. El uso de mutantes de Arabidopsis deficientes en la actividad de distintas enzimas que participan en la síntesis de ácido ascórbico ha permitido el estudio de las funciones de este metabolito principalmente en hojas. La obtención reciente de dos líneas independientes (slggp1) de plantas de tomate de la variedad Micro-Tom, con mutaciones que generan la pérdida de función de la enzima GDP-L-galactosa fosforilasa, permitió estudiar en esta tesis la participación del ácido ascórbico en la maduración de los frutos.

Se midió el contenido de ascórbico en hojas, raíces, flores y frutos. La deficiencia de esta enzima no afectó por igual el contenido de ácido ascórbico en los distintos órganos de la planta. Se observó una reducción del $65 \%$ en hojas, $55 \%$ en frutos, $48 \%$ en raíz, y $45 \%$ en flores, del contenido de ascórbico con respecto al genotipo silvestre. Sin embargo, no se observó un efecto de la deficiencia de esta enzima sobre el balance redox del pool de ácido ascórbico en ningún órgano.

Se realizó una caracterización fenológica y morfológica de las plantas mutantes. Se observó que la deficiencia en GDP-L-galactosa fosforilasa produce alteraciones morfológicas, como una mayor longitud del tallo; y alteraciones en el desarrollo, como un retraso en la floración y en el tiempo de maduración de los frutos en planta. 
Además, los mutantes slggp1 presentaron una disminución del cuajado de frutos y un menor rendimiento que la línea silvestre. Por otro lado, se observó un mayor tamaño de los frutos en los mutantes slggp1, que aumentó en compensación a la reducción del número, pero no lo suficiente como para alcanzar el rendimiento de plantas silvestres.

También, se llevó a cabo un análisis del efecto de la deficiencia en GDP-L-galactosa fosforilasa en la actividad fotosintética. Los mutantes slggp1 presentan una reducción del $50 \%$ en la tasa de asimilación de $\mathrm{CO}_{2}$ asociada a una reducción del $65 \%$ en la conductancia estomática. La tasa fotosintética de transporte electrónico, medida por fluorescencia modulada de la clorofila y la fotosíntesis potencial, medida como producción de $\mathrm{O}_{2}$ en concentraciones saturantes de $\mathrm{CO}_{2}$ mostraron una menor reducción, 10 y 19\% respectivamente. Estos resultados sugieren que la conductancia estomática limita la fotosíntesis en las plantas mutantes.

Para determinar si la reducción de la fotosíntesis impacta en el rendimiento se realizaron experimentos con distintas relaciones fuente-destino. Los resultados obtenidos en estos ensayos indican que el suministro de asimilados no constituye un factor limitante para el rendimiento ya que la reducción de la fuente no genera un impacto sobre el porcentaje de cuajado de frutos.

Se observó que la disminución en el cuajado de frutos en los mutantes slggp1 es causada directamente por la deficiencia de ácido ascórbico, dado que esto puedo ser revertido parcialmente mediante la suplementación de este antioxidante de forma exógena.

A partir de la determinación del contenido de hormonas en flores se observó una reducción del contenido de giberelinas en los mutantes deficientes en ácido ascórbico. Esta modificación hormonal podría ser la causa de la menor eficiencia en el cuajado de frutos de los genotipos. 
Se caracterizó el efecto de la mutación durante la maduración en planta y durante la maduración en postcosecha de los frutos. Se observaron efectos de la deficiencia en GDP-L-galactosa fosforilasa en la producción de etileno, la tasa de ablandamiento y la acumulación de azúcares durante la maduración.

A partir de un análisis de expresión génica se observó que la deficiencia en GDP-Lgalactosa fosforilasa aumenta la expresión de genes cuesta arriba en la vía de síntesis de ácido ascórbico y en genes que codifican enzimas que vinculan la ruta de síntesis de ácido ascórbico con el metabolismo de pared celular. Además, se observó una mayor expresión de genes del reciclado del ácido ascórbico en los mutantes slggp1 y de la isoenzima GDP-L-galactosa fosforilasa 2, lo que podría indicar una compensación ante la deficiencia en GDP-L-galactosa fosforilasa 1. Por otro lado, se analizó la expresión de genes que codifican receptores de etileno. Se observó una mayor expresión de estos genes tanto en hojas como en frutos de los mutantes slggp1, indicando que la deficiencia de GDP-L-galactosa fosforilasa o particularmente la deficiencia de ácido ascórbico tienen un efecto tanto sobre la síntesis como sobre los mecanismos de percepción de etileno en plantas de tomate.

En conjunto estos resultados indican que las deficiencias de GDP-L-galactosa fosforilasa y de ácido ascórbico, provocan un impacto sobre el desarrollo fenológico, el proceso de cuajado y la maduración de los frutos, posiblemente a través de alteraciones hormonales. 


\section{ABSTRACT}

Ascorbate is one of the most abundant compounds in plants. The functions of this metabolite are very diverse and its most important functions are the role as an antioxidant, its participation in the optimization of photosynthesis, and its participation in growth and cell division processes. It also plays an important role as a cofactor of dioxygenase enzymes that participate in the synthesis of polysaccharides and in the synthesis of hormones such as gibberellins, ethylene and abscisic acid.

The main route of synthesis of ascorbic acid in plants is the L-galactose pathway also called Smirnoff-Wheeler pathway. In this pathway, the GDP-L-galactose phosphorylase enzyme is the first enzyme considered to be specific to ascorbate synthesis and therefore a key point in the regulation of the synthesis of this metabolite. The use of Arabidopsis mutants deficient in the activity of different enzymes that participate in the main pathway of ascorbic synthesis, has allowed the study of the functions of this metabolite mainly in leaves. The recent availability of two independent lines of tomato plants of the Micro-Tom variety, with a mutation that generates the loss of function of the GDP-L-galactose phosphorylase enabled to study in this thesis the participation of ascorbic acid in fruit ripening.

Ascorbic acid measurements were made in leaves, roots, flowers and fruits. The deficiency of this enzyme did not affect equally the content of ascorbic acid in the different organs of the plant. A reduction of the ascorbic content of $65 \%$ was observed in leaves, $55 \%$ in fruits, $48 \%$ in roots and $45 \%$ in flowers, compared with the wild genotype. However, the deficiency of this enzyme did not affect the redox state of the ascorbic pool in any of the organs examined.

A phenological and morphological characterization of the mutant plants was carried out. Morphological alterations were recorded as a result of the enzyme deficiency, such 
as a greater length of the stem, and also alterations in development such as a delay in flowering and in fruit ripening in planta. In addition, the slggp1 mutants presented a decrease in fruit set and a lower productivity compared to the wild genotype. On the other hand, a larger fruit size was observed in both slggp1 mutants, which increased in compensation for the reduction in number, but not enough to achieve the yield of wild plants.

An analysis of the effect of GDP-L-galactose phosphorylase deficiency on photosynthetic activity was performed. A reduction of $50 \%$ in the $\mathrm{CO}_{2}$ assimilation rate was observed, and this was associated with a $65 \%$ reduction in stomatal conductance. The photosynthetic rate of electron transport, measured by modulated fluorescence of chlorophyll and potential photosynthesis, measured as $\mathrm{O}_{2}$ production under saturating concentrations of $\mathrm{CO}_{2}$ showed a lower reduction, 10 and $19 \%$ respectively. These results suggest that stomatal conductance limits photosynthesis in mutant plants.

To determine if the reduction in photosynthesis has an impact in yield, experiments with different source-sink relationships were carried out. The results obtained from these experiments indicate that the supply of photoassimilates does not constitute a limiting factor for the yield since the reduction of the source does not generate an impact on the percentage of fruit set.

It was observed that the decrease in fruit set in the mutants is mainly caused by ascorbic acid deficiency since its exogenous supplementation partially reverses the decrease in fruit number.

From the measurements of the hormone contents in flowers, a lower level of gibberellins was observed in mutants deficient in ascorbic acid. This hormonal modification could be the cause of the lower efficiency in the fruit set of both mutants.

The effect of the mutation was characterized during plant maturation and during postharvest maturation of the fruits. Effects on ethylene production, softening rate, and 
accumulation of sugars during ripening were observed as a consequence of deficiency in GDP-L-galactose phosphorylase.

Gene expression analysis showed that GDP-L-galactose phosphorylase deficiency increased the expression of genes upstream in the ascorbic acid synthesis pathway and of genes encoding enzymes that link the ascorbic acid synthesis pathway with cell wall metabolism.

In addition, a higher expression of genes for the recycling of ascorbic acid was observed in the slggp1 mutants and in the GDP-L-galactose phosphorylase 2, which could indicate a compensation for the deficiency in GDP-L-galactose phosphorylase 1.

On the other hand, the expression of genes encoding ethylene receptors was analyzed. Higher expression of these genes was observed both in leaves and in fruits of the slggp1 mutants, indicating that GDP-L-galactose phosphorylase deficiency or particularly ascorbic acid deficiency may have an effect on both synthesis and perception mechanisms of ethylene in tomato plants.

Taken as a whole, these results indicate that the deficiency of GDP-L-galactose phosphorylase and of ascorbic acid causes an impact on the phenological development, the fruit setting process and the ripening of the fruits, possibly through hormonal alterations. 


\section{INTRODUCCIÓN GENERAL}


Introducción general

\section{Importancia del tomate como fuente de vitamina C}

El tomate Solanum lycopersicum, pertenece a la familia de las solanáceas junto con otras especies vegetales de importancia económica como la papa, los pimientos, la berenjena, el tabaco y las petunias. Esta especie es originaria del oeste de Sudamérica (Ecuador, Perú y Chile) donde otras especies de tomates silvestres, pertenecientes al género Solanum, aún pueden ser encontradas a lo largo de la costa, en los Andes, y en Las Islas Galápagos. Aunque se piensa que el centro de la diversidad de tomates silvestres es Perú, análisis genéticos de los cultivares más primitivos muestran que el centro de diversidad del tomate cultivado es México. Esto indica que la domesticación del tomate puede haber ocurrido en América central y que el cultivo del tomate ya existía en esa región cuando los conquistadores europeos llegaron a América, quienes distribuyeron el tomate desde América hacia Europa y otras colonias europeas durante el siglo XVI (Rick, 1991). Posteriormente en Europa se produjo el surgimiento de las variedades cultivadas que conocemos hoy en día a través de la selección de variedades en función de caracteres deseables como el tamaño de los frutos, el color, la calidad nutricional y las características arquitectónicas de las plantas.

Durante el último siglo este fruto se ha incorporado en diferentes costumbres gastronómicas alrededor del mundo, siendo consumido como fruto fresco o en una gran variedad de productos industrializados y actualmente es el fruto más consumido por la especie humana. En 2018, según datos de la Organización de las Naciones Unidas para la Alimentación y la Agricultura la producción de tomate a nivel mundial alcanzó los 182.256.458 millones de toneladas. Por este motivo y otros, que derivan en la importancia económica de este fruto, se ha invertido mucho tiempo y dinero en el estudio de esta planta. Actualmente el genoma de tomate está completamente secuenciado, existen protocolos de cultivo puestos a punto que facilitan la utilización de esta especie en experimentos científicos y sus frutos se han convertido en un 
Introducción general

modelo para el estudio de los frutos carnosos (Meissner y col., 1997). Esta gran popularidad y los grandes volúmenes de consumo per cápita lo convierten en una fuente muy importante de vitamina $\mathrm{C}$ y otros compuestos con características saludables reconocidas como licopeno, vitamina A, E, y flavonoides (Frusciante y col., 2007; Borguini y col., 2009)

Nuestra especie y otras como los conejitos de indias, primates, algunas aves, no son capaces de sintetizar ascórbico como consecuencia de una mutación que genera la inactividad de la enzima L-gulono-y-lactona oxidasa de la vía de síntesis de ácido ascórbico en animales (Burns, 1957; Nishikimi y col., 1994). Es por este motivo que estas especies necesitan incorporar ácido ascórbico (vitamina C) periódicamente en la dieta a partir de la ingesta de tejidos vegetales como frutos y hortalizas, ya que una dieta deficiente en vitamina C provoca la enfermedad conocida como escorbuto (Svirbely y Szent-Gyorgyi, 1932). Este término procede de una palabra del antiguo escandinavo, "scorbruck", que significa hinchazones ulceradas. La versión latina del término es del holandés John Echth en una publicación de 1556 , pero el cuadro de síntomas de esta enfermedad fue reconocido anteriormente por los egipcios, antiguos griegos y romanos, y fue la causa de muerte de millones de marineros en los largos viajes de barcos veleros durante el siglo XV y XVI (Baron, 2009). Diferentes teorías sobre la causa de esta enfermedad prevalecieron según la doctrina filosófica del periodo de la medicina que se considere. En 1747 James Lind realizó el primer estudio sistemático a bordo de un buque de la Marina Real Británica poniendo a prueba la hipótesis que apuntaba al déficit nutricional como causal de la enfermedad. En estos ensayos, considerados los primeros ensayos clínicos de la historia de la medicina, Lind determinó que el consumo de cítricos prevenía y curaba la enfermedad y publicó sus resultados en 1753 en su libro "Tratado sobre el Escorbuto". Recién en 1795, un año después de la muerte de Lind, la Marina Real Británica finalmente aceptó las recomendaciones de sus propios médicos y aprobó que fuera obligatorio llevar jugo de limón en todos sus barcos. Esto redujo notoriamente la muerte por escorbuto de los 
marineros. No obstante, no fue sino hasta 1907 cuando se comprobó de manera fidedigna que se trataba de una deficiencia de vitamina $C$ en la dieta, tanto de humanos como de ciertos animales (Holst y Frôlich, 1907).

En 1928 Szent-Györgyi logró aislar y cristalizar un compuesto a partir de corteza adrenal de buey así como también a partir de jugo de naranja y extracto acuoso de repollo, un compuesto al que denomino ácido hexurónico y remarcó su gran similitud de esta sustancia y la vitamina C. A partir de experimentos posteriores con conejitos de indias (Cavia porcellus) se determinó fehacientemente que el ácido hexurónico poseía propiedades antiescorbúticas y correspondía al mismo compuesto que a la vitamina C (Svirbely y Szent-Gyorgyi 1932). Posteriormente Szent-Gyorgyi envió grandes cantidades de este compuesto aislado a partir de paprika, al británico Walter Norman Haworth y su equipo de investigación en la Universidad de Birmingham quienes determinaron la estructura del ácido hexurónico y acuñaron el término ácido ascórbico en 1932 (Szent-Gyorgyi y Haworth, 1932). En la actualidad se sabe que el escorbuto es el resultado de una deficiencia severa de ácido ascórbico en la dieta y sus síntomas son el resultado de la alteración de la síntesis de colágeno.

La formación de los residuos de hidroxiprolina por parte de la enzima prolil-hidroxilasa requiere ácido ascórbico como cofactor. La hidroxiprolina proporciona átomos adicionales capaces de formar puentes de hidrógeno que estabilizan la triple hélice de colágeno, la proteína más abundante en animales y principal componente del tejido conectivo (Gorres y Raines, 2010; Shoulders y Raines, 2009). El ácido ascórbico es también necesario para el normal funcionamiento de los fibroblastos y osteoblastos, para la biosíntesis de Carintia y hormonas adrenales, cicatrización de heridas y síntesis de ácido fólico (Davey y col., 2000). Aunque la cantidad de ácido ascórbico requerida para prevenir el escorbuto es relativamente baja $\approx 10 \mathrm{mg} \mathrm{dia}^{-1}$ (Krebs, 1954), la ingesta diaria recomendada es cien veces más alta que la de muchas otras vitaminas (National Academies Press (US); 2000). Una ingesta de 100 a $200 \mathrm{mg} \mathrm{dia}^{-1}$ de vitamina C proporciona concentraciones plasmáticas adecuadas en individuos 
Introducción general

sanos y cubre los requisitos generales para la reducción del riesgo de enfermedades crónicas. (Carr y Maggini, 2017; Traber y Stevens, 2011). En comparación con las células animales, las células vegetales pueden acumular niveles mucho más altos de ácido ascórbico (Foyer y Shigeoka, 2011) Es por esto que las plantas son la principal fuente de ácido ascórbico para aquellas especies que no pueden sintetizarlo por su cuenta. Específicamente, los niveles de ácido ascórbico en las células de las hojas a menudo superan los de la clorofila y representan más del $10 \%$ de los carbohidratos solubles (Noctor y Foyer, 1998). No obstante, los frutos se consideran la fuente más popular de esta vitamina para nuestra especie.

\section{Acción biológica del ascórbico}

La presencia de ácido ascórbico en las células vegetales es de vital importancia para la supervivencia, plantas mutantes que son incapaces de producir ácido ascórbico son inviables, pero su viabilidad pueden ser recuperada mediante la suplementación exógena de este metabolito (Dowdle y col., 2007). Solo el estereoisomero L-Ascórbico tiene actividad biológica tanto en sistemas vegetales como animales. La estructura molecular del ácido ascórbico le permite donar electrones con facilidad, confiriéndole una gran capacidad antioxidante. El primer producto de la oxidación del ácido ascórbico es el monodehidroascorbato (MDHA). Esta molecula permanece estable al deslocalizar las cargas positivas mediante la resonancia de los electrones restantes alrededor de un anillo de carbono central y sus tres grupos carbonilo (Bielski, 1982; Davey y col., 2000). A diferencia de otros antioxidantes de bajo peso molecular ( $\alpha$ tocoferol, carotenoides, flavonoides, etc.), la importancia biológica del ácido ascórbico radica en que este es capaz de poner fin a reacciones de oxidación en cadena, mediante la desprotonación del MDHA y la formación de productos no tóxicos, sin radicales, como el deshidroascorbato (DHA) y ácido 2,3-dicetogulónico (Foyer y Noctor, 2011; Noctor y Foyer, 1998). Este potencial de óxido-reducción le permite 
Introducción general

interactuar con especies reactivas de oxigeno (ROS) como radicales hidroxilo, oxígeno singlete, superóxido generados como consecuencia de metabolismo celular. Estas reacciones de desintoxicación pueden considerarse una parte integral de las tareas básicas necesarias para una existencia aeróbica en células eucariotas. Las altas concentraciones intracelulares de ácido ascórbico son un indicio de la importancia de estas funciones en organismos eucariotas (Gest y col., 2013). Además, dado que el ácido ascórbico es levemente electronegativo, puede donar electrones a una amplia gama de sustratos como por ejemplo los radicales derivados del glutatión y del tocoferol (Noctor y Foyer, 1998) y también puede reparar moléculas orgánicas oxidadas de forma más eficiente que el glutatión (Niki, 1991; Tsuchiya y col., 1985), generando intermediarios que son menos tóxicos que los radicales de glutatión (Sturgeon y col., 1998). Otra función importante de la actividad antioxidante no enzimática del ácido ascórbico es su participación en la regeneración del radical cromanoxil derivado de la oxidación del a-tocoferol (vitamina E), un compuesto antioxidante lipofílico asociado a las membranas. Además participa en el mantenimiento en estado de oxidación reducido de los metales de transición que forman parte de grupos prostéticos de proteínas (Davey y col., 2000; Sharma y col., 1993). Otra característica que contribuye a la propiedad de esta molécula como dador de electrones es la capacidad de regeneración del ácido ascórbico a partir de sus formas oxidadas por la acción de monodehidro ascorbato reductasa (MDHAR) y dehidro ascorbato reductasa (DHAR) y electrones aportados por el glutatión, NADH, o NADPH en el ciclo ascorbato-glutatión (Foyer y Noctor, 2011) (Fig. 1). Además la dismutación espontánea de dos radicales MDHA produce una molécula de ácido ascórbico y una molécula de DHA, que no es un radical (Smirnoff, 2000). 


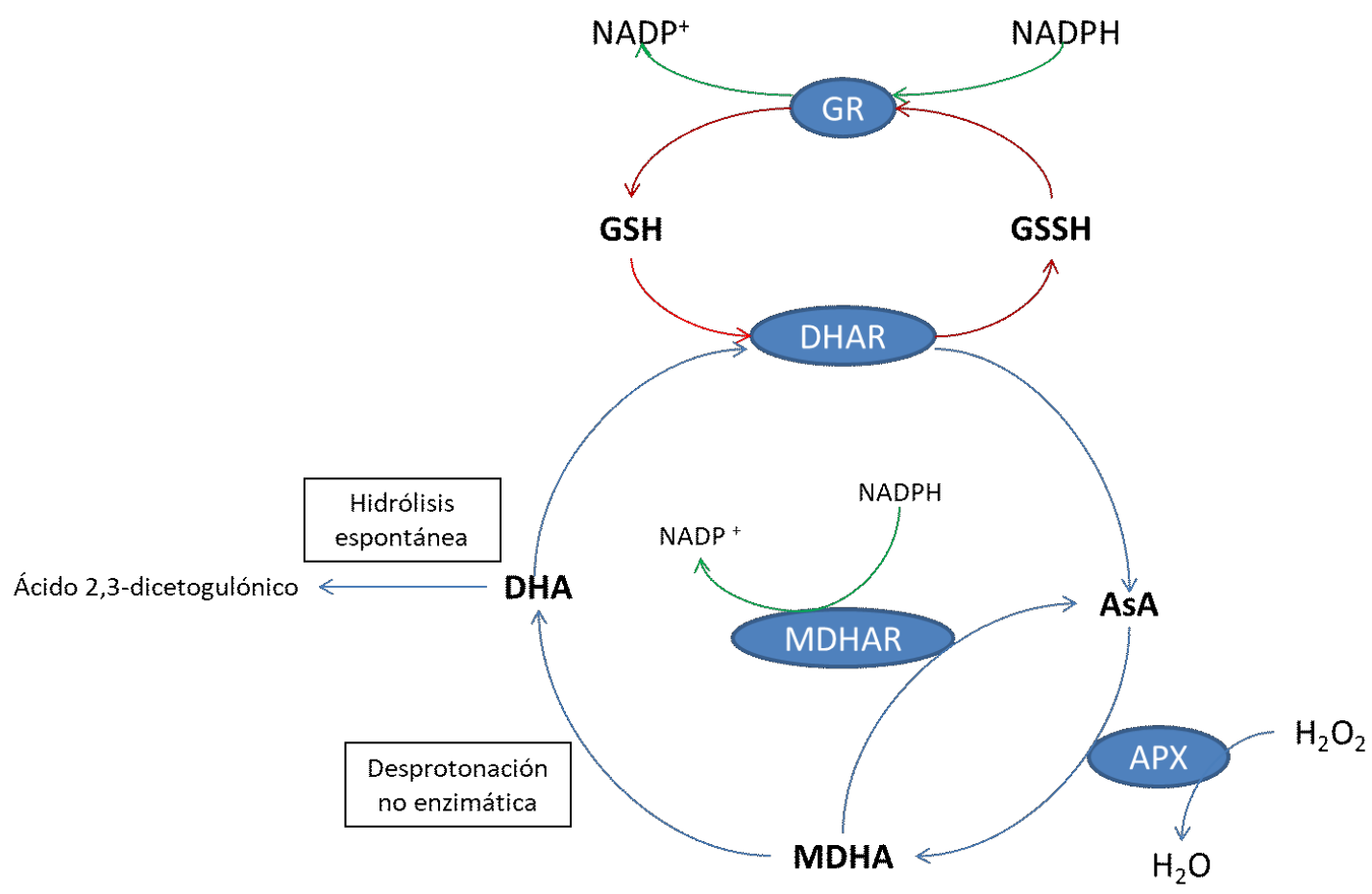

Figura 1-Ciclo ascorbato-glutatión.

El esquema muestra el consumo y regeneración de ácido ascórbico (AsA) y glutatión GSH. Glutation oxidado (GSSH), monodehidro ascorbato (MDHA), dehidroascorbato (DHA), peróxido de hidrogeno $\left(\mathrm{H}_{2} \mathrm{O}_{2}\right)$, agua $\mathrm{H}_{2} \mathrm{O}$, nicotinamida adenina dinucleótido fosfato oxidado (NADP), nicotinamida adenina dinucleótido fosfato reducido (NADPH). Ascorato peroxidasa APX, dehidroascorbato reductasa DHAR, monodehidroascorbato reductasa MDHAR, glutatión reductasa GR. Modificado a partir de "Ascorbate-Glutathione Cycle and Abiotic Stress Tolerance in Plants" (Bartoli y col., 2017).

\section{Funciones del ascórbico en plantas}

Al igual que en animales, en las plantas el ascórbico tiene una amplia variedad de funciones fisiológicas (Conklin y Barth, 2004). Este se destaca por su papel central en la defensa antioxidante de los diversos compartimentos subcelulares su participación en procesos de foto-protección como son la disipación térmica de exceso de energía y el ciclo agua-agua asociados a la fotosíntesis. (Asada, 1999; Demmig-Adams y Adams, 1996; Smirnoff y Wheeler, 2000).

Cuando la intensidad lumínica es muy alta las clorofilas del centro de reacción no pueden entregar sus electrones a la cadena transportadora de electrones tilacoidal dado que ésta se encuentra totalmente reducida. En esta situación los centros de reacción entregan sus electrones al oxígeno formando especies reactivas que pueden 
Introducción general

dañar el aparato fotosintético. Las xantofilas tienen la capacidad de aceptar el exceso de electrones proveniente de los centros de reacción y disipar el exceso de energía como calor. Cuando la energía lumínica aumenta la zeaxantina cumple la función de disipador térmico, oxidándose al aceptar los electrones provenientes de los centros de reacción y dando lugar a la formación de anteraxantina y violoxantina. A través de la acción de enzimas de-epoxidasas y del ácido ascórbico como aceptor de electrones, las xantofilas oxidadas vuelven a reducirse en lo que se conoce como ciclo de las xantofilas (Demmig-Adams y Adams, 1996).

Por otro lado, ante una situación de estrés térmico y lumínico, los estomas se cierran y se limita el $\mathrm{CO}_{2}$ para ingresar en el ciclo de Calvin, por lo tanto tampoco se utiliza el NADPH como poder reductor para generar compuestos carbonados. Como consecuencia de esto no se regenera el $\mathrm{NADP}^{+}$necesario para cumplir la función de aceptor final de electrones en el fotosistema I de la cadena transportadora de electrones en la membrana tilacoidal. En esta situación los electrones que provienen de la fotólisis del agua, en lugar de ser entregados al $\mathrm{NADP}^{+}$, son entregados al oxígeno y se genera un radical superóxido. La superóxido dismutasa transforma el radical superóxido en peróxido de hidrógeno, y posteriormente la ascorbato peroxidasa (APX), transforma el peróxido de hidrógeno en agua con el ácido ascórbico como aceptor de electrones. Por último el ácido ascórbico se recicla con gasto de NADPH, por lo tanto este mecanismo, conocido como ciclo agua-agua, evita que se acumulen especies reactivas de oxigeno potencialmente dañinas para las proteínas del aparato fotosintético y a la vez genera $\operatorname{NADP}^{+}$(Asada, 1999). La participación del ácido ascórbico en estos mecanismos fisiológicos es crucial para optimizar la actividad fotosintética (Asada, 1999; Demmig-Adams y Adams, 1996; Foyer y Noctor, 2011; Smirnoff, 1996).

Otra de las funciones claramente definidas del ácido ascórbico, en el metabolismo de plantas, es la modulación de numerosos procesos mediante la participación como cofactor de enzimas mono o dioxigenasas. La función del ácido ascórbico es mantener 
Introducción general

los metales de los sitios activos de estas enzimas en su forma reducida y potenciar su actividad (Padh, 1990). El ácido ascórbico es cofactor de las peptidil-prolil y -lisil hidroxilasas, un tipo de enzimas Fe-dioxigenasas, que participan de la síntesis de hidroxiprolina e hidroxilisina (Padh, 1990). En las plantas, las glicoproteínas ricas en hidroxiprolina (HRGP), ampliamente estudiadas y muy abundantes, son componentes clave de la pared celular (Fry, 1986). Estas glicoproteínas están implicadas en el soporte estructural de la pared celular y son inducidas (junto con la reacción de prolil hidroxilación) por heridas, etileno y patógenos (Sommer-Knudsen y col., 1997). La inhibición de la peptidil-prolil hidroxilasa da como resultado cambios importantes en la organización de las zonas celulares del desarrollo de la raíz (De Tullio y col., 1999). La inducción de la síntesis de HRGP aumenta la demanda de ácido ascórbico. Se ha visto que heridas en diferentes tejidos de tomate provoca la mayor expresión de MDHAR (Grantz y col., 1995). Niveles elevados de reductasa ayudarían a mantener el nivel de ácido ascórbico necesario para una hidroxilación eficaz. La participación del ácido ascórbico en la síntesis de proteínas ricas en hidroxiprolina de plantas (Arrigoni y col., 1977) tiene implicaciones en la expansión y crecimiento celular (Tabata y col., 2001).

Por otro lado, se ha destacado la participación del ácido ascórbico en la división celular. Mutantes vtc2 con bajo contenido de este metabolito muestran un mayor nivel de oxidación en los núcleos y un retraso en el progreso del ciclo celular en la zona de proliferación de raíces embrionarias (De Simone y col., 2017).

El ácido ascórbico participa de la síntesis de hormonas que son importantes para la regulación del metabolismo y el crecimiento de las plantas. La 1-aminociclopropano-1carboxilato oxidasa (ACC-oxidasa) y la 3-giberelin dioxigenasa, requieren ácido ascórbico como co-sustrato para la biosíntesis de etileno y giberelinas respectivamente. Además el ácido ascórbico está involucrado con la modulación de señales redox en procesos tales como respuestas a patógenos, la determinación del tiempo de floración, y la regulación de varios genes involucrados en el crecimiento, la 
Introducción general

señalización por parte de otras hormonas y en respuesta al estrés, como consecuencia de la capacidad intrínseca de este metabolito para interactuar con especies reactivas del oxígeno (ROS) generados fisiológicamente (Barth y col., 2006a; Conklin y Barth, 2004; Gao y col., 2011; Noctor, 2006; Pastori y col., 2003).

\section{La síntesis de ácido ascórbico en plantas}

Se conocen cuatro rutas diferentes para la biosíntesis de ácido ascórbico en las células vegetales: 1) La ruta de la D- manosa/L-galactosa o ruta de Smirnoff-Wheeler. (Wheeler y col., 1998), y otras rutas alternativas como 2) la ruta del D-galacturonato (Agius y col., 2003), 3) la ruta de la L-gulosa (Wolucka y Van Montagu, 2003) y 4) la ruta del mio-inositol (Lorence y col., 2004).

\section{Ruta de la D-manosa / L-galactosa:}

La ruta de la D-manosa/L-galactosa o ruta de Smirnoff-Wheeler (Fig. 2) se ha reconocido como la predominante en las hojas de las plantas superiores (Melino y col, 2009). La importancia de esta ruta ha sido puesta de manifiesto por el efecto que producen las mutaciones sobre los genes que codifican enzimas involucradas en esta ruta, en los niveles de ascórbico registrados en los tejidos vegetales (Conklin y col., 2000). La primera enzima de esta vía, que se considera específica de la síntesis de ascórbico, es la GDP-L-galactosa fosforilasa (Dowdle y col., 2007; Laing y col., 2007). La expresión de GDP-L-galactosa fosforilasa está fuertemente controlada por la luz y es reprimida por las altas concentraciones de ácido ascórbico, en parte por medio de un fragmento de lectura abierto (uORF en inglés) en la región no traducida cinco prima (5'-UTR en inglés). Esto, junto con experimentos de sobreexpresión, respalda firmemente su papel en el control de la biosíntesis de ácido ascórbico(Dowdle y col., 2007b; Gao y col., 2011; Laing y col., 2015a; Li y col., 2018). El último paso de esta vía consiste en la conversión de la L-galactona-1,4-lactona (L-GalL) en ácido ascórbico que es llevado a cabo por acción de la enzima L-GalL deshidrogenasa (GLDH) 
(Wheeler y col., 1998). Esta enzima se encuentra anclada a la membrana interna de la mitocondria con el sitio catalítico hacia el espacio intermembrana y está acoplada a la cadena de electrones dado que el citocromo $c$ es aceptor de los electrones provenientes de la reducción del sustrato, la L-GalL (Bartoli y col., 2000). La mayoría de estos estudios han sido realizados en tejidos foliares, no obstante se ha informado de la participación de esta ruta en la síntesis de ácido ascórbico en frutos como kiwis, acerola, manzana, durazno cítricos y tomate ( Badejo y col., 2009; Bulley y col., 2009; Imai y col., 2009; loannidi y col., 2009; Li y col., 2009) aunque la contribución de esta ruta al control de los niveles de ácido ascórbico durante la maduración de la fruta todavía está en debate.

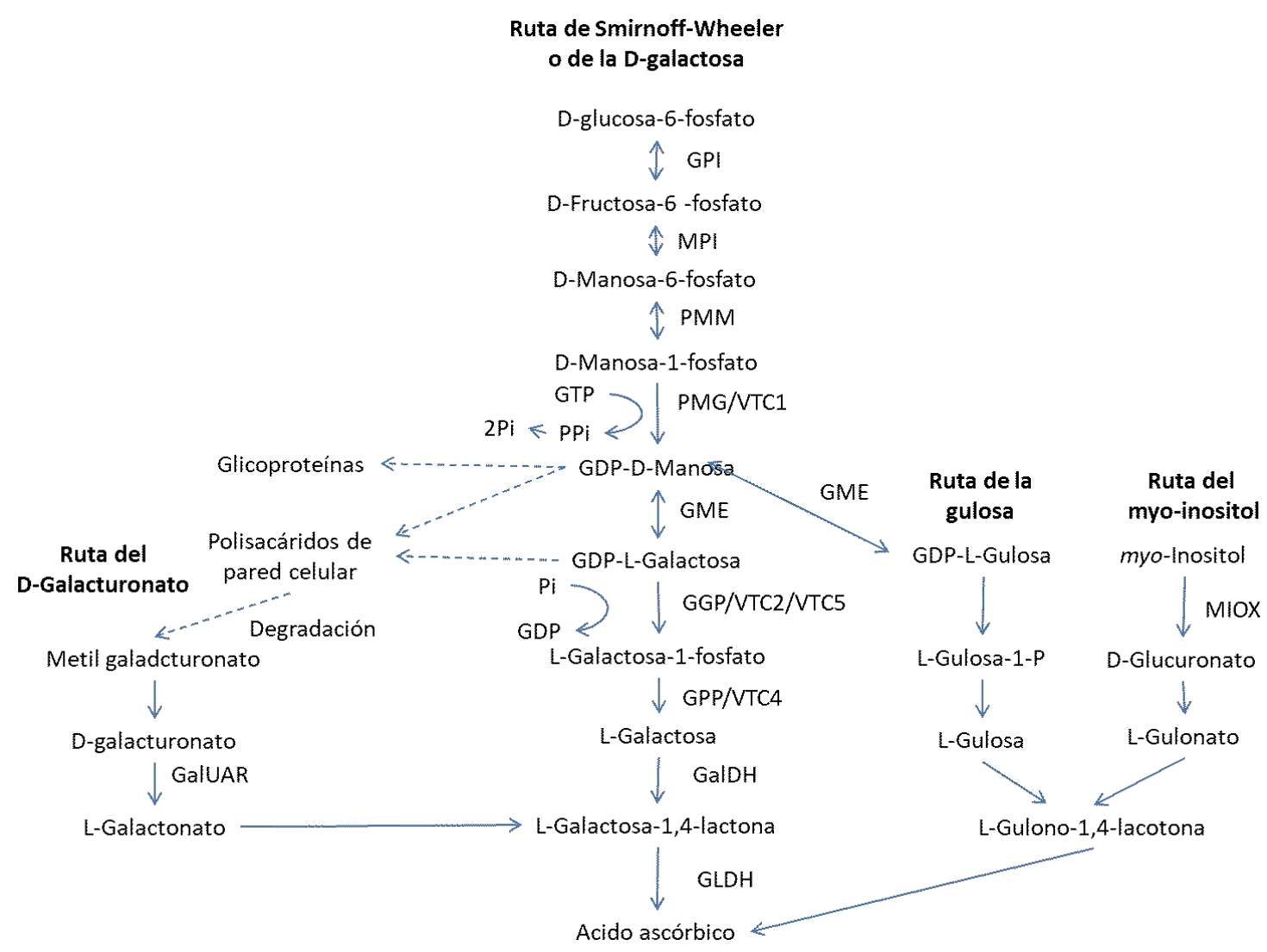

Figura 2-Rutas de biosíntesis de ácido ascórbico en plantas superiores.

PGI fosfoglucosa isomerasa; PMI fosfomanosa isomerasa; PMM fosfomanomutasa; GMP GDPD-manosa pirofosforilasa; GME GDP-D-manosa-3,5-epimerasa; GGP GDP-L-galactosa fosforilasa; GPP L-galactosa-1-P fosfatasa; GalDH L-galactosa deshidrogenasa; GLDH Lgalactono-1,4-lactona deshidrogenasa; MIOX mio-inositol oxigenasa; GalUAR D-galacturonato reductasa.Traducido de Hossain y col., (2017). 
Introducción general

\section{Ruta del D-galacturonato}

Otra ruta importante para la síntesis de ácido ascórbico es la ruta del L-galacturonato (Fig. 2). En esta ruta el ácido D-galacturónico proveniente de la hidrolisis de pectinas (las cuales son un componente importante de la pared celular), es reducido a Lgalactonato por acción de la enzima D-galacturonato reductasa (GalUAR) y luego este intermediario es convertido en L-Galactona-1,4-lactona, el precursor inmediato del ácido ascórbico, por la enzima aldonolactonasa la cual hasta el momento no ha sido identificada en plantas superiores (Yoshimura y col., 2018). Se ha demostrado que la biosíntesis del ácido ascórbico en frutos maduros de frutilla puede ocurrir a través del ácido D-galacturónico mediante la sobreexpresión transciente de GalUAR de frutilla en Arabidopsis, lo que resultó en un aumento de 2 a 3 veces en los niveles de ácido ascórbico (Agius y col., 2003). Esto también fue demostrado en tomate (Lim y col., 2016) y en papa (Hemavathi y col., 2009) lo que indica que las plantas pueden sintetizar ascórbico a través de la ruta del galacturonato. Sin embargo para demostrar que la enzima GalUAR es una enzima clave en esta ruta debería demostrarse el impacto de plantas deficientes en esta enzima para la acumulación de ácido ascórbico, lo cual no ha sido realizado hasta el momento. Se ha sugerido que en ciertos órganos esta vía podría constituir un mecanismo de reciclado de carbono después de la ruptura de las paredes celulares, como ocurre durante la maduración de la fruta (Conklin, 2001; Davey y col.,, 2000). Por otro lado Badejo y col., (2012), a partir de estudios en tomate, propusieron que la translocación desde las hojas y la biosíntesis a través de la ruta D-manosa/L-galactosa son fuentes dominantes de ácido ascórbico en frutos inmaduros, mientras que la ruta alternativa D-galacturonato contribuye a la acumulación de ácido ascórbico en frutos maduros de tomate cv Micro-Tom. 
Introducción general

\section{Ruta de la Gulosa}

Por otro lado la enzima GME cataliza tanto la conversión de GDP-D-manosa en GDPL-galactosa como en GDP-L-gulosa y constituye una intersección entre la ruta de Smirnoff-Wheeler y la ruta de la gulosa. Esta ruta, ha sido bien caracterizada en animales pero en plantas superiores todavía no han sido identificadas la totalidad de las enzimas involucradas en esta ruta. Sin embargo, se ha visto que la sobreexpresión transciente de la enzima L-gulono-1,4-lactona oxidasa (ALO) de rata produce un incremento de los niveles de ácido ascórbico en tabaco y lechuga (Jain y Nessler, 2000). Radzio y col., (2003) reportaron que la sobreexpresión de la enzima ALO de rata en mutantes vtc de Arabidopsis, restaura completamente los niveles de ácido ascórbico a pesar de la extrema deficiencia de ácido ascórbico en estos mutantes. Por otro lado, el efecto de la suplementación de hojas de tabaco con L-gulono-1,4-lactona sobre los niveles de ácido ascórbico resultó ser limitado al compararlo con los efectos de la suplementación con L-galactono-1,4-lactona (Jain y Nessler, 2000). Por lo tanto, la ruta gulosa puede considerarse como una ruta alternativa para la biosíntesis de ácido ascórbico en las plantas.

\section{Ruta del mio-inositol}

La síntesis de ácido ascórbico también ocurre a partir del mio-inositol a través de los intermediarios D-glucuronato, L-gluconato y L-gulono-1,4-lactona (Lorence y col., 2004). La enzima mio-inositol oxidasa (MIOX) cataliza la conversión de mio-inositol en D-glucuronato, y esta enzima es considerada clave dado que la sobreexpresión de MIOX resulta en un incremento de 2 a 3 veces en el contenido de los niveles de ácido ascórbico en Arabidopsis (Lorence y col., 2004). Por otro lado, Endres y Tenhaken, (2009) reportaron que la sobreexpresión de MIOX no muestra efectos en los niveles de ácido ascórbico en Arabidopsis. Aunque varios estudios soportan la existencia de la ruta del mio-inositol, todavía permanece bajo discusión cual es el grado de aporte de esta ruta a la biosíntesis de ácido ascórbico en plantas. 
Introducción general

No está claro cuánto contribuyen esta y otras rutas alternativas a los niveles de ácido ascórbico registrados en los distintos órganos, en comparación con el aporte realizado por la ruta de Smirnoff-Wheeler. Además los niveles de ácido ascórbico y su estado redox, no son determinados sólo mediante la biosíntesis de ácido ascórbico sino también por su reciclado a partir de la acción de enzimas que catalizan la reducción de moléculas de ácido ascórbico oxidadas como la Monodehidro ascorbato reductasa y la Dehidro ascorbato reductasa en el ciclo Foyer-Halliwell-Asada (Asada, 1999; Foyer y Halliwell, 1976).

\section{Definición del problema, hipótesis y objetivos}

Como se ha mencionado anteriormente el ácido ascórbico es uno de los compuestos más abundantes en las plantas y posee funciones como antioxidante y cofactor enzimático (Foyer y Noctor, 2011; Smirnoff, 2018). Se sintetiza principalmente a través de la vía de Smirnoff-Weeler y la GDP-L-galactosa fosforilasa es primera enzima de esta vía considerada específica para la síntesis de ácido ascórbico (Dowdle y col., 2007; Laing y col., 2007). Dos genes VTC2 y VTC5 codifican la GDP-L-galactosa fosforilasa en Arabidopsis (Dowdle y col., 2007). Existe una gran variedad de mutantes vtc ("vitamina C deficiente") y plantas transgénicas en diferentes partes de la vía de biosíntesis que presentan solo un $10-20 \%$ de las concentraciones de ácido ascórbico registradas en su genotipo silvestre correspondiente. Estas plantas deficientes en ácido ascórbico crecen de manera relativamente normal, pero exhiben varios cambios sutiles de desarrollo, aumento de la sensibilidad al estrés ambiental y aumento de la resistencia basal a los patógenos (Barth, De Tullio, y Conklin, 2006b; Caviglia y col., 2018; Pavet y col., 2005; Plumb y col., 2018; Senn y col., 2016). Por lo tanto, es evidente que las disminuciones relativamente severas de ácido ascórbico aún permiten sus funciones esenciales, mientras que se debe suponer que concentraciones más altas son beneficiosas. 
El tomate es un importante fuente de ácido ascórbico en la dieta y el control de su síntesis y funciones se han investigado alterando la expresión de diversos genes implicados en su biosíntesis (Alhagdow y col., 2007; Gilbert y col., 2009; MounetGilbert y col., 2016). La disponibilidad de plantas de tomate con deficiencia de GDP-Lgalactosa fosforilasa permite estudiar el papel de esta enzima y del ácido ascórbico en la producción y calidad de la fruta (Baldet y col., 2013). Dos genes con función complementaria, SIGGP1 y SIGGP2, codifican la GDP-L-galactosa fosforilasa en tomate, y SIGGP1 se expresa aproximadamente mil veces más que SIGGP2 (Dowdle y col., 2007). El mutante slggp1 posee una baja concentración de ascórbico en sus hojas debido a la expresión de SIGGP2. Cuando este mutante slggp1 fue sometido a condiciones de alta irradiancia, se observó fotohinibición y blanqueamiento de la clorofila (Baldet y col., 2013). Además, en estudios realizados con plantas de tomate transgénicas antisentido con expresión disminuida de SIGGP1 con solo $50-75 \%$ de nivel de ácido ascórbico del tipo salvaje (WT), se observó que bajo estrés por frío estas plantas acumularon más malondialdehído (MDA) y más $\mathrm{O}_{2}{ }^{\circ}$, mostraron mayor pérdida de electrolitos, una menor eficiencia fotoquímica máxima de PSIl (Fv/Fm) y menor tasa fotosintética neta (Pn) en comparación con plantas WT (Yang y col., 2017). Además, las plantas transgénicas antisentido exhibieron un mayor nivel de $\mathrm{H}_{2} \mathrm{O}_{2}$ y una menor actividad de ascorbato peroxidasa (APX) (Wang y col., 2013). Por lo que estos resultados sugieren que GDP-L-galactosa fosforilasa 1 juega un papel importante en la protección de las plantas contra el estrés por frío al mantener la reserva de ácido ascórbico y su estado redox.

Estos resultados proporcionan evidencia de la mayor susceptibilidad de las plantas de tomate deficientes en GDP-L-galactosa fosforilasa al estrés, sin embargo, aún no se han realizado estudios enfocados en los efectos de estas modificaciones a nivel del fruto. La obtención de mutantes de tomate deficientes en la enzima GDP-L-galactosa fosforilasa 1 (SIGGP1) que poseen una reducción notable en el contenido de ácido 
Introducción general

ascórbico (Baldet y col. 2013), permitió investigar la participación de este metabolito y de la enzima GDP-L-galactosa fosforilasa, en la maduración este fruto modelo, en la productividad y fenología de las plantas de tomate.

\section{Hipótesis:}

La hipótesis que se va a contrastar es que la diminución del contenido de ácido ascórbico produce modificaciones en las características fisiológicas de los frutos mediadas por alteraciones hormonales.

\section{Objetivo general:}

El objetivo general de esta tesis consistió en determinar el efecto de modificaciones en el contenido de ácido ascórbico sobre el proceso de la maduración de frutos.

\section{Objetivos específicos:}

Objetivo específico 1: Caracterizar los mutantes deficientes en la actividad de GDP-Lgalactosa fosforilasa 1.

\section{Actividades:}

1.1. Determinar el contenido de ácido ascórbico y su estado rédox en raíces, hojas y frutos.

1.2. Determinar las características fenológicas

1.3. Determinar los parámetros de crecimiento de las plantas enteras y sus diversos órganos.

Objetivo específico 2: Evaluar el impacto de la deficiencia en la expresión de GDP-Lgalactosa fosforilasa sobre la productividad en tomate.

\section{Actividades:}


Introducción general

2.1 Determinar el efecto de la deficiencia de GDP-L-galactosa fosforilasa en la actividad fotosintética en hojas maduras.

2.2 Evaluar el efecto de la deficiencia de GDP-L-galactosa fosforilasa en las relaciones fuente-destino.

2.3 Establecer un tratamiento exógeno con ácido ascórbico que restablezca en mutantes slggp1, niveles similares de este antioxidante a los encontrados en plantas de la línea silvestre.

2.4 Determinar el efecto de la deficiencia de GDP-L-galactosa fosforilasa sobre la concentración de hormonas en flores.

Objetivo específico 3: determinar el efecto de modificaciones en el contenido de ácido ascórbico sobre el proceso de la maduración de frutos.

\section{Actividades:}

3.1 Evaluar la maduración y la producción de etileno (en planta) de frutos de plantas deficientes en GPP-L-galactosa fosforilasa.

3.2 Caracterizar la participación del etileno en la maduración postcosecha de frutos de tomate de plantas deficientes en GPP-L-galactosa fosforilasa.

Objetivo específico 4: Determinar el efecto de la mutación en el gen SIGGP1 sobre la expresión de genes involucrados en la síntesis del ácido ascórbico, de rutas asociados y de la señalización por etileno en hojas y frutos.

\section{Actividades:}

4.2 Determinar la expresión de genes correspondientes a enzimas de la síntesis de ácido ascórbico en hojas y frutos.

4.2 Determinar la expresión de genes que codifican a enzimas que participan en la síntesis y degradación de componentes de pared celular en hojas y frutos. 
Introducción general

4.3 Determinar la expresión de enzimas que participan en el reciclado del ácido ascórbico en hojas y frutos.

4.4 Determinar la expresión de genes correspondientes a receptores de etileno en hojas y frutos. 


\section{CAPÍTULO I}

Caracterización de plantas de tomate

mutantes deficientes en GDP-L-

galactosa fosforilasa: Fenología y

parámetros de crecimiento. 
CAPÍTULO I: Caracterización de plantas de tomate mutantes deficientes en GDP-L-galactosa fosforilasa: Fenología y parámetros de crecimiento.

\subsection{Introducción:}

El tomate (Solanum lycopersicum) es una planta herbácea anual, bianual o perenne. Las hojas son compuestas y presentan una filotaxis espiral. Existe una gran diversidad en hábitos de crecimiento aunque la mayoría son de tipo indeterminado, con algunas variedades que son semideterminadas o determinadas. En las variedades de tomate de crecimiento indeterminado el eje principal de la planta joven es monopodial. Sin embargo, una vez que se induce la floración en el ápice del eje principal el crecimiento vertical continúa desde un brote lateral que surge de la yema axilar más proximal, justo debajo de la inflorescencia terminal. Este segundo brote, formará tres nudos vegetativos y terminará nuevamente con una inflorescencia. El ciclo de tres hojas y una inflorescencia terminal se repiten de manera indeterminada, siguiendo un patrón de crecimiento simpodial. Por otro lado, en las variedades de crecimiento determinado como por ejemplo la variedad Micro-Tom estudiada en esta tesis, la floración se induce luego de un periodo de crecimiento vegetativo. El meristema apical del eje principal de la planta da lugar a una o más inflorescencias terminales. El crecimiento continúa a partir de los meristemas laterales basales, que también dan lugar a ejes de crecimiento determinado. En estas variedades el crecimiento es exclusivamente monopodial y la arquitectura de las plantas es de tipo arbustiva (Nuez, 1999).

La planta de tomate es considerada de día neutro para la inducción floral. Las flores se disponen en cimas de tipo helicoide, estas se caracterizan por tener un crecimiento indeterminado (Welty y col., 2007). La flor de tomate se compone de un pedúnculo corto, un cáliz gamosépalo y una corola gamopétala de color amarillo. Los estambres en las flores se alternan con los pétalos y tienen filamentos muy cortos. Las anteras a medida que se desarrollan se van uniendo lateralmente a través de la generación de tricomas que se entretejen partiendo del centro de la antera hacia la base y la punta. De esta manera se forma el cono estaminal. El gineceo presenta desde 2 a 30 carpelos. Normalmente el pistilo es más corto que el cono estaminal y presenta un 
CAPÍTULO I: Caracterización de plantas de tomate mutantes deficientes en GDP-L-galactosa fosforilasa: Fenología y parámetros de crecimiento.

estigma lobulado. El cuello del cono está constituido por extensiones estériles de las anteras que envuelven al estigma. Las anteras son bilobuladas y contienen varios cientos de granos de polen que son liberados a través de la hendidura longitudinal. Normalmente la liberación del polen ocurre antes de la maduración del estigma, por lo que durante la finalización del crecimiento del estilo el estigma maduro atraviesa el cono formado por las anteras y arrastra consigo los granos de polen adheridos, de manera tal que al emerger el estigma la autopolinización ya ha ocurrido y las probabilidades de polinización cruzada son muy bajas (Contreras-Magaña y col., 2013). Si la polinización es exitosa se induce el cuajado del fruto que botánicamente es considerado una baya que consta de un tejido epidérmico, un pericarpio carnoso y una placenta gelatinosa que envuelve a las semillas en el interior de dos o más lóculos. Los frutos maduros son de color rojo característico debido principalmente a la presencia de grandes cantidades de licopeno (Frusciante y col., 2007)

El tomate posee un ciclo de vida relativamente corto en condiciones de cultivo controladas que junto con otras características como el genoma diploide de tamaño medio (950 Mb), la elevada similitud genética con otros miembros de la familia Solanaceae y su gran importancia económica, lo convierten en la especie más ampliamente estudiada, sobre todo a nivel de la biología de sus frutos (Giovannoni, 2007; Seymour y col., 2013; The Tomato Genome Consortium, 2012). Además, existe una enorme cantidad de herramientas desarrolladas para su estudio (Bombarely y col., 2011; Fernandez y col., 2009). Por otro lado, aproximadamente el 30\% de los genes de tomate no tienen similitud significativa con genes de Arabidopsis (Matsukura y col., 2008) al menos en sus estructuras primarias. Por ende, el análisis funcional de estos genes de tomate provee información sobre mecanismos que controlan funciones biológicas que no existen en Arabidopsis. Sin embargo la utilización de plantas de tomate de tamaño regular para ensayos de laboratorio implica una demanda de espacio muy grande. Es por esto que la variedad de tomate enana Micro-Tom fue 
CAPÍTULO I: Caracterización de plantas de tomate mutantes deficientes en GDP-L-galactosa fosforilasa: Fenología y parámetros de crecimiento.

propuesta como un modelo conveniente para estudiar el proceso de desarrollo y maduración de frutos debido a su pequeño tamaño, rápido crecimiento y fácil transformación (Emmanuel y Levy, 2002; Meissner y col., 1997). Esta variedad que tiene frutos pequeños y de color rojo intenso fue creada con fines ornamentales cruzando los cultivares Florida Basket y Ohio 40133 (Scott y Harbaugh, 1989). E cultivar Micro-Tom posee un crecimiento determinado como resultado de la presencia de un alelo recesivo del gen Self-Pruning (Pnueli y col., 1998) que controla el fenotipo determinado/indeterminado. Existe evidencia que el mismo alelo recesivo de este gen está presente en dos cultivares no relacionados con Micro-Tom, Severianin (Martí y col., 2006) y M82 (Pnueli y col., 1998) lo que sugiere que el fenotipo determinado sería de un evento de mutación único (Martí y col., 2006). Pero el fenotipo enano de MicroTom no se debe a la mutación Self-Pruning sino a otras dos mutaciones. Una de ellas corresponde a una mutación en el gen que codifica 6-deoxocatasterona deshidrogenasa, de la vía de síntesis de barasinoesteroides. El cultivar Micro-Tom poseen el alelo recesivo ( $d w a r f)$ de este gen y esto genera la reducción de la longitud de entrenudos como producto de una deficiencia en brasinoesteroides. El fenotipo de Micro-Tom (entrenudos cortos y hojas pequeñas, rugosas y de color verde oscuro) es similar al de otros mutantes de tomate deficientes en brasinoesteroides (Bishop y col.,1996; Bishop y col., 1999). Por otro lado el fenotipo enano de Micro-Tom no es el resultado de una deficiencia en giberelinas. Los niveles de giberelinas registrados en Micro-Tom son similares a los registrados en cultivares altos como Ailsa Craig, UC-82, y Rutgers (Martí y col., 2006). La otra mutación presente en MicroTom se encuentra en el gen putativo Miniature (Mnt) asociada con un fenotipo de entrenudo corto probablemente por una reducción en la señalización por parte de giberelinas (Marti y col., 2006). Sin embargo aún no se ha identificado la secuencia del gen responsable de este fenotipo. 
CAPÍTULO I: Caracterización de plantas de tomate mutantes deficientes en GDP-L-galactosa fosforilasa: Fenología y parámetros de crecimiento.

A pesar de que estas mutaciones alteran la arquitectura de la planta de manera tan dramática, los ovarios polinizados se desarrollan normalmente lo que indica que MicroTom es un sistema útil para investigar cuajado y desarrollo de frutos (Dan y col., 2007; Martí y col., 2006). Los mutantes de la variedad Micro-Tom utilizados en esta tesis poseen cada uno una mutación independiente sobre el gen que codifica la enzima GDP-L-galactosa foforilasa 1. Como se mencionó en el capítulo introductorio la GDP-Lgalactosa foforilasa es la primera enzima de la ruta dedicada exclusivamente a la síntesis de ascórbico. Estas mutaciones fueron identificadas mediante la técnica de TILLING (Targeting Induced Local Lesions IN Genomes) a partir de poblaciones de mutantes generadas con el agente mutagénico EMS (Etil metil sulfonato).

\subsection{Objetivos}

En este capítulo se abordó el objetivo específico 1 que consistió en caracterizar los mutantes deficientes en la actividad de GDP-L-galactosa fosforilasa 1.

En función de éste, se fijaron tres actividades a realizar:

1.2.1. Determinar el contenido de ácido ascórbico y su estado rédox en raíces, hojas y frutos.

1.2.2. Determinar las características fenológicas.

1.2.3. Determinar parámetros de crecimiento de las plantas enteras y sus diversos órganos. 
CAPÍTULO I: Caracterización de plantas de tomate mutantes deficientes en GDP-L-galactosa fosforilasa: Fenología y parámetros de crecimiento.

\subsection{Materiales y métodos}

\subsubsection{Material vegetal: Características genéticas de los mutantes slggp1.}

Se utilizaron dos líneas de mutantes independientes deficientes en GDP-L-galactosa fosforilasa 1. La línea GGP-5261 proveniente de una población de mutantes EMS generados en la universidad de Tsukuba de Japon (NBRP-Tomato population) y la línea GGP-49C12 proveniente de una población de mutantes EMS generada en el INRA de Bordeux, Francia (TILLING-Tomato collection). El mutante GGP-49C12 posee una mutación en el intrón $n^{\circ} 5$ que genera el cambio de una guanina ( $G$ en violeta) por una adenina (A), esto da como resultado la desaparición del sitio de splicing alternativo. Consecuentemente se genera un cambio en el marco de lectura que da como resultado la aparición de un codón de terminación en la secuencia 5'-3' del intrón 5 (TGA en marrón) y una transcripción incompleta de la secuencia (Figura 1.1). El mutante GGP-5261 una mutación genera el cambio de un nucleótido guanina (G) por un nucleótido timina (T) en la secuencia del exón $n^{\circ} 7$ en la que el codón $\mathrm{GAG}$ (azul), cambia y se genera un codón TAG (codón de terminación), esto resulta en la transcripción y traducción incompleta de la secuencia (Figura 1.1). Como resultado de estas mutaciones, en ambos mutantes la enzima GDP-L-galactosa fosforilasa 1 es incompleta y no funcional (Figura 1.2). Información proporcionada por el Dr. Pierre Baldet (INRA Bordeux) en comunicaciones personales. 
CAPÍTULO I: Caracterización de plantas de tomate mutantes deficientes en GDP-L-galactosa fosforilasa: Fenología y parámetros de crecimiento.

ACACACAAAAAGAAGTAAAGATGATGCTCAAAATTAAGAGGGTTCCTACGCTTGTTTCTAACTTTCAAAAGGATGAGGCTGATGAAAT TGCTGCTCGTGGTGCTGGTTGTGGCCGGAATTGCCTCAGGAATTGCTGCCTTCCAGGTACTGTATACTCCCTTTTCCCAATTGTTTGT TCATCTAAAGCTGATTTAGCAGAATATTGATTTTGTTGTTATGTGTTTGTACTGTTGAAGGTTCAAAGCTGCCACTGTATGGTTTCAA AAATTTGAGCTACGGCAAGTCTGTCGCCGATGAAACAAAGGAATCTCCGATCGACTTTCTGGAATCCCTTGTTCTTGGGGAAGTAAGT GCGAAGCTTCTTATTTTGGTTACTGTTTTGTTATTTTAAAATTGCCAATCTTGAGATATTTTGATTTGATTACTCACTTTTTTGGTCA ATTTTGATGTGCAGTGGGAGGATCGTCAGCAGAAAGGCCTCTTTCGCTATGATGTCACTGCTTGCGAAACCAAGGTATTTTTTTCTTC TCTCTTCTGGTTTGTGGTTACTGTATTTGATGCCTACACGTTCTGCTTTAGTTATTACCAGTTAGATAGACTTGGTTTAGAAAGGCTG AGTACTTAAAGGGTAAACAGGTATAACAAAATGGAATATTATCTCTTGATTTGTCAAACTGGACAAGTAAAAGTGGACATATTGTTTT TAGTATAGTAGACGAGTAAAACATAGATGGAGGGAAGATTATAATCACAGGAAGTGAATAGGGAAATTTTGAAACGGTATAAGGTCTI ATAATTCCGGAAACTAGGGTAATGTCTTTTGGAGGTTAACTTGGTTATTGATTATGATCTGCAAGTGATATATAGCGTTGAACCAATT CTTACCTTAAGAGACTAAGGTTGACGAAGATGTAGTCATTTTATGTCTTACTATTACATAGTAAATTGATGTTATGTAGTGTTTAAAT TGAACTAGCGTTTTTTGTCGGTGTGTGGCAAATTTGAAATGAGTGTTGTGCTATTGCTCAGCGCTTGCTTTTCAAGTTGTTGCTTTGG AGACTTACTGATTTTGATTGATGTGAAGAAAGGACACTTCATTTGTGAATCGGCAATTTGATTTAAAATAAATGGTTATAGGTGATTC CTGGAGAATATGGTTTCGTTGCTCAACTGAATGAGGGAAGGCACCTCAAGAAGCGGCCAACTGAGTTTCGAGTTGATAAGGTTCTGCA GCCTTTTGATGGAAGCAAGTTCAACTTCACTAAGGTTGGACAGGAAGAGTTGCTCTTTCAGTTTGAAGCAAGTGAGGAAGATGAAGTC CAGCTCTATCCAGATGCGCCAATTGATCCTGAGAAATCTCCAAGTGTCGTTGCCATAAATGTATGTTCTTAGTTAGTTTTGCACATAT ACTGGAACCTTTTGGTAAGTAGAGACAGTGATTAATGAGTTTATTGGTTTTCAATGCAACAGGTCAGTCCCATTGAGTACGGACACGT GCTTTTGATCCCTAAGGTCCTTGAATGCCTTCCCCAGAGGATTGACAGGGACAGCTTCCTGCTTGCACTGCACATGGCTGCCGAAGCA GCAAACCCTTACTTCCGATTGGGTTACAACAGCTTGGGTGCATTTGCCACCATCAACCATCTTCACTTCCAGGTAGAGTCCACGACAC TTCCCATAATTGACATGGTTTTGGAATTGTCAGTTCTAGTTGTTTGCTCTAGTGCTGACTGCTGAGACCTTAATAAAGAAGAAGGAAC TCACTTTCATTGTTTTTGCTCTTCAGGCTTATTTCTTGGCTGTGCAATTTCCCATTGAGAAGGCCCCAACTCAGAAGATAACTGTCAC TGATGCTGGAGTGAAGATATCGGAGATGCTGCATTACCCAGTTCGAGGTCTTGTCTTTGAGGGTGGAAATACTTTGGAGGATTTGGCC GATGTTGTCTCAGATTCTTGCATTTGTCTGCAAGAGAACAACATCCCTTACAATGTCCTAATCTCTGATTCAGGGAAAAGGATATTCC TTCTCCCACAGGTATAACTCTTTGAACCACATTTTTACAACTACTTTGGGATTGCTTAATTATTAGCAGTTCCCAACAATTGATCACT TTCCTAACTTACATGTGTTTTGGTGGATTGGAACAGTGCTATGCGGAGAAACAAGCGCTTGGAGAGGTCAGCGCTGAACTCCTCGACA CCCAAGTCAATCCTGCTGTTTGGGAGATTAGTGGACACATGGTCTTGAAGAGGAAGGAGGATTATGAGGGTGCAACTGAGGCAAATGC ATGGAGGCTTCTCGCAGAGGTCTCACTCTCTGAAGCAAGGTTCCAAGAAGTGACTGCTCTCATCTTTGAAGCCATTAGTCTCAGTGTT GAAGAGAACGAGGACGGCACTGATGGTTCTCCTGAGGATCTAGATGTCACACCTCCACAGCCCATGGAGGAGATTGATGGTCTCAACA CCCACAGTACCATGGTTCCCGCCTAGGGTTTTCACGGCCCAGCTCTGGTGTTCATCGCATGTTATTATTTCATGAGTTTCCATCTCTA GCTGCCCTTGTGAAA

Figura 1.1-Secuencia correspondiente al gen SIGGP1 silvestre (Solyc06g073320).

Los codones de inicio ATG y de stop TGA se muestran subrayados. En gris las secuencias codificantes (exones) En verde las secuencias no codificantes (intrónes). En el intrón $n^{\circ} 5$ se puede ver en rosa que en el sitio de splicing $\mathrm{G}$ cambia por $\mathrm{A}$ y en marrón se muestra el codón de stop resultante (mutante GGP-49C12). En azul se muestra el codón GAG que en el mutante GGP 5261 resulta en un codón TAG (codón de stop) como producto de la mutación. Información proporcionada por el Dr. Pierre Baldet (INRA Bordeux) en comunicaciones personales.

a) MMLKIKRVPTLVSNFQKDEADEIAARGAGCGRNCLRNCCLP

KLPLYGEKNLSYGKSVADETKESPIDFLESLVLGEWED RQQKGLFRYDVTACETKVI PGEYGFVAQLNEGRHLKKRPTEFRVDKVLQPFDGSKFNFTKVGQEELLFOFEASEEDEVQLY PDAP I DPEKSPSVVAINVSP IEYGHVLLIPKVLECLPQRIDRDSFLLALHMAAEAANPYFRLGYNSLGAFAT INHLHFQAY FLAVQFPIEKAPTQKITVTDAGVKISEMLHYPVRGLVFEGGNTLEDLADVVSDSC ICLQENNI PYNVLISDSGKRIFLLPC CYAEKQALGEVSAELLDTQVNPAVWEISGHMVLKRKEDYEGATEANAWRLLAEVSLSEARFQEVTALIFEAISLSVEENED GTDGSPEDLDVTPPQPMEEIDGLNTHSTMVPA*

b) MMLKIKRVPTLVSNFQKDEADEIAARGAGCGRNCLRNCCLPGSKLPLYGFKNLSYGKSVADETKESPIDFLESLVLGEWED RQQKGLFRYDVTACETKVIPGEYGFVAQLNEGRHLKKRPTEFRVDKVLQPEDGSKFNFTKVGQEELLFQFEASEEDEVQLY PDAP I DPEKSPSVVAINVSPIEYGHVLLI PKVLECLPQRIDRDSFLLALHMAAEAANPYFRLGYNSLGAFAT INHLHFQVE STTLPIIDMVLELSVLVVCSSADC*

C) MMLKIKRVPTLVSNFQKDEADEIAARGAGCGRNCLRNCCLP

KLPLYGFKNLSYGKSVADETKESPIDFLESLVLG RQQKGLFRYDVTACETKVIPGEYGFVAQLNEGRHLKKRPTEFRVDKVLQPFDGSKFNFTKVGQEELLFQFEASEEDEVQLY PDAPIDPEKSPSVVAINVSPIEYGHVLLI PKVLECLPQRIDRDSFLLALHMAAEAANPYFRLGYNSLGAFAT INHLHFC FLAVQFPIEKAPTQKITVTDAGVKISEMLHYPVRGLVFEGGNTLEDLADVVSDSCICLQENNIPYNVLISDSGKRIFLLPQ CYAEKQALG

Figura 1.2-Secuencia proteica de la enzima GDP-L-galactosa fosforilasa.

a) Genotipo silvestre; b) Mutante GGP-P49C12; c) Mutante GGP 5261. Los sitios de unión de intrones luego del splicing se señalan en rojo. Información proporcionada por el Dr. Pierre Baldet (INRA Bordeux) en comunicaciones personales.

\subsubsection{Condiciones de cultivo}

Semillas de tomate (Solanum licopersicum cv Micro-Tom) de las líneas mutantes

(GGP-49C12 y GGP-5261) y la línea silvestre (WT) fueron sembradas en cámaras 
CAPÍTULO I: Caracterización de plantas de tomate mutantes deficientes en GDP-L-galactosa fosforilasa: Fenología y parámetros de crecimiento.

húmedas confeccionadas con una cápsula de Petri y varias capas de papel absorbente en la base de la cápsula sobre las que fueron dispuestas aproximadamente 50 semillas y se humedecieron con agua destilada (Fig. 1.3 a). Las cápsulas fueron envueltas en papel aluminio y se depositaron en estufa de germinación a $28{ }^{\circ} \mathrm{C}$. Luego de aproximadamente 3 días, cuando las plántulas desarrollaron una radícula de aproximadamente $2 \mathrm{~cm}$, un hipocótilo de $1 \mathrm{~cm}$ y los cotiledones apenas emergieron de la testa seminal, fueron transferidas cuidadosamente a bandejas de crecimiento inicial con sustrato comercial (Fig1.3 b). En la primera semana posterior al trasplante las plántulas fueron mantenidas a una irradiancia media, $\left(\approx 100 \mu\right.$ moles $\mathrm{m}^{-2} \mathrm{~s}^{-1}$ ) posteriormente fueron transferidas a la irradiancia de crecimiento definitiva $\left(\approx 400 \mu\right.$ moles $\left.\mathrm{m}^{-2} \mathrm{~s}^{-1}\right)$ y regadas con solución nutritiva de igual formulación que la solución utilizada para el crecimiento posterior. Las plantas fueron mantenidas en esta condición durante aproximadamente 10-15 días hasta observarse el inicio del crecimiento de la tercera hoja (Fig. 1.3 c). En este momento los plantines fueron trasplantados a recipientes de 1,5 litros con solución nutritiva de la siguiente formulación: $1,7 \mathrm{mM} \mathrm{Ca}\left(\mathrm{NO}_{3}\right)_{2}, 1,7 \mathrm{mM} \mathrm{KNO}_{3}, 2 \mathrm{mM} \mathrm{MgSO}_{4}, 1$ $\mathrm{mM} \mathrm{KH_{2 }} \mathrm{PO}_{4}, 20 \mu \mathrm{M}$ FeNaEDTA, $5 \mu \mathrm{M} \mathrm{H}_{3} \mathrm{BO}_{3}, 0,9 \mu \mathrm{M} \mathrm{MnCl}_{2}, 0,8 \mu \mathrm{M} \mathrm{ZnCl}, 0,3 \mu \mathrm{M}$ $\mathrm{CuSO}_{4}$ y $0,01 \mu \mathrm{M} \mathrm{Na} \mathrm{MoO}_{4}$ según Leggett y Frere, (1971) con modificaciones. Las plantas fueron sostenidas en la tapa de cada recipiente con gomaespuma en las etapas iniciales del crecimiento (Fig. $1.3 \mathrm{~d}$ ) y cuando alcanzaron un mayor tamaño y peso, fueron atadas del techo del invernáculo con tutores de hilo para mantenerlas erguidas (Fig. 1.3 e). La solución nutritiva se cambió cada 10 días y el volumen de agua consumido fue repuesto diariamente con agua destilada para evitar desbalances en la proporción de nutrientes. Se retiraron todas las ramas laterales emergidas del tallo principal al momento de su aparición, una práctica habitual en los sistemas de producción de tomate. 
CAPÍTULO I: Caracterización de plantas de tomate mutantes deficientes en GDP-L-galactosa fosforilasa: Fenología y parámetros de crecimiento.

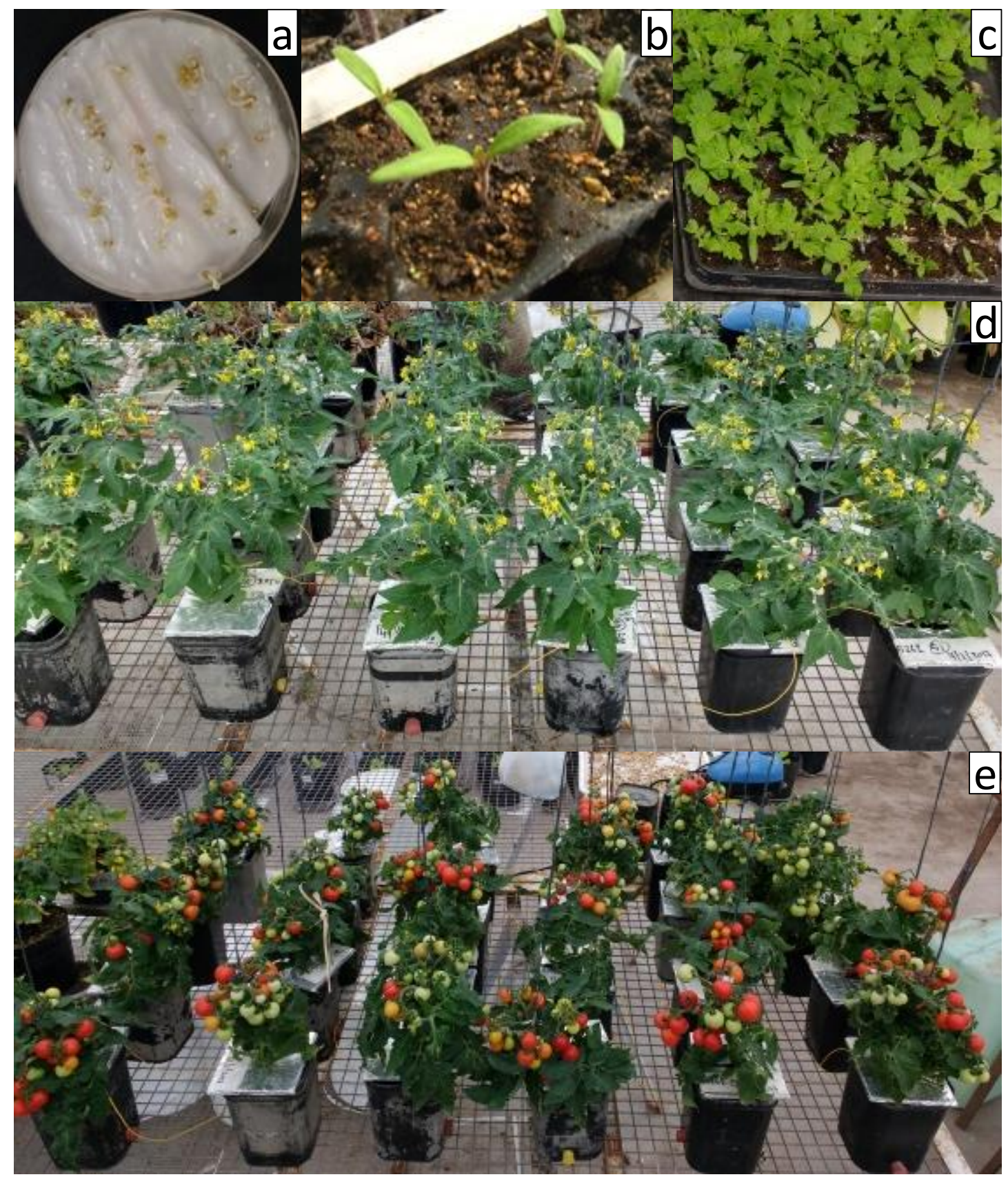

Figura 1.3-Sistema de cultivo.

a) germinación en placas de Petri. b) Bandejas de crecimiento, desarrollo inicial de cotiledones. c) Bandejas de crecimiento, plantines listos para el transplante. d) Sistema hidropónico, plantas en antesis. E) Sistema hidropónico, plantas con frutos rojos.

Cultivos sucesivos fueron realizados en invernáculo desde el mes de agosto hasta el mes de abril, durante estos meses la radiación fotosintéticamente activa registrada fue de $700-400 \mathrm{mM}$ fotones. $\mathrm{m}^{-2} \cdot \mathrm{s}^{-1}$ (Fig 1.4), la temperatura promedio de $25^{\circ} \mathrm{C}$ durante el día y $20^{\circ} \mathrm{C}$ durante la noche y la humedad relativa de 55 y $80 \%$ durante el día y la noche respectivamente (Fig. 1.5). A partir del mes de octubre hasta el mes de febrero inclusive fue activado un sistema automático de sombreo, con apertura y cierre 
CAPÍTULO I: Caracterización de plantas de tomate mutantes deficientes en GDP-L-galactosa fosforilasa: Fenología y parámetros de crecimiento.

controlado por temporizador, con el objetivo regular la temperatura del invernáculo en torno a los $25-27^{\circ} \mathrm{C}$. Por este motivo es que se observa una caída en la irradiancia entre las $12 \mathrm{~h}$ y hasta las $16 \mathrm{~h}$ (Fig. 1.4).

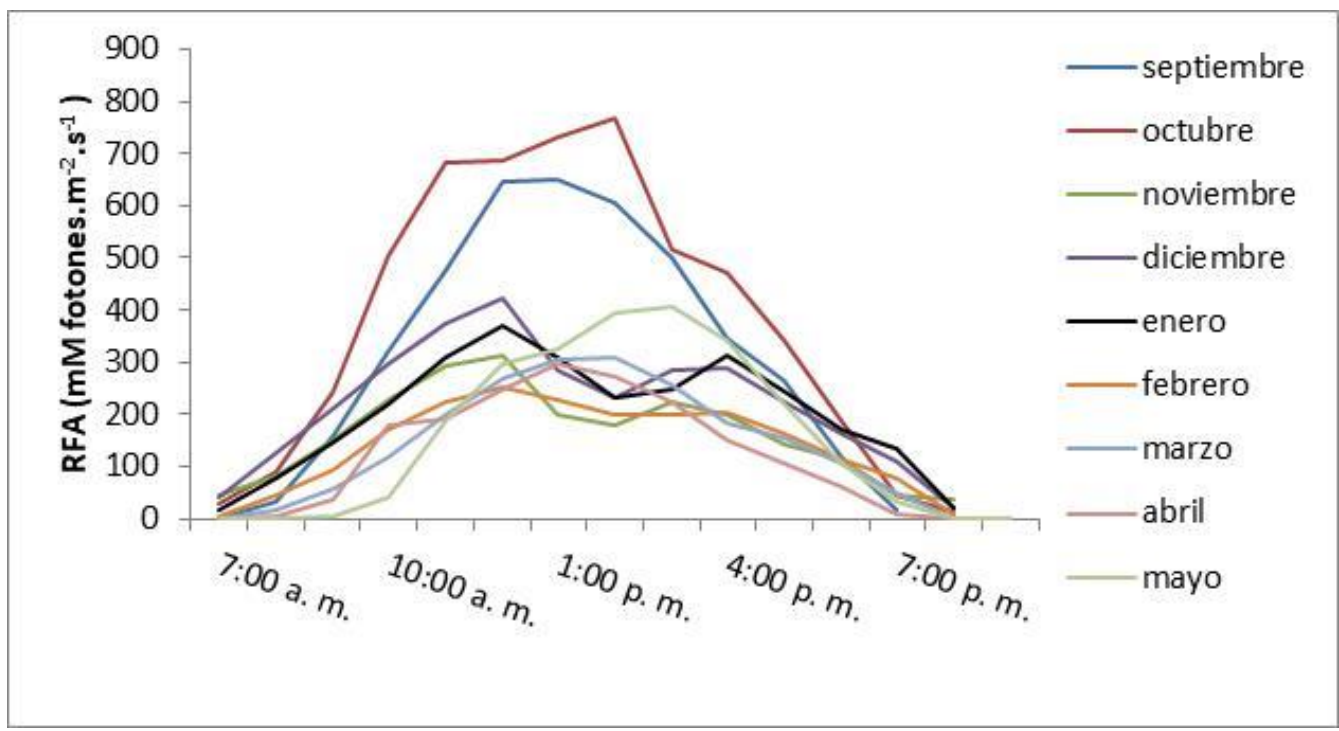

Figura 1.4-Irradiancias de cultivo.

Registradas a lo largo del día con un sensor cuántico LI-140. Radiación fotosintéticamente activa (RFA).

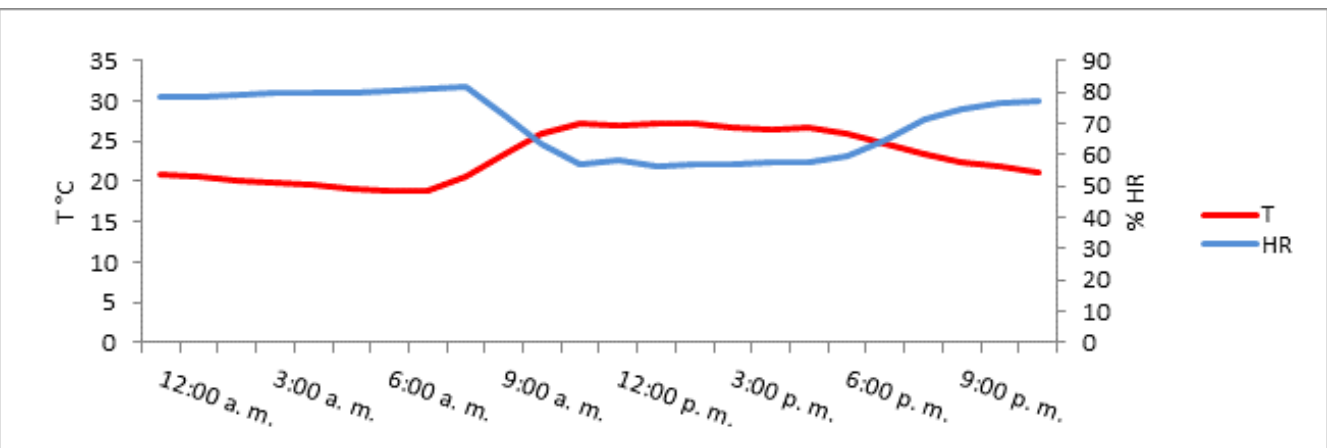

Figura 1.5-Temperatura y humedad relativa de cultivo.

Temperatura $\left(\mathrm{T}^{\circ} \mathrm{C}\right)$ y humedad relativa $(\mathrm{HR} \%)$ registradas durante las $24 \mathrm{~h}$ del día con un sensor digital HOBOware UX100-003.

\subsubsection{Determinación de los contenidos de ácido ascórbico y dehidroascórbico}

Cuando las plantas de cada genotipo alcanzaron el $50 \%$ de antesis $(50 \%$ de las plantas con al menos una flor en estado de antesis) se tomaron muestras de hojas, raíces y flores. Las muestras foliares $(200 \mathrm{mg})$ fueron tomadas a partir de hojas totalmente expandidas y expuestas a la luz en horas del mediodía. Se colecto una muestra foliar por planta de al menos 10 plantas de cada genotipo. Las muestras de 
CAPÍTULO I: Caracterización de plantas de tomate mutantes deficientes en GDP-L-galactosa fosforilasa: Fenología y parámetros de crecimiento.

raíz (200 mg) fueron tomadas del extremo más distal de la cabellera de raíces de plantas crecidas en hidroponía. Se colecto una muestra de raiz por planta de al menos 10 plantas de cada genotipo. Para las muestras de tejido floral se colectaron flores completas en estado de antesis de diferentes inflorescencias y diferentes plantas para crear al menos 10 muestras compuestas por cada genotipo. Se colectaron al menos 10 muestras de frutos por genotipo a partir de pericarpio-mesocarpio de diferentes frutos en tres estados de maduración diferentes, verde maduro $(\mathrm{VM})$, pink $(\mathrm{P})$ y rojo (R). (U.S.D.A., 1975). Las muestras de frutos en cada estado de maduración se confeccionaron de manera compuesta, tomando una porción de pericarpio de al menos tres frutos provenientes de plantas diferentes del mismo genotipo. Todas las muestras de tejido fueron congeladas en nitrógeno líquido y guardadas a $-80{ }^{\circ} \mathrm{C}$. Los muestreos se repitieron 3 veces a partir de diferentes tandas de plantas cultivadas bajo las mismas condiciones. Las mediciones de ácido ascórbico fueron realizadas mediante HPLC según Bartoli y col., (2006). Los distintos tejidos (hojas, raíz, flores, frutos) fueron congelados en nitrógeno líquido, homogeneizados en mortero con ácido trifluoracético $6 \%$ v/v y los homogenatos centrifugados a 13000 x g durante 5 min en centrífuga refrigerada a $4{ }^{\circ} \mathrm{C}$. Los sobrenadantes fueron recuperados y eludidos a través de columnas C-18 (Bond Elute, C18, Agilent Technologies, Santa Clara, United States). Las columnas de elución fueron equilibradas previamente con buffer fosfato $0,1 \mathrm{M} \mathrm{pH}=7$.

Para cuantificar el contenido de ácido ascórbico total (ácido ascórbico en su forma reducida + ácido dehidroascórbico) se realizó una mezcla de partes iguales de la

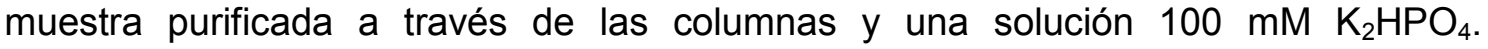
Posteriormente se agregó Ditritriotreitol (DTT) $3 \mathrm{mM}$. Y se incubó la mezcla durante 5 min a temperatura ambiente, por último se agregó un $10 \%$ del volumen de una solución de ácido trifluoracetico (TFA) $3 \%$ v/v, para re-acidificar la mezcla. Para la determinación de ácido ascórbico en su forma reducida (AA) en lugar de DTT se 
CAPÍTULO I: Caracterización de plantas de tomate mutantes deficientes en GDP-L-galactosa fosforilasa: Fenología y parámetros de crecimiento.

agregó agua. Las muestras fueron filtradas en columnas C-18 (Bond Elut C18, Agilent Technologies, Santa Clara, United States) e inyectadas en un sistema HPLC (Shimatzu LC-10Atvp solvent delivery module) equipado con una columna C-18 (ChromeSep HPLC Column SS 100x4.6mm MicroSpher C18, Varian, Santa Clara, United States). El buffer de corrida utilizado fue $100 \mathrm{mM}$ fosfato de potasio $\mathrm{pH}=3$, con un caudal de $0,5 \mathrm{ml} \mathrm{min}^{-1}$. La longitud de onda utilizada para la determinación fue de $\lambda$ $=265 \mathrm{~nm}$ (Shimadzu Co. UV- VIS Detector SPV-10AV, Japan). El estándar utilizado fue L-ácido ascórbico con una pureza del 99,9\% (Sigma-Aldrich®). Por diferencia entre el contenido de ácido ascórbico total y ácido ascórbico reducido se obtuvo el contenido de ácido dehidroascórbico. A partir de esto se caculó el porcentaje de oxidación del contenido total de ácido ascórbico de cada tejido. Durante todos los pasos del protocolo de extracción y cuantificación las muestras fueron mantenidas en un baño de agua y hielo para evitar oxidaciones indeseables, salvo cuando se indica lo contrario.

\subsubsection{Fenología}

Para llevar a cabo la caracterización fenológica de estas líneas de plantas se tomó como referencia la escala fenológica BBCH (Feller y col., 1995) cuya sigla deriva de las siguientes instituciones: Biologische Bundesanstalt, Bundessortenamt y CHemische Industrie; es un sistema para una codificación uniforme e identificación fenológica de estadios de crecimiento para especies de plantas mono- y dicotiledóneas. Es el resultado de un grupo de trabajo conformado por el Centro Federal de Investigaciones Biológicas para Agricultura y Silvicultura de la República Federal Alemana, el Instituto Federal de Variedades de la República Federal de Alemania, la Asociación Alemana de Agroquímicos y el Instituto para la Horticultura y Floricultura en Grossbeeren/ Erfurt, Alemania. Este código decimal se divide principalmente entre los estadios de crecimiento principal y secundario, y está basado en el código desarrollado por Zadozks y col. (1974). En esta tesis fue utilizada como referencia la escala adaptada para solanáceas por Meier, (2001). Dado que esta 
CAPÍTULO I: Caracterización de plantas de tomate mutantes deficientes en GDP-L-galactosa fosforilasa: Fenología y parámetros de crecimiento.

escala fue desarrollada para cultivares de tomate de crecimiento indeterminado se realizó una adaptación de esta para describir al cultivar Micro-Tom que presenta desarrollo determinado. De acuerdo con esto se eligieron los siguientes estadios fenológicos.

1. Inicio de imbibición de la semilla

2. Cotiledones completamente desplegados.

3. Expansión foliar completa.

$3.1,3.2,3.3 \ldots$ (Segundo dígito indica el número de hoja según orden cronológico de aparición)

4. Aparición de inflorescencias

$4.1,4.2,4.3,4.4 \ldots$ (Segundo digito indica cada inflorescencia en orden de aparición)

5. Antesis.

5.1.1, 5.1.2, 1.1.3... Tercer dígito indica cada una de las flores en orden de aparición.

6. Cuajado de frutos.

$6.1 .1,6.1 .2,6.1 .3, \ldots$ Tercer dígito indica cada uno de los frutos en orden de aparición

7. Estado de maduración Verde maduro.

$7.1 .1,7.1 .2,7.1 .3, \ldots$

8. Estado de maduración Pink.

8.1.1, 8.1.2, 8.1.3...

9. Estado de maduración Rojo.

8.1.1, 8.1.2, 8.1.3...

Las observaciones fueron realizadas cada dos días durante todo el desarrollo de las plantas y se registró el estado fenológico de cada planta a partir de la asignación del código correspondiente. Las inflorescencias se marcaron con una etiqueta en orden cronológico de aparición. Posteriormente, cada uno de los pimpollos florales, se marcó y numeró en orden de aparición. Estas marcas permanecieron en la planta y permitieron la identificación de cada uno de los frutos (Figura 1.6). 


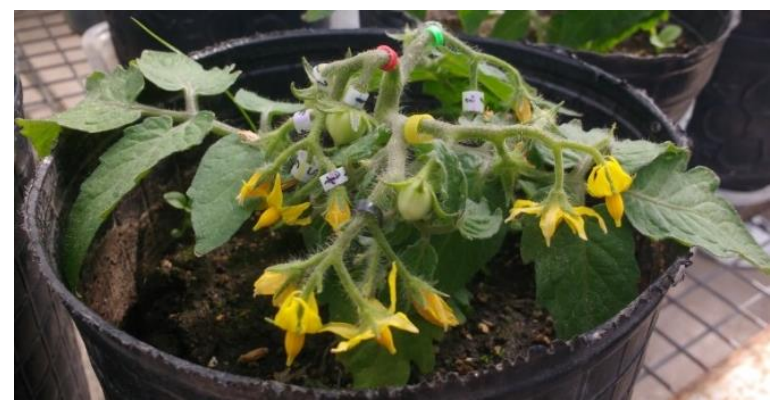

Figura 1.6- Etiquetas en flores e inflorescencias.

Marcas de color en las primeras 4 inflorescencias y marcas numeradas en cada una de las flores.

El tiempo de aparición de cada una de las hojas fue calculado como el tiempo transcurrido entre la imbibición de la semilla y el momento en el que cada una de las hojas llegó hasta su máxima expansión. El tiempo hasta la aparición de cada una de las inflorescencias fue calculado como el tiempo transcurrido entre la imbibición de la semilla y la visualización del primer pimpollo de cada inflorescencia (Fig. 1.7. a).

El tiempo de floración fue calculado a partir del número de días transcurridos entre la imbibición de la semilla y la antesis de cada una de las flores de las primeras 4 inflorescencias de cada planta (Fig. 1.7. b). A partir de estos valores ( $n^{\circ}$ días) se obtuvo un promedio que fue considerado como el tiempo de antesis plena de cada planta. Luego se calculó la cantidad de días promedio en alcanzar la floración de cada genotipo mediante el promedio del tiempo de antesis plena de cada planta (momento del desarrollo en el cual se concentró la mayor cantidad de flores en estado de antesis en el set de plantas). El tiempo de cuajado de los frutos fue calculado a partir del tiempo ( $\mathrm{n}^{\circ}$ días) transcurrido entre la imbibición de la semilla y la visualización de la corola floral marchita y el fruto de 1-2 mm iniciando el crecimiento (Fig. 1.7. c) de cada una de las flores de las primeras 4 inflorescencias de cada planta, se obtuvo un promedio de estos valores que fue considerado como el tiempo de cuajado de cada planta para cada inflorescencia y a partir de estos valores se calculó el tiempo promedio hasta el cuajado de los frutos de cada genotipo en cada una de las inflorescencias. En cada ensayo se siguió el desarrollo fenológico de 15 plantas por 
CAPÍTULO I: Caracterización de plantas de tomate mutantes deficientes en GDP-L-galactosa fosforilasa: Fenología y parámetros de crecimiento.

genotipo y fueron realizados tres ensayos independientes. Los datos obtenidos se procesaron mediante un análisis de varianza de una vía con un diseño completamente al azar. Se utilizó el test Tukey (ANOVA P <0,05).

La información obtenida a partir de estos ensayos fue utilizada en ensayos posteriores para definir de manera objetiva los momentos fenológicos para la toma de muestras, inicio o finalización de tratamientos.

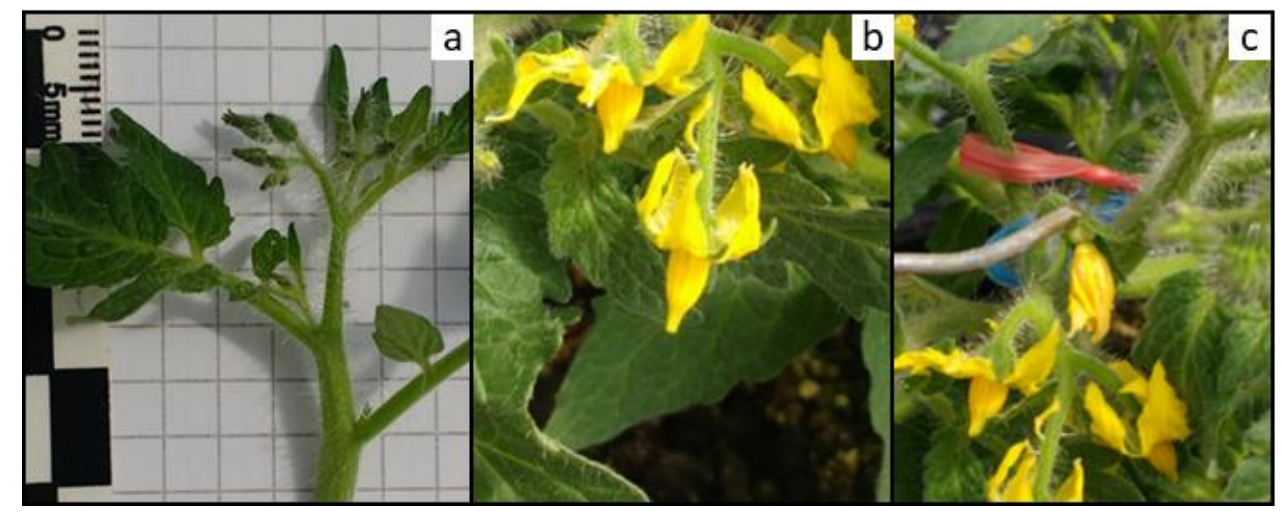

Figura 1.7-Organos reproductivos del tomate.

a) Inflorescencia con pimpollos. b) flores en antesis. c) cuajado de fruto.

\subsubsection{Parámetros de crecimiento}

Para el estudio de los parámetros de crecimiento de los mutantes slggp1 y el genotipo silvestre, 40 plantas de cada genotipo fueron cultivadas en medio hidropónico completo, como se detalló previamente. Tomando como referencia los estadios fenológicos comentados antes se realizó una selección de los 7 momentos más relevantes a lo largo del desarrollo para realizar muestreos destructivos y cuantificar la partición de la biomasa en cada en cada uno de los genotipos. El primer muestreo (I) fue realizado sobre plántulas luego de 3 días de germinación en cápsulas de Petri, en este caso 30 plántulas de cada genotipo fueron pesadas con una balanza de precisión (Mettler 5 decimales). El segundo muestreo (II) fue realizado en el momento de trasplante de los plantines desde la bandeja de crecimiento al sistema hidropónico definitivo, en este muestreo se registró el peso fresco total (PF total) de 15 plantines 
CAPÍTULO I: Caracterización de plantas de tomate mutantes deficientes en GDP-L-galactosa fosforilasa: Fenología y parámetros de crecimiento.

de cada genotipo y además se registró el peso por separado de la parte aérea (tallo principal PF) y de la raíz (raíz PF). El tercer (III) muestreo fue realizado cuando las plantas presentaron la hoja 4 completamente expandida. El cuarto (IV) muestreo se realizó cuando el $50 \%$ de las plantas silvestres presentaron al menos una flor en estado de antesis en la primera inflorescencia. El quinto (V) muestreo fue realizado cuando el $50 \%$ de las plantas mutantes slggp1 presentaron al menos una flor en estado de antesis en la primera inflorescencia. El sexto (VI) muestreo se realizó cuando el $50 \%$ de las plantas silvestres presentaron al menos un fruto en estado de maduración rojo en la primera inflorescencia. El séptimo (VII) muestreo se realizó cuando el $50 \%$ de las plantas mutantes slggp1 presentaron al menos un fruto en estado de maduración rojo en la primera inflorescencia (Fig. 1.8 a, b, c, d, e, f, g respectivamente)

\subsubsection{Parámetros registrados}

En los muestreos IV, V, VI y VII 5 plantas de cada genotipo fueron elegidas mediante el sorteo al azar y los siguientes parametros de crecimiento fueron registrados:

- Peso fresco de las hojas.

- Peso fresco del tallo, incluyendo tallo principal más inflorescencias.

- Peso de la raiz completa.

- Peso fresco de cada fruto individual.

- Peso fresco del total de frutos por planta.

- Longitud de entrenudos.

- Número de frutos por planta en cada estado de maduración.

- Numero de flores por planta en cada estado de maduración.

- Área foliar total por planta.

El peso fresco de cada órgano fue determinado inmediatamente luego de tomar la muestra con una balanza portátil de precisión (Schimadzu; d=0.001). Luego el material fresco fue colocado dentro de sobres de papel y secado en estufa a $60^{\circ} \mathrm{C}$ hasta peso constante para registrar el peso seco (PS) en una balanza de precisión analógica (Mettler; $d=0.0005)$. 
CAPÍTULO I: Caracterización de plantas de tomate mutantes deficientes en GDP-L-galactosa fosforilasa: Fenología y parámetros de crecimiento.

La longitud de la raíz se midió desde el cuello de la planta, donde aparece la primera raíz adventicia, hasta el extremo más distal de la cabellera de raíces y la longitud de entrenudos fue determinada con un calibre digital desde una base foliar a la siguiente base foliar.

El número de frutos fue registrado para cada uno de los siguientes estados de maduración de los mismos: verde inmaduro, verde maduro, pink, rojo y el número de flores fue registrado contando el número de pedúnculos florales-frutales presentes en el raquis de cada inflorecencia, esto permitió el registro del número total de flores en los muestreos realizados en etapas finales del desarrollo.

Para determinar el área foliar se escanearon las hojas junto con un patrón y posteriormente se realizó el cálculo del área foliar mediante el análisis de las imágenes (ImageJ Fiji). 


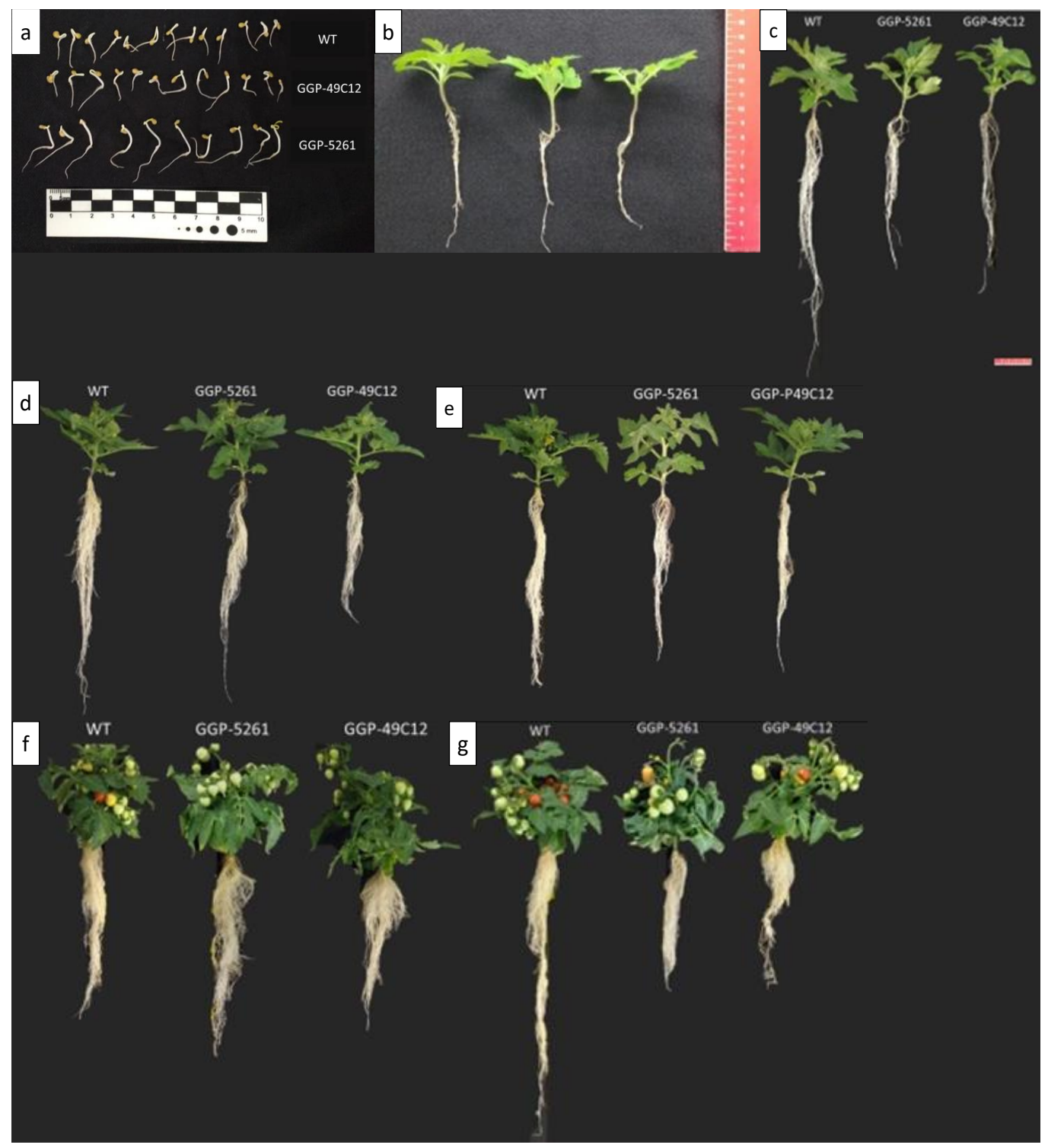

Figura 1.8-Estados fenológicos elegidos para la realización de muestreos y estudio del desarrollo.

a) Plántulas germinadas en capsulas de Petri; b) Plantines trasplante desde el bandejas de crecimiento inicial a las macetas de hidroponía; c) Hoja 4 completamente expandida; d) $50 \%$ de antesis del genotipo silvestre (WT); e) $50 \%$ de antesis de mutantes slggp1 (GGP-49C12 y GGP-5261); f) 50\% de frutos rojos en el genotipo silvestre; g) $50 \%$ de frutos rojos en mutantes sggp 1

\subsection{Resultados}

\subsubsection{Contenido de ácido ascórbico en hojas, raíz, flores y frutos en distintos} estados de madurez.

Los dos mutantes deficientes en GDP-L-galactosa fosforilasa presentaron una considerable reducción del contenido de ácido ascórbico con respecto al genotipo silvestre, en todos los órganos analizados (Fig. 1.9 a,b,c,d). Se cuantificó el contenido 
CAPÍTULO I: Caracterización de plantas de tomate mutantes deficientes en GDP-L-galactosa fosforilasa: Fenología y parámetros de crecimiento.

de ascórbico total y su estado redox en hojas, frutos, flores y raíces, estos órganos presentaron diferencias en el contenido de este metabolito.

La mayor concentración de ácido ascórbico fue registrada en los tejidos foliares. En el genotipo silvestre la concentración de ácido ascórbico total alcanzó una media de 10,35 $\mu \mathrm{mol} \mathrm{g}{ }^{-1}$ PF (Fig.1.9. a). La hoja fue el órgano más afectado por la deficiencia en GDP-L-galactosa fosforilasa 1 ya que el contenido de ascórbico solo alcanzó un 34 y un $36 \%$ en GGP-49C12 y GGP-5261 (3,47 y 3,67 $\mu \mathrm{mol} \mathrm{g}^{-1} \mathrm{PF}$ ) respectivamente, del contenido registrado en el genotipo silvestre (Fig. 1.9. a). El porcentaje del pool de ácido ascórbico en estado oxidado no fue afectado por la deficiencia en GDP-Lgalactosa fosforilasa 1 en hojas. En el genotipo silvestre un $20,3 \%$ del total de ácido ascórbico fue registrado en su forma oxidada y en los genotipos GGP-49C12 y GGP5261 un 19,2 y $22,2 \%$ respectivamente (Fig. 1.9. a).

En las flores se registró un contenido de ácido ascórbico similar a los tejidos foliares, que alcanzó una media de $9,87 \mu \mathrm{mol} \mathrm{g}{ }^{-1}$ PF en el genotipo silvestre (Fig. 1.9. c). En estos órganos los mutantes slggp1 presentaron un contenido medio de ácido ascórbico equivalente al 50,5 y 59,0 \% en GGP-49C12 y GGP-5261, respectivamente, comparado con el contenido de ácido ascórbico registrado en las flores del genotipo silvestre (Fig. 1.9. c). En estos tejidos el pool de ácido ascórbico en estado oxidado sólo fue afectado por la deficiencia en slggp1 en el mutante GGP-49C12. En el genotipo silvestre un $19,2 \%$ del total de ácido ascórbico fue registrado en su forma oxidada $y$ en los genotipos GGP-49C12 y GGP-5261 un 35,64 y 21,46 \% respectivamente (Fig. 1.9. c).

La concentración más baja de ácido ascórbico fue registrada en las raíces, aquí el genotipo silvestre presentó un contenido medio de $1,48 \mu \mathrm{mol} \mathrm{g}^{-1} \mathrm{PF}$ (Fig. 1.9. b). En este órgano los mutantes presentaron un 50 y $54 \%$ del contenido medido en el genotipo silvestre en GGP-49C12 y GGP-5261, respectivamente (Fig. 1.9. b). En estos 
CAPÍTULO I: Caracterización de plantas de tomate mutantes deficientes en GDP-L-galactosa fosforilasa: Fenología y parámetros de crecimiento.

tejidos la mayor parte del pool se encontró en forma oxidada aunque este parámetro no fue afectado por la deficiencia en GDP-L-galactosa fosforilasa 1. En el genotipo silvestre un $63,4 \%$ del total de ácido ascórbico fue registrado en su forma oxidada y en los genotipos GGP-49C12 y GGP-5261 un 71,0 y 67,35 \% respectivamente; estas diferencias en el porcentaje de oxidación no resultaron significativas (Fig. 1.9. b).

En los frutos del genotipo silvestre se registró un contenido de ascórbico total promedio de 2,$35 ; 2,11$ y $2,35 \mu \mathrm{mol} \mathrm{g}^{-1} \mathrm{PF}$ en $\mathrm{VM}, \mathrm{P}$ y $\mathrm{R}$ respectivamente, que no representaron diferencias significativas entre estados de maduración (Fig. 1.9. d). En este órgano el contenido de ascórbico en los genotipos mutantes slggp1 fue de un 40$50 \%$ con respecto al genotipo silvestre y tampoco se observaron variaciones significativas entre los estadios de maduración para ninguno de los genotipos (Fig. 1.9. d). El porcentaje de ácido ascórbico oxidado mostró una variación de un 15-20 \% entre el estado VM y el estadio R, pero esta variación no representó una diferencia estadística significativa entre estadios de maduración en este órgano. Tampoco se observaron diferencias entre genotipos con respecto al porcentaje de ácido ascórbico oxidado en frutos (Fig. 1.9. d). 
CAPÍTULO I: Caracterización de plantas de tomate mutantes deficientes en GDP-L-galactosa fosforilasa: Fenología y parámetros de crecimiento.
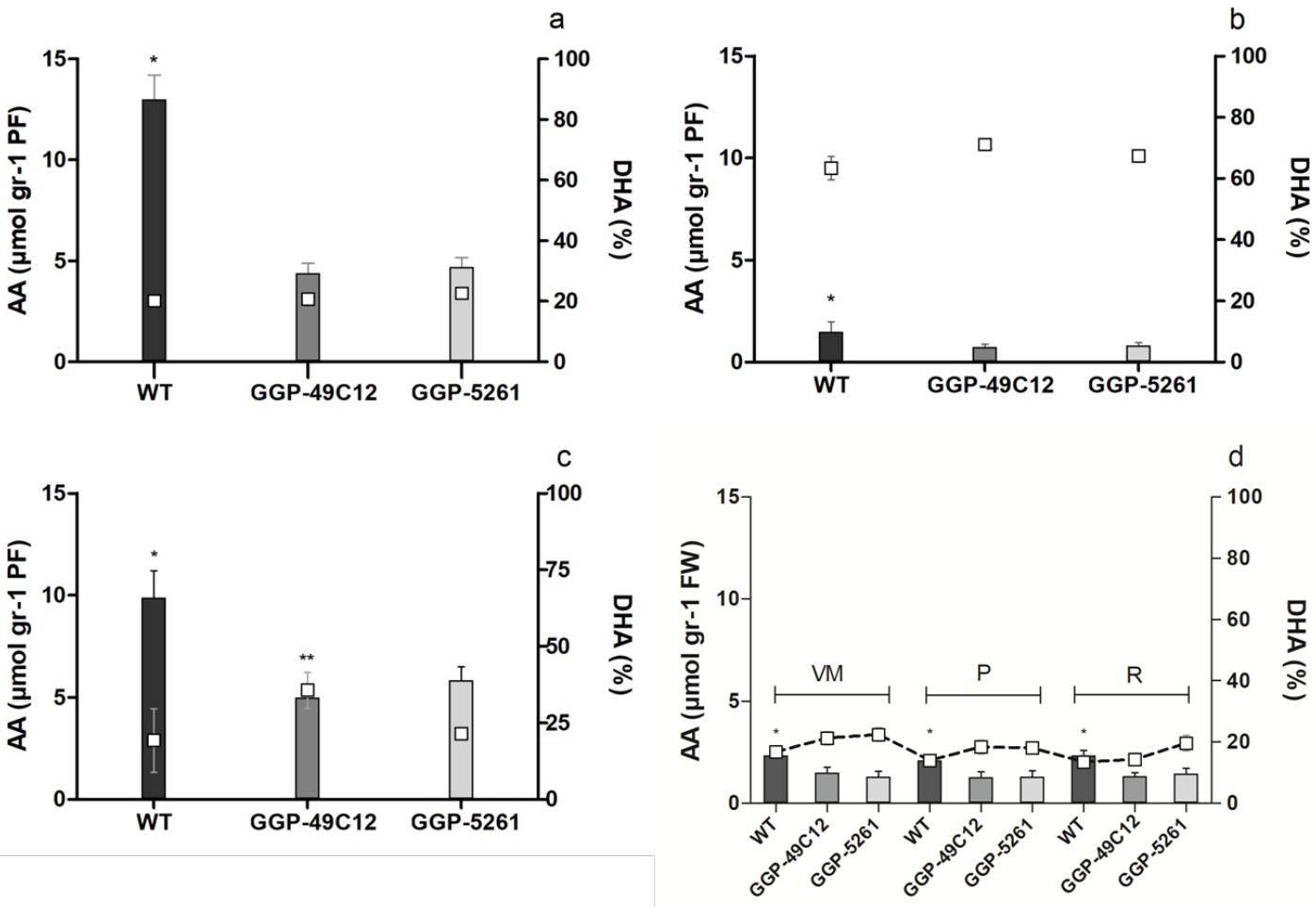

Figura 1.9-Contenido de ácido ascórbico en distintos órganos de mutantes slggp1 (GGP49C12 y GGP-5261) y genotipo silvestre (WT).

Las barras indican concentración de ascórbico total (AA) y los diamantes vacíos indican el porcentaje de ácido ascórbico oxidado en: a) hojas, b) raíces, c) flores y d) frutos en estado de maduración verde maduro (VM), pintón $(P)$ y rojo $(R)$. Los valores fueron obtenidos de al menos tres experimentos diferentes y expresados como promedios \pm SD. $\left({ }^{*}\right)$ Indica diferencias significativas entre genotipos (ANOVA, $P<0.05$ )

\subsubsection{Caracterización fenológica}

En los genotipos mutantes slggp1, se observó un retraso en el tiempo hasta la expansión completa de cada una de sus hojas (Fig. 1.10 .a) y un retraso en la aparición de las primeras 4 inflorescencias (Fig. 1.10. b) con respecto al genotipo silvestre. Como consecuencia de este retraso en su desarrollo, las plantas mutantes slggp1 necesitaron un mayor número de días para alcanzar el estado de antesis plena (Fig. 1.10. c) y también se vio retrasado el tiempo hasta el cuajado de los frutos en ambos genotipos deficientes en GDP-L-galactosa fosforilasa 1 (Fig. 1.10. d) 


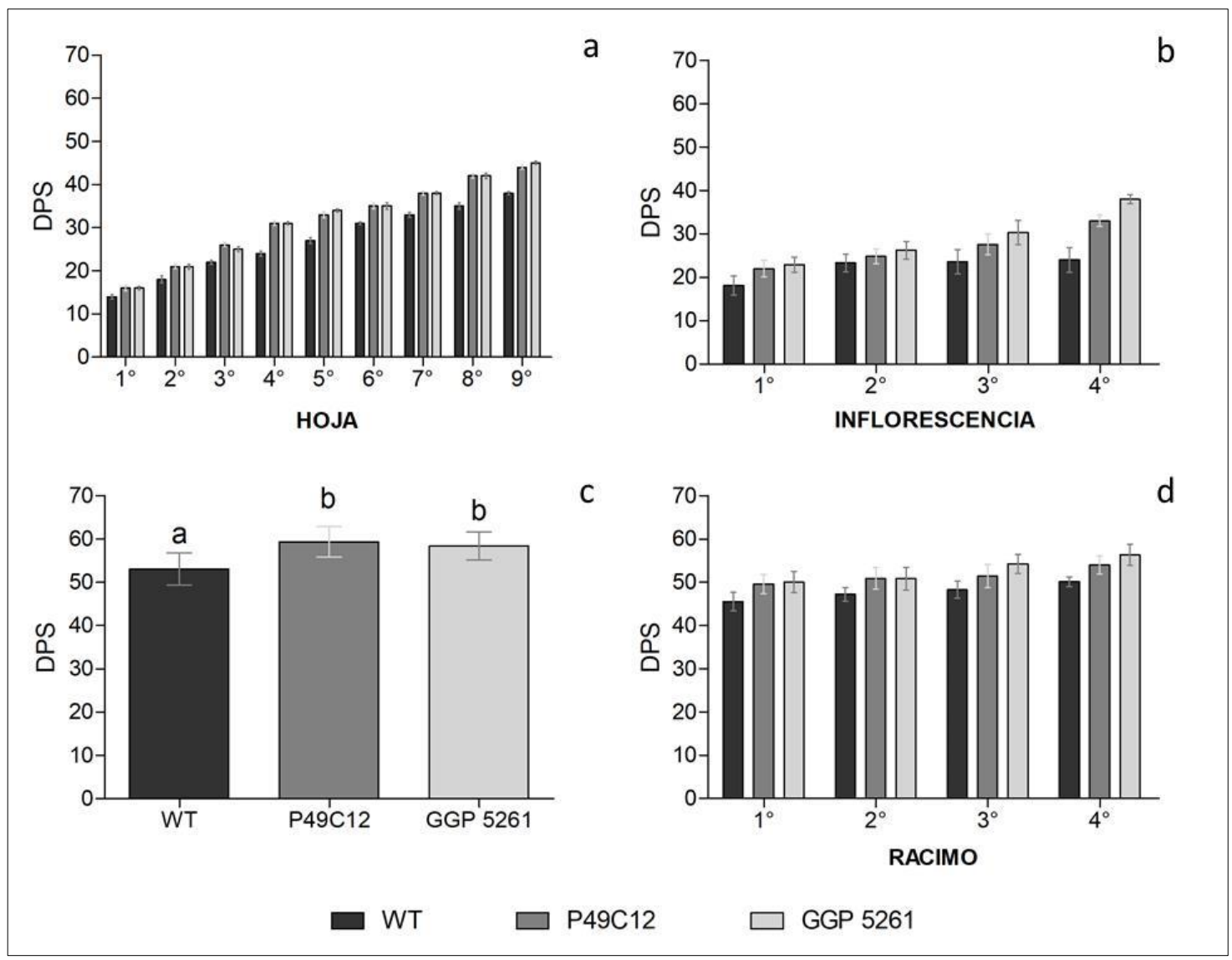

Figura 1.10-Tiempo de desarrollo vegetativo y reproductivo.

Días posteriores a la siembra (DPS) hasta: a) la expansión completa de las primeras 9 hojas b); Aparición de cada una de las primeras 4 inflorescencias; c); antesis promedio y d); cuajado de los frutos en los primeras 4 racimos. En los genotipos mutantes slggp1 (GGP-49C12 y GGP5261) y silvestre (WT).

La maduración en planta de los frutos mutantes slggp1 presentó un retraso con respecto a los frutos del genotipo silvestre (Fig. 1.11 d). Al observar el tiempo necesario para alcanzar el estadio VM a partir del momento de cuajado de los frutos, no se observan diferencias entre los genotipos (Fig. 1.11 a). En cambio a partir del estadio VM, los frutos de los mutantes slggp1 tardaron más tiempo en alcanzar el estadio P (Fig. 1.11 b). Luego a partir del estadio $\mathrm{P}$ los distintos genotipos no presentaron diferencias en el tiempo requerido para alcanzar el estadio R (Fig. $1.11 \mathrm{c}$ ). 

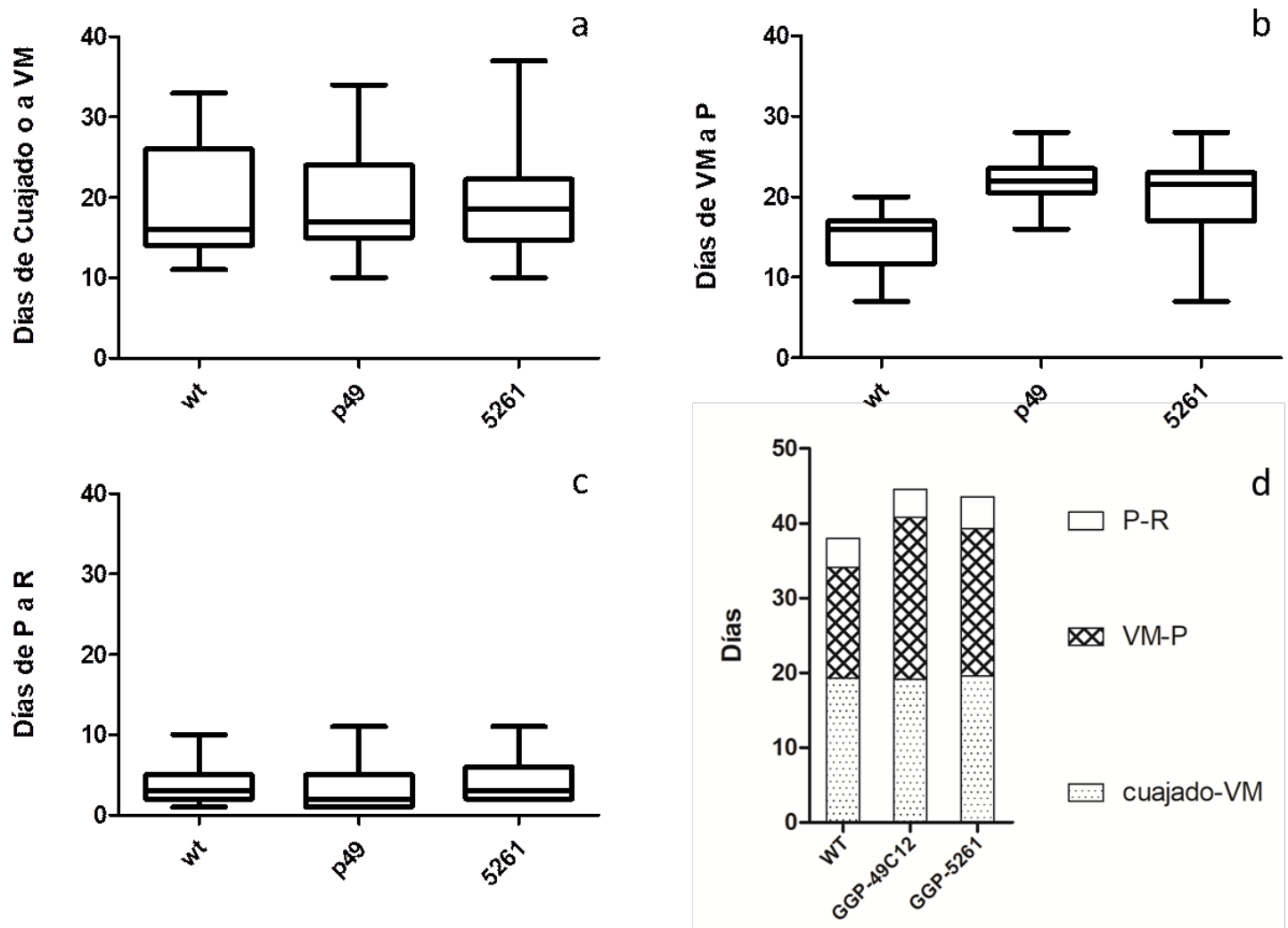

Figura 1.11-Tiempo en días requerido por cada genotipo para pasar de un estado de maduración a otro.

a) Desde el cuajado de fruto a el estadio VM; b) desde el estadio verde maduro (VM) al estadio pintón $(P)$; c) desde el estadio $P$ al estadio rojo $(R)$; d) representación gráfica del tiempo en días requerido por cada genotipo para alcanzar el estado de maduración $\mathrm{R}$ y los estadios anteriores VM y P. En los genotipos mutantes slggp1 (GGP-49C12 y GGP-5261) y silvestre (WT).

\subsubsection{Parámetros de crecimiento durante el desarrollo}

\subsubsection{Peso de los distintos órganos y área foliar}

El peso total de las plantas muestra una variación significativa al momento de trasplante (II) donde las plantas GGP-49C12 muestran un mayor peso fresco total y esto se debe a un mayor peso de la porción radical de estas plantas (Tabla 1.1). Posteriormente en el desarrollo vegetativo (muestreos III, IV, y V) no se observan diferencias en la biomasa total entre las líneas mutantes y la línea silvestre. En los muestreos finales (VI y VII) cuando las plantas tienen frutos se observan diferencias significativas en la biomasa total siendo las plantas de la línea silvestre más pesadas que las plantas mutantes. (Figura 1.12). En la figura 1.12 se puede observar que en los dos muestreos finales (VI y VII) el porcentaje del peso total representado por los 
CAPÍTULO I: Caracterización de plantas de tomate mutantes deficientes en GDP-L-galactosa fosforilasa: Fenología y parámetros de crecimiento.

frutos es inferior en los genotipos mutantes con respecto al genotipo silvestre, mientras que el peso vegetativo no muestra diferencias entre los genotipos.

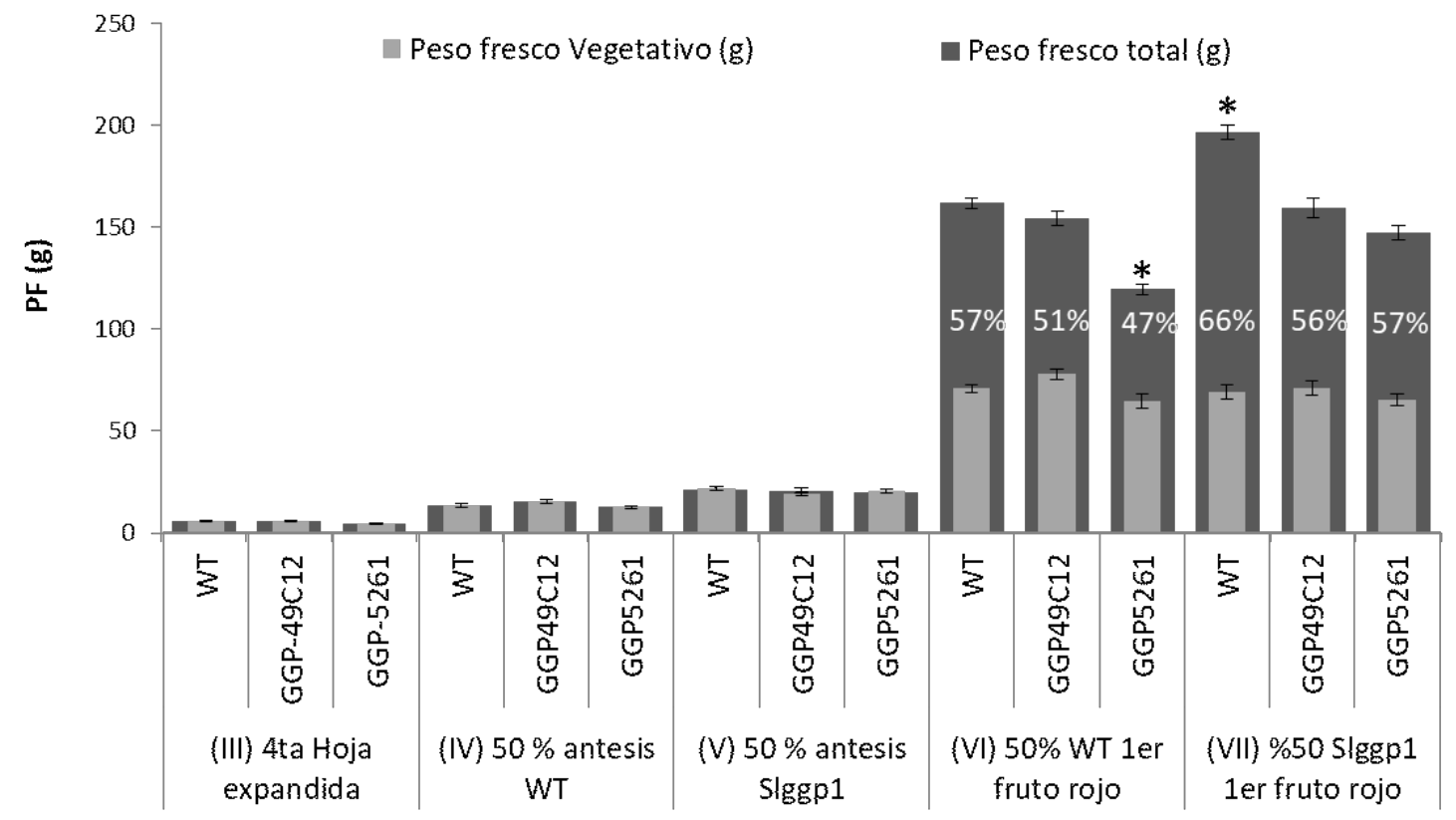

Figura 1.12 Peso fresco total y peso fresco vegetativo a lo largo del desarrollo.

Peso fresco (PF) total y vegetativo en gramos (g). Parámetros registrados en los genotipos mutantes slggp1 (GGP-49C12 y GGP-5261) y silvestre (WT).a lo largo del desarrollo en los muestreos III, IV, V, VI y VII.Se indica el porcentaje del peso fresco total que corrsponde al peso fresco de frutos. Se indican con asteriscos $\left({ }^{*}\right)$ las diferencias significativas entre genotipos para cada muestreo.

La biomasa foliar y el área foliar no muestran diferencias significativas entre ninguna de las líneas de plantas a lo largo del desarrollo (Tabla 1.1). El peso del tallo principal así como también la suma de la longitud de entrenudos es mayor en los genotipos mutantes con respecto al genotipo silvestre y estas diferencias se observan sobre el final del desarrollo (muestreos VI y VII) (Tabla 1.1). Se determinó el peso de las inflorescencias (raquis y pedicelos florales) y se observó que en el momento en que las plantas tenían la cuarta hoja completamente expandida (muestreo III), las plantas silvestres presentaron mayor peso de este órgano que las plantas mutantes slggp1 así como también en el muestreo IV, pero en esta ocasión se encontró que las plantas del genotipo silvestre presentaron mayor peso de inflorescencias que el mutante GGP49C12 sin mostrar diferencias con respecto al mutante GGP-5261(Tabla 1.1). 
CAPÍTULO I: Caracterización de plantas de tomate mutantes deficientes en GDP-L-galactosa fosforilasa: Fenología y parámetros de crecimiento.

A pesar de encontrarse una mayor biomasa radicular en plántulas GGP-49C12 al momento de trasplante (II), la biomasa radicular presentó una tendencia a ser mayor en el genotipo silvestre cuando el desarrollo de las plantas alcanzó el período de antesis avanzada y fructificación (muestreos V, VI, y VII) (Tabla 1.1). En el muestreo realizado durante la antesis de los mutantes (muestreo $\mathrm{V}$ ) se observó que la biomasa radicular resultó mayor en el genotipo silvestre con respecto al mutante GGP-5261 y no se observaron diferencias significativas con respecto al mutante GGP-49C12 (Tabla 1.1). Posteriormente en los muestreos realizados durante el período de fructificación (muestreos VI y VII) se observó una tendencia similar presentando mayor biomasa radicular el genotipo silvestre con respecto al mutante GGP5261 pero sin diferencias significativas con respecto al mutante GGP-49C12 (Tabla 1.1). Con respecto a la arquitectura de la raíz, se observó una menor longitud de las raíces en los genotipos mutantes en la mayoría de los muestreos realizados a lo largo del desarrollo (Figura1.13; Tabla 1.1). Por otro lado, las plantas mutantes slggp1 presentaron una mayor longitud de entrenudos que las plantas del genotipo silvestre, y esto resultó en una mayor altura de las plantas mutantes (Figura1.13 a y b; Tabla 1.1) 
Tabla 1. 1 Parámetros de crecimiento de los genotipos mutantes slggp1 y silvestre.

\begin{tabular}{|c|c|c|c|c|c|c|c|c|}
\hline Muestreos & Genotipo & $\begin{array}{l}\text { Hojas } \\
\text { PF(g) }\end{array}$ & $\begin{array}{c}\text { Tallo } \\
\text { principal } \\
\text { PF(g) }\end{array}$ & $\begin{array}{l}\text { Raquis y } \\
\text { pedúnculos } \\
\text { florales } \\
\text { PF (g) }\end{array}$ & $\begin{array}{l}\text { Raíz } \\
\text { PF(g) }\end{array}$ & $\begin{array}{c}\text { Suma de } \\
\text { distancia } \\
\text { entrenudos } \\
\text { (mm) }\end{array}$ & $\begin{array}{l}\text { Área foliar } \\
\text { (cm2) }\end{array}$ & $\begin{array}{l}\text { Longitud de } \\
\text { la raíz }\end{array}$ \\
\hline \multirow[t]{3}{*}{ (II) Trasplante } & WT & $0,434 \pm 0,087 a$ & & & $0,057 \pm 0,022 a$ & & & \\
\hline & GGP-49C12 & $0,567 \pm 0,077 b$ & & & $0,077 \pm 0,022 b$ & & & \\
\hline & GGP-5261 & $0,470 \pm 0,049 a$ & & & $0,045 \pm 0,021$ a & & & \\
\hline \multirow{3}{*}{$\begin{array}{l}\text { (III) } 4^{\text {ta }} \text { Hoja } \\
\text { expandida }\end{array}$} & WT & $3,01 \pm 0,45 a$ & $0,82 \pm 0,08 a$ & $1,672 \pm 0,08 a$ & $1,29 \pm 0,40 a$ & $30,4 \pm 7,4$ a & $95,0 \pm 13,2 a$ & $34,9 \pm 6,9$ a \\
\hline & GGP-49C12 & $3,29 \pm 0,80 a$ & $0,91 \pm 0,24 a$ & $0,037 \pm 0,07 b$ & $0,10 \pm 0,27 a$ & $33,1 \pm 6,5$ a & $98,8 \pm 23,4$ a & $24,2 \pm 2,5 b$ \\
\hline & GGP-5261 & $2,58 \pm 0,37 a$ & $0,86 \pm 0,12 a$ & $0,039 \pm 0,02 b$ & $0,85 \pm 0,20 a$ & $32,5 \pm 9,8$ a & $81,7 \pm 11,6$ a & $23,4 \pm 6,5 b$ \\
\hline \multirow{3}{*}{$\begin{array}{c}\text { (IV) } 50 \% \text { antesis } \\
\text { WT }\end{array}$} & WT & $7,40 \pm 1,67 a$ & $1,75 \pm 0,32 a$ & $0,77 \pm 0,31 \mathrm{a}$ & $3,03 \pm 0,67 a$ & $46,2 \pm 4,9 a$ & $230,9 \pm 57,1 a$ & $43,4 \pm 8,9 a$ \\
\hline & GGP49C12 & $8,53 \pm 1,67 a$ & $2,57 \pm 0,24 b$ & $0,63 \pm 0,28 a$ & $3,12 \pm 1,02$ a & $53,7 \pm 4,0 b$ & $248,9 \pm 38,9$ a & $35,0 \pm 2,1 a b$ \\
\hline & GGP5261 & $7,23 \pm 1,45 a$ & $2,72 \pm 0,52 b$ & $0,53 \pm 0,24 a$ & $2,01 \pm 0,48 a$ & $59,1 \pm 3,1 b$ & $214,9 \pm 33,9 a$ & $32,0 \pm 6,0 b$ \\
\hline \multirow{3}{*}{$\begin{array}{c}\text { (V) } 50 \% \text { antesis } \\
\text { slggp1 }\end{array}$} & & $11,34 \pm 1,49 a$ & $3,34 \pm 0,52 a$ & $1,67 \pm 0,46 a$ & $4,90 \pm 1,45 a$ & $62,1 \pm 5,8 a$ & $333,6 \pm 30,3 a$ & $45,5 \pm 3,7$ a \\
\hline & GGP49C12 & $11,42 \pm 1,82 a$ & $3,24 \pm 0,43 a$ & $0,91 \pm 0,22 b$ & $3,25 \pm 0,93 a b$ & $67,0 \pm 8,1 \mathrm{ab}$ & $334,7 \pm 32,3 a$ & $36,0 \pm 2,9 b$ \\
\hline & GGP5261 & $11,06 \pm 1,89 a$ & $4,26 \pm 0,84 b$ & $1,24 \pm 0,30 a b$ & $3,10 \pm 0,38 b$ & $80,0 \pm 13,0 b$ & $316,8 \pm 57,6$ a & $35,3 \pm 7,4 b$ \\
\hline \multirow{3}{*}{$\begin{array}{l}(\mathrm{VI}) 50 \% \mathrm{WT} 1^{\mathrm{er}} \\
\text { fruto rojo }\end{array}$} & WT & $35,60 \pm 2,61 a$ & $8,07 \pm 1,36 a$ & $8,82 \pm 1,35 a$ & $16,69 \pm 2,10 a$ & $80,6 \pm 11,1 a$ & $925,5 \pm 155,8 a$ & $51,7 \pm 10,9 a$ \\
\hline & GGP49C12 & $38,83 \pm 3,53 a$ & $10,12 \pm 1,10 b$ & $10,02 \pm 1,64 a$ & $16,83 \pm 3,85 a$ & $102,1 \pm 14,9 a b$ & $958,1 \pm 108,8$ a & $41,7 \pm 6,2$ a \\
\hline & GGP5261 & $33,54 \pm 7,03 a$ & $10,34 \pm 1,08 b$ & $8,54 \pm 2,83 a$ & $10,83 \pm 2,27 b$ & $124,8 \pm 40,6 b$ & $859,6 \pm 168,2 a$ & $47,0 \pm 11,6 a$ \\
\hline \multirow{3}{*}{$\begin{array}{l}\text { (VII) \%50 slggp1 } \\
1^{\text {er }} \text { fruto rojo }\end{array}$} & WT & $34,1 \pm 7,2$ a & $7,2 \pm 1,4 a$ & $8,5 \pm 1,6 a$ & $20,3 \pm 4,2 a$ & $78,8 \pm 15,1$ a & $853,2 \pm 165,8 a$ & $63,0 \pm 4,2 a$ \\
\hline & GGP49C12 & $32,7 \pm 6,2 a$ & $8,9 \pm 1,3 a$ & $10,1 \pm 1,4 a b$ & $15,7 \pm 3,6 b$ & $99,5 \pm 15,8 a b$ & $887,8 \pm 236,8 a$ & $45,0 \pm 7,3 b$ \\
\hline & GGP5261 & $30,4 \pm 4,8$ & $9,0 \pm 2,1 \quad a$ & $11,0 \pm 1,5 b$ & $12,7 \pm 3,4 \mathrm{c}$ & $108,4 \pm 11,5 b$ & $906,1 \pm 116,2$ & $46,4 \pm 11,5 b$ \\
\hline
\end{tabular}

Peso fresco promedio total por planta y de los distintos órganos (hojas, tallo principal, raquis de inflorescencia y pedúnculos florales, raíz) suma de las distancias entre nudos, y área foliar total por planta. Parámetros registrados en los genotipos mutantes slggp1 (GGP-49C12 y GGP-5261) y silvestre (WT) a lo largo del desarrollo en los muestreos II, III, IV, V, VI y VII. 
Capítulo I: Caracterización de plantas de tomate mutantes deficientes en GDP-L-galactosa fosforilasa-Fenología y parámetros de crecimiento.

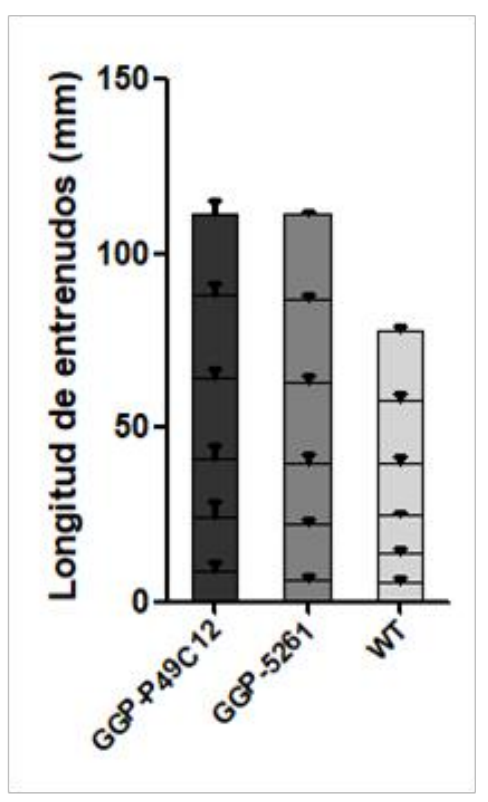

a
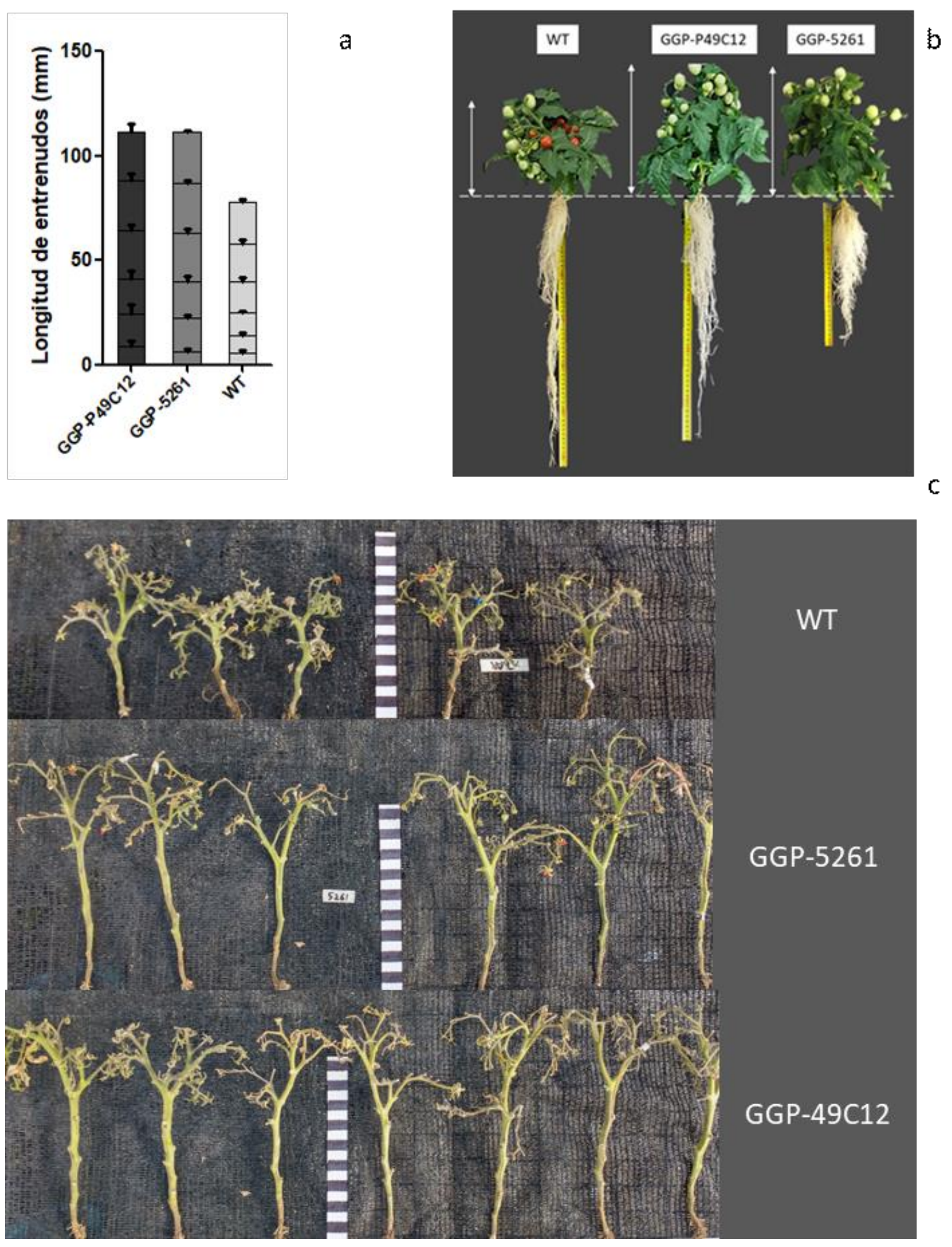

Figura 1.13 Altura de los genotipos mutantes slggp1 y silvestre.

a) Sumatoria gráfica de la distancia entre nudos promedio para cada uno de los genotipos. b) Altura y longitud de la raíz de mutantes GGP-49C12, GGP-5261 y el genotipo silvestre. c) Imagen de la diferencia de altura observada entre los genotipos mutantes slggp1 (GGP-49C12 y GGP-5261) y silvestre (WT). 


\subsubsection{Productividad de mutantes deficientes en GDP-L-Galactosa fosforilasa}

La productividad de las plantas mutantes slggp1 resultó ser significativamente menor que la de las plantas de la línea silvestre. En el muestro realizado al final del experimento (VII) se registró un menor peso fresco y peso seco total de frutos en la plantas mutantes con respecto al genotipo silvestre (Tablas 1.2 y 1.3). En cambio se observa que la biomasa individual de fruto individual resultó ser mayor en los genotipos mutantes con respecto al genotipo silvestre tanto (Tablas 1.2 y 1.3 ) en el muestreo realizado al final del desarrollo (VII). Teniendo en cuenta el número de flores y el número final de frutos producidos por planta se obtiene el porcentaje de cuajado de frutos, este parámetro es $30 \%$ menor ambos genotipos mutantes con respecto al genotipo silvestre (tabla 1.2).

Tabla 1. 2-Productividad de los genotipos mutantes slggp1 y silvestre.

\begin{tabular}{|c|c|c|c|c|c|c|}
\hline Muestreo & Genotipo & $\begin{array}{l}\text { Total frutos PF } \\
\text { (productivida } \\
\text { d) }\end{array}$ & $n^{\circ}$ flores & $n^{\circ}$ frutos & \% cuajado & $\begin{array}{c}\text { Fruto } \\
\text { individual PF }\end{array}$ \\
\hline \multirow{3}{*}{$\begin{array}{l}\text { VI } \\
(50 \% \text { wt 1 } \\
\text { fruto rojo) }\end{array}$} & WT & $75,1 \pm 10,9 a$ & $55,8 \pm 8,0 a$ & $35,0 \pm 6,4 a$ & $62,6 \pm 4,8$ a & $3,34 \pm 1,15 a$ \\
\hline & GGP49C12 & $70,9 \pm 5,71$ a & $55,0 \pm 5,4 a$ & $25,2 \pm 1,5 b$ & $46,1 \pm 4,6 b$ & $3,73 \pm 1,10 \quad a$ \\
\hline & GGP5261 & $61,3 \pm 14,9 a$ & $35,8 \pm 9,0 \mathrm{~b}$ & $17,6 \pm 2,5 \mathrm{c}$ & $44,2 \pm 3,5 b$ & $4,86 \pm 1,95 b$ \\
\hline \multirow{3}{*}{$\begin{array}{c}\text { (VII) } \\
\% 50 \text { slggp1 } 1^{\mathrm{er}} \\
\text { fruto rojo }\end{array}$} & WT & $115,9 \pm 13,8 a$ & $48,8 \pm 7,5 \mathrm{a}$ & $36,0 \pm 4,3 a$ & $74,2 \pm 6,5$ a & $3,63 \pm 1,25 a$ \\
\hline & GGP49C12 & $87,8 \pm 13,8 b$ & $52,8 \pm 8,0 \quad a$ & $24,3 \pm 3,6 b$ & $46,8 \pm 9,1 b$ & $4,61 \pm 1,30 \quad b$ \\
\hline & GGP5261 & $76,5 \pm 24,4 \quad b$ & $49,8 \pm 8,8 a$ & $20,2 \pm 5,7 b$ & $40,5 \pm 9,4 b$ & $5,17 \pm 1,98 \quad c$ \\
\hline
\end{tabular}

Peso fresco total de frutos y peso fresco de fruto individual, numero de frutos, número de flores y $\%$ de cuajado registrado en los muestreos VI y VII, en los genotipos mutantes slggp1 (GGP49C12 y GGP-5261) y silvestre (WT).

En el muestreo realizado al finalizar el experimento (VII) se observó un estado de maduración más avanzado en los frutos del genotipo silvestre (Fig. 1.14). El número de frutos en estado de maduración Rojo $(R)$ y Pink $(P)$ es mayor en esta línea que en ambas líneas mutantes. Sin embargo no se observaron diferencias en el número de frutos en estados de maduración verde inmaduro (VI) y verde maduro (VM) (Tabla 1.4). Esto refleja por un lado el retraso de la maduración de las plantas de las líneas 
Capítulo I: Caracterización de plantas de tomate mutantes deficientes en GDP-L-galactosa fosforilasa-Fenología y parámetros de crecimiento.

mutantes slggp1 con respecto a las plantas del genotipo silvestre, y por otro lado el mayor número de frutos registrado en estas últimas.

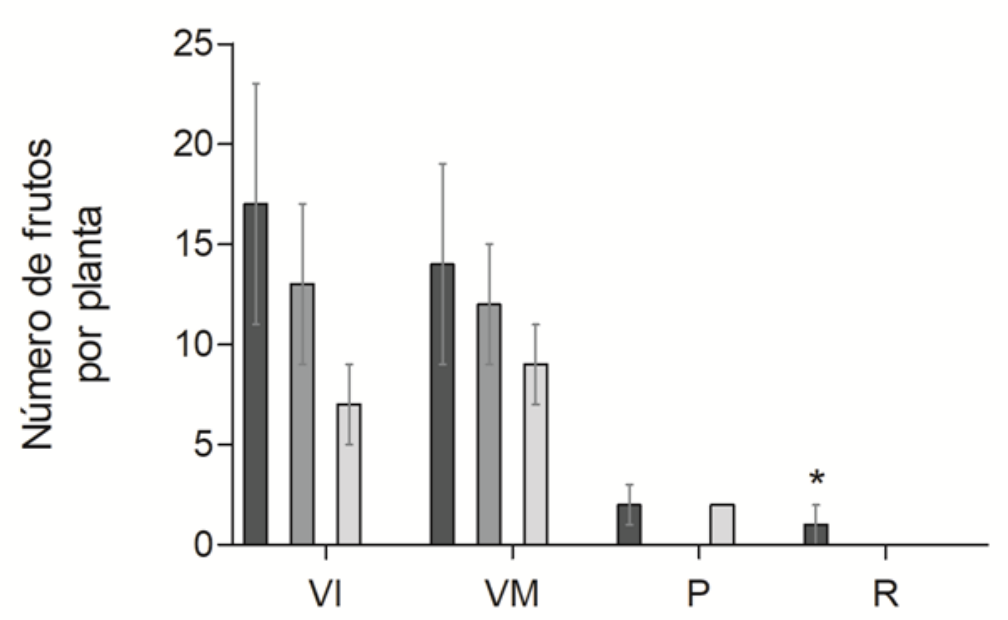

a

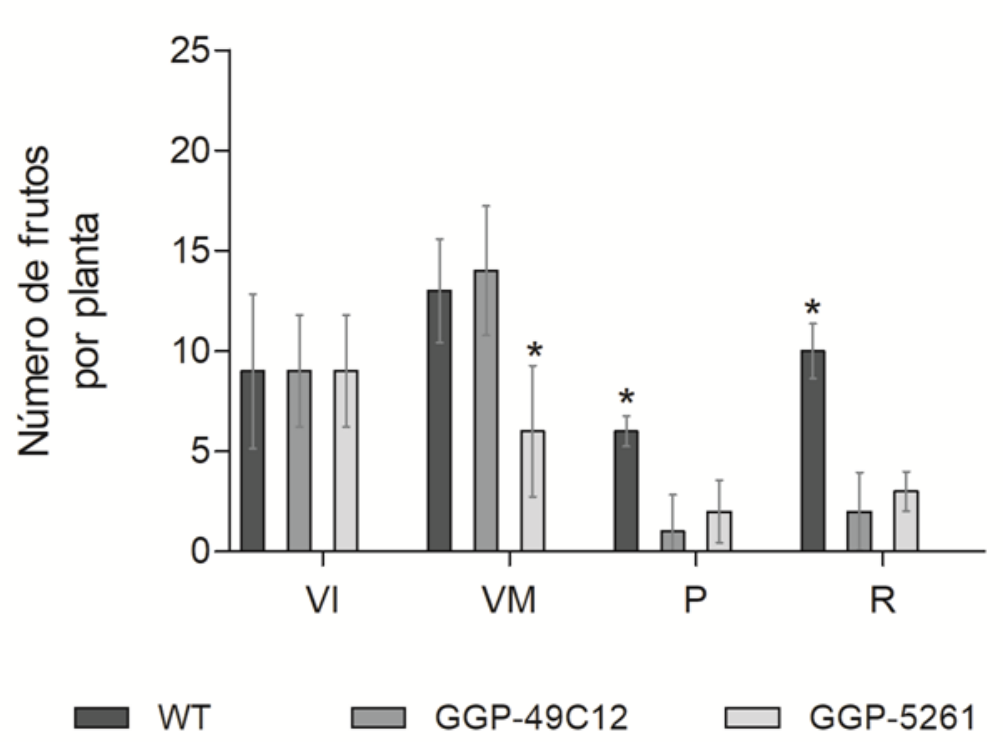

b

Figura 1.14-Distribución de la cantidad de frutos en cada estado de maduración.

Verde inmaduro $(\mathrm{VI})$, verde maduro $(\mathrm{VM})$, pink $(\mathrm{P})$, y rojo $(\mathrm{R})$ en los genotipos mutantes slggp1 (GGP-49C12, GGP-5261) y el genotipo silvestre (WT). a) Muestreo (VI) realizado cuando el genotipo silvestre presentó al menos un fruto rojo en el $50 \%$ de las plantas; b) Muestreo (VII) realizado cuando los genotipos mutantes presentaron al menos un fruto rojo en el $50 \%$ de las plantas 
Capítulo I: Caracterización de plantas de tomate mutantes deficientes en GDP-L-galactosa fosforilasa-Fenología y parámetros de crecimiento.

\subsection{Discusión}

El objetivo principal de este capítulo fue caracterizar las dos líneas de mutantes slggp1 (GGP-49C12 y GGP-5261) y de esta manera determinar el efecto que la mutación en el gen que codifica la enzima GDP-L-galactosa fosforilasa genera sobre el contenido de ácido ascórbico en diferentes tejidos, sobre la fenología y sobre los parámetros de crecimiento de plantas de tomate.

A partir de la cuantificación del contenido de ácido ascórbico en diferentes tejidos se observó que no todos los órganos se encuentran afectados de la misma manera por la deficiencia de GDP-L-galactosa fosforilasa. Las hojas son el órgano más afectado presentando solo un $33 \%$ del contenido de ascórbico presente en el genotipo silvestre. Mutantes de Arabidopsis equivalentes a los mutantes slggp1, presentan un contenido de ascórbico equivalente al $20 \%$ del contenido encontrado en el genotipo silvestre en sus hojas (Dowdle y col., 2007). Estos mutantes son menos eficientes en adaptarse a altas intensidades lumínicas y presentan fotoinhibición, peroxidación lipídica así como también blanqueamiento de las hojas (Müller-Moulé y col., 2002). Baldet y col., (2013) observaron el blanqueamiento de la clorofila ("Bleaching" en inglés) al someter de manera brusca a mutantes slggp1 a condiciones de alta irradiancia, sacándolas del invernáculo y exponiéndolas al pleno sol entre las 9 h y las 15 h UT (Universal Time) en un día soleado. Ante una misma condición lumínica sería esperable que las plantas mutantes slggp1 presentaran su pool de ácido ascórbico foliar en un estado de oxidación más alto que las plantas silvestres, dado que este metabolito se convertiría en un recurso limitante durante el momento de mayor irradiancia durante el transcurso del día. Sin embargo no se observó tal resultado en las hojas ni tampoco en los demás órganos analizados. Si bien las muestras de hoja para realizar las determinaciones fueron tomadas en el momento de mayor intensidad lumínica del día, es posible que esta no haya resultado saturante bajo las condiciones de cultivo establecidas. Por otro lado, estos resultados sugieren que la capacidad de 
Capítulo I: Caracterización de plantas de tomate mutantes deficientes en GDP-L-galactosa fosforilasa-Fenología y parámetros de crecimiento.

recuperación de las formas oxidadas está incrementada en los mutantes, aspecto que analizaremos en otro capítulo.

En las flores el nivel de ascórbico registrado fue similar al registrado en los tejidos foliares. En estos órganos el efecto de la mutación sobre el contenido de este metabolito fue levemente menor al observado en hojas. Las flores son órganos en rápido crecimiento, con elevada tasa respiratoria y un fuerte destino. La translocación de ascórbico a través del floema desde las hojas hacia las flores ha sido evidenciada en tomate mediante la administración exógena de ácido L- $\left[6-{ }^{14} \mathrm{C}\right]$ ascórbico (Badejo y col., 2012). Esto también fue demostrado en otras especies como Medicago sp. y Arabidopsis thaliana (Franceschi y col., 2002). De esta manera parte del ascórbico que se genera en las hojas pueda traslocarse a las flores y posiblemente éste sea el motivo de que el efecto de la mutación sobre el contenido de ácido ascórbico sea menos evidente en este órgano.

En los frutos de los mutantes slggp1 se registró una reducción de aproximadamente el $50 \%$ del contenido de ácido ascórbico con respecto al genotipo silvestre. La síntesis de ascórbico en los frutos por medio de la vía de la galactosa prevalece en las etapas tempranas del desarrollo. Se ha visto que el perfil de expresión de los genes relacionados con la vía de la L-galactosa se regula negativamente a medida que progresa la maduración de la fruta y esto no se correlaciona con los niveles de ácido ascórbico que aumentan durante la maduración (Badejo y col., 2012; Ioannidi ycol., 2009). Además, durante estas primeras etapas del desarrollo los frutos al igual que las flores, son un destino fuerte y parte del ascórbico es conducido a través del floema desde las hojas también a estos órganos en rápido crecimiento (Badejo y col., 2012). En estos mutantes slggp1 en los que la vía de la galactosa está interrumpida, podría pensarse que el contenido final de ascórbico en los frutos es, en parte, producto de la translocación de ascórbico desde las hojas. Además, existe evidencia que la síntesis de ácido ascórbico a partir de la ruta del ácido galacturónico contribuye al contenido de 
ascórbico final en frutillas así como también en tomate (Agius y col., 2003; Badejo y col., 2012; Suekawa y col., 2016).

Por otro lado, las raíces de los genotipos mutantes poseen aproximadamente el $50 \%$ del contenido de ascórbico registrado en el genotipo silvestre. Dowdle y col. (2007) reportaron que en este órgano la expresión de la isoenzima GDP-L-galactosa fosforilasa 2 (vtc5) podría ser lo suficientemente alta como para contribuir de manera significativa al contenido de ácido ascórbico, a diferencia de lo que ocurre en hojas en donde la expresión del gen que codifica la enzima GDP-L-galactosa fosforilasa 2 es mucho más baja que la expresión del gen que codifica la enzima GDP-L-galactosa fosforilasa 1. En el capítulo (IV) se analizará la contribución relativa de la expresión de ambos genes al contenido de ácido ascórbico en los diferentes tejidos. Por otro lado, se observó que en raíces aproximadamente el $80 \%$ del pool de ascórbico se encuentra oxidado, tanto en mutantes como en el genotipo silvestre. Esto también fue observado en raíces de Cucurbita máxima L. (Liso y col., 2004) y previamente en raíces de maíz por (Kerk y Feldman, 1995). Como se mencionó en la introducción general, el ácido ascórbico juega un rol muy importante en varios aspectos del control de la división y expansión celular. La principal evidencia que relaciona el ácido ascórbico con el crecimiento y desarrollo de las plantas se obtuvo en modelos de raíz de cebolla (Liso y col., 1988). Las células del centro quiescente son células que generalmente no se dividen y se mantienen en fase G1 durante períodos prolongados. Sin embargo, después de tratamientos con ácido ascórbico, se encontró que la mayoría de las células del centro quiescente de raíces de cebolla pasaban de la fase G1 a la fase S y se promovía la proliferación celular (Liso y col., 1984, 1988). Este resultado fue validado posteriormente por Kerk y Feldman (1995) quienes mostraron que las células del centro quiescente de raíces de maíz (Zea mays L.) contenían niveles bajos de ácido ascórbico que se correlacionaban con cantidades altas de ascorbato oxidasa. Además, pudieron demostrar que el gen que codifica acorbato 
oxidasa era inducible por auxina. Dado que la evidencia disponible indica el transporte polar de auxinas hacia el meristema apical radicular, estos autores propusieron que el flujo de auxinas hacia el centro quiescente inducía la enzima ascorbato oxidasa. Una cantidad baja de ácido ascórbico y una gran cantidad de ascorbato oxidasa, que modula el estado redox, pueden explicar porque las células de centro quiescente de la punta de la raíz se mantienen en una fase G1 extendida del ciclo celular (Kerk and Feldman, 1995; Jiang y col,, 2003). Esto sugiere que el ácido ascórbico es un componente crítico requerido por las células del centro quiescente para entrar en la fase S desde la fase G1 en el ciclo celular (Kka y col., 2018; Potters y col., 2018). Esto podría explicar la menor longitud y biomasa radicular observada en los mutantes slggp1 deficientes en ácido ascórbico. (Tabla 1.1)

En lo que respecta al meristema apical del tallo (Stasolla y col. (2006) demostraron que la aplicación exógena de ácido ascórbico intensifica el crecimiento del meristema apical e induce la organogénesis del tallo en plántulas de Abeto blanco (Picea glauca L.). Un trabajo posterior demostró que la aplicación exógena de ácido ascórbico también alargaba el período de activo crecimiento en ápices de Populus deltoides y que la aplicación de giberelinas $\left(\mathrm{AG}_{3}\right)$ producía un aumento en la síntesis de este antioxidante (Grozeff y Bartoli, 2013). En esta tesis se observó un crecimiento ralentizado de los mutantes slggp1 deficientes en ácido ascórbico con respecto al genotipo silvestre, estos mutantes durante la durante el desarrollo vegetativo siempre mantuvieron un retraso de al menos una hoja en el desarrollo ontológico. Si el ascórbico participa promoviendo la división celular en los tejidos meristemáticos, la deficiencia de este metabolito en los mutantes podría afectar a la velocidad de desarrollo ontogénico. Además existe evidencia que respalda la participación del ácido ascórbico en la elongación celular.

Por otro lado estos mutantes presentaron una mayor elongación de los entrenudos del tallo durante el desarrollo vegetativo, que se ve reflejado en la mayor altura de las 
plantas al final del desarrollo. Aunque la biomasa del tallo es mayor en los genotipos mutantes, no se observan diferencias en área foliar ni en biomasa vegetativa total durante el desarrollo, con respecto al genotipo silvestre. Por el contrario se ha observado que mutantes vtc2 de Arabidopsis presentan una reducción del área foliar y la biomasa total de la roseta (Caviglia y col., 2018; Plumb y col. 2018).

Los efectos de la deficiencia en GDP-L-Galactosa fosforilasa son más evidentes en el desarrollo reproductivo. Si bien no se observa diferencia en el número total de flores producidas por los mutantes slggp1 con respecto al genotipo silvestre, en los mutantes slggp1 el porcentaje de cuajado de frutos resultó significativamente menor al porcentaje de cuajado observado en el genotipo silvestre. Aunque los frutos de los genotipos mutantes tienen un peso promedio mayor a los frutos del genotipo silvestre, la biomasa total de frutos registrada en los mutantes slggp1 no alcanza a compensar la biomasa total de frutos por planta registrada en el genotipo silvestre. Estos resultados muestran que la deficiencia en GDP-L-galactosa fosforilasa1 afecta directamente la productividad de las plantas de tomate a través de la reducción del número de frutos. Las posibles causas de este efecto de la mutación sobre GDP-Lgalactosa fosforilasa1 se exploran en el próximo capítulo.

Como se ha mencionado anteriormente, los mutantes slggp1 presentan un desarrollo ontogénico más lento durante la etapa vegetativa, una demora en la aparición de los órganos reproductivos (Fig. 1.10 a) y una floración más tardía que las plantas del genotipo silvestre. Sin embargo una floración más temprana que los genotipos silvestres ha sido reportada en varios mutantes de Arabidopsis deficientes en ácido ascórbico (Barth y col., 2006; Kotchoni y col., 2009). En este caso la floración de los mutantes vtc2 de Arabidopsis ocurre cuando las plantas presentan un menor número de hojas que el genotipo silvestre y los autores concluyen que las alteraciones en el contenido de ácido ascórbico confieren perturbaciones en el metabolismo de las plantas y la expresión génica que afectan indirectamente el tiempo de floración. A 
Capítulo I: Caracterización de plantas de tomate mutantes deficientes en GDP-L-galactosa fosforilasa-Fenología y parámetros de crecimiento.

diferencia de lo ocurrido en los mutantes vtc2 de Arabidospsis, los mutantes slggp1 de tomate estudiados aquí, presentan igual número de hojas que el genotipo silvestre al en el momento de la floración. En cualquiera de los casos, ya sea un efecto de retraso o de anticipo de la floración, estos resultados en conjunto sugieren que la concentración de ascórbico en las plantas está relacionada con la regulación del tiempo de floración. Además del retraso en el tiempo de floración también se observó un retraso en el tiempo de maduración de los frutos mutantes slggp1 con respecto a los frutos del genotipo silvestre. Este retraso se produjo en el tiempo transcurrido entre el estadio VM y el estadio P. La Licenciada Charlotte Steelheart, quien se encuentra desarrollando su tesis doctoral actualmente en nuestro grupo de trabajo, confirmó ente resultado y además demostró que es posible revertir el efecto de la deficiencia en GDP-L-Galactosa fosforilasa1 e igualar el tiempo de maduración de los frutos mutantes slggp1 con el de los frutos silvestres mediante la aplicación exógena de ácido ascórbico.

En resumen, los resultados de este capítulo muestran que la deficiencia de GDP-Lgalactosa fosforilasa no afecta por igual el contenido de ácido ascórbico a los distintos órganos de la planta, registrándose un 30-50 \% del contenido de ascórbico registrado en el genotipo silvestre. Por otro lado no se observó un efecto de la mutación sobre el estado redox del pool de ascórbico en ninguno de los tejidos analizados. Como producto de la deficiencia en GDP-L-galactosa fosforilasa se registraron alteraciones morfológicas y una reducción del porcentaje de cuajado de frutos que genera un impacto evidente sobre el rendimiento de las plantas de tomate. Además los mutantes slggp1 presentaron un retraso en la floración y en el tiempo de maduración de los frutos en planta. 


\section{CAPÍTULO II}

"Efectos de la deficiencia en GDP-L-

galactosa fosforilasa y la deficiencia

de ácido ascórbico sobre la

productividad de plantas de tomate" 
Capítulo II: Efectos de la deficiencia en GDP-L-galactosa fosforilasa y la deficiencia de ácido ascórbico sobre la productividad de plantas de tomate.

\section{$\underline{2.1 \quad \text { Introducción }}$}

Las proyecciones a futuro muestran un aumento en la demanda de alimentos, por lo tanto es un desafío para la agricultura lograr un aumento en la productividad de los cultivos optimizando el uso de la superficie (Alexandratos y Bruinsma, 2012). El tomate (Solanum lycopersicum L.) es el fruto más consumido en el mundo y particularmente en Argentina su cultivo representa uno de los más importantes dentro del mercado de hortalizas. Uno de los factores más importantes que afecta el rendimiento del cultivo de tomate es el número de frutos, que está determinado por la eficiencia del establecimiento o cuajado (Tanaka y Fujita, 1974). Esta etapa presenta una transición de óvulo a semilla y de ovario a fruto. Se caracteriza por una fase inicial de división celular y un desarrollo coordinado de los tejidos maternos y embrionarios. Posteriormente, el fruto recién formado experimenta expansión celular y acumulación de productos de almacenamiento, principalmente proteínas y azúcares, durante las etapas de crecimiento y maduración (Gillaspy col., 1993). La investigación sobre el desarrollo de semillas y frutos se ha centrado principalmente en las últimas etapas. Por el contrario, es menor el conocimiento acerca de los mecanismos que regulan su desarrollo temprano durante la fase de cuajado. Debido a su importancia económica y disponibilidad en todo el mundo, el tomate se ha convertido en un sistema modelo ampliamente aceptado para el estudio de este proceso (Ruan y col., 2012). Una característica de la fase de cuajado es su alta sensibilidad al estrés generado por factores externos como la sequía y las altas temperaturas, que a menudo provocan un importante aborto de flores y frutos y, por tanto, pérdidas irreversibles de rendimiento. Por ejemplo, el déficit de agua durante la floración genera una reducción del número de flores y del porcentaje de cuajado en variedades de tomate de crecimiento determinado e indeterminado (Ganeva y col., 2019; Wudiri y Henderson, 1985). De manera similar, el estrés por altas temperaturas puede resultar en una pérdida de rendimiento del $70 \%$ en tomate como resultado del aborto de flores y frutos (Sato y 
Capítulo II: Efectos de la deficiencia en GDP-L-galactosa fosforilasa y la deficiencia de ácido ascórbico sobre la productividad de plantas de tomate.

col., 2004). Otro factor importante para el establecimiento de los frutos es la provisión suficiente de fotoasimilados por parte de las hojas, una relación fuente-destino alta favorece el cuajado de frutos, en caso contrario se produce el aborto de destinos (Heuvelink, 2018). Esta provisión de fotoasimilados está directamente relacionada con la cantidad de luz absorbida (interceptada) por las hojas y esto depende principalmente del área foliar. La tasa fotosintética depende de diversos componentes del cloroplasto (v.g. clorofila por unidad de área foliar) y de la conductancia del $\mathrm{CO}_{2} \mathrm{a}$ través de los estomas y del mesófilo. Los sistemas de captación de luz y transporte de electrones convierten la energía lumínica absorbida en moléculas de almacenamiento de energía útil como por ejemplo, adenosin trifosfato (ATP), ferredoxina reducida (Fd), Nicotinamida adenina dinucleótido fosfato (NADPH), que son utilizadas en el proceso de asimilación de $\mathrm{CO}_{2}$. La enzima RuBisCO (ribulosa-1,5-bis-fosfato-carboxilasaoxigenasa) cataliza la incorporación de $\mathrm{CO}_{2}$ (carboxilación), pero RuBisCO también tiene afinidad por el $\mathrm{O}_{2}$ (oxigenación), lo que produce la liberación de $\mathrm{CO}_{2} \mathrm{O}$ fotorrespiración (Taiz, Zeiguer, Moller, y Murphy, 2015)

Durante el proceso de fotosíntesis se generan normalmente especies reactivas de oxígeno como producto de la transferencia de electrones de alta energía desde la ferrodoxina reducida al oxígeno, en lugar de ser transferidos al NADP, aceptor final de electrones en la cadena de transporte electrónico tilacoidal (Davey y col., 2000). Como se mencionó en la introducción general, cuando las plantas están expuestas a altas intensidades de luz, las especies reactivas de oxígeno pueden alcanzar niveles altos y generar daños mediante la oxidación de los componentes de las membranas tilacoidales del cloroplasto. Estos daños en su conjunto provocan estrés lumínico y una disminución en la tasa fotosintética (Foyer y Noctor, 2011). El ácido ascórbico cumple un papel muy importante contrarrestando el aumento de las especies reactivas de oxígeno. Particularmente este metabolito participa como aceptor de electrones en el ciclo Agua-Agua y en el ciclo de las xantofilas ante situaciones de alta irradiancia 
Capítulo II: Efectos de la deficiencia en GDP-L-galactosa fosforilasa y la deficiencia de ácido ascórbico sobre la productividad de plantas de tomate.

(Asada, 1999), procesos que contribuyen a la optimización de la fotosíntesis. El mutante vtc2-1 de Arabidopsis, deficiente en GDP-L-galactosa fosforilasa, presenta una mayor sensibilidad al exceso de luz, manifestándose en un aumento de la peroxidación de lípidos y degradación de la clorofila (Müller-Moulé y col., 2002). Se ha observado que estos mutantes presentan una menor tasa de transporte electrónico así como también una menor biomasa total al final del crecimiento (Caviglia y col., 2018) indicando que la deficiencia en GDP-L-Galactosa fosforilasa y en última instancia, la deficiencia de ascórbico, podrían tener un impacto sobre la tasa de asimilación neta de $\mathrm{CO}_{2}$ y la generación de fotoasimilados.

Además de la provisión de fotoasimilados, existen otros factores importantes para el cuajado de los frutos. En general, esto ocurre luego de una polinización y fertilización exitosa, siendo coordinado por señales producidas por los embriones en desarrollo (Gillaspy y col., 1993). Recientemente se ha observado que en tomate, los brasinoesteroides regulan el número de óvulos mediante la regulación negativa de la biosíntesis de giberelinas (GA) (Barro-Trastoy y col., 2020). Ante una menor concentración de GA se promueve la estabilización de las proteínas DELLA que en este caso en particular se ha visto que promueven el inicio del crecimiento de los óvulos través de su acción en el meristema medial del carpelo (Gomez y col., 2018). Por otro lado, se ha reportado que la aplicación de GA promueve el crecimiento del tubo polínico (Kato, 1995). Plantas de Arabidopsis que sobreexpresan GA 2-oxidasa, una enzima del catabolismo de GA, presentan una reducción en el crecimiento del tubo polínico (Singh y col., 2002). Mutantes rpe1 (reduced pollen tube elongation) de arroz, presentan una reducción del crecimiento del tubo polínico que puede ser revertida mediante la aplicación de GA exógena (Chhun y col., 2007). El éxito del desarrollo de los óvulos y del tubo polínico permite la fertilización. Esto desencadena el programa de desarrollo inicial del fruto mediante la activación de las vías de señalización de auxinas y giberelinas (Gillaspy y col., 1993; Ruan y col., 2012). 
Capítulo II: Efectos de la deficiencia en GDP-L-galactosa fosforilasa y la deficiencia de ácido ascórbico sobre la productividad de plantas de tomate.

Tanto en tomate como en Arabidopsis, la aplicación externa de $\mathrm{GA}_{3}$ o la modificación genética de señales activadas por GA, desencadenan el crecimiento espontáneo del fruto, fenómeno conocido como partenocarpia (Martí y col., 2006; Serrani y col., 2007a). La sobreexpresión de genes de la biosíntesis de GA, como GA 20-oxidasa, genera la acumulación de $\mathrm{GA}$ activas $\left(\mathrm{GA}_{1}\right.$ y $\left.\mathrm{GA}_{3}\right)$ en ovarios de tomate luego de la polinización, pero si se bloquea la biosíntesis de GA, el desarrollo de ovarios polinizados se detiene (Serrani y col., 2007b). Las auxinas y GA interactúan entre sí durante las primeras etapas del desarrollo del fruto y según un modelo propuesto, las auxinas inducen la biosíntesis y acumulación de GA activas que promueven la desestabilización de proteínas DELLA, y se desencadena el crecimiento del fruto (Mignolli y col., 2019; Tang y col., 2015). Sin embargo, los mecanismos claves y la compleja interacción de señales que son desencadenados por estas hormonas vegetales para inducir el cuajado y establecimiento de los frutos aún no han sido esclarecidos por completo.

Como se mencionó en el Capítulo I, en los mutantes slggp1 estudiados en esta tesis, las hojas son el órgano más afectado por la deficiencia en GDP-L-galactosa fosforilasa ya que presentan un menor contenido de ácido ascórbico que el resto de los órganos. Estos mutantes no presentan una reducción del área foliar ni de biomasa vegetativa, pero sí se observa una reducción en la producción de frutos. Esta disminución de la productividad observada en los mutantes slggp1 se relaciona directamente con una marcada reducción en el cuajado y número de frutos. Esto sugiere que la deficiencia en GDP-L-Galactosa fosforilasa tiene efectos sobre aspectos del desarrollo reproductivo. Por un lado, dado que el ascórbico juega un papel en la optimización de la fotosíntesis, se planteó que la deficiencia de GDP-L-galactosa fosforilasa y ácido ascórbico provoca una reducción en la fuente de fotoasimilados que impacta en el porcentaje de cuajado de frutos y en la capacidad de llenado de los frutos. Por otro lado, como se mencionó en la introducción general el ascórbico participa como 
Capítulo II: Efectos de la deficiencia en GDP-L-galactosa fosforilasa y la deficiencia de ácido ascórbico sobre la productividad de plantas de tomate.

cofactor enzimático en la síntesis de varias hormonas relacionadas al proceso de cuajado de frutos como las GA y las auxinas (Arrigoni y De Tullio, 2000). En este sentido se propuso que la deficiencia de GDP-L-galactosa fosforilasa y ácido ascórbico generan un desbalance hormonal que provoca una disminución del porcentaje de cuajado de frutos y de la productividad.

\subsection{Objetivos}

En este capítulo se abordó el objetivo específico 2 que consistió en evaluar el impacto de la deficiencia en la expresión de GDP-L-Galactosa fosforilasa sobre la productividad en tomate.

En función de éste, se fijaron cuatro actividades a realizar:

2.2.1 Determinar el efecto de la deficiencia de GDP-L-galactosa fosforilasa en la actividad fotosintética en hojas maduras.

2.2.2 Evaluar el efecto de la deficiencia de GDP-L-galactosa fosforilasa en las relaciones fuente-destino.

2.2.3 Establecer un tratamiento exógeno con ácido ascórbico que restablezca en mutantes slggp1, niveles similares de este antioxidante a los encontrados en plantas de la línea silvestre.

2.2.4 Determinar el efecto de la deficiencia de GDP-L-galactosa fosforilasa sobre la concentración de hormonas en flores. 
Capítulo II: Efectos de la deficiencia en GDP-L-galactosa fosforilasa y la deficiencia de ácido ascórbico sobre la productividad de plantas de tomate.

\section{$\underline{2.3}$ Materiales y métodos}

\subsubsection{Condiciones de crecimiento}

Semillas de tomate (Solanum lycopersicum cv Micro-Tom) de las líneas mutantes (GGP 49C12 y GGP 5261) y la línea silvestre fueron germinadas y transferidas a bandejas de crecimiento como se describe en el capítulo 1. Posteriormente los plantines fueron trasplantados a macetas de 3 litros con sustrato compuesto por tierra negra, arena y perlita (3:1:1). Las plantas crecieron durante primavera y verano en un invernáculo con sistema de control de la temperatura bajo una irradiancia al medio día de $700 \mu$ mol fotones $\mathrm{m}^{-2} \mathrm{~s}^{-1}$ y temperatura promedio de $25 \pm 2$ durante el día y $20 \pm 3$ ${ }^{\circ} \mathrm{C}$ durante la noche. Se retiraron los brotes laterales al eje de crecimiento principal en el momento de su aparición y se permitió el desarrollo de las primeras 4 inflorescencias terminales del eje principal, todas las demás fueron retiradas al momento de su aparición.

\subsubsection{Parámetros fotosintéticos}

La tasa de asimilación máxima de $\mathrm{CO}_{2}\left(A_{\max }\right)$ fue medida en hojas completamente desarrolladas utilizando un analizador infrarrojo de gases (CIRAS-2 PP Systems) a irradiancia saturante $\left(1200 \mu \mathrm{mol}\right.$ fotones $\left.\mathrm{m}^{-2} \mathrm{~s}^{-1}\right)$ como se ilustra en la Fig. 2.1. La fotosíntesis potencial $\left(P_{\text {pot }}\right)$ fue medida como la tasa de producción de $\mathrm{O}_{2}$ en condiciones de irradiancia y concentración de $\mathrm{CO}_{2}$ saturantes. Discos de hoja fueron colocados en una cámara de gas hermética equipada con un electrodo tipo Clark (Hansatech, UK). La atmósfera saturante de $\mathrm{CO}_{2}$ fue generada incluyendo un disco de papel de filtro embebido en una solución de $\mathrm{NaHCO}_{3} 1 \mathrm{M}$ (Walker, 1997). La tasa de transporte electrónico fotosintética (ETR), el quenching no fotoquímico (NPQ) y el rendimiento cuántico máximo del fotosistema $I I\left(F_{v} / F_{m}\right)$ fueron medidos utilizando un equipo portátil que mide la fluorescencia modulada de la clorofila (FMS-2, Hansatech Instruments Ltd., Norfolk, UK) de acuerdo a Bartoli y col., (2005) y calculado según 
Capítulo II: Efectos de la deficiencia en GDP-L-galactosa fosforilasa y la deficiencia de ácido ascórbico sobre la productividad de plantas de tomate.

Genty y col., (1989). Las mediciones de la temperatura foliar fueron realizadas con una cámara termográfica (FLUKE Ti 400) y emisividad de 0,95. Las mediciones fueron realizadas al mediodía, entre las 11 y las $13 \mathrm{~h}$ aproximadamente, en plantas bien regadas expuestas a una irradiancia de $700 \mu \mathrm{mol}$ fotones $\mathrm{m}^{-2} \mathrm{~s}^{-1}$ en el interior del invernáculo Fig. 2.2).

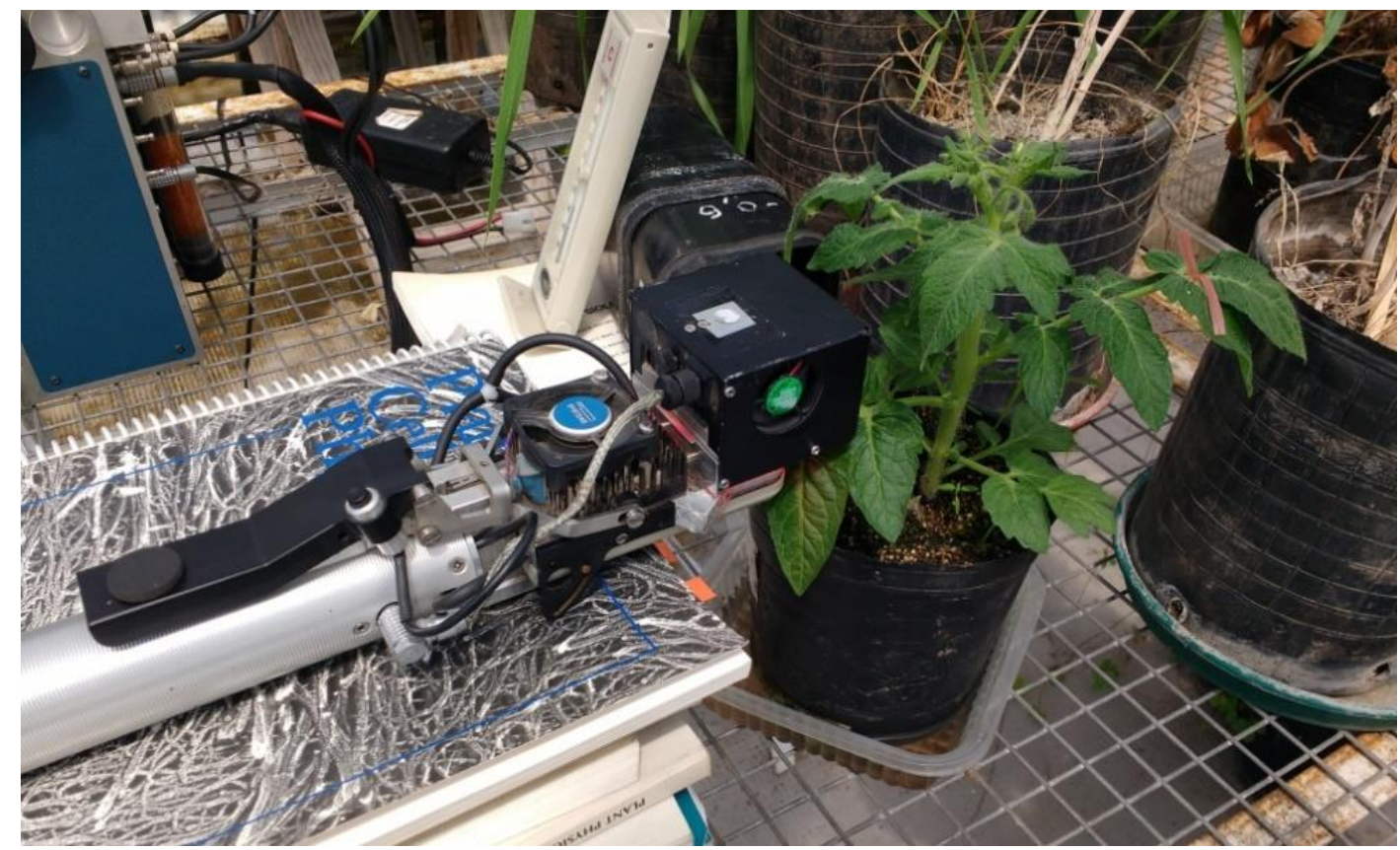

Figura 2.1- Medición de tasa de asimilación de $\mathrm{CO}_{2}$ Equipo analizador infrarrojo de gases (CIRAS-2 PP Systems).

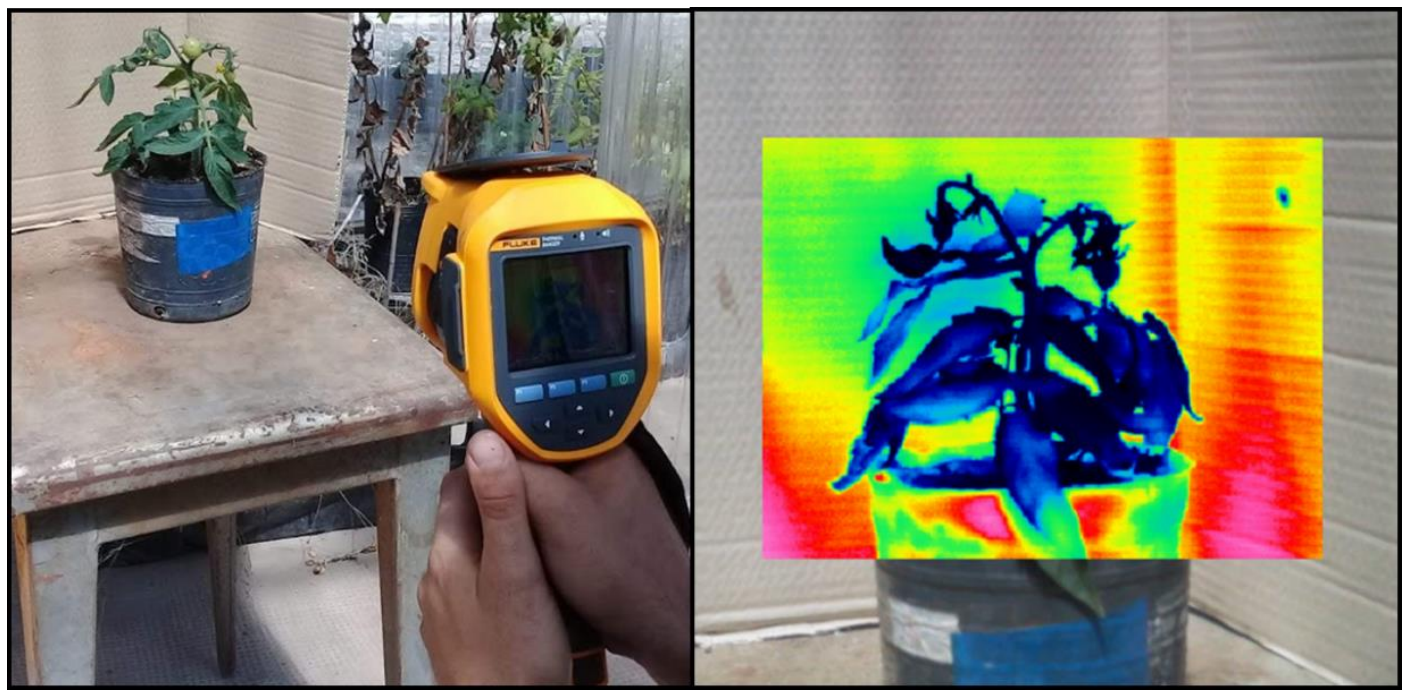

Figura 2.2-Medición de la temperatura foliar. Imágenes registradas mediante la utilización de una cámara infrarroja (FLUKE Ti 400) 
Capítulo II: Efectos de la deficiencia en GDP-L-galactosa fosforilasa y la deficiencia de ácido ascórbico sobre la productividad de plantas de tomate.

\subsubsection{Diseño experimental ensayo fuente destino}

Se realizaron tratamientos para reducir la fuente de fotoasimilados por medio de dos niveles de desfoliado, un desfoliado intenso en el que se removió el $75 \%$ del área foliar $(=\mathrm{H})$ y un segundo nivel de desfoliado en el cual se removió un $50 \%$ del área foliar $(-\mathrm{H})$. Los tratamientos de desfoliado se realizaron cuando las plantas de cada genotipo alcanzaron el 50\% de floración (50 \% de las plantas con al menos una flor en estado de antesis). Además, se realizaron tratamientos de desfrutado para reducir el número de destinos, en el primer nivel de desfrutado se conservaron 2 frutos por inflorescencia y 4 inflorescencias por planta (2F). En el segundo nivel de desfrutado se conservó sólo un fruto por inflorescencia y 4 inflorescencias por planta (1F). El procedimiento de desfrutado se realizó cuando se observó el cuajado del primero o de los dos primeros frutos de cada inflorescencia. En el tratamiento control se conservaron las primeras 4 inflorescencias de cada planta y no se realizó desfrutado ni tampoco desfoliado (C).

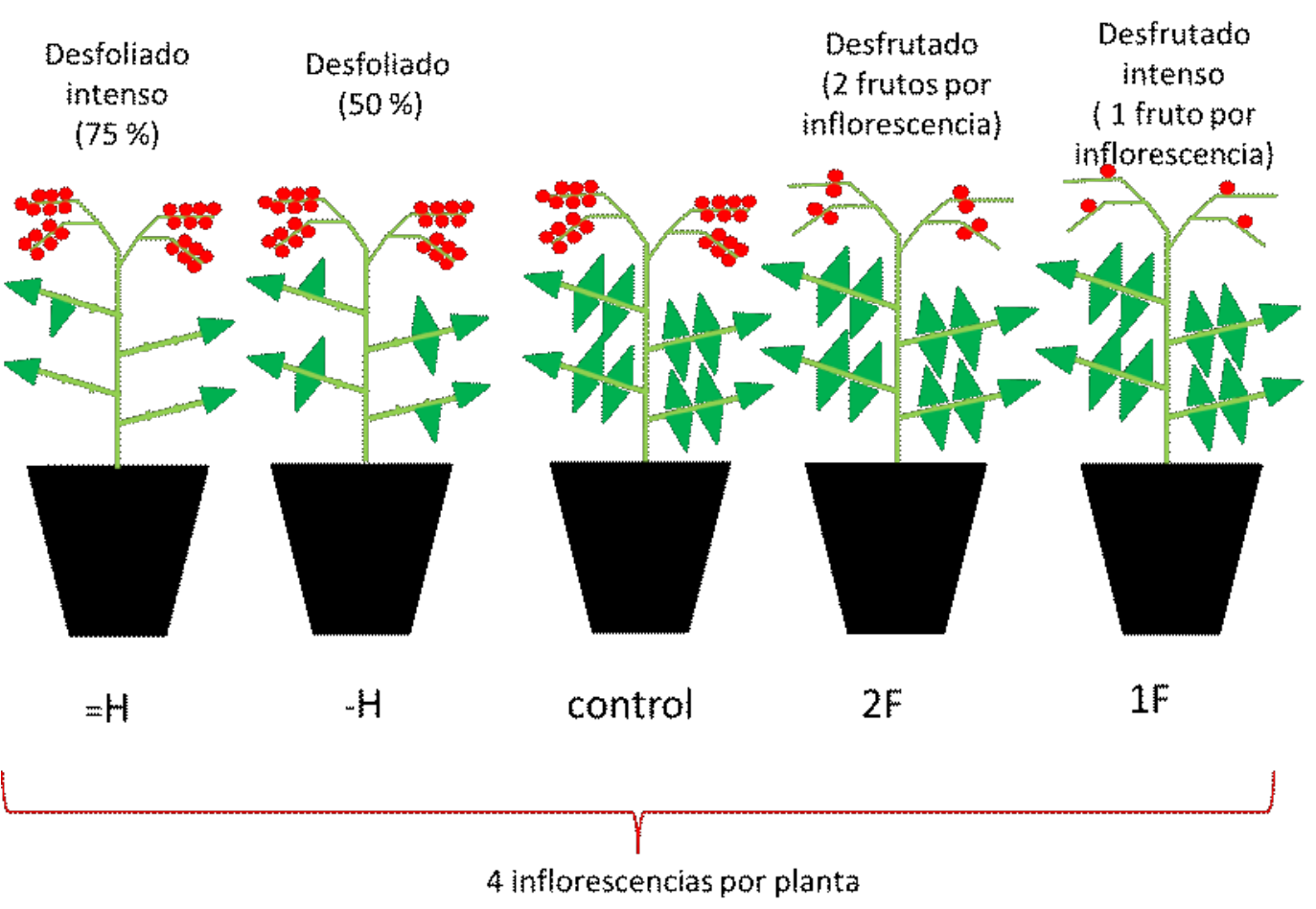

Figura 2.3-Diseño experimental ensayo fuente destino.

Tratamientos aplicados a cada genotipo. Desfoliado del 75\% (=H); desfoliado del $50 \%(-\mathrm{H})$; dos frutos por inflorescencia (2F); 1 fruto por inflorescencia (1F). 
Capítulo II: Efectos de la deficiencia en GDP-L-galactosa fosforilasa y la deficiencia de ácido ascórbico sobre la productividad de plantas de tomate.

Cuando el $50 \%$ de las plantas mutantes presentaron al menos un fruto en estado de madurez rojo, se procedió a la finalización del ensayo y muestreo final en el cual se determinó el área foliar total por planta mediante el escaneo de las hojas y el posterior análisis de imagen así como también el peso fresco y seco foliar total. También se determinó el peso fresco y seco del tallo sin incluir el peso de las 4 inflorescencias, y se midió la longitud de entrenudos. Luego se registró el peso fresco individual y total de frutos por planta. Por último, se registró el número de frutos por planta y también el número de flores totales por planta mediante el conteo de los pedicelos florales de las 4 inflorescencias. Se realizaron 4 ensayos independientes incluyendo 10 plantas de cada uno de los genotipos mutantes s/ggp1 y 10 plantas del genotipo silvestre por tratamiento y los resultados fueron analizados mediante el test de Tukey (ANOVA $p<0.05)$. 
Capítulo II: Efectos de la deficiencia en GDP-L-galactosa fosforilasa y la deficiencia de ácido ascórbico sobre la productividad de plantas de tomate.

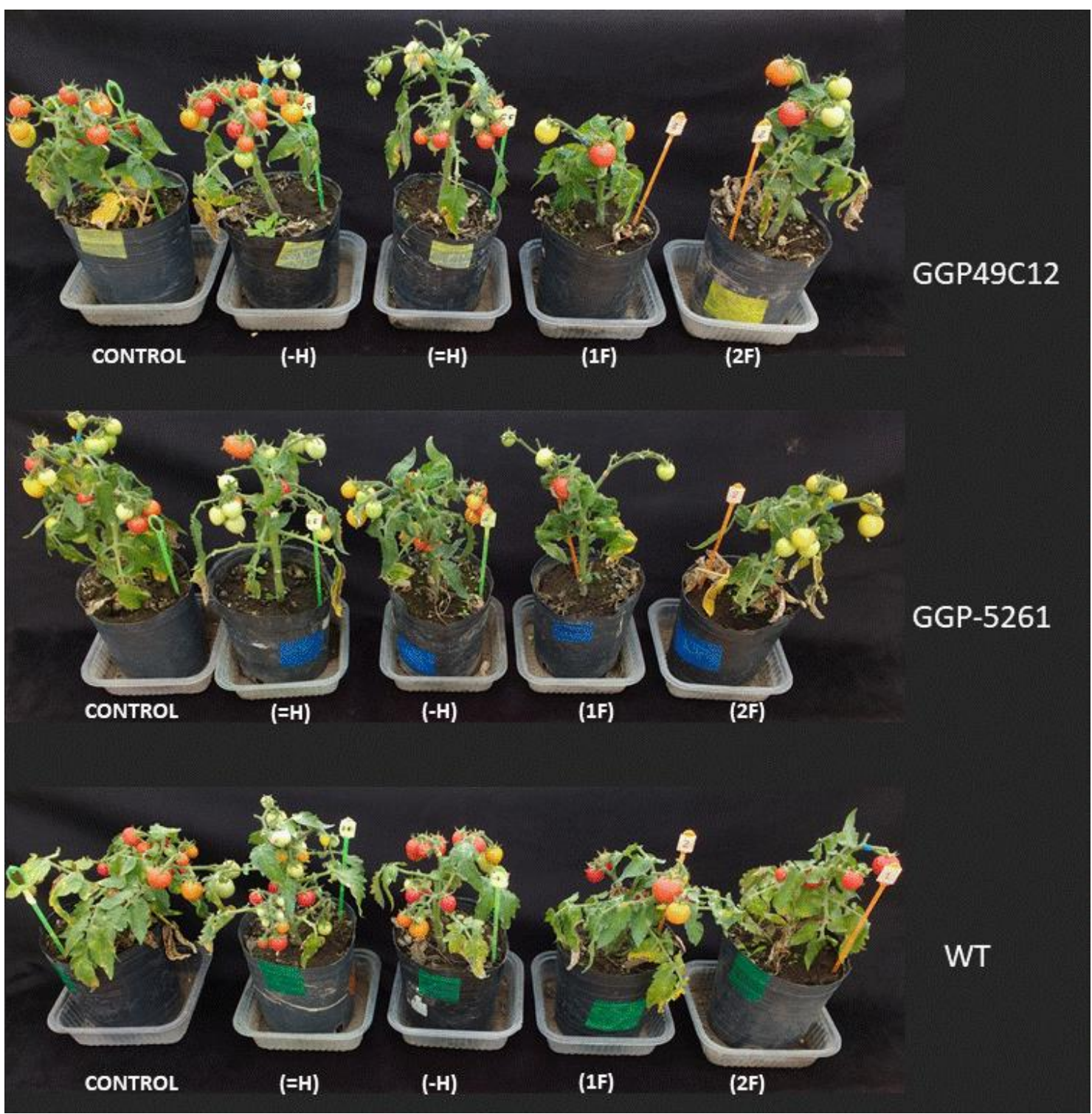

Figura 2.4-Ensayo fuente destino.

Imagen de las plantas de los genotipos mutantes (GGP-49C12 y GGP-5261) y el genotipo silvestre (WT) al momento de la finalización del ensayo y muestreo final. Desfoliado del $75 \%$ $(=\mathrm{H})$; desfoliado del $50 \%(-\mathrm{H})$; dos frutos por inflorescencia $(2 \mathrm{~F}) ; 1$ fruto por inflorescencia $(1 \mathrm{~F})$.

\subsubsection{Ensayo de restitución de los niveles de ascórbico}

Para este ensayo 10 plantas de cada uno de los genotipos mutantes y 10 plantas del genotipo silvestre con 4 hojas completamente expandidas y los primordios de las inflorescencias visibles fueron asperjadas con una solución de ácido ascórbico $20 \mathrm{mM}$, incluyendo $0,01 \% \mathrm{v} / \mathrm{v}$ Tween 20 ® como surfactante. De la misma manera, 10 plantas de cada genotipo fueron asperjadas con una solución control compuesta por agua y $0,01 \% \mathrm{v} / \mathrm{v}$ Tween $20 \AA$. El asperjado se realizó hasta el punto de goteo durante las primeras horas de la mañana cada $48 \mathrm{~h}$. En cada una de las plantas sólo las primeras 
Capítulo II: Efectos de la deficiencia en GDP-L-galactosa fosforilasa y la deficiencia de ácido ascórbico sobre la productividad de plantas de tomate.

4 inflorescencias fueron conservadas y las demás fueron descartadas al igual que los brotes laterales.

En el momento en que las plantas de los genotipos mutantes alcanzaron el $50 \%$ de antesis se tomaron muestras de hoja para cuantificar el contenido de ácido ascórbico. Las muestras foliares $(200 \mathrm{mg})$ fueron tomadas a partir de hojas totalmente expandidas y expuestas a la luz en horas del mediodía, al día siguiente del tratamiento de asperjado. Éstas fueron lavadas con agua destilada, congeladas en nitrógeno líquido y almacenadas a $-80{ }^{\circ} \mathrm{C}$ para su posterior análisis mediante la utilización del protocolo descripto en el capítulo 1 para la medición de ácido ascórbico.

Cuando el $50 \%$ de los frutos de las plantas de los genotipos mutantes alcanzaron el estado rojo de maduración, se cosecharon los frutos y se contaron así como también se registró el número de pedicelos florales. El porcentaje de cuajado se calculó como: Cuajado $(\%)=\frac{\text { Número de frutos }}{\text { Número de flores }} \times 100$

Se realizaron 3 ensayos independientes y se tomaron al menos tres réplicas de cada ensayo. Los resultados fueron analizados mediante el test de Tukey (ANOVA p<0.05).

\subsubsection{Medición de hormonas}

La medición de hormonas vegetales se realizó en flores completas colectadas en antesis, utilizando varias plantas de cada genotipo de tres experimentos independientes. El tejido liofilizado se utilizó para realizar las determinaciones mediante cromatografía líquida acoplada a espectrometría de masa. Estas determinaciones fueron realizadas mediante la modalidad de servicio a terceros en la Universidad Nacional de Rio Cuarto. El protocolo utilizado fue facilitado por el Dr. Masciarelli quien realizó las determinaciones y se describe brevemente a continuación. Aproximadamente $100 \mathrm{mg}$ de tejido liofilizado fueron acidificados con $1 \% \mathrm{v} / \mathrm{v}$ ácido 
Capítulo II: Efectos de la deficiencia en GDP-L-galactosa fosforilasa y la deficiencia de ácido ascórbico sobre la productividad de plantas de tomate.

acético $\mathrm{pH} 2,5\left(40 \mathrm{mg} \mathrm{ml}^{-1}\right)$ y $50 \mathrm{ng}$ de las siguientes hormonas deuteradas: ${ }^{2} \mathrm{H}_{5}$ ácido indol acetico (IAA), ${ }^{2} \mathrm{H}_{2}$-giberelina (GA), ${ }^{2} \mathrm{H}_{2}$-GA4, ${ }^{2} \mathrm{H}_{2}$-GA8, ${ }^{2} \mathrm{H}_{5}$-zeatina and ${ }^{2} \mathrm{H}_{6}-\mathrm{ABA}$ (OIChemIm Ltd., Olomouc, Czech Republic) fueron adicionadas como estándar interno. La solución acuosa fue particionada tres veces con acetato de etilo pH=3. Luego de la última partición el acetato de etilo fue evaporado completamente a una temperatura de $36^{\circ} \mathrm{C}$. Las muestras secas fueron disueltas en $1500 \mu \mathrm{l}$ de metanol. Los extractos fueron resuspendidos en $50 \mu \mathrm{l}$ de metanol y colocados en viales. Posteriormente $10 \mu \mathrm{l}$ de cada muestra fueron inyectados en un sistema de cromatografía líquida acoplado a espectrometría de masas con ionización por electroespray (Waters Corp., New York, NY, USA). Para el análisis cromatográfico de las muestras se utilizó un módulo de separación equipado con una bomba cuaternaria (Alliance 2695 Waters, USA) y una columna C-18 Rastek 2.1x100 mm (Restek, USA). El sistema binario de solventes utilizado para el gradiente de elución consistió en ácido acético en $\mathrm{H}_{2} \mathrm{O}$ 0,2\% (v/v) (Solvente B) y $\mathrm{MeOH}$ (Solvente A) a flujo constante de 200 $\mu \mathrm{l} \cdot \mathrm{min}^{-1}$. Los análisis MS/MS fueron realizados con un espectrómetro de masas (Micromass Quatro Ultima TM Manchester City, UK) como describieron Masciarelli y col., (2014). 
Capítulo II: Efectos de la deficiencia en GDP-L-galactosa fosforilasa y la deficiencia de ácido ascórbico sobre la productividad de plantas de tomate.

\section{$2.4 \quad$ Resultados}

\subsubsection{Parámetros fotosintéticos}

La tasa de asimilación máxima de $\mathrm{CO}_{2}$ en los mutantes slggp1 fue de 10,5 $\pm 0,85$ y $13,7 \pm 2,6 \mu \mathrm{mol} \mathrm{CO}_{2} \mathrm{~m}^{-2} \mathrm{~s}^{-1}$ en GGP5261 y GGP49C12, respectivamente. Mientras que en el genotipo silvestre la tasa de asimilación neta de $\mathrm{CO}_{2}$ registrada en el genotipo silvestre fue de $23,6 \pm 1,6 \mu \mathrm{mol} \mathrm{CO}_{2} \mathrm{~m}^{-2} \mathrm{~s}^{-1}$. Esto representa una disminución de $A_{\max }$, en los genotipos GGP5261 y GGP49C12 de un 50,5 y un 41,9\%, respectivamente con respecto al genotipo silvestre (Fig. 2.5 a). Por otro lado, el valor de ETR registrado en los mutantes slggp1 fue de $122,1 \pm 9,4$ y $127,9 \pm 11,2 \mu$ mol electrones $\mathrm{m}^{-2} \mathrm{~s}^{-1}$ en GGP5261 y GGP-49C12, respectivamente, mientras que en el genotipo silvestre ETR fue de $140,4 \pm 8,4 \mu \mathrm{mol}$ electrones $\mathrm{m}^{-2} \mathrm{~s}^{-1}$. Esto representa una disminución de ETR con respecto al genotipo silvestre, de un 13 y un $9 \%$ en los genotipos GGP-5261 y GGP49C12, respectivamente (Fig. 2.5 b). Además, $P_{p o t}$ que fue de $28,6 \pm 2,7$ y de $27,4 \pm 3,3$ $\mu \mathrm{mol} \mathrm{O}_{2} \mathrm{~m}^{-2} \mathrm{~s}^{-1}$ en GGP-5261 y GGP-49C12, respectivamente mientras que en el genotipo silvestre la $P_{\text {pot }}$ fue de $34,5 \pm 2,55 \mu \mathrm{mol} \mathrm{O}_{2} \mathrm{~m}^{-2} \mathrm{~s}^{-1}$. Esto representa una disminución de $P_{\text {pot }}$ un 17,1 y un 20,5 \% en los genotipos GGP-5261 y GGP-49C12 respectivamente, con respecto al genotipo silvestre (Fig. 2.5 c). De forma consistente con el pequeño efecto observado en ETR y $P_{\text {pot, }}$ no se registró un efecto significativo de la mutación en $F_{v} / F_{m}$ (Fig. 2.6 a) y NPQ tampoco resultó afectado en los mutantes de tomate slggp1 (Fig. 2.6 b). 
Capítulo II: Efectos de la deficiencia en GDP-L-galactosa fosforilasa y la deficiencia de ácido ascórbico sobre la productividad de plantas de tomate.

a

b
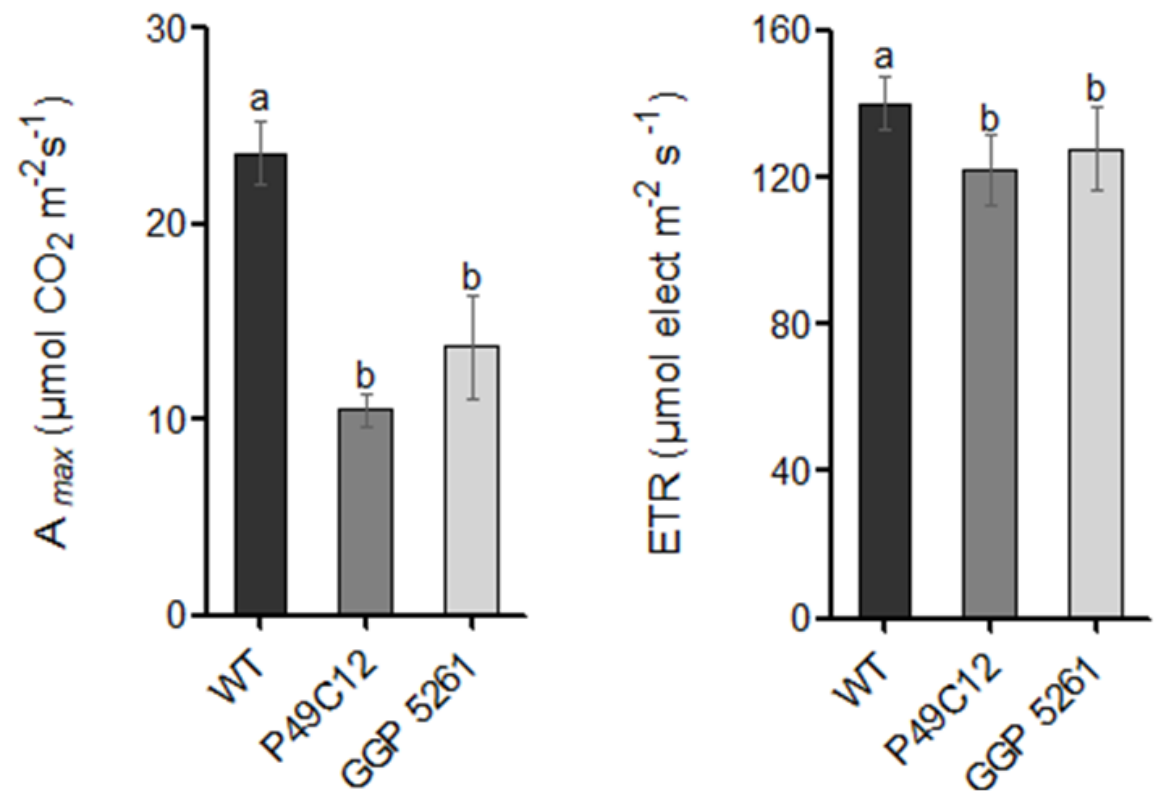

C

d
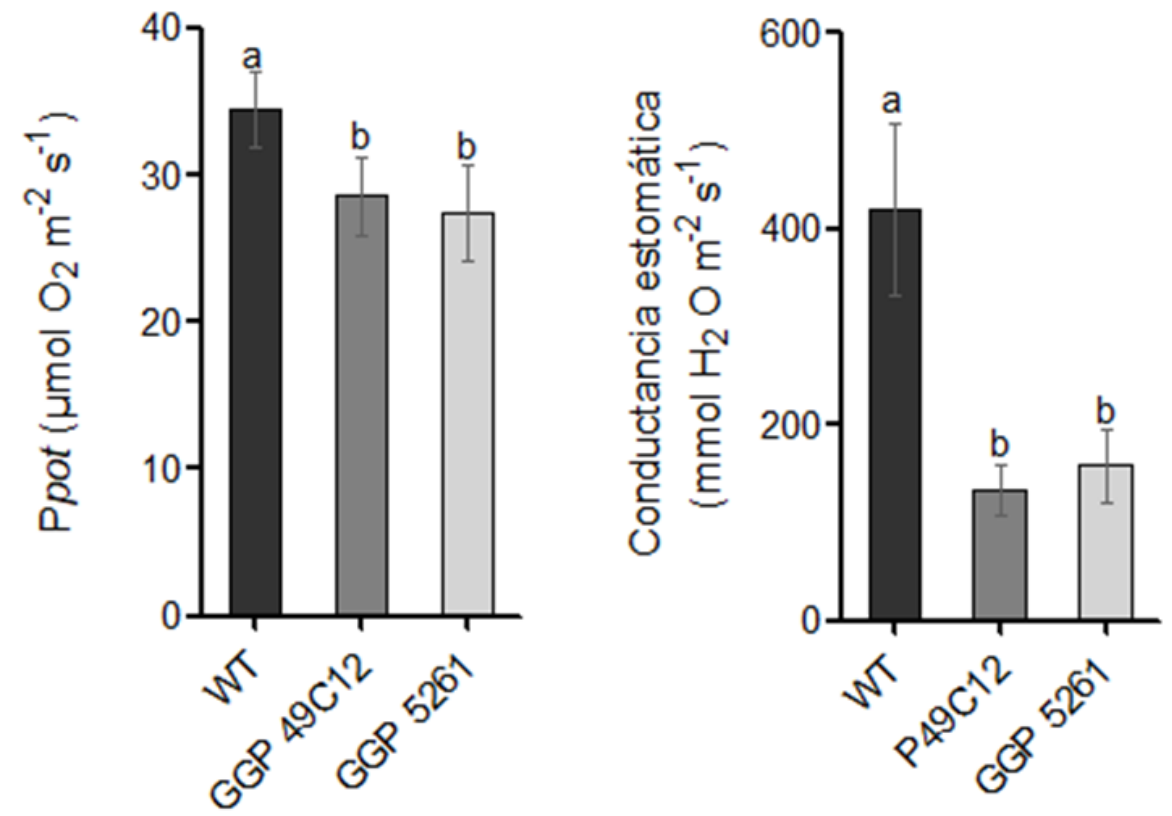

Figura 2.5- Parámetros fotosintéticos.

Mediciones realizadas en genotipos mutantes slggp1 (GGP-5261 y GGP-49C12) y silvestre (WT).a) Asimilación máxima de $\mathrm{CO}_{2},\left(\mathrm{~A}_{\mathrm{max}}\right)$; b) Tasa de transporte electrónico (ETR; c) Producción de oxígeno en condiciones de saturación de $\mathrm{CO}_{2}\left(P_{p o t}\right)$; fotosíntesis potencial); d) conductancia estomática. 
Capítulo II: Efectos de la deficiencia en GDP-L-galactosa fosforilasa y la deficiencia de ácido ascórbico sobre la productividad de plantas de tomate.

La conductancia estomática registrada en los mutantes slggp1 fue de $134 \pm 26$ y de $158 \pm 37 \mathrm{mmol} \mathrm{H}_{2} \mathrm{O} \mathrm{m}^{-2} \mathrm{~s}^{-1}$ en GGP-5261 y GGP-49C12, respectivamente, mientras que en el genotipo silvestre fue de $420 \pm 87 \mathrm{mmol} \mathrm{H}_{2} \mathrm{O} \mathrm{m} \mathrm{m}^{-2}$. Esto representa una disminución de 68 y $62 \%$ con respecto al genotipo silvestre en la conductancia estomática de los mutantes GGP-5261 y GGP-49C12, respectivamente (Fig. 2.5 d). En relación con esto la temperatura foliar, registrada mediante imágenes termográficas, fue $1,8-2,5^{\circ} \mathrm{C}$ más alta en los genotipos mutantes slggp1 que en el genotipo silvestre, siendo estas diferencias estadísticamente significativas (Figura 2.7).

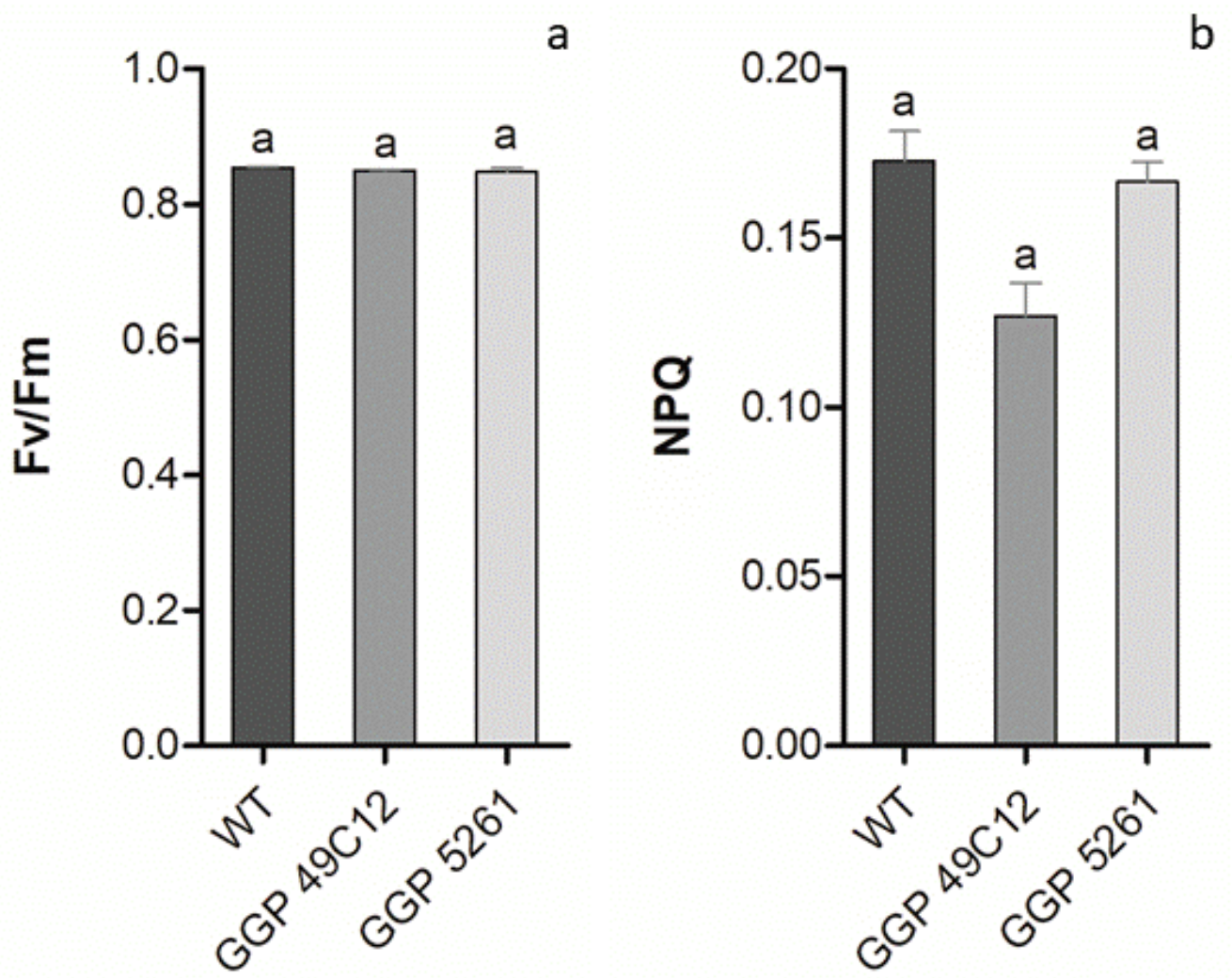

Figura 2.6-Mediciónes de fluorescencia modulada de la clorofila.

Mediciones realizadas en genotipos mutantes slggp1 (GGP-5261 y GGP-49C12) y silvestre (WT).a) Rendimiento cuántico máximo del fotosistema II $\left(F_{v} / F_{m}\right)$ y b) Quenching no fotoquímico (NPQ) Los valores fueron obtenidos de tres experimentos independientes y expresados como promedios \pm desvío estándar. 
Capítulo II: Efectos de la deficiencia en GDP-L-galactosa fosforilasa y la deficiencia de ácido ascórbico sobre la productividad de plantas de tomate.

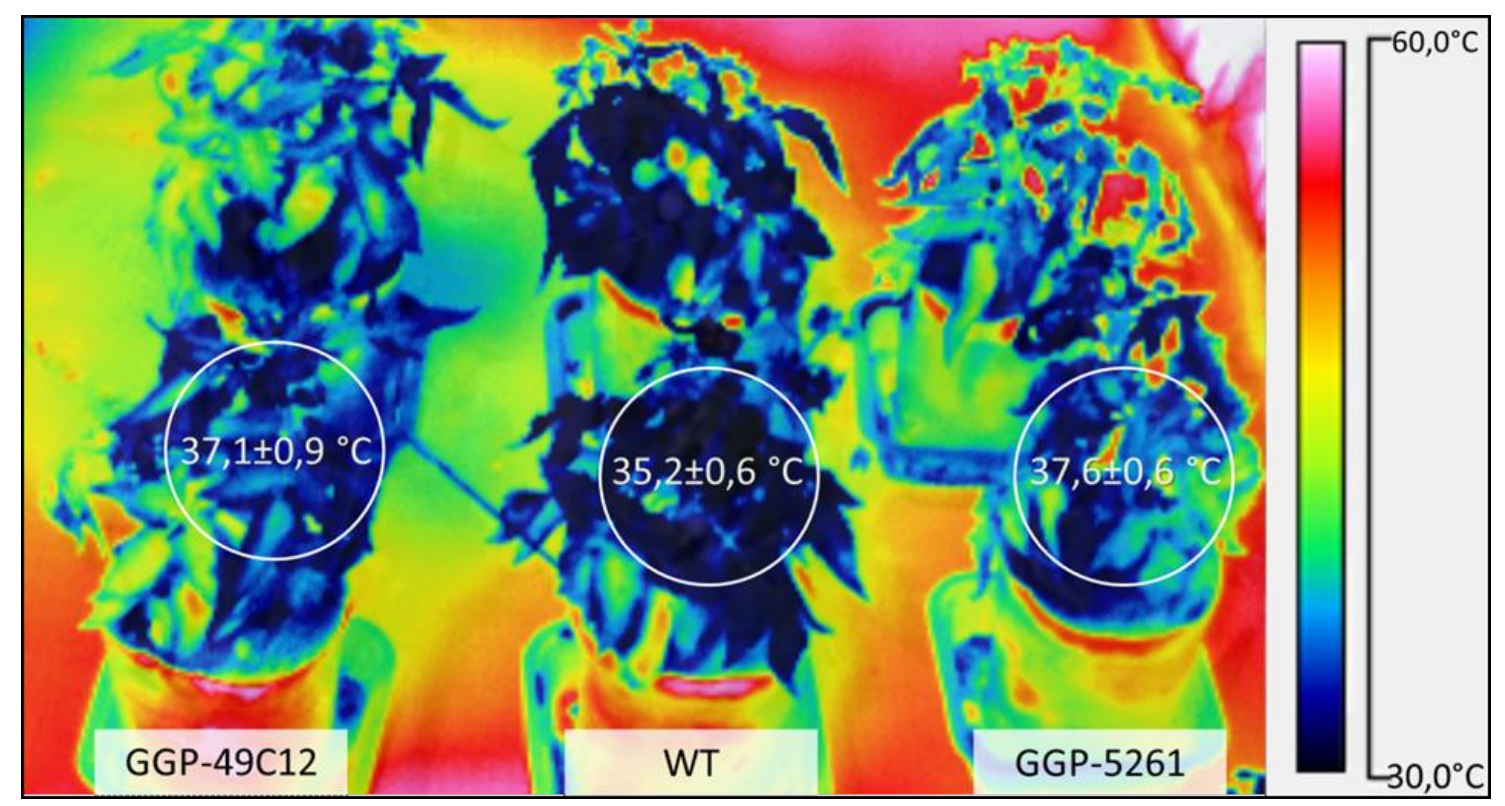

Figura 2.7- Imagen termográfica.

Se indican las temperaturas promedio \pm SD de plantas de los genotipos mutantes slggp1 (GGP49C12 y GGP5261) y el genotipo silvestre (WT).

\subsubsection{Efecto de la manipulación de las relaciones fuente-destino en el rendimiento}

Para investigar la importancia relativa de las limitaciones por fuente o por destino en el rendimiento fueron realizados distintos tratamientos de desfoliado y desfrutado. Al comparar los distintos tratamientos aplicados con respecto a cada uno de los genotipos se observó que los dos niveles de desfoliado realizados no afectaron el número de flores ni de frutos en los mutantes slggp1 ni tampoco en el genotipo silvestre. De igual manera, el rendimiento tampoco resultó afectado por los tratamientos de desfoliado con respecto al tratamiento control en ninguno de los genotipos (Tabla 2.1). Sin embargo cuando los destinos de las plantas fueron limitados a dos frutos por inflorescencia (ocho tomates por planta), los mutantes mantuvieron el peso total de frutos por planta en el mismo nivel que el tratamiento control a diferencia de las plantas del genotipo silvestre las cuales presentaron una menor productividad (Tabla 2.1). 
Capítulo II: Efectos de la deficiencia en GDP-L-galactosa fosforilasa y la deficiencia de ácido ascórbico sobre la productividad de plantas de tomate.

El peso individual de los frutos en los genotipos mutantes slggp1 resultó mayor al peso registrado en el genotipo silvestre, tanto en el tratamiento control como así también en ambos tratamientos de desfoliado y desfrutado. En el tratamiento de desfrutado más severo se observó una disminución drástica en la productividad en todos los genotipos con respecto al tratamiento control (Tabla 2.1). Con respecto al efecto de los tratamientos sobre los tejidos vegetativos se observó un mayor peso seco de las hojas y raíces en el genotipo silvestre con respecto a los genotipos mutantes slggp1 ante la aplicación de los tratamientos de desfrutado. El rendimiento de los genotipos mutantes slggp1 bajo tratamiento control fue menor que el rendimiento de las plantas del genotipo silvestre, de igual manera a lo observado en el capítulo 1. Sin embargo tanto la biomasa total como el rendimiento presentaron valores inferiores a los mostrados en el capítulo 1. Esto posiblemente es consecuencia del establecimiento de un número fijo de 4 inflorescencias por planta tanto en el tratamiento control como en los tratamientos de desfoliado y desfrutado. 
Tabla 2. 1-Ensayo fuente-destino.

\begin{tabular}{|c|c|c|c|c|c|c|c|c|c|}
\hline Genotipo & Tratamiento & $\begin{array}{l}\text { PF Total } \\
\left(\mathrm{g} \mathrm{pl}^{-1}\right)\end{array}$ & $\begin{array}{l}\text { Rendimiento } \\
\qquad\left(\mathrm{g} \mathrm{fr} \mathrm{pl}^{-1}\right)\end{array}$ & $\begin{array}{c}\text { PF } \\
\text { Individual } \\
\left(\mathrm{g} \mathrm{fr}^{-1}\right)\end{array}$ & $\begin{array}{l}\text { Número de } \\
\text { frutos } \\
\left(\text { fr } \mathrm{pl}^{-1}\right)\end{array}$ & $\begin{array}{l}\text { Número de } \\
\text { flores } \\
\left(\text { flores } \mathrm{pl}^{-1} \text { ) }\right.\end{array}$ & $\begin{array}{l}\text { PS Hojas } \\
\left(\text { g PS pl }^{-1}\right)\end{array}$ & $\begin{array}{l}\text { PS Tallo } \\
\left(\text { g PS pl }^{-1}\right)\end{array}$ & $\begin{array}{l}\text { PS Raíz } \\
\left(\text { g PS pl }^{-1}\right)\end{array}$ \\
\hline \multirow[t]{4}{*}{ WT } & $=\mathrm{H}$ & $75,1 \pm 0,6 \mathbf{A}$ & $56,7 \pm 0,5 \mathbf{A}$ & $2,48 \pm 0,29 A$ & $21,5 \pm 1,3 \mathbf{A}$ & $29,7 \pm 1,6 \mathbf{A}$ & $1,15 \pm 0,10 \mathrm{~B}$ & $1,27 \pm 0,04 \mathrm{~B}$ & $0,90 \pm 0,09 \mathrm{~B}$ \\
\hline & $-\mathrm{H}$ & $79,4 \pm 3,7 \mathbf{A}$ & $59,1 \pm 2,7 \mathbf{A}$ & $2,36 \pm 0,23 \mathrm{~A}$ & $21,7 \pm 0,75 \mathrm{~A}$ & $29,2 \pm 0,9 \mathbf{A}$ & $1,32 \pm 0,09 \mathrm{~B}$ & $1,41 \pm 0,03 \mathrm{BC}$ & $1,25 \pm 0,14 \mathrm{AB}$ \\
\hline & C & $90,2 \pm 6,0 \mathbf{A}$ & $59,0 \pm 2,6 \mathbf{A}$ & $2,63 \pm 0,36 \mathbf{A}$ & $23,3 \pm 1,6 \mathbf{A}$ & $29,3 \pm 2,3 \mathbf{A}$ & $2,39 \pm 0,2 \mathbf{A}$ & $1,85 \pm 0,1 \mathrm{AC}$ & $1,65 \pm 0,2 \mathrm{AB}$ \\
\hline & $2 \mathrm{~F}$ & $58,1 \pm 2,4 \mathrm{~B}$ & $30,4 \pm 2,3 \mathrm{C}$ & $4,49 \pm 0,16 \mathrm{~B}$ & $8,0 \pm 0$ & \# & $2,38 \pm 0,1 \mathbf{A}$ & $1,89 \pm 0,1 \mathbf{A}$ & $1,75 \pm 0,2 \mathbf{A}$ \\
\hline \multirow[t]{5}{*}{ GGP 49C12 } & $=\mathrm{H}$ & $68,6 \pm 3,9 A$ & $49,2 \pm 2,7 \mathbf{A}$ & $3,70 \pm 0,57 \mathbf{A}^{*}$ & $15,4 \pm 2,4 \mathbf{A}$ & $33,4 \pm 4,2 \mathrm{~A}$ & $0,96 \pm 0,05 B$ & $1,44 \pm 0,13 \mathbf{A}$ & $0,76 \pm 0,09 \mathrm{~B}$ \\
\hline & $-\mathrm{H}$ & $77,6 \pm 1,3 \mathbf{A}$ & $55,4 \pm 2,1 \mathbf{A}$ & $3,62 \pm 0,48 \mathbf{A}^{*}$ & $16,2 \pm 1,4 \mathbf{A}$ & $30,7 \pm 3,6 \mathbf{A}$ & $1,30 \pm 0,08 \mathbf{A B}$ & $1,73 \pm 0,08 \mathbf{A}$ & $1,020,04 \mathrm{AB}$ \\
\hline & C & $69,9 \pm 6,7 \mathbf{A}$ & $49,6 \pm 5,3 \mathbf{A}$ & $3,69 \pm 0,60 \mathbf{A}^{*}$ & $11,7 \pm 2,9 \mathbf{A}$ & $29,0 \pm 3,0 \mathbf{A}$ & $1,94 \pm 0,1 \mathbf{A}$ & $1,59 \pm 0,2 \mathbf{A}$ & $0,98 \pm 0,1 \mathrm{AB}$ \\
\hline & $2 \mathrm{~F}$ & $66,4 \pm 5,7 \mathbf{A}$ & $43,1 \pm 5,4 \mathbf{A}$ & $6,73 \pm 0,75 B$ & $8,0 \pm 0$ & \# & $1,78 \pm 0,15 A$ & $1,57 \pm 0,16 \mathbf{A}$ & $1,07 \pm 0,08 \mathbf{A B}^{*}$ \\
\hline & $1 \mathrm{~F}$ & $47,1 \pm 2,3 \mathbf{B}$ & $26,3 \pm 2,8 \mathrm{~B}$ & $5,76 \pm 0,59 \mathrm{~B}$ & $4,0 \pm 0$ & \# & $1,89 \pm 0,2 A^{*}$ & $1,72 \pm 0,2 \mathbf{A}$ & $1,44 \pm 0,2 A^{*}$ \\
\hline \multirow{2}{*}{ GGP 5261} & $2 \mathrm{~F}$ & $61,8 \pm 3,3 \mathrm{AB}$ & $39,1 \pm 2,30 \mathbf{A}$ & $5,47 \pm 0,41 \mathrm{~B}$ & $8,0 \pm 0$ & \# & $2,03 \pm 0,26 \mathbf{A}$ & $1,73 \pm 0,23 \mathbf{A}$ & $1,09 \pm 0,15 A^{*}$ \\
\hline & $1 \mathrm{~F}$ & $44,3 \pm 3,1 \mathrm{~B}$ & $20,9 \pm 2,3 \mathrm{~B}$ & $4,98 \pm 1,02 B$ & $4,0 \pm 0$ & \# & $1,75 \pm 0,1 A^{*}$ & $1,82 \pm 0,1 \mathrm{~A}$ & $0,99 \pm 0,2 A^{*}$ \\
\hline
\end{tabular}

Acumulación de biomasa en diferentes órganos de plantas de tomate mutantes slggp1 (GGP-5261 y GGP-49C12) y silvestres (WT) al imponer limitaciones de tamaño a tejidos fuente y destino. Los tratamientos consistieron en Desfoliado del $75 \%$ ( $=\mathrm{H}$ ); desfoliado del $50 \%(-\mathrm{H})$; dos frutos por inflorescencia $(2 \mathrm{~F})$; 1 fruto por inflorescencia (1F); plantas control (C). Las flores fueron cortadas para para establecer el número limitado de frutos (\#). Media \pm SD (ANOVA P < $0.05)$. Letras Mayúsculas indican diferencias significativas entre los tratamientos. Los asteriscos $\left(^{*}\right)$ indican diferencias significativas entre los genotipos mutantes y el genotipo silvestre para el mismo tratamiento (Prueba $t$ de Student $\mathrm{p}<0.05$ ) 
Para una interpretación más simple de los resultados, se realizó un análisis de componentes principales (Fig. 2.8). Éste muestra una relación contraria entre diferentes características tales como número de frutos, número de flores y rendimiento con respecto al peso fresco individual de fruto. A su vez a lo largo del componente 1 (CP1) las características relacionadas al crecimiento vegetativo presentan una relación opuesta con características reproductivas como el número de frutos, flores y el rendimiento. Por otro lado, se puede observar que el componente 1 distingue los tratamientos independientemente de los genotipos y el componente 2 (CP2) distingue claramente los genotipos mutantes del genotipo silvestre (de forma más marcada para el tratamiento de desfrutado).

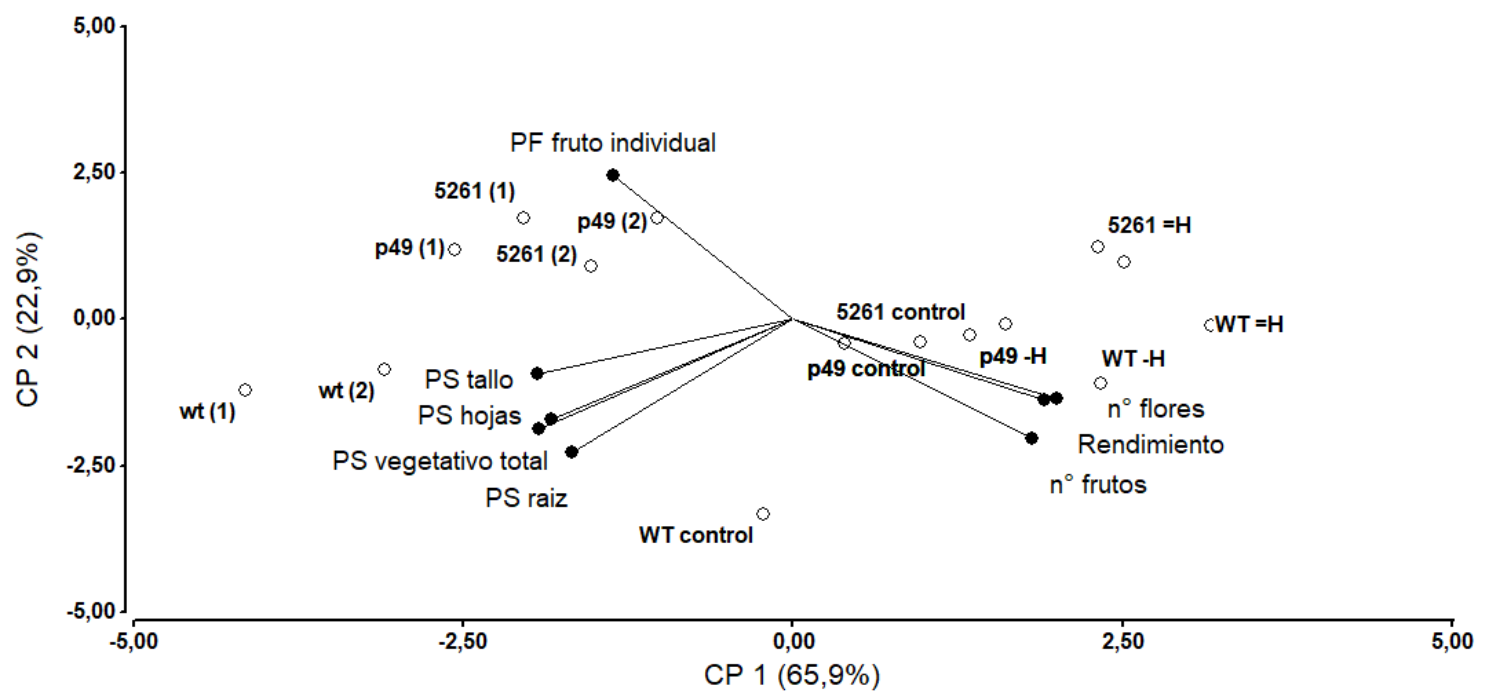

Figura 2. 8-Análisis de componentes principales para parámetros de desarrollo en tomate. Cada parámetro está representado por una línea continua terminada en un punto negro. Peso seco (PS); peso fresco (PF); número $\left(n^{\circ}\right)$. Los genotipos silvestre (WT), GGP $49 \mathrm{C} 12$ (p49) y GGP 5261 (5261) con cada tratamiento desfoliado del 75\% (=H); desfoliado del 50\% (-H); dos frutos por inflorescencia (2F); 1 fruto por inflorescencia (1F); plantas control (C), están representados por círculos vacíos.

\subsubsection{Hormonas en tejidos florales}

Dado que la reducción en el cuajado de los frutos en los genotipos mutantes slggp1 puede ser el resultado de alteraciones hormonales, la concentración de distintas hormonas vegetales fue medida en flores en estado de antesis (Tabla 2.2). Se observó una menor concentración de todas las giberelinas medidas $\left(\mathrm{GA}_{1}, \mathrm{GA}_{4}\right.$ y $\left.\mathrm{GA}_{8}\right)$ en los genotipos mutantes con respecto al genotipo silvestre, pero no se observaron diferencias en Acido Indol Acético (IAA), Zeatina y Acido Abscísico (ABA). 
Capítulo II: Efectos de la deficiencia en GDP-L-galactosa fosforilasa y la deficiencia de ácido ascórbico sobre la productividad de plantas de tomate.

Tabla 2. 2-Medición de hormonas en flores.

\begin{tabular}{|c|c|c|c|c|c|c|}
\hline Genotipos & $\begin{array}{c}\mathrm{GA}_{1} \\
\mu \mathrm{g} \mathrm{g}^{-1} \mathrm{DW}\end{array}$ & $\begin{array}{c}\mathrm{GA}_{4} \\
\mu \mathrm{g} \mathrm{g}^{-1} \mathrm{DW}\end{array}$ & $\begin{array}{c}\mathrm{GA}_{8} \\
\mu \mathrm{g} \mathrm{g}^{-1} \mathrm{DW}\end{array}$ & $\begin{array}{c}\text { AIA } \\
\mu g^{-1} D W\end{array}$ & $\begin{array}{c}\text { Zeatina } \\
\mu \mathrm{g} \mathrm{g}^{-1} \mathrm{DW}\end{array}$ & $\begin{array}{c}\text { ABA } \\
\mu \mathrm{g} \mathrm{g}^{-1} \mathrm{DW}\end{array}$ \\
\hline WT & $2,9 \pm 0,15 A$ & $19,5 \pm 1,9 \mathrm{~A}$ & $1,6 \pm 0,08 A$ & $1,1 \pm 0,07 A$ & $1,3 \pm 0,08 \mathrm{~A}$ & $16,2 \pm 0,6 \mathbf{A}$ \\
\hline GGP 5261 & $1,8 \pm 0,06 \mathrm{~B}$ & $9,3 \pm 0,3 \mathbf{B}$ & $0,3 \pm 0,03 \mathbf{B}$ & $1,1 \pm 0,03 \mathrm{~A}$ & $1,4 \pm 0,2 \mathrm{~A}$ & $16,0 \pm 1,1 \mathrm{~A}$ \\
\hline GGP P49C12 & $2,2 \pm 0,11 \mathrm{~B}$ & $7,7 \pm 0,4 \mathrm{~B}$ & $0,3 \pm 0,02 \mathrm{~B}$ & $1,1 \pm 0,02 \mathrm{~A}$ & $1,1 \pm 0,03 \mathrm{~A}$ & $18,1 \pm 1,1 \mathrm{~A}$ \\
\hline
\end{tabular}

Concentración de giberelinas $\left(\mathrm{GA}_{1}, \mathrm{GA}_{4}\right.$ y $\left.\mathrm{GA}_{8}\right)$, auxinas (AIA), zeatina y ácido abscísico (ABA) en flores de plantas de tomate mutantes slggp1 (GGP 5261 y GGP 49C12) y silvestre (WT). Los datos se muestran como medias \pm S.D. de tres experimentos diferentes. Las letras indican diferencias entre genotipos (ANOVA, $P<0.05$ )

\subsubsection{Restitución de los niveles de ácido ascórbico}

La suplementación exógena con ácido ascórbico incrementó el nivel de ascórbico foliar en ambos mutantes pero no se registró un aumento significativo en las hojas del genotipo silvestre (Tabla 2.3). Por otro lado el tratamiento de suplementación de ascórbico incrementó el cuajado de frutos en ambos mutantes pero no en el genotipo silvestre (Tabla 2.3). Tanto el contenido de ácido ascórbico como el porcentaje de cuajado de frutos en ambos mutantes, no recuperaron los niveles encontrados en el genotipo silvestre, aún con la suplementación exógena de ácido ascórbico (Tabla 2.3).

Tabla 2. 3-Ensayo de suplementación exógena con ácido ascórbico

\begin{tabular}{|lcc|}
\hline $\begin{array}{l}\text { Tratamiento } \\
\text { Wt }\end{array}$ & $\begin{array}{r}\text { Contenido de ácido ascórbico } \\
\text { en hoja } \\
\mu \text { mol g }^{-1} \mathbf{P F} \\
10,0 \pm 0,6\end{array}$ & $\begin{array}{c}\text { Cuajado de frutos } \\
\%\end{array}$ \\
\hline Wt + AA & $11,3 \pm 0,3$ & $62,7 \pm 10,3$ \\
\hline GGP-5261 & $5,0 \pm 0,6$ & $57,3 \pm 10,9$ \\
\hline GGP-5261 + AA & $8,3 \pm 0,9 *$ & $25,0 \pm 8,6$ \\
\hline GGP-P49 C12 & $4,3 \pm 0,3$ & $38,3 \pm 6,4^{*}$ \\
\hline GGP-P49 C12 + AA & $7,7 \pm 1,2^{*}$ & $29,7 \pm 1,2$ \\
\hline
\end{tabular}

Efecto de la suplementación con ácido ascórbico (+ AA) en el contenido de ascórbico en hoja $\mu \mathrm{mol} \mathrm{g}^{-1}$. peso fresco (PF) y el porcentaje de cuajado de frutos (\%) en plantas de tomate mutantes (GG-5261 y GGP- 49C12) y silvestres (WT). Las diferencias estadísticas entre el tratamiento control y el tratamiento $+A A$ se indican con *. (ANOVA, $P<0.05$ ) 
Capítulo II: Efectos de la deficiencia en GDP-L-galactosa fosforilasa y la deficiencia de ácido ascórbico sobre la productividad de plantas de tomate.

\subsection{Discusión}

Este capítulo se ha centrado en estudiar diversos procesos fisiológicos que podrían estar implicados en la modificación del rendimiento de plantas deficientes en GDP-Lgalactosa fosforilasa. Para ello se analizó el efecto de la deficiencia en GDP-Lgalactosa fosforilasa sobre los parámetros fotosintéticos, las relaciones fuente destino y la concentración de diferentes hormonas en flores.

Los resultados muestran una disminución de la actividad fotosintética reflejada en una reducción de un 50,5 y un 41,9 \% de la $A_{\max }$ en los genotipos GGP-5261 y GGP-49C12 (Fig. 2.5 a). Estos mutantes también presentaron una disminución de ETR de un 13 y un $9 \%$ en GGP-5261 y GGP-49C12, respectivamente con respecto al genotipo silvestre (Fig. 2.5 b). Los mutantes vtc2-1 de Arabidopsis también presentan una reducción en ETR, que puede ser revertida a los niveles del genotipo silvestre, mediante la aplicación del precursor del ácido ascórbico L-galactona-1,4-lactona (Senn y col., 2016). De la misma manera los genotipos GGP-5261 y GGP-49C12 presentan una disminución de $P_{\text {pot }}$ de un 17,1 y $20,5 \%$ respectivamente con respecto al genotipo silvestre (Fig. 2.5 b). Ello no estaría vinculado a daño en fotosistemas pues no se registró un efecto significativo de la mutación sobre el Rendimiento Cuántico del Fotosistema II ( $\left.F_{v} / F_{m}\right)$ (Fig. 2.6 a). Tampoco se observa una condición de estrés, pues $\mathrm{NPQ}$, relacionado con la disipación de exceso de energía en forma de calor, no se evidencia alterado en los mutantes (Fig. 2.6 b). Plantas de tomate con una reducción transciente de la expresión de GDP-L-Galactosa fosforilasa, que presentan una disminución del contenido de ácido ascórbico de un $50 \%$, sólo presentaron una disminución de $A_{\max }$ y $\mathrm{F}_{\mathrm{v}} / \mathrm{F}_{\mathrm{m}}$ bajo condiciones de estrés por frio; mientras que bajo condiciones no estresantes este efecto no fue observado (Wang y col., 2013). De manera similar mutantes vtc2-1 de Arabidopsis no presentaron una disminución $A_{\max }$ bajo condiciones de crecimiento normales (Senn y col., 2016). Esta disminución en $A_{\max }$ en los mutantes deficientes en GDP-L-galactosa fosforilasa no se vio 
Capítulo II: Efectos de la deficiencia en GDP-L-galactosa fosforilasa y la deficiencia de ácido ascórbico sobre la productividad de plantas de tomate.

acompañada por una disminución de la biomasa vegetativa (Tabla2.1), pero sí podría haber tenido un impacto en el rendimiento total de frutos, que fue significativamente menor en estos mutantes $(\sim 72 \%$ del rendimiento observado en el genotipo silvestre; Tabla 2.1). Este moderado efecto observado sobre parámetros fotosintéticos como ETR y $P_{p o t}$, no se corresponden con la gran disminución observada en $A_{\max } \mathrm{y}$ muestran que la deficiencia en GDP-L-Galactosa fosforilasa no limita la capacidad fotosintética (Fig. 2.5). Es probable que la limitación en $A_{\max }$ sea causada por un cierre estomático parcial, ya que la disminución de la conductancia estomática registrada en los mutantes GGP-5261 y GGP-49C12 fue de un 68 y $62 \%$, respectivamente, con respecto al genotipo silvestre (Fig. 2.5 d). Esta disminución en la conductancia estomática pudo ser evidenciada en la menor capacidad de refrigeración de las plantas mutantes que presentaron temperaturas mayores que las plantas del genotipo silvestre en horas del mediodía (Fig. 2.7)

Los resultados presentados aquí sugieren que la deficiencia en GDP-L-galactosa fosforilasa tiene un efecto importante sobre la asimilación de $\mathrm{CO}_{2}$, que es generado en mayor medida por la disminución de la conductancia estomática. En estudios en donde se generó la sobreexpresión de la enzima dehidroascorbato reductasa, se observó un aumento en el porcentaje de ascórbico reducido (Chen y col., 2003). Esto generó una disminución del contenido de $\mathrm{H}_{2} \mathrm{O}_{2}$ en las células guarda, donde esta especie reactiva de oxígeno tiene la capacidad de inducir el cierre estomático. En consecuencia, en estas plantas con mayor porcentaje de ácido ascórbico reducido la conductancia estomática es mayor (Chen y col., 2003). Por el contrario, plantas con una expresión disminuida de la enzima Dehidroascorbato Reductasa presentaron un mayor porcentaje de ácido ascórbico oxidado y una menor conductancia estomática. Estos datos permitieron concluir de que el estado redox del ácido ascórbico es un regulador de la apertura estomática (Chen y Gallie, 2004). Si bien los mutantes slggp1 estudiados en esta tesis no presentaron diferencias significativas en el estado redox 
Capítulo II: Efectos de la deficiencia en GDP-L-galactosa fosforilasa y la deficiencia de ácido ascórbico sobre la productividad de plantas de tomate.

del ácido ascórbico foliar con respecto al genotipo silvestre (Capitulo 1 fig. 1.9), en otros estudios se ha observado que el incremento del contenido de ascórbico en mutantes vtc2-1 de Arabidopsis, mediante la suplementación con L-galactono-1,4lactona, genera un aumento de la conductancia estomática (Senn y col., 2016). Esto sugiere que la disminución del contenido de ascórbico en los mutantes slggp1 podría tener un efecto sobre la conductancia estomática. Por otro lado, si se tiene en cuenta que la conductancia estomática fue medida en horas del mediodía, es posible que los estomas los mutantes slggp1 estén más abiertos durante periodos del día con menor irradiancia. De esta manera se compensaría la reducción en la tasa de fijación de $\mathrm{CO}_{2}$, minimizando de esta forma el efecto general sobre la asimilación de $\mathrm{CO}_{2}$, generado por la deficiencia en GDP-L-galactosa fosforilasa y el menor contenido de ácido ascórbico.

Para determinar si esta reducción fotosintética limita la producción de frutos, se realizaron experimentos con diversas relaciones fuente-destino. La disminución en la fuente de fotoasimilados realizada a través de tratamientos de reducción del área foliar no generaron un impacto estadísticamente significativo en el porcentaje de cuajado de frutos ni del rendimiento con respecto al tratamiento control en ninguno de los genotipos (Tabla 2.1). Esto indicaría que la fuente de fotoasimilados no limita el establecimiento de los frutos, en los mutantes deficientes en GDP-L-galactosa fosforilasa. De manera similar, (Tanaka y Fujita, 1974) demostraron, a través de ensayos de remoción parcial de frutos y hojas, que la fuente no es limitante del rendimiento en tomate y también que el tamaño del fruto tiene una flexibilidad limitada. Esto último fue observado en los mutantes slggp1 que presentan frutos de mayor peso individual que los frutos del genotipo silvestre. Este mayor peso individual de los frutos mutantes puede ser explicado por una disminución de la competencia entre frutos por los fotoasimilados, dado que el experimento de desfrutado genera un incremento en el peso individual de los frutos tanto en el genotipo mutante como silvestre (Tabla 2.1). 
Capítulo II: Efectos de la deficiencia en GDP-L-galactosa fosforilasa y la deficiencia de ácido ascórbico sobre la productividad de plantas de tomate.

Los resultados aquí obtenidos muestran que los frutos presentan un límite al aumento de tamaño, especialmente observable en plantas silvestres y los mutantes slggp1, que no compensan el rendimiento del genotipo silvestre en condiciones control. Es interesante que esta mayor capacidad de crecimiento individual de los frutos de los mutantes, genere que ante la realización del tratamiento de desfrutado intermedio $(2 \mathrm{~F})$, estos no presenten una merma en el rendimiento (Tabla 2.1). Estos resultados muestran que el número de frutos (tamaño del destino) limita el rendimiento en tomate. Por otra parte es destacable el incremento del porcentaje de cuajado de frutos que ocurre en los mutantes slggp1 suplementados con ácido ascórbico (Tabla 2.3). Esto sugiere que este metabolito juega un papel importante en este proceso y que la limitación por fotoasimilados (Ruan y col., 2012) sería parcialmente responsable de la reducción del cuajado de frutos observada en este caso. Serán necesarios futuros experimentos para registrar si durante la suplementación con ascórbico exógeno, se reestablece la tasa de asimilación neta y la conductancia estomática. Por otro lado, la modificación de las relaciones fuente-destino también generó efectos sobre la distribución de biomasa entre los tejidos vegetativos. Ante el tratamiento de desfrutado se observó una mayor biomasa de hojas y de raíces en el genotipo silvestre con respecto al tratamiento control (Tabla 2.1). Este efecto no fue observado en los genotipos mutantes, lo que sugiere una menor capacidad de translocación de fotoasimilados en estos genotipos.

Para investigar con más detalle la causa de la reducción del cuajado de frutos, se determinó el efecto de las mutaciones en GDP-L-Galactosa fosforilasa sobre la concentración de hormonas en flores y se encontró una reducción del contenido de $\mathrm{GA}_{1}, \mathrm{GA}_{4}, y \mathrm{GA}_{8}$ en los mutantes (Tabla 2.2). La inhibición química de la síntesis de giberelinas en tomate genera una reducción del cuajado de frutos y esto puede ser revertido mediante la aplicación exógena de hormonas (Serrani y col., 2007b). Por lo tanto la baja concentración de GA observada en las flores de los mutantes podría 
Capítulo II: Efectos de la deficiencia en GDP-L-galactosa fosforilasa y la deficiencia de ácido ascórbico sobre la productividad de plantas de tomate.

contribuir al bajo porcentaje de cuajado. Tratamientos con etileno generan una reducción del cuajado de frutos en tomate, posiblemente por inhibición de la síntesis de GA (Shinozaki y col., 2015). Teniendo en consideración que los mutantes vtc2 de Arabidopsis presentan una producción aumentada de etileno (Caviglia y col., 2018), la deficiencia de ascórbico también podría generar un aumento en la producción de etileno en plantas de tomate; esto podría causar una disminución de la concentración de GA y del cuajado de frutos en los mutantes slggp1. Como se mencionó en la introducción a este capítulo un alto contenido de brasinoesteroides provoca una disminución en la síntesis de GA y como consecuencia de esto un aumento en la estabilidad de proteínas DELLA que particularmente en el meristema medial del carpelo, influyen positivamente en el desarrollo de los óvulos (Barro-Trastoy y col., 2020; Gomez y col., 2018). Esto es contradictorio con el hecho de que Micro-Tom presenta menor contenido de brasinoesteroides como consecuencia de una mutación en el gen Dwarf (D) de la vía de síntesis de brasinoesteroides, por lo que en principio esta no sería la causa de la menor concentración de GA registrada en las flores de los mutantes slggp1.

En resumen los resultados de este capítulo sugieren que esta disminución en la expresión de GDP-L-galactosa fosforilasa y en la concentración de ascórbico influyen en el rendimiento de plantas de tomate. En parte a través de un impacto negativo en el proceso de cuajado de frutos, posiblemente como consecuencia de una disminución en la concentración de GA, y también en el tamaño final de los frutos. La disminución en el cuajado de frutos en los mutantes slggp1 es causada directamente por la deficiencia de ácido ascórbico, dado que esto puede revertirse parcialmente mediante la suplementación de este antioxidante de forma exógeno. El tamaño de los frutos en los mutantes slggp1 aumenta en compensación a la reducción del número, pero no lo suficiente como para alcanzar el rendimiento de plantas silvestres. Además, los datos 
Capítulo II: Efectos de la deficiencia en GDP-L-galactosa fosforilasa y la deficiencia de ácido ascórbico sobre la productividad de plantas de tomate.

indican que el suministro de asimilados no constituyen un factor limitante para la producción de biomasa y de frutos en particular. 


\section{CAPÍTULO III:}

"Efecto de la deficiencia en

GDP-L-galactosa fosforilasa en

la maduración en planta y

postcosecha de frutos de

tomate." 
Capítulo III: Efecto de la deficiencia en GDP-L-galactosa fosforilasa en la maduración en planta y postcosecha de frutos de tomate.

\subsection{Introducción}

El fruto es un órgano vegetal que tiene como objetivo dispersar las semillas para que la especie pueda alcanzar nuevos territorios. Entre las diferentes estrategias para la dispersión de las semillas, la zoocoria y principalmente la endozoocoria ha sido producto de la coevolución de plantas y animales, y ha dado lugar a la aparición de los frutos carnosos. En este tipo de frutos el tejido "carnoso" se desarrolla a partir de diferentes órganos florales e incluso a partir de tejidos cercanos a la flor (Strasburguer y col. 1990). Luego de alcanzar la madurez fisiológica, atraviesan un proceso de maduración (Watada y col., 1984). De esta forma pasan de ser unos órganos verdes y camuflados entre las hojas, a ser órganos con colores, aromas y sabores atractivos para especies de aves y mamíferos, que a cambio de una recompensa nutritiva, dispersan las semillas de estas especies vegetales (Seymour y col., 2013).

El proceso de maduración de los frutos carnosos ha sido muy estudiado por la importancia que estos tienen en la nutrición humana, ya que si bien no son el principal aporte de carbohidratos y proteínas, estos son una fuente muy importante de fibra, azúcares, vitaminas, antioxidantes y minerales. Este proceso, comprende una serie de cambios químicos y fisiológicos coordinados que resultan en la conversión de almidón en azúcares; la síntesis y acumulación de pigmentos característicos; la evolución de los compuestos aromáticos volátiles y modificaciones en la textura a través de cambios en las paredes celulares, cutícula y contenido hídrico, que colectivamente se manifiestan como ablandamiento y determinan, en última instancia, las características organolépticas y nutricionales del fruto maduro (Klee y Giovannoni, 2011). Luego de alcanzar las características óptimas para el consumo, los frutos pasan a otra fase, que en biología postcosecha se conoce como sobremaduración, y posteriormente deviene la senescencia del fruto, en la cual la integridad celular se ve comprometida y se produce la descomposición del fruto (Biale, 1961). Teniendo en cuenta esto, resulta de mucha importancia para la industria frutícola y hortícola desarrollar estrategias que permitan retrasar en el tiempo el decaimiento de los frutos, una vez que estos han sido retirados de la planta para su comercialización (Crisosto y col., 2015). En este sentido, la clasificación de los frutos carnosos en climatéricos y no climatéricos en función de su patrón de producción de $\mathrm{CO}_{2}$ durante el proceso de maduración ha resultado de utilidad. Los frutos climatéricos presentan un clímax en la producción de $\mathrm{CO}_{2}$ que es precedido por un pico en la producción de etileno, mientras que los frutos no climatéricos no presentan este aumento brusco de la respiración ni tampoco producen grandes cantidades de etileno. 
Capítulo III: Efecto de la deficiencia en GDP-L-galactosa fosforilasa en la maduración en planta y postcosecha de frutos de tomate.

El etileno es un compuesto simple, gaseoso, que constituye una hormona en los vegetales y participa de muchos procesos fisiológicos, principalmente relacionados con la senescencia, respuestas al estrés y la maduración de los frutos (Burg y Burg, 1965). Los frutos climatéricos poseen dos sistemas de producción de etileno, el sistema 1, el cual es autoinhibitorio y está activo durante la fase de crecimiento del fruto, hasta un momento de transición, en la cual la fruta pasa a ser competente para la maduración en ausencia de signos evidentes de maduración real y coincide estrechamente con el momento en que se completa la maduración de la semilla. A partir de este momento de transición entra en competencia el sistema 2, que es autocatalítico, ya que la síntesis de etileno puede ser activada en respuesta al etileno proporcionado exógenamente (Giovannoni y col., 2017; McMurchie y col., 1972). Esta respuesta se inicia con la percepción del etileno por parte de receptores ETRs ubicados en membranas del retículo endoplásmico (Gallie, 2015). En ausencia de etileno los receptores ETRs inhiben las respuestas aguas abajo a través de CTR1 que fosforila al regulador positivo EIN2 impidiendo que éste se mueva al núcleo. Cuando el etileno se une a los receptores ETR, CTR1 deja de fosforilar EIN2 y entonces un fragmento c-terminal de este regulador positivo se mueve al núcleo en donde transmite la señal a los factores de transcripción EIN3 y EIL que a su vez activan factores de transcripción de genes de respuesta a etileno (Bouzayen y col., 2010; Gallie, 2015). Entre estos genes de respuesta a etileno, se encuentran genes que participan de la hidrólisis de pared celular, del catabolismo de azúcares, relacionados al cambio de color y la producción de compuestos volátiles que le confieren aromas a la fruta madura. Además, se activa la transcripción de genes relacionados a la síntesis de etileno y se genera el fenómeno autocatalítico, que involucra el aumento brusco de esta hormona en frutos climatéricos (Bapat y col., 2010). Este pico en la síntesis de etileno, desencadena el proceso de maduración de los frutos climatéricos que progresa rápidamente y provoca una disminución acelerada del tiempo de vida postcosecha de estos frutos.

Tratamientos utilizados para prolongar la vida postcosecha de los frutos como las bajas temperaturas (Cheng y col., 1988), los recubrimientos comestibles (Ali y col., 2010), las atmósferas controladas (Artés y col., 2006) y el 1-metilcciclopropeno (1MCP) han resultado ser eficientes, evitando un gran porcentaje de pérdidas por deterioro de frutos durante el almacenamiento previo a la distribución y venta. El 1MCP es un compuesto que bloquea irreversiblemente los receptores de etileno (ETRs), ubicados en el retículo endoplasmático (Sisler y Serek, 1997). En tomate, el tratamiento con 1-MCP genera la disminución de los niveles de transcripto de los 
Capítulo III: Efecto de la deficiencia en GDP-L-galactosa fosforilasa en la maduración en planta y postcosecha de frutos de tomate.

genes que codifican la ACC sintasa y ACC oxidasa, indicando un efecto sobre el "feedback" positivo que genera la síntesis de etileno al inicio del climaterio (Nakatsuka y col., 1997).

Durante la maduración, se produce en el tomate un aumento del nivel de especies reactivas de oxígeno, principalmente durante la etapa de transición en la que el fruto cambia de color (Jiménez y col., 2002). Esto está acompañado por un aumento en el contenido de antioxidantes totales, entre los que se encuentran los $\beta$-carotenos, principalmente el licopeno, y el ácido ascórbico que fue registrado durante la maduración en planta (Cano y col., 2003), como también en tomates madurados durante almacenamiento postcosecha (Steelheart y col., 2019). Este metabolito es considerado el principal antioxidante no enzimático presente en los tejidos vegetales (Foyer y Noctor, 2011) y tiene la capacidad de modular los niveles de especies reactivas de oxígeno (ROS en inglés), que además de oxidar y dañar componentes subcelulares, son capaces de participar en procesos de señalización (Foyer y Noctor, 2011). Además, se ha demostrado la interacción de este metabolito con los procesos de la respiración y la fotosíntesis en hojas (Bartoli y col., 2009, 2006) y una relación entre su vía de síntesis y el proceso de formación de azúcares destinados a la síntesis de la pared celular en frutos de tomate (Gilbert y col., 2009). También se han reportado evidencias de que el ácido ascórbico actúa como cofactor de la ACC oxidasa en la síntesis de etileno (Dong y col., 1992). Por otro lado se ha observado una regulación negativa del etileno sobre el contenido de ácido ascórbico en hojas de Arabidopsis sp. (Gergoff Grozeff y col., 2010). Plantas de tomate con una mutación que produce una deficiencia en la síntesis y contenido de brasinosteroides presentan mayor producción de etileno, y una menor acumulación de ácido ascórbico en hojas y ello es revertido por el tratamiento con 1-MCP (Mazorra y col., 2014). Mutantes de Arabidopsis deficientes en ácido ascórbico (vtc2), poseen una mayor expresión de genes correspondientes a señalización por etileno y además presentan una mayor producción de etileno en los tejidos vegetativos aéreos (Caviglia y col., 2018; Kerchev y col., 2011). Estos antecedentes que muestran una fuerte interacción entre los niveles de ácido ascórbico y el etileno en tejidos vegetativos ponen de manifiesto la importancia del estudio del papel del ácido ascórbico en frutos. En esta Tesis son utilizados mutantes deficientes en ácido ascórbico (slggp1) para demostrar la interacción entre este antioxidante y los procesos de maduración de tomates. 
Capítulo III: Efecto de la deficiencia en GDP-L-galactosa fosforilasa en la maduración en planta y postcosecha de frutos de tomate.

\subsection{Objetivos}

En este capítulo se abordó el objetivo específico 3 que consistió en determinar el efecto de modificaciones en el contenido de ácido ascórbico sobre el proceso de la maduración de frutos.

En función de este, se fijaron dos actividades a realizar:

3.2.1 Evaluar la maduración y la producción de etileno (en planta) de frutos de plantas deficientes en GPP-L-Galactosa fosforilasa (slggp1).

3.2.2 Caracterizar la participación del etileno en la maduración postcosecha de frutos de tomate en líneas slggp1. 
Capítulo III: Efecto de la deficiencia en GDP-L-galactosa fosforilasa en la maduración en planta y postcosecha de frutos de tomate.

\subsection{Materiales y métodos}

\subsubsection{Cuantificación del color superficial}

Los frutos fueron cosechados en los estadios de maduración verde maduro (VM), pintón $(P)$, y rojo $(R)$ (Fig. 3.1). La selección de los frutos se realizó visualmente y luego se determinó el color superficial de los mismos con un colorímetro (Chroma CR300, Minolta, Osaka, Japón). Se registraron los parámetros $L^{*}, a^{*}$ y b*, y a partir de éstos se calculó el ángulo de matiz, ( $\mathrm{HUE}^{\circ}$, tono) usando las siguientes fórmulas: $\mathrm{HUE}^{\circ}=\arctan (\mathrm{b} / \mathrm{a})$ cuando $\mathrm{a}>0$ y $\mathrm{b}>0 ; \mathrm{HUE}^{\circ}=180^{\circ}-\arctan (\mathrm{b} / \mathrm{a})$ cuando $\mathrm{a}<0$ y b>0 (Fig. 3.2). Se realizaron tres medidas en la zona ecuatorial por cada fruto ensayado. Se determinó el color de 20 frutos de cada estado de maduración en cada uno de cuatro ensayos independientes.

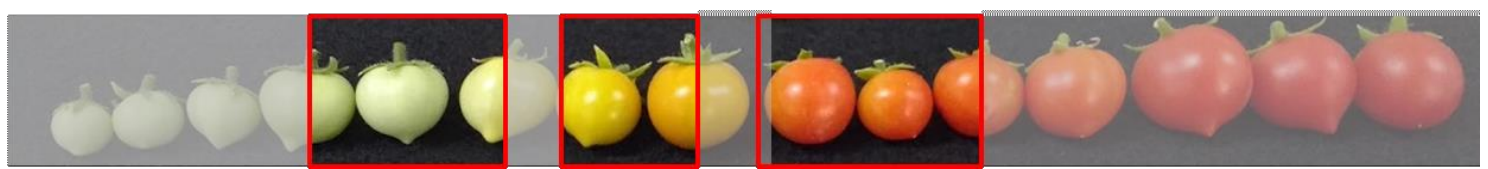

Figura 3.1 Rango de color correspondiente al estadio de maduración.

En cada cuadro rojo. Verde maduro (VM), pintón (P) y rojo(R) de izquierda a derecha respectivamente.

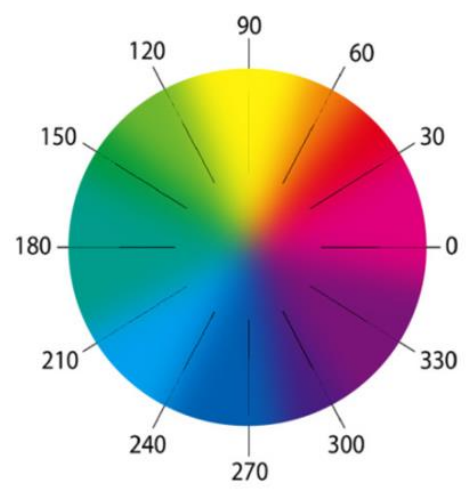

Figura 3.2 -Representación esquemática de la variación del ángulo de matiz o tono ( ${ }^{\circ} \mathrm{HUE}$ ).

Este angulo varía entre $0^{\circ}$ y $360^{\circ}$. Según el modelo cromático CIELAB (CommissionInternationaled'Eclairage). 
Capítulo III: Efecto de la deficiencia en GDP-L-galactosa fosforilasa en la maduración en planta y postcosecha de frutos de tomate.

\subsubsection{Determinación de la actividad respiratoria}

La actividad respiratoria de los frutos se midió utilizando un sensor de $\mathrm{CO}_{2}$ infrarrojo

(IR) (Lutron Electronic Enterprise Co. L.T.D., Model GC-2028). Aproximadamente $20 \mathrm{~g}$ de frutos fueron incubados en una cámara hermética de $1470 \mathrm{ml}$, en el interior de la cual se dispuso el censor IR y un dispositivo con ventilador para homogeneizar el aire en el interior de la cámara. Luego de 3 min de incubación se registró la concentración de $\mathrm{CO}_{2}$ cada 5 min durante un lapso de $20 \mathrm{~min}$. A partir de estos registros se calculó la tasa respiratoria que fue expresada como $\mathrm{ml}$ de $\mathrm{CO}_{2} . \mathrm{Kg}^{-1} \mathrm{PF} . \mathrm{h}^{-1}$ (Fig. 3.3).

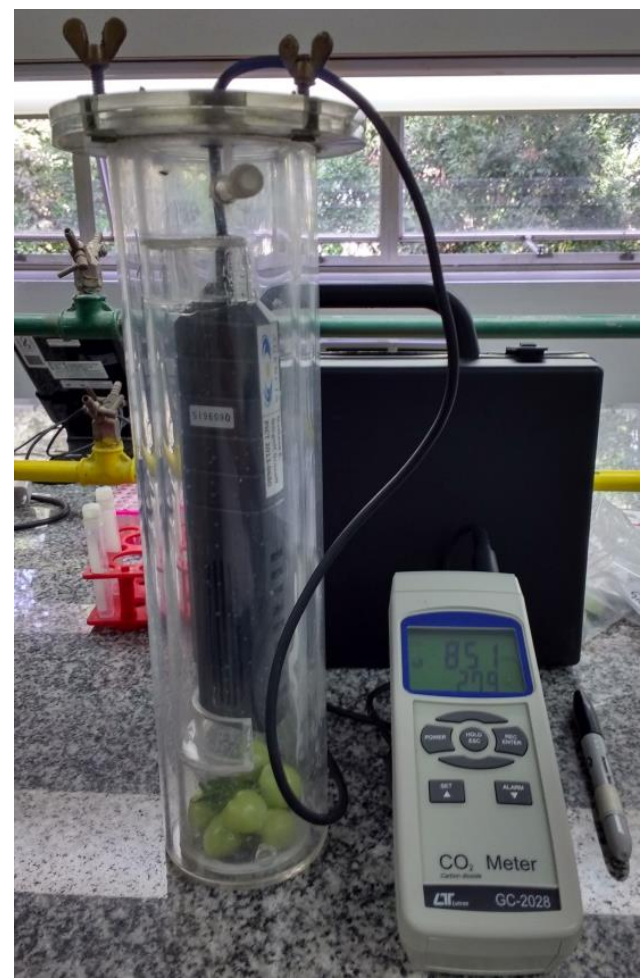

Figura 3. 3. Determinación de la actividad respiratoria. Sensor de $\mathrm{CO} 2$ infrarrojo (Lutron Electronic Enterprise Co. L.T.D., Model GC-2028) y cámara hermética de $1470 \mathrm{ml}$. 
Capítulo III: Efecto de la deficiencia en GDP-L-galactosa fosforilasa en la maduración en planta y postcosecha de frutos de tomate.

\subsubsection{Determinación de la tasa de producción de etileno}

La producción de etileno fue medida mediante un sistema de cromatografía gaseosa (Konik, KNK-3000-HGRC) compuesto por una columna de alúmina y un detector de ionización de llama. Frutos en tres estadios de maduración (VM, $\mathrm{P}$ y $\mathrm{R})$ de cada genotipo fueron pesados, $(\approx 10 \mathrm{~g})$ e incubados durante $3 \mathrm{~h}$ en tubos cerrados herméticamente de $50 \mathrm{ml}$ con (tapones de goma). Con una jeringa de cromatografía gaseosa se tomó $1 \mathrm{ml}$ de aire del interior del envase y se inyectó en el cromatógrafo. Los resultados fueron expresados como $\mathrm{nl} \mathrm{g}^{-1} \mathrm{PF} \mathrm{h}^{-1}$ de etileno. La concentración de etileno se estimó a partir de una curva patrón realizada con diferentes concentraciones de un patrón de etileno.

\subsubsection{Determinación de la firmeza}

Se evaluó la firmeza del fruto midiendo la fuerza máxima $(\mathrm{N})$ generada cuando el fruto es comprimido $6 \mathrm{~mm}$ con una sonda de acero cilíndrica de $2,5 \mathrm{~mm}$ con punta roma instalada en un dispositivo analizador de textura (TA.XTplus, Stable Micro Systems, Texture Technologies ${ }^{\circledR}$, Scarsdale, NY) (Fig. 3.4). Los parámetros de ajustes utilizados fueron: celda de carga PL/CEL/30; modo de prueba: compresión; velocidad pre-prueba: $2 \mathrm{~mm} \mathrm{~s}^{-1}$; velocidad de prueba: $0,5 \mathrm{~mm} \mathrm{~s}^{-1}$; velocidad post-prueba: $10 \mathrm{~mm}$ $\mathrm{seg}^{-1}$. Cada fruto fue medido dos veces en lados opuestos de la zona ecuatorial central. Los datos se registraron utilizando el adquisidor de datos proporcionado por el equipo (Exponent Lite Análisis Software $®$ ), a una tasa de adquisición de 200 datos por segundo. 
Capítulo III: Efecto de la deficiencia en GDP-L-galactosa fosforilasa en la maduración en planta y postcosecha de frutos de tomate.

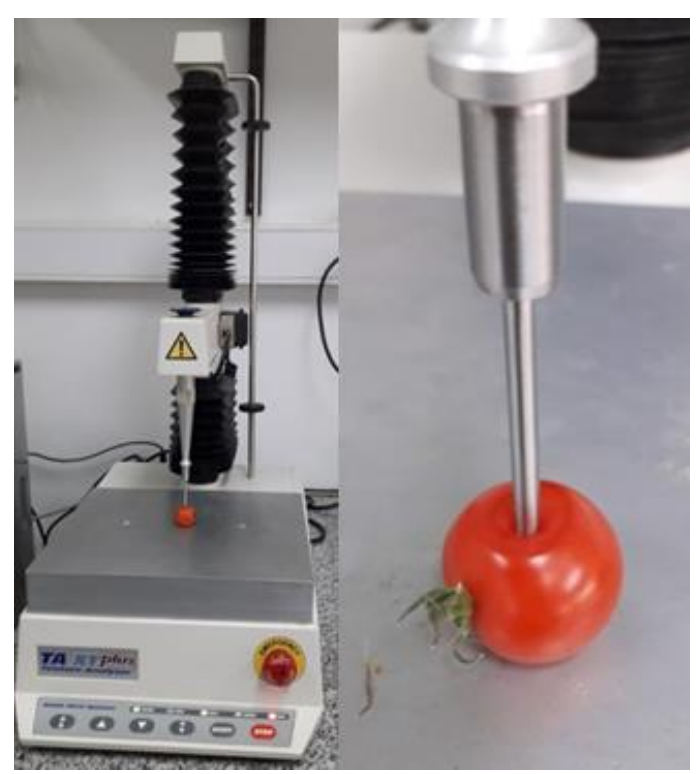

Figura 3. 4 Analizador de textura.

Analizador de textura (TA.XTplus, Stable Micro Systems, Texture Technologies ${ }^{\circledR}$, Scarsdale, NY). Sonda de acero cilíndrica de $2,5 \mathrm{~mm}$ con punta roma.

A partir de los valores de fuerza máxima, se calculó una tasa de ablandamiento para el periodo de almacenamiento postcosecha. Esta tasa de ablandamiento fue expresada como $\mathrm{N} \mathrm{d}^{-1}$.

\subsubsection{Pérdida de peso}

Los frutos cosechados en el estadio VM se pesaron para determinar su peso inicial en una balanza con una precisión de 0,001 g. Posteriormente los mismos frutos se pesaron a los 7 y 14 días de almacenamiento. La pérdida de peso se calculó como el porcentaje de pérdida de peso respecto al peso inicial.

\subsubsection{Determinación de sólidos solubles totales}

El contenido de sólidos solubles totales (SST) se midió utilizando un refractómetro digital (Milwaukee MA871, RockyMount, USA) a partir de jugo extraído de cada fruto mediante compresión. Los resultados fueron expresados en ${ }^{\circ}$ Brix, equivalentes al \% $\mathrm{p} / \mathrm{p}$ de sacarosa. 
Capítulo III: Efecto de la deficiencia en GDP-L-galactosa fosforilasa en la maduración en planta y postcosecha de frutos de tomate.

\subsection{7 $\mathrm{Ph}$ y acidez total titulable}

Frutos congelados en nitrógeno líquido se procesaron en un molinillo (Peabody PEMC9100) cuyo recipiente metálico fue enfriado con nitrógeno líquido para evitar el descongelamiento de la muestra. Diez gramos del polvo resultante se suspendieron en $100 \mathrm{ml}$ de agua. Se midió el pH del homogenato y la acidez total titulable (ATT) se determinó titulando con 0,1 N NaOH hasta pH 8,2 (AOAC, 1980). La acidez se expresó como $\mathrm{mM}$ de $\mathrm{H}^{+} \mathrm{kg}^{-1}$ fruto fresco por medio de un peachímetro. Tres muestras independientes se analizaron por cada condición analizada y cada una se tituló por duplicado.

\subsubsection{Determinación de azúcares}

Se utilizó el método de Somogyi-Nelson (Somogyi, 1952; Nelson, 1944). Este método tiene como fundamento que los azúcares reductores al ser calentados en medio alcalino, reducen el ion cúprico presente en la solución del "reactivo A" (18 \% p/v Na $\mathrm{SO}_{4} ; 1,2 \% \mathrm{p} / \mathrm{v}$ tartrato de sodio y potasio; $2,4 \% \mathrm{p} / \mathrm{v} \mathrm{Na} \mathrm{NaO}_{3}$ (anhidro); 0,4 \% p/v $\mathrm{CuSO}_{4} .5 \mathrm{H}_{2} \mathrm{O} ; 1,2 \% \mathrm{p} / \mathrm{v} \mathrm{NaHCO}$ ) a ion cuproso. El óxido cuproso formado de esta manera, reduce el complejo arseno-molibdato presente en el "reactivo B" (5 \% p/v $\left(\mathrm{NH}_{4}\right)_{6} \mathrm{Mo}_{7} \mathrm{O}_{24} .4 \mathrm{H}_{2} \mathrm{O} ; 4,4 \% \mathrm{p} / \mathrm{v} \mathrm{H}_{2} \mathrm{SO}_{4}$ y $\left.0,6 \% \mathrm{p} / \mathrm{v} \mathrm{Na} \mathrm{HAsO}_{4} .7 \mathrm{H}_{2} \mathrm{O}\right)$ generando óxido de molibdeno dando coloración azul, cuya intensidad de color es proporcional a la cantidad de azúcares reductores (glucosa y fructosa) existentes en la muestra analizada. Para la determinación de azúcares totales se realizó previamente la hidrólisis de los disacáridos no reductores (fundamentalmente sacarosa) con ácido clorhídrico $0,1 \mathrm{~N}$ caliente y posteriormente el contenido de azúcares reductores totales se midió utilizando el método de Somogyi-Nelson. 
Capítulo III: Efecto de la deficiencia en GDP-L-galactosa fosforilasa en la maduración en planta y postcosecha de frutos de tomate.

\subsubsection{Preparación del extracto}

Frutos congelados en nitrógeno líquido se trituraron en un molinillo y $0,5 \mathrm{~g}$ del polvo resultante se calentó por $5 \mathrm{~min}$ con $5 \mathrm{ml}$ de $85 \% \mathrm{v} / \mathrm{v}$ etanol en un baño a $100{ }^{\circ} \mathrm{C}$. Se extrajo el sobrenadante y se conservó en otro tubo. Luego al tubo con el pellet se le agregaron nuevamente $5 \mathrm{ml}$ de $85 \% \mathrm{v} / \mathrm{v}$ etanol y se mantuvo durante $5 \mathrm{~min}$ en un baño a $100{ }^{\circ} \mathrm{C}$, este proceso se repitió 3 veces en total. A partir de la colección de los sobrenadantes de las tres extracciones se obtuvo un extracto que fue enrasado a 20 $\mathrm{ml}$ adicionando $85 \% \mathrm{v} / \mathrm{v}$ etanol.

\subsubsection{Determinación de azúcares totales}

Del extracto de cada muestra se realizaron 3 repeticiones. Se tomaron $25 \mu \mathrm{l}$ de extracto etanólico y se mezclaron con $100 \mu \mathrm{l}$ de $85 \% \mathrm{v} / \mathrm{v}$ etanol, $500 \mu \mathrm{l}$ de agua destilada y $250 \mu \mathrm{l}$ de $0,1 \mathrm{~N} \mathrm{HCl}$. La mezcla se llevó a un baño a $100{ }^{\circ} \mathrm{C}$ durante $5 \mathrm{~min}$. Luego de dejar enfriar, se agregaron a la mezcla $500 \mu \mathrm{l}$ de "reactivo 1" y se llevó a un baño a $100{ }^{\circ} \mathrm{C}$ durante $10 \mathrm{~min}$. Nuevamente se dejó enfriar la muestra y se agregó a la mezcla $250 \mu \mathrm{l}$ de "reactivo 2". La mezcla resultante se agitó suavemente durante 10 seg y se midió la absorbancia en espectrofotómetro a $\lambda=520$ nm (Shimadzu UV-160).

\subsubsection{Determinación de azúcares reductores}

Del extracto de cada muestra se realizaron 3 repeticiones. Se tomaron $25 \mu \mathrm{de}$ extracto etanólico y se mezclaron con $100 \mu \mathrm{l}$ de $85 \%$ v/v etanol, $750 \mu \mathrm{l}$ de agua destilada y $500 \mu \mathrm{l}$ de "reactivo 1". La mezcla se llevó a un baño a $100{ }^{\circ} \mathrm{C}$ durante 10 min. Posteriormente se dejó enfriar la muestra y se agregó $250 \mu$ de "reactivo 2". La mezcla resultante se agitó suavemente durante 10 seg y se midió la absorbancia a $\lambda=$ $520 \mathrm{~nm}$.

En ambas determinaciones se utilizó agua destilada como control. La concentración de azúcares se estimó a partir de una curva patrón realizada con diferentes concentraciones de sacarosa $\left(0\right.$ a $\left.8 \mathrm{mg} \mathrm{ml}^{-1}\right)$. 
Capítulo III: Efecto de la deficiencia en GDP-L-galactosa fosforilasa en la maduración en planta y postcosecha de frutos de tomate.

\subsubsection{Ensayo de almacenamiento postcosecha de tomates en estado verde maduro}

Se conformaron 6 grupos de 4 ó 5 tomates en estadio VM, de cada uno de los tres genotipos (WT, GGP-49C12 y GGP-5261), y fueron dispuestos en contenedores plásticos con tapa perforada (Fig. 3.5 y Fig.3.6). Posteriormente se colocaron tres grupos de tomates de cada genotipo en una cuba hermética de $40 \mathrm{~L}$ con $0,5 \mu \mathrm{L}^{-1}$ de 1-metilciclopropeno (1-MCP) (SmartFresh ${ }^{\mathrm{TM}}$, AgroFresh@ USA) y otros tres grupos control de cada genotipo en otra cuba hermética de $40 \mathrm{~L}$ con $0,0 \mu \mathrm{L}^{-1}$ de 1 -MCP por un lapso de $24 \mathrm{~h}$.

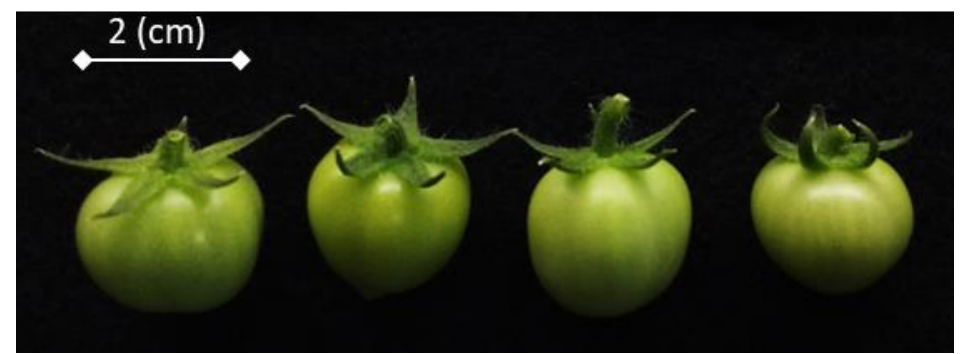

Figura 3. 5 Frutos en estadio VM utilizados en el ensayo de maduración en almacenamiento postcosecha.
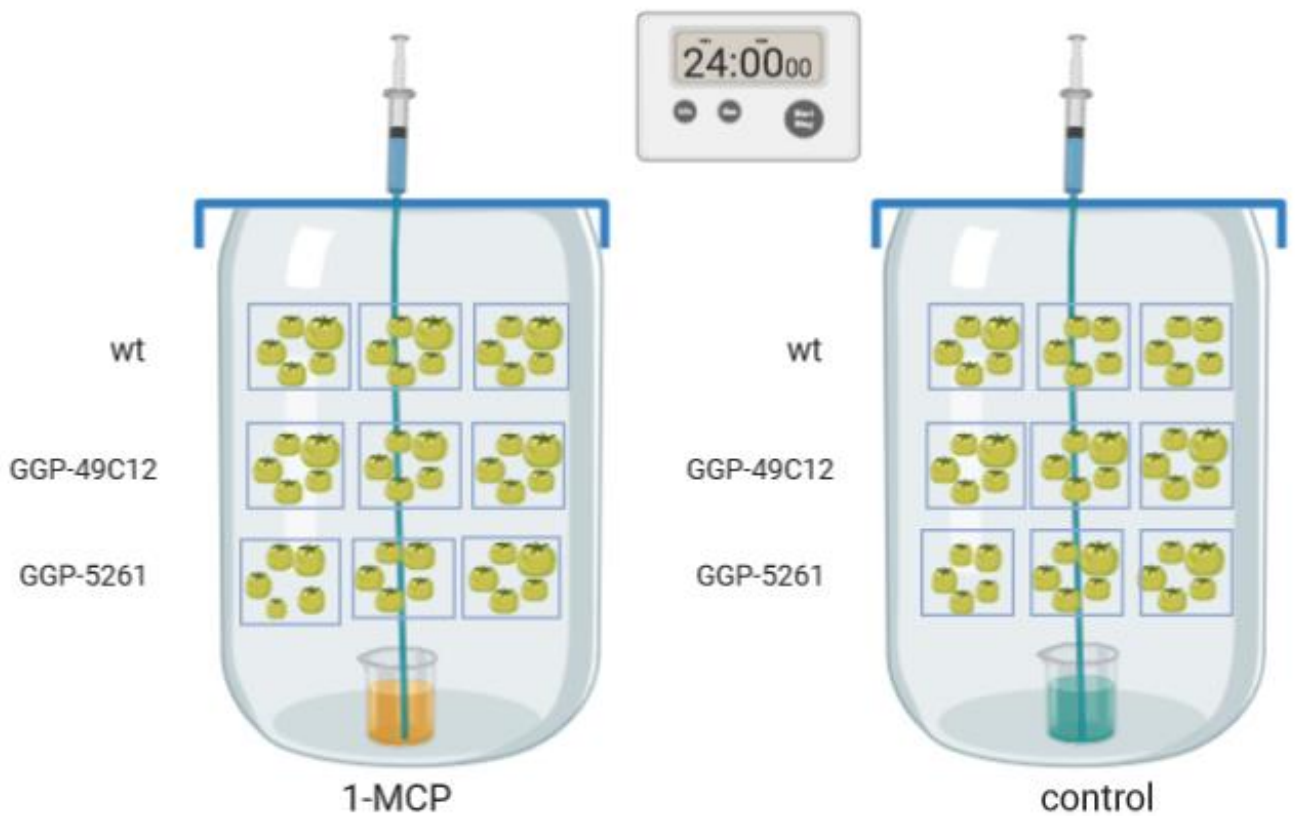

Figura 3. 6 Representación esquemática del tratamiento con 1-metilciclopropeno (1-MCP). 
Capítulo III: Efecto de la deficiencia en GDP-L-galactosa fosforilasa en la maduración en planta y postcosecha de frutos de tomate.

Luego los grupos de frutos de cada uno de los genotipos fueron retirados de las cubas y almacenados en oscuridad a una temperatura de $23{ }^{\circ} \mathrm{C}$ en una cámara con temperatura controlada por termostato. Se realizaron cuatro ensayos independientes $(n=4)$ realizados en dos años sucesivos.

Se tomó una muestra inicial de frutos inmediatamente después de finalizado el tratamiento y posteriormente se tomaron muestras sucesivas a los 7 y 14 días (Fig. 3.7). En cada muestreo se determinó el color, peso, firmeza y sólidos solubles.

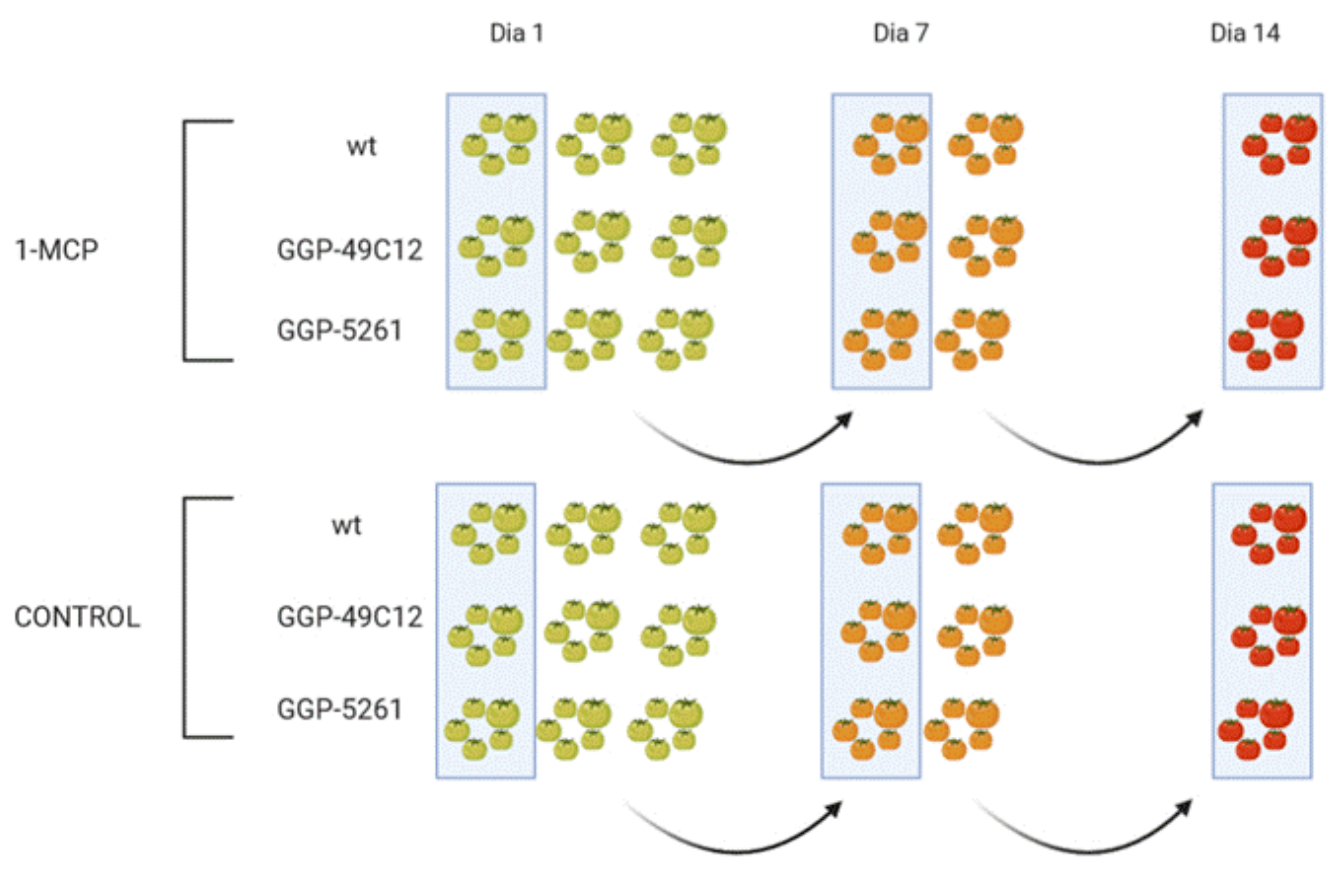

Figura 3.7-Representación esquemática de los muestreos realizados durante el periodo de almacenamiento postcosecha. 
Capítulo III: Efecto de la deficiencia en GDP-L-galactosa fosforilasa en la maduración en planta y postcosecha de frutos de tomate.

\section{$\underline{3.4 \quad \text { Resultados }}$}

\subsubsection{Maduración en planta de frutos deficientes en GPP-L-Galactosa fosforilasa.}

\subsubsection{Color de los frutos}

Para cosechar los frutos de los genotipos mutantes slggp1 y silvestres en un grado de maduración equivalente, dentro de cada uno de los estadios de maduración elegidos, el color superficial de los frutos fue utilizado como parámetro de referencia los frutos fueron clasificados en los estadios de maduración VM, $\mathrm{P}$ y $\mathrm{R}$ mencionados anteriormente según el color observado a ojo desnudo y posteriormente se realizó una medición del color superficial. En la figura 3.8 se muestra el promedio de las mediciones del ángulo de HUE registrado en las diferentes tandas de frutos utilizadas para la realización de todas las mediciones que se comentarán a continuación. No se observan diferencias significativas entre ninguno de los genotipos indicando que los frutos de encuentran en el mismo estadio de maduración tomando como referencia su color superficial.

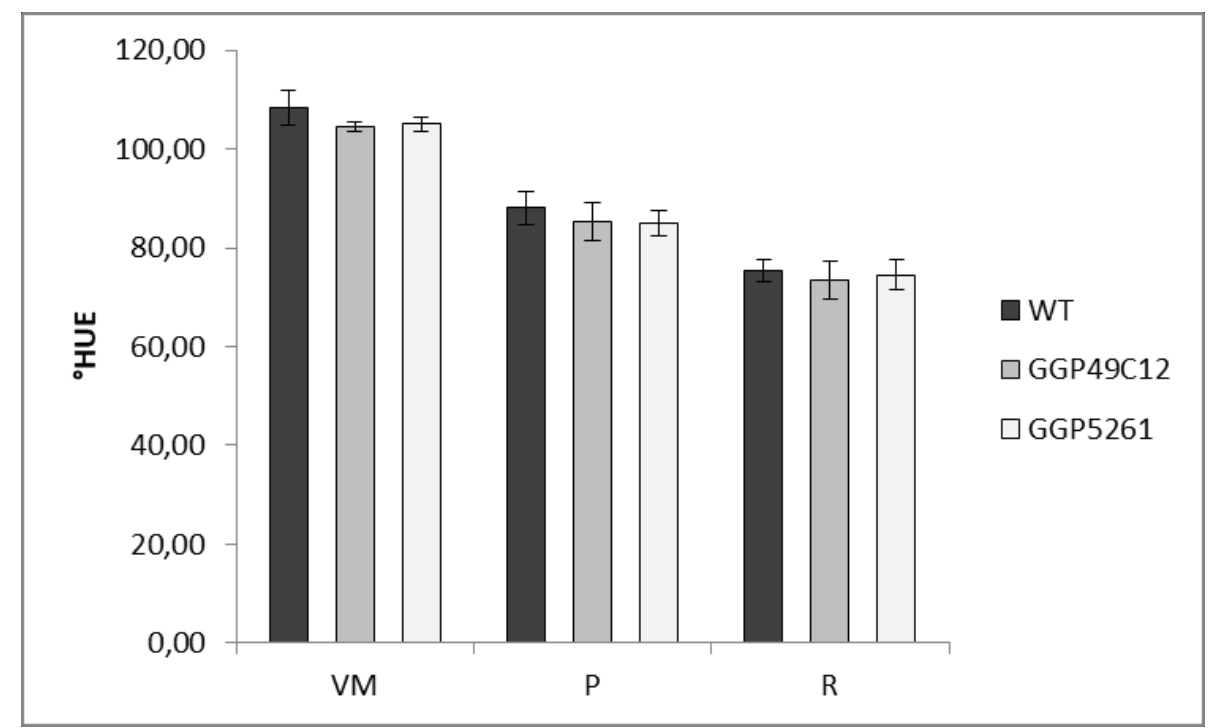

Figura 3. 8- Angulo de HUE.

Determinado en frutos verde maduro (VM), pintón $(P)$ y rojo $(R)$ de los genotipos mutantes slggp1 (GGP49C12 y GGP5261) y el genotipo silvestre (WT). Se registraron diferencias significativas entre estadios de maduración para cada genotipo ANOVA $(p<0,05)$. 
Capítulo III: Efecto de la deficiencia en GDP-L-galactosa fosforilasa en la maduración en planta y postcosecha de frutos de tomate.

\subsubsection{Firmeza}

Otro parámetro evaluado en estos tres estadios de maduración fue la firmeza, en este caso sólo se observan diferencias significativas entre los frutos de ambos mutantes y los frutos silvestres en los frutos cosechados en el estadio de maduración R (Fig. 3.9).

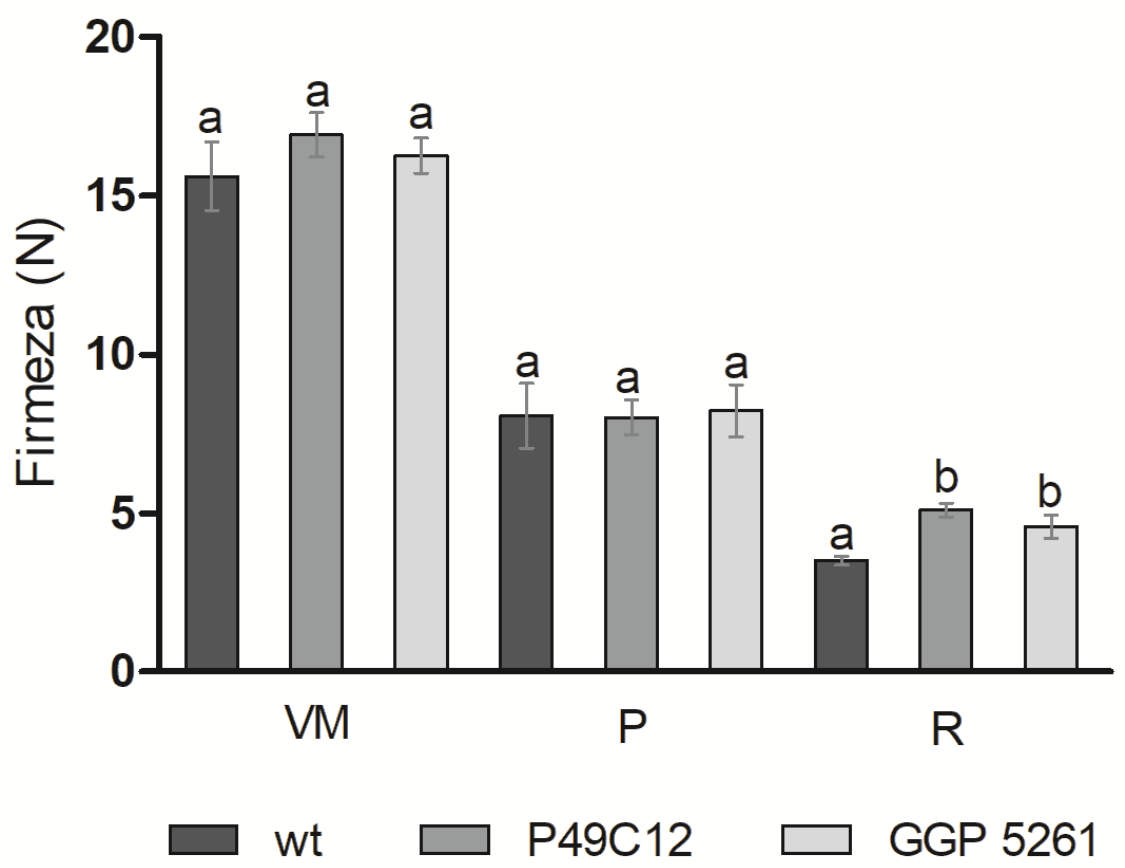

Figura 3.9-Firmeza de los frutos madurados en planta.

Firmeza en Newton $(N)$ determinada en frutos verde maduro $(V M)$, pintón $(P)$ y rojo $(R)$ de los genotipos mutantes slggp1 (GGP49C12 y GGP5261) y el genotipo silvestre (WT).. Las letras indican diferencias estadísticas entre distintos genotipos para un mismo estadio de maduración ANOVA $(p<0,05)$.

\subsubsection{3}

Producción de etileno en frutos

La producción de etileno a lo largo de la maduración presentó la misma tendencia tanto en los genotipos mutantes slggp1 como en el genotipo silvestre. La tasa de producción de etileno en el estadio VM fue muy baja, luego se registró un aumento estadio $\mathrm{P}$ y finalmente un descenso en la tasa de producción de etileno cuando los frutos alcanzaron el estadio R (Fig. 3.10). 
Capítulo III: Efecto de la deficiencia en GDP-L-galactosa fosforilasa en la maduración en planta y postcosecha de frutos de tomate.

Al comparar entre genotipos se observó que la producción de etileno en los genotipos mutantes slggp1 fue mayor que la del genotipo silvestre. El genotipo mutante GGP5261 presentó una tasa de producción de etileno significativamente mayor que el genotipo silvestre en los estadios $P$ y $R$, mientras que el genotipo GGP-49C12 presentó una tendencia similar (Fig. 3.10.)

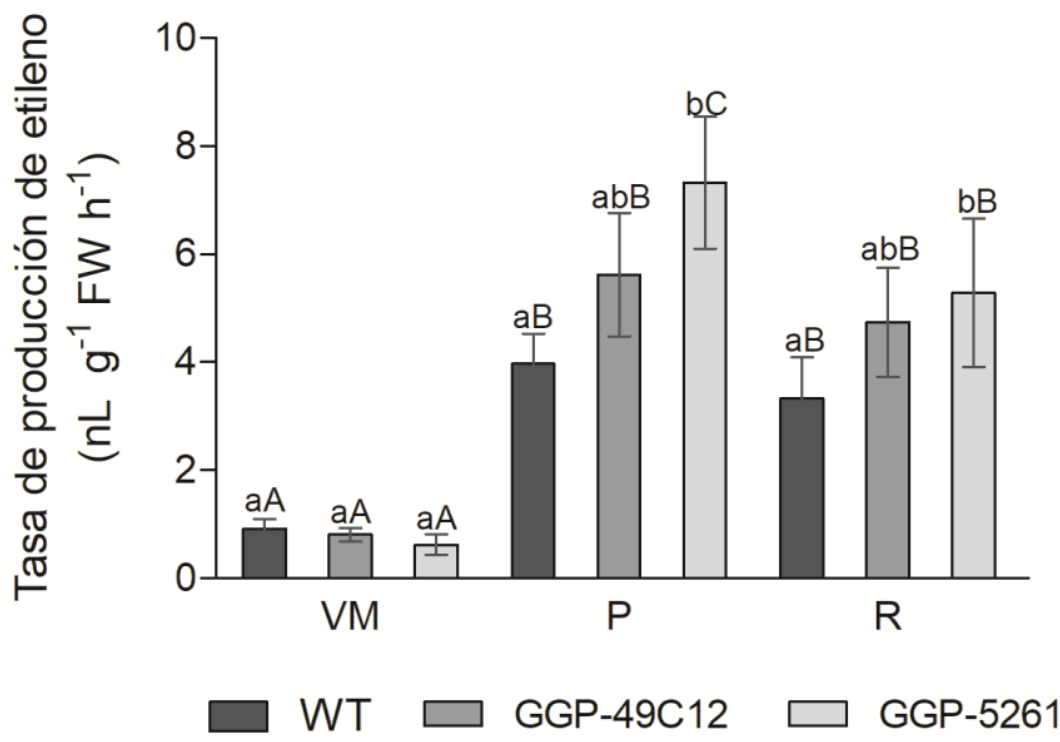

Figura 3.10-Tasa de producción de etileno.

Determinada en frutos verde maduro $(\mathrm{VM})$, pintón $(P)$ y rojo $(R)$ de los genotipos mutantes slggp1 (GGP49C12 y GGP5261) y el genotipo silvestre (WT). Letras minúsculas indican diferencias entre genotipos y letras mayúsculas indican diferencias entre estadios. ANOVA $(p<0,05)$.

\subsubsection{Respiración}

Se observó una tendencia al aumento en la tasa respiratoria en el genotipo mutante GGP-5261 en el estadio $P$ en coincidencia con la mayor producción de etileno observada en este mutante. Sin embargo no se registró el aumento en la respiración característico de los frutos climatéricos en ninguno de los genotipos (Fig. 3.11.). 
Capítulo III: Efecto de la deficiencia en GDP-L-galactosa fosforilasa en la maduración en planta y postcosecha de frutos de tomate.

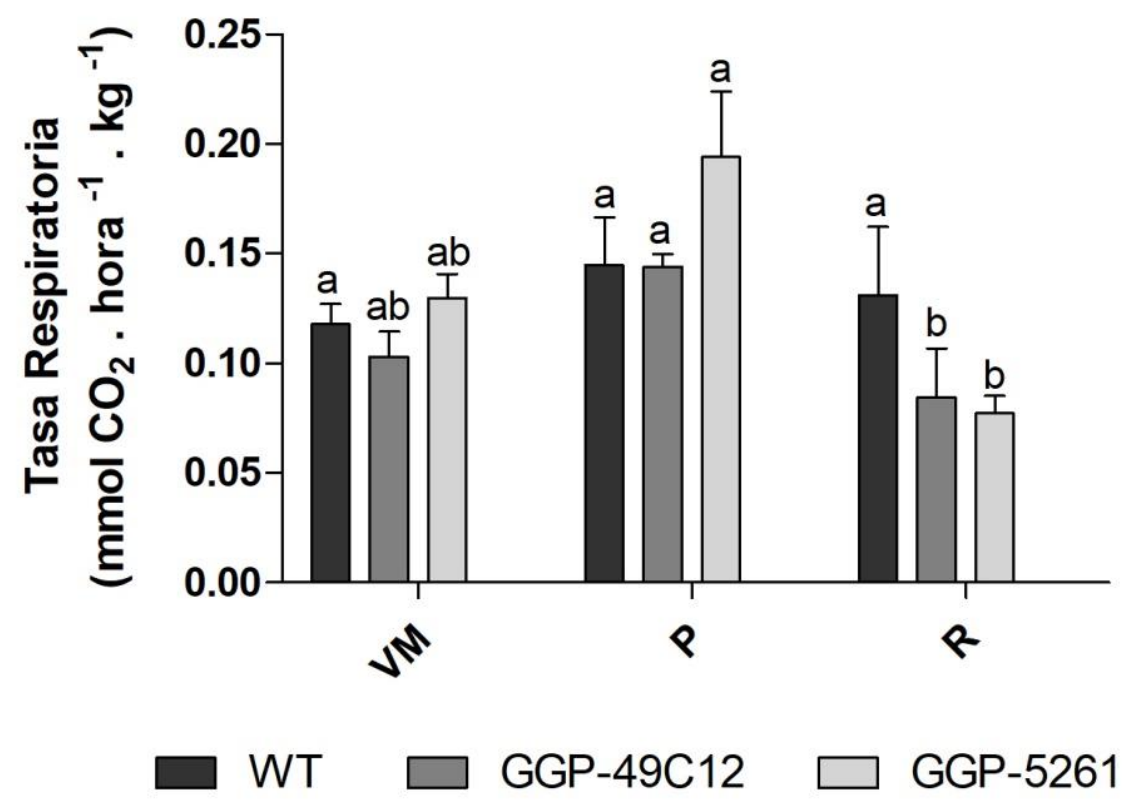

Figura 3.11-Tasa respiratoria.

Determinada en frutos verde maduro $(V M)$, pintón $(P)$ y rojo $(R)$ de los genotipos mutantes slggp1 (GGP49C12 y GGP5261) y el genotipo silvestre (WT). Las letras indican diferencias estadísticas entre distintos estadios de maduración para un mismo genotipo $(p<0,05)$

\subsubsection{5}

Parámetros clásicos de maduración

Otros parámetros de maduración registrados fueron el contenido de sólidos solubles totales, el pH y la acidez total titulable. En todos los genotipos se observó un aumento de los sólidos solubles conforme avanza la maduración. En el estadio R se registraron los mayores niveles de sólidos solubles (Tabla 3.1). Además en el genotipo GGP-5261 se observó un mayor contenido de sólidos solubles en el estadio P con respecto al estadio VM. Al comparar entre genotipos se observó que ambos genotipos mutantes slggp1 presentaron mayores contenidos de sólidos solubles en los estadios P y R con respecto al genotipo silvestre (Tabla 3.1).

El pH de los frutos de ambos genotipos mutantes presento una disminución en los estadios $\mathrm{P}$ y $\mathrm{R}$ con respecto al estadio VM. En cambio en el genotipo silvestre no se observaron cambios de este parámetro a lo largo de los tres estadios de maduración. 
Capítulo III: Efecto de la deficiencia en GDP-L-galactosa fosforilasa en la maduración en planta y postcosecha de frutos de tomate.

Al evaluar la variación de este parámetro entre genotipos, no se observaron diferencias significativas para ninguno de los estadios de maduración (Tabla 3.1).

La ATT corresponde al porcentaje total de ácidos presentes en el fruto. Al analizar la variación de este parámetro a lo largo de los tres estadios de maduración observados, se observó que la ATT es alta en el estadio VM y luego se produce un descenso cuando se alcanza el estadio P. Finalmente, se registró un aumento de este parámetro en el estadio $\mathrm{R}$, repitiéndose esta tendencia en los tres genotipos. No se encontraron diferencias significativas al comparar la ATT entre genotipos para cada uno de los estadios de maduración (Tabla 3.1).

Tabla 3. 1-Parámetros de maduración.

\begin{tabular}{|c|c|c|c|c|}
\hline Genotipo & $\begin{array}{l}\text { Estadío de } \\
\text { maduración }\end{array}$ & $\begin{array}{c}\text { SST } \\
\text { ( }{ }^{\circ} \text { Brix) }\end{array}$ & $\mathrm{pH}$ & $\begin{array}{c}\text { ATT } \\
\text { (g ác. cítrico } \mathrm{kg}^{-1} \\
\text { PF) }\end{array}$ \\
\hline \multirow[t]{3}{*}{ WT } & VM & $4,54 \pm 0,29$ aAB & $4,25 \pm 0,51$ aA & $8,82 \pm 1,13$ aA \\
\hline & $P$ & $4,02 \pm 0,24 a A$ & $4,73 \pm 0,62$ aA & $5,20 \pm 0,51 a B$ \\
\hline & $\mathrm{R}$ & $5,05 \pm 0,23 a B$ & $4,00 \pm 0,03 a A$ & $7,46 \pm 0,81$ aA \\
\hline \multirow[t]{3}{*}{ GGP-49C12 } & VM & $4,14 \pm 0,23$ aA & $4,61 \pm 0,14$ aA & $8,84 \pm 0,57$ aA \\
\hline & $P$ & $4,90 \pm 0,21 b A$ & $3,99 \pm 0,05 a B$ & $5,36 \pm 0,20 \mathrm{aC}$ \\
\hline & $\mathrm{R}$ & $5,82 \pm 0,31$ bA & $4,07 \pm 0,04 a B$ & $6,78 \pm 0,21 a B$ \\
\hline \multirow[t]{3}{*}{ GGP-5261 } & VM & $4,22 \pm 0,16$ aA & $4,44 \pm 0,07$ aA & $8,42 \pm 0,58$ aA \\
\hline & $P$ & $5,27 \pm 0,15$ bAB & $3,97 \pm 0,07 a B$ & $4,18 \pm 0,26 a B$ \\
\hline & $\mathrm{R}$ & $5,87 \pm 0,32 b B$ & $4,08 \pm 0,04 a B$ & $7,67 \pm 0,64 \mathrm{aC}$ \\
\hline
\end{tabular}

Sólidos solubles totales (SST), $\mathrm{pH}$ y acidez total titulable (ATT), determinados en frutos verde maduro (VM), pintón ( $\mathrm{P})$ y rojo $(\mathrm{R})$ de los genotipos mutantes slggp1 (GGP49C12 y GGP5261) y el genotipo silvestre (WT). Letras minúsculas indican diferencias entre genotipos y letras mayúsculas indican diferencias entre estadios. ANOVA $(p<0,05)$.

\subsubsection{Azúcares reductores y totales}

El contenido de azúcares totales y reductores mostró un aumento en todos los genotipos desde el estadio VM hacia estadios de maduración más avanzados. Por otro lado, ambos genotipos mutantes presentaron un mayor contenido de azúcares totales que el genotipo silvestre en el estadio de maduración $\mathrm{R}$ y mostraron una tendencia 
Capítulo III: Efecto de la deficiencia en GDP-L-galactosa fosforilasa en la maduración en planta y postcosecha de frutos de tomate.

similar en estadios $\mathrm{P}$ y VM. Estos datos indican que los genotipos mutantes slggp1 poseen una mayor proporción de azúcares no reductores, como la sacarosa, a diferencia del genotipo silvestre en el cual la mayor parte de los azúcares serian reductores (Fig. 3.12.). Esto explicaría en parte el mayor porcentaje de sólidos solubles observado en los genotipos mutantes slggp1 (Tabla 3.1).

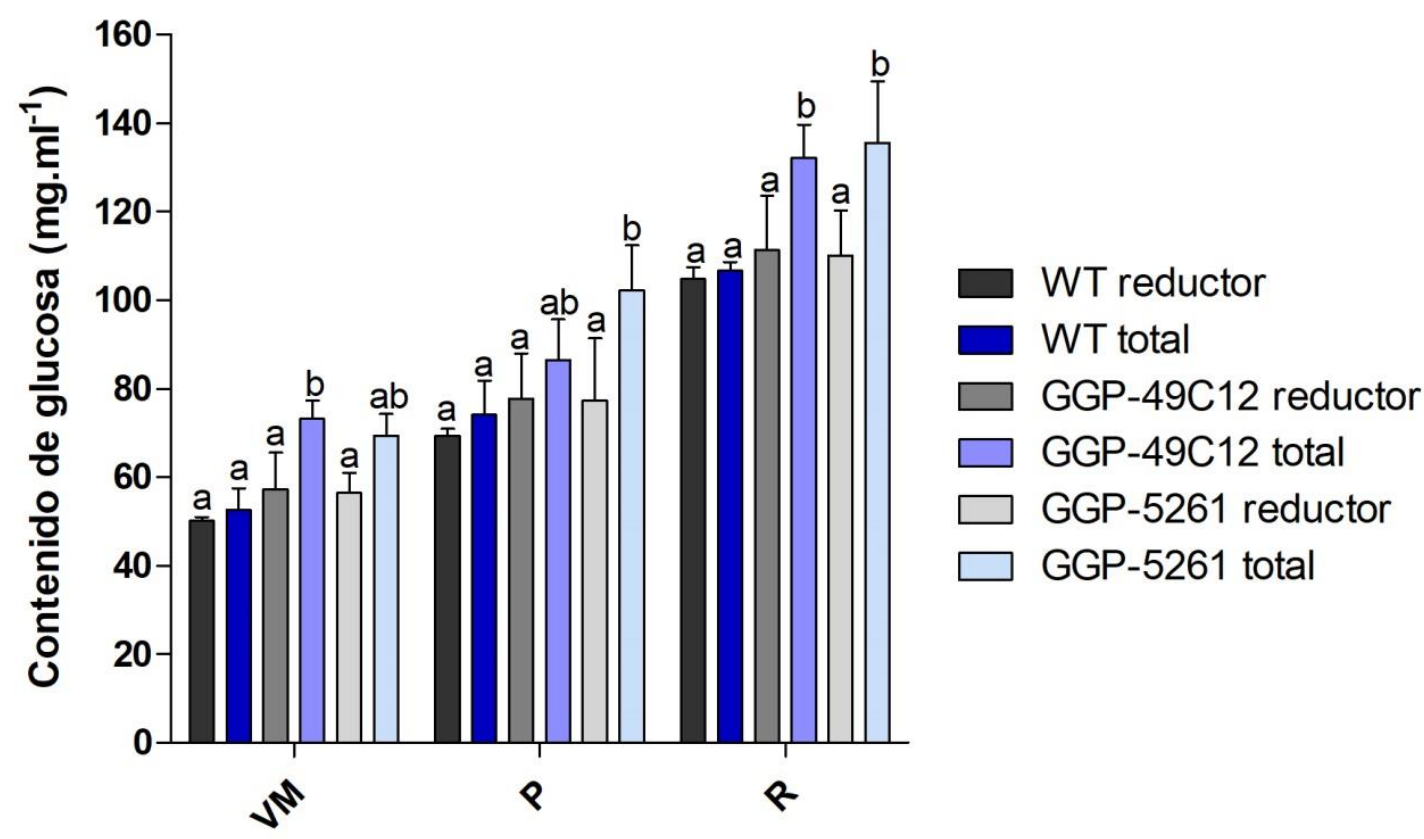

Figura 3.12-Contenido de azúcares totales y reductores en frutos madurados en planta. Contenido de glucosa expresado en $\mathrm{mg} \mathrm{ml}^{-1}$. Determinados en frutos verde maduro (VM), pintón $(P)$ y rojo $(R)$, de los genotipos mutantes slggp1 (GGP49C12 y GGP5261) y el genotipo silvestre (WT). Letras minúsculas indican diferencias entre genotipos. ANOVA $(p<0,05)$.

\subsubsection{Maduración postcosecha de frutos deficientes en GPP-L-Galactosa fosforilasa.}

\subsubsection{Cambio de color a lo largo del almacenamiento}

En el primer día de muestreo no se observaron diferencias en el color ( $\left.{ }^{\circ} \mathrm{HUE}\right)$ entre los tres genotipos y el tratamiento con 1-MCP no mostró un efecto significativo sobre el color superficial de ninguno de los genotipos. En el muestreo realizado luego de 
Capítulo III: Efecto de la deficiencia en GDP-L-galactosa fosforilasa en la maduración en planta y postcosecha de frutos de tomate.

transcurridos 7 días de almacenamiento, se observó un efecto significativo del tratamiento con 1-MCP en todos los genotipos ya que presentaron un valor de ${ }^{\circ} \mathrm{HUE}$ más elevado con respecto al tratamiento control y no se observaron diferencias en HUE entre los distintos genotipos tratados con 1-MCP pero sí se observaron diferencias entre los genotipos bajo tratamiento control en el cual los mutantes presentaron valores más bajos de ${ }^{\circ} \mathrm{HUE}$ que el genotipo silvestre (Fig. 3.13). En el muestreo realizado el día 14 de almacenamiento se repitió una tendencia similar a la observada en el muestreo anterior. El tratamiento con 1-MCP mostró un efecto significativo en todos los genotipos por igual. Los frutos mutantes slggp1 bajo tratamiento control presentaron valores de HUE significativamente más bajos que los frutos del genotipo silvestre bajo tratamiento control.

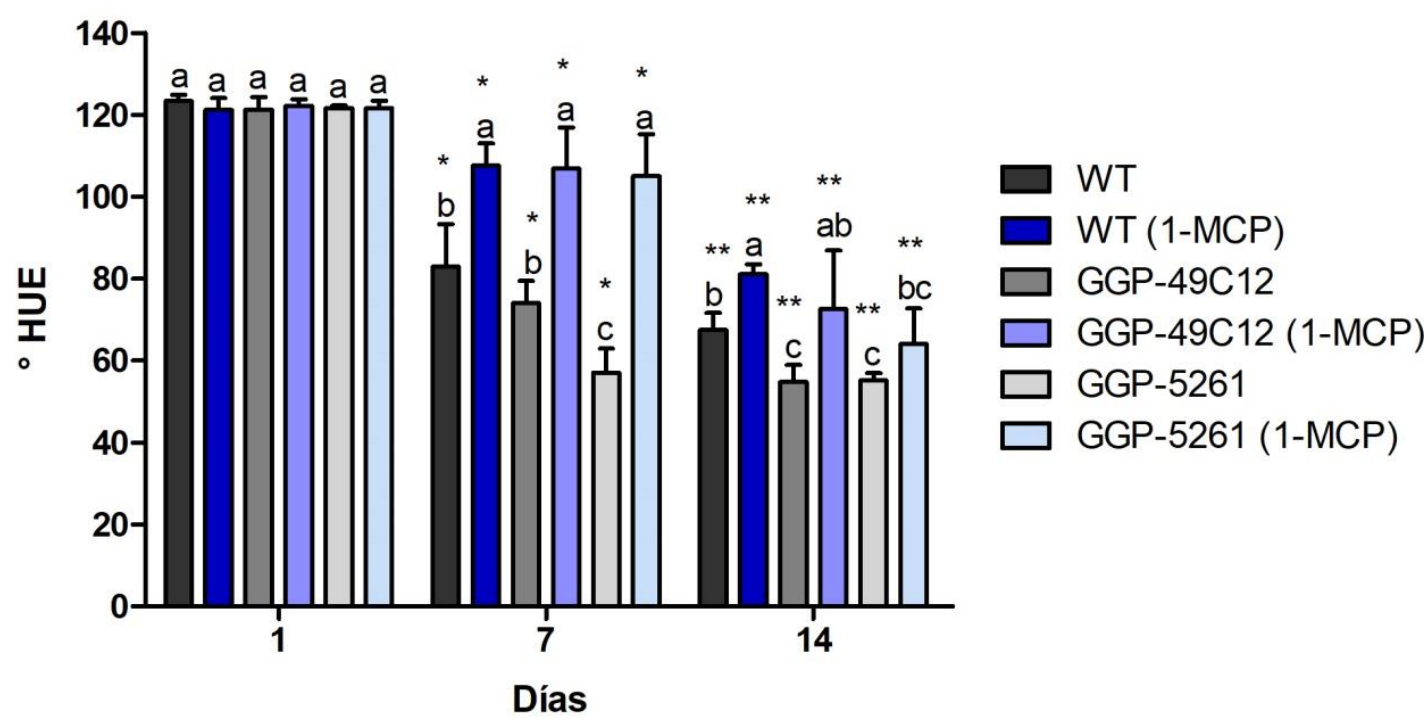

Figura 3.13- Ángulo de HUE de frutos en almacenamiento postcosecha.

Determinado en frutos de los genotipos mutantes slggp1 (GGP49C12 y GGP5261) y el genotipo silvestre (WT) a lo largo de 14 días de almacenamiento postcosecha. Letras distintas indican diferencias estadísticas para cada día de muestreo; $\left(^{*}\right)$ diferencias significativas entre día 1 y día $7 ;{ }^{* *}$ ) diferencias significativas entre día 1 y día 14 (ANOVA, $p \leq 0,05$ ). 
Capítulo III: Efecto de la deficiencia en GDP-L-galactosa fosforilasa en la maduración en planta y postcosecha de frutos de tomate.

\subsubsection{Cambio de la firmeza a lo largo del almacenamiento}

Al inicio del almacenamiento (día 1) los frutos de ambos genotipos mutantes slggp1 presentaron una firmeza mayor que los frutos del genotipo silvestre y no se observó un efecto del tratamiento con 1-MCP. Luego de transcurridos 7 días de almacenamiento, el tratamiento con 1-MCP generó un efecto significativo retardando el ablandamiento en todos los genotipos por igual con respecto al tratamiento control, en el cual tampoco se observaron diferencias en la firmeza entre los genotipos. En el muestreo realizado luego de 14 días de almacenamiento se observó una tendencia similar a la observada en el día 7, los frutos tratados con 1-MCP mostraron una firmeza superior a los frutos control en todos los genotipos por igual y no se observaron diferencias en firmeza entre los genotipos bajo tratamiento control (Fig. 3.14).

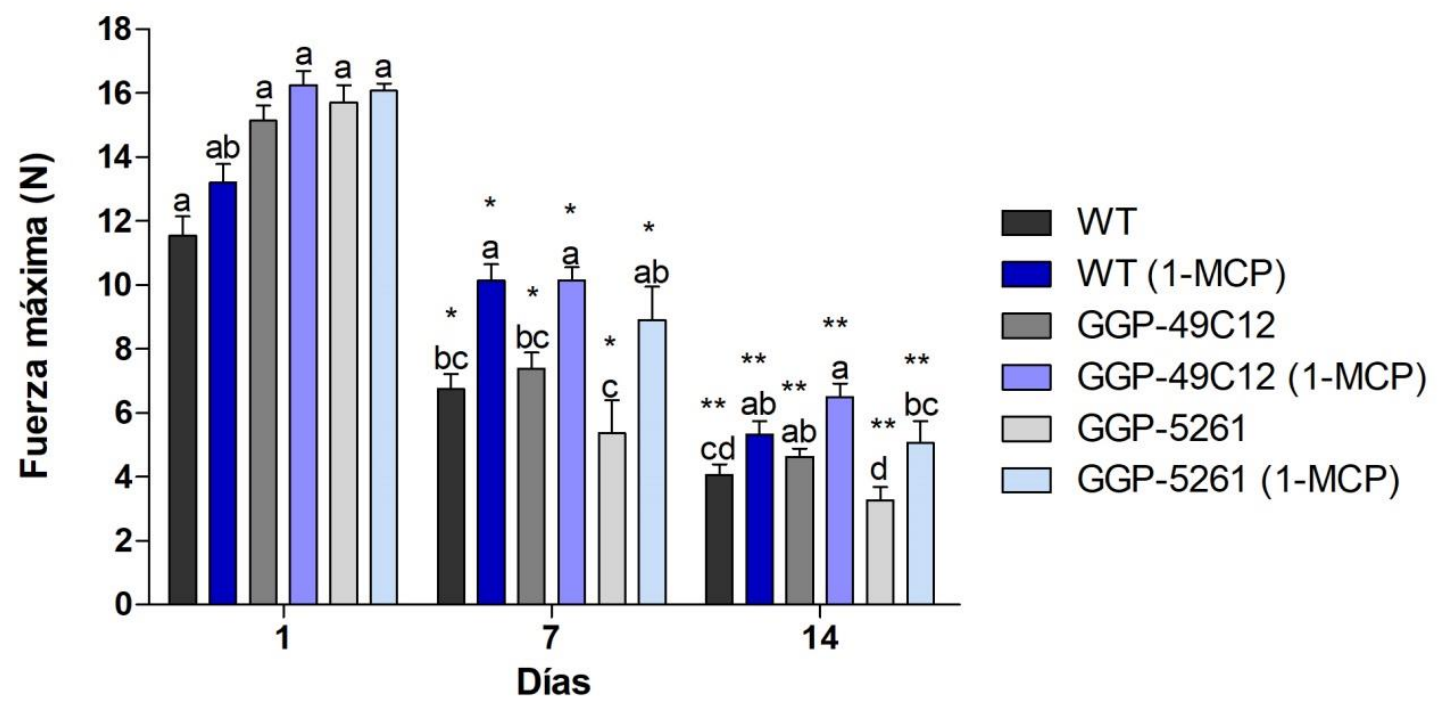

Figura 3.14-Firmeza de frutos madurados en almacenamiento postcosecha.

Firmeza registrada como fuerza máxima en Newtons $(\mathrm{N})$, determinada en frutos de los genotipos mutantes slggp1 (GGP49C12 y GGP5261) y el genotipo silvestre (WT) a lo largo de 14 días de almacenamiento. Letras distintas indican diferencias estadísticas para cada día de muestreo; $\left({ }^{*}\right)$ diferencias significativas entre día 1 y día $7 ;\left({ }^{* *}\right)$ diferencias significativas entre día 7 y día 14. (ANOVA, $p \leq 0,05$ ).

Teniendo en cuenta que los genotipos mutantes slggp1 presentaron una firmeza inicial superior a la del genotipo silvestre y que al final del periodo de almacenamiento no se observan diferencias en firmeza entre los genotipos, se calculó la tasa de 
Capítulo III: Efecto de la deficiencia en GDP-L-galactosa fosforilasa en la maduración en planta y postcosecha de frutos de tomate.

ablandamiento para cada uno de los genotipos bajo tratamiento control y tratamiento con 1-MCP. Los frutos mutantes slggp1 presentaron una tasa de ablandamiento superior a la observada en los frutos del genotipo silvestre y esta diferencia fue significativa en los frutos bajo tratamiento control. En los frutos tratados con 1-MCP las tasas de ablandamiento mostraron la misma tendencia que en el tratamiento control y sólo el genotipo GGP-5261 presentó una tasa de ablandamiento significativamente mayor al genotipo silvestre. Por último, al comparar para cada genotipo la tasa de ablandamiento de los frutos bajo tratamiento control y los frutos tratados con 1-MCP, no se encontraron diferencias, indicando que el tratamiento con 1-MCP no generó un efecto significativo sobre la tasa de ablandamiento en ninguno de los genotipos (Fig. 3.15. y Tabla 3.2.).

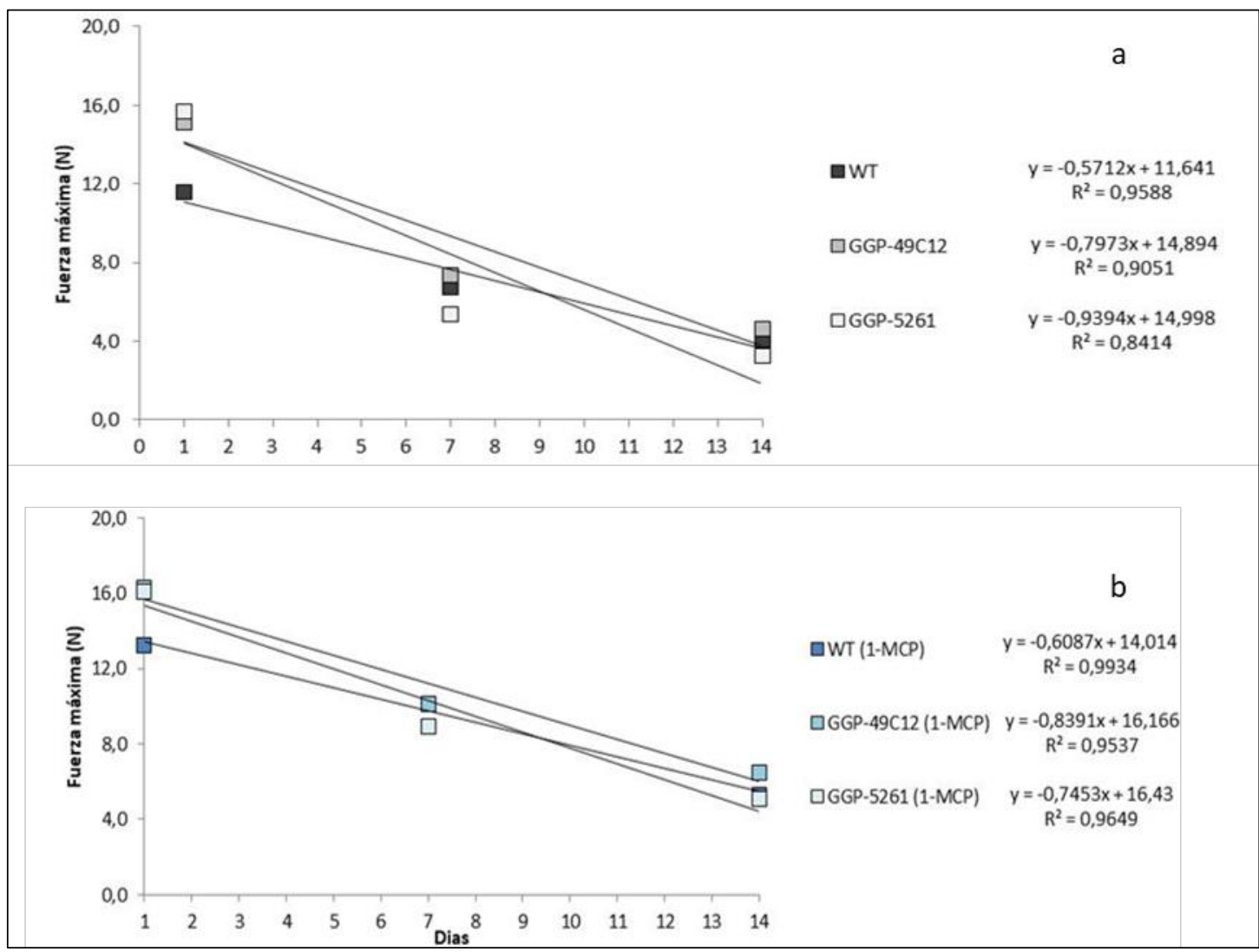

Figura 3.15-Ablandamiento durante el almacenamiento postcosecha.

Ablandamiento de frutos de los genotipos mutantes slggp1 (GGP49C12 y GGP5261) y el genotipo silvestre (WT). a) Control b) tratado con 1-metilciclopropeno (1-MCP). 
Capítulo III: Efecto de la deficiencia en GDP-L-galactosa fosforilasa en la maduración en planta y postcosecha de frutos de tomate.

Tabla 3. 2-Tasa de ablandamiento.

\begin{tabular}{|ccc|}
\hline & $\begin{array}{c}\text { Tasa de ablandamiento } \\
\text { Tratamiento }\end{array}$ & $\mathbf{R}^{\mathbf{2}}$ \\
\hline WT control & $-0,57 \pm 0,031 \mathrm{c}$ & 0,9666 \\
\hline WT 1-MCP & $-0,60 \pm 0,119 \mathrm{c}$ & 0,9641 \\
\hline GGP-49C12 control & $-0,80 \pm 0,146 \mathrm{ab}$ & 0,9768 \\
\hline GGP-49C12 1-MCP & $-0,74 \pm 0,143 \mathrm{bc}$ & 0,9687 \\
\hline GGP-5261 control & $-0,92 \pm 0,075$ a & 0,9871 \\
\hline GGP-5261 1-MCP & $-0,84 \pm 0,167$ ab & 0,9453 \\
\hline
\end{tabular}

Tasa de ablandamiento (N.d-1) de los frutos de los genotipos mutantes slggp1 (GGP49C12 y GGP5261) y el genotipo silvestre (WT) tratados o no con 1-MCP durante el almacenamiento postcosecha. Letras distintas indican diferencias estadísticas (ANOVA, $p \leq 0,001$ realizado a partir de variables Dummy. El mismo resultado fue obtenido a partir de un análisis de regresión lineal realizado a partir de variables Dummy).

\subsubsection{Porcentaje de pérdida de peso a lo largo del almacenamiento}

Durante el almacenamiento postcosecha se produce una pérdida de peso en los frutos que se debe principalmente a deshidratación y representa un factor importante que determina la firmeza del fruto. En este ensayo el porcentaje de pérdida de peso total al final del almacenamiento fue de aproximadamente un $10 \%$ y no se observó un efecto significativo del tratamiento con 1-MCP sobre este parámetro así como tampoco una diferencia entre genotipos (Fig. 3.16). 
Capítulo III: Efecto de la deficiencia en GDP-L-galactosa fosforilasa en la maduración en planta y postcosecha de frutos de tomate.

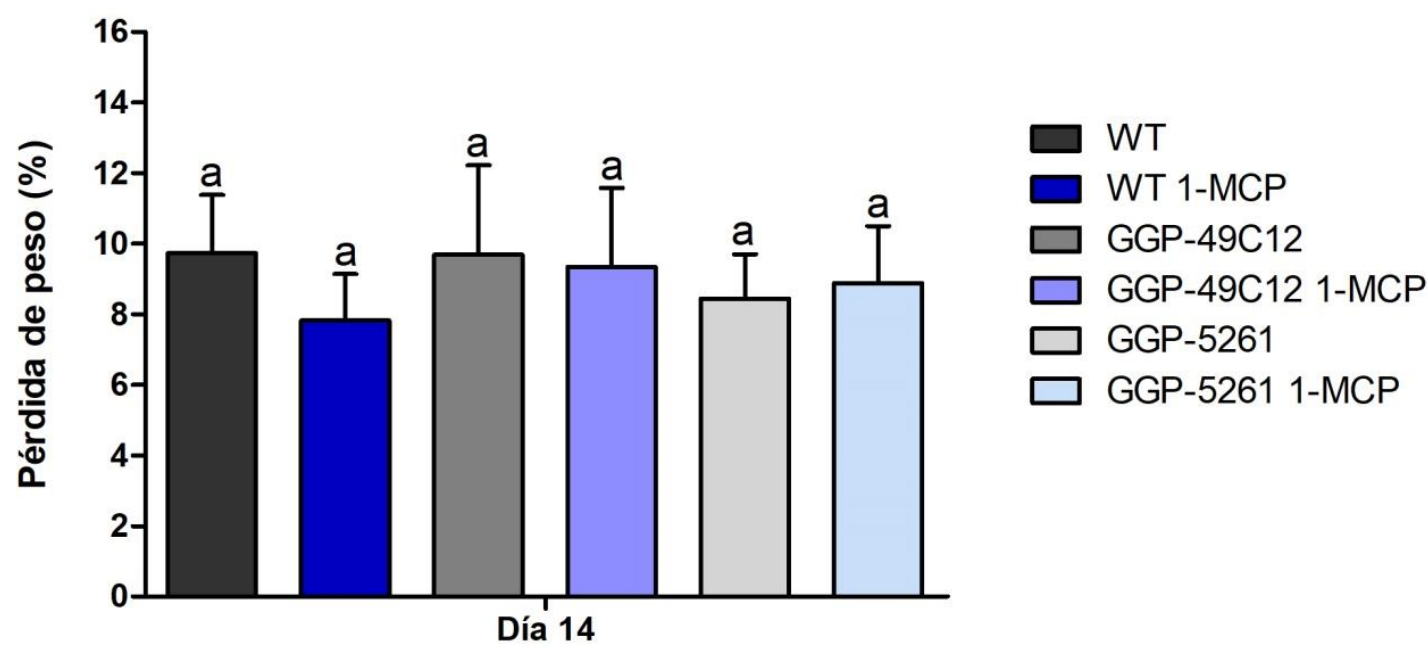

Figura 3.16-Porcentaje de pérdida de peso en almacenamiento postcosecha.

Registrado al final del periodo de almacenamiento postcosecha (día 14) de los frutos de los genotipos mutantes slggp1 (GGP49C12 y GGP5261) y el genotipo silvestre (WT) tratados o no con 1-MCP. (ANOVA, $p \leq 0,05)$.

\subsubsection{Cambio en el contenido de sólidos solubles a lo largo del almacenamiento}

El contenido de sólidos solubles en los frutos está determinado principalmente por azúcares y es esperable que se produzca un aumento en este parámetro a lo largo de la maduración. En este ensayo se registró un aumento significativo del contenido de sólidos solubles en los genotipos mutantes hacia el final del ensayo (día 14). Por otro lado el tratamiento con 1-MCP no generó ningún efecto significativo sobre este parámetro en ninguno de los genotipos (Fig. 3.17). 
Capítulo III: Efecto de la deficiencia en GDP-L-galactosa fosforilasa en la maduración en planta y postcosecha de frutos de tomate.

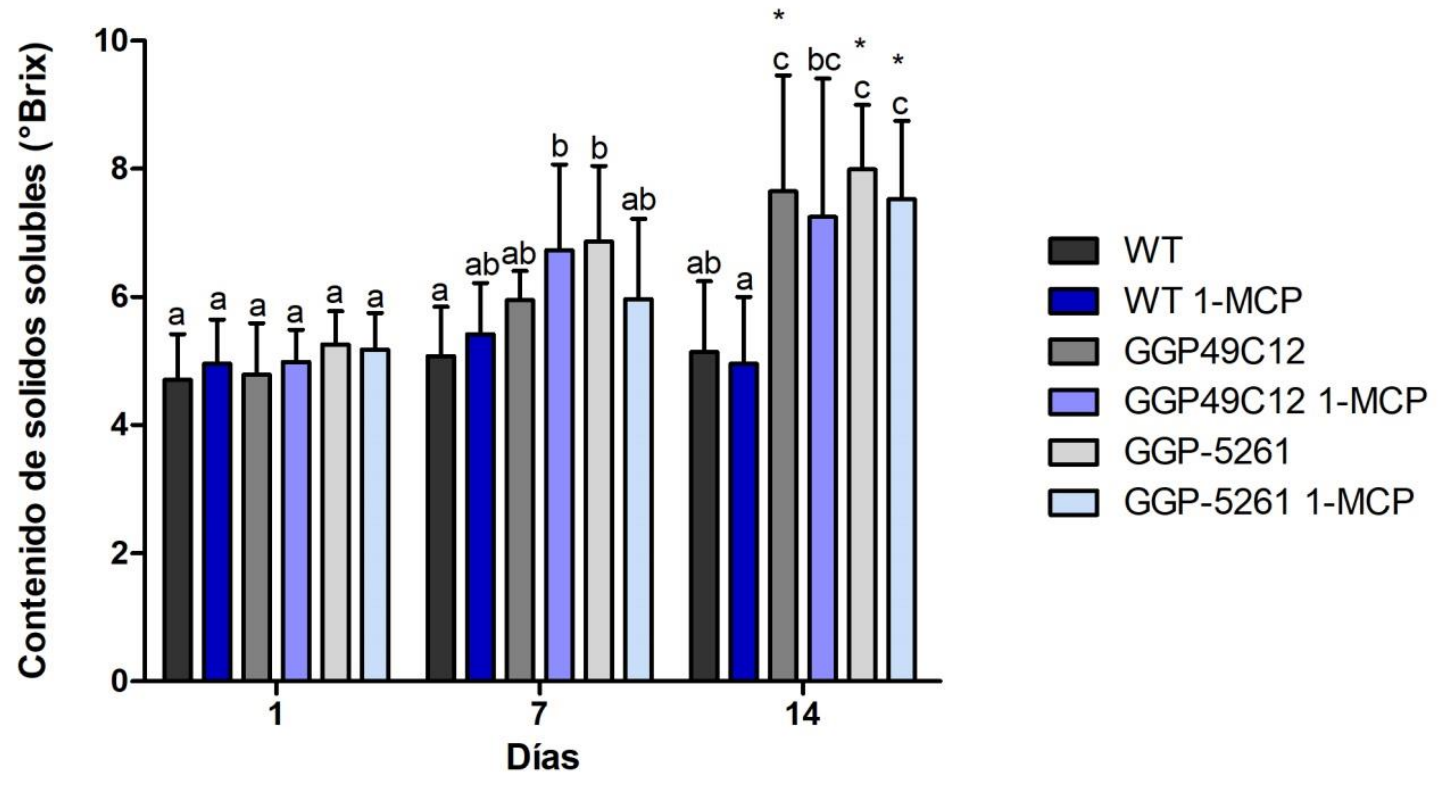

Figura 3.17-Contenido de sólidos solubles en frutos madurados en almacenamiento postcosecha.

Contenido de sólidos solubles ( ${ }^{\circ}$ Brix) de los frutos de los genotipos mutantes slggp1 (GGP49C12 y GGP5261) y el genotipo silvestre (WT) tratados o no con 1-MCP durante el almacenamiento postcosecha (días). Letras distintas indican diferencias estadísticas para cada día de muestreo; $\left({ }^{*}\right)$ diferencias significativas entre día 1 y día 14 (ANOVA, $p \leq 0,05$ ). 
Capítulo III: Efecto de la deficiencia en GDP-L-galactosa fosforilasa en la maduración en planta y postcosecha de frutos de tomate.

\subsection{Discusión}

El ácido ascórbico constituye un atributo nutricional importante de los frutos (Lee y Kader, 2000). Sin embargo, el impacto de la disminución de la concentración de ácido ascórbico sobre el proceso de maduración de la fruta aún no ha sido dilucidado completamente. Reportes previos sobre plantas de tomate con mutaciones en enzimas de etapas tempranas de la vía de síntesis de ascórbico y compartidas con la vía de síntesis de azúcares destinados a la pared celular, de la D-manosa/L-galactosa (GDPmanosapirofosforilasa y GDP-manossa-3,5-epimerasa (Fig. 2; Introducción general), muestran efectos en el desarrollo y la calidad de los frutos (Gilbert y col., 2009; Mounet-Gilbert y col., 2016; Zhang, 2013). Sin embargo éstos podrían ser consecuencia tanto de la deficiencia de ascórbico como de efectos en la composición de la pared celular. Por lo tanto, es más probable que los efectos sobre la maduración evaluados en estos experimentos sean consecuencia en la deficiencia de ascórbico ya que la inactivación de la enzima GDP-L-galactosa fosforilasa 1, afecta su síntesis de forma más específica (Bulley y Laing, 2016).

Como se mencionó anteriormente, los frutos climatéricos como el tomate, presentan un aumento exponencial de la respiración al inicio de la maduración, que es precedido por un aumento en la producción de etileno. Se ha reportado que plantas mutantes de Arabidopsis vtc2-1, presentan una mayor producción de etileno y una mayor expresión de genes relacionados a la señalización por etileno en sus hojas (Caviglia y col., 2018; Kerchev y col., 2011). En los resultados mostrados en esta tesis, los frutos de tomate deficientes en GDP-L-galactosa fosforilasa presentaron una mayor producción de etileno durante la maduración en planta, con respecto a los frutos del genotipo silvestre. Esto fue observado más específicamente en el estadio P (Fig. 3.10).

Uno de los efectos generados por el etileno durante la maduración es la estimulación de enzimas que participan en la degradación de la pared celular durante la maduración 
Capítulo III: Efecto de la deficiencia en GDP-L-galactosa fosforilasa en la maduración en planta y postcosecha de frutos de tomate.

del fruto (Osorio y col., 2011). Sin embargo los resultados observados en mutantes deficientes en GDP-L-galactosa fosforilasa sugieren que otros procesos prevalecen, ya que durante la maduración en planta se observa una mayor firmeza en los frutos de estos mutantes (Fig. 3.9). Por ejemplo, cambios en la cutícula podrían estar relacionados con el retraso en el ablandamiento de los frutos (Saladié y col., 2007).

La disminución de la firmeza de los frutos coincide típicamente con la disolución de la laminilla media, resultando en una disminución de la adhesión intercelular, despolimerización y solubilización de polisacáridos de la pared celular como hemicelulosas y pectinas (Brummell y Harpster, 2001). Estos eventos están acompañados por el incremento de la expresión de numerosas enzimas involucradas en degradar la pared celular, como hidrolasas, transglicolasas, liasas y otras proteínas como las expansinas que cumplen la función de desorganizar el entramado de polisacáridos que constituye la pared celular (Brummell, 2006; Harker y col., 1997; Rose y col., 2003). Sin embargo, se ha observado que la supresión de la expresión individual de varias de estas enzimas, resultan en mínimos efectos sobre el ablandamiento de los frutos (Brummell y Harpster, 2001; Rose y col., 2003), lo que estaría indicando que este proceso de desmantelamiento de la pared celular y ablandamiento es un proceso llevado a cabo de manera coordinada por numerosas enzimas. Además, se han reportado mecanismos no enzimáticos como la acción del radical hidroxilo $(\cdot \mathrm{OH})$, una especie reactiva de oxígeno $(\mathrm{ROS})$ altamente reactiva, que produce la escisión de cadenas de polisacáridos durante la maduración de los frutos (Airianah y col., 2016; Fry, 2004).

La participación de ROS, podría tener importancia en el ablandamiento de la pared celular en los frutos de las líneas mutantes deficientes en ácido ascórbico durante la maduración postcosecha. Dado que de manera contraria a lo ocurrido durante la maduración en planta, durante el almacenamiento postcosecha los frutos de los mutantes slggp1, deficientes en ácido ascórbico, presentaron una tasa de 
Capítulo III: Efecto de la deficiencia en GDP-L-galactosa fosforilasa en la maduración en planta y postcosecha de frutos de tomate.

ablandamiento mayor que los frutos del genotipo silvestre (Fig. 3.15 y Tabla 3.2). Por otro lado, esta mayor tasa de ablandamiento no fue causada por diferencias en la pérdida de peso registrada durante el almacenamiento, ya que este parámetro no mostró diferencias estadísticamente significativas entre los genotipos mutantes slggp1 y el genotipo silvestre (Fig. 3.16).

Se ha observado que el daño mecánico ocasionado al separar el cáliz del fruto desencadena un rápido aumento en la producción de etileno en tomates (De Vries y col., 1995). Estos autores registraron la producción de etileno en tiempo real y observaron un aumento de la producción de esta hormona antes del transcurso de la primera hora desde la realización del daño mecánico. Además observaron que la producción de etileno como producto de daño en la zona del pedúnculo fue mayor que la producción de etileno generada como consecuencia de daños en la epidermis o el pericarpio.

Si bien los frutos utilizados en los experimentos de esta tesis fueron cortados a través de la zona de abscisión del pedúnculo y no se separó el cáliz del fruto, los estudios realizados por De Vries y col., (1995) sugieren que también podría existir un aumento de la producción de etileno como consecuencia de este daño mecánico. Teniendo en cuenta la mayor producción de etileno observada en los mutantes slggp1, un pico en la producción de etileno como consecuencia de la separación del fruto de la planta, podría desencadenar una maduración más acelerada en los frutos de estos mutantes.

Por otro lado, el tratamiento realizado con 1-MCP generó un retraso en el cambio de color y una disminución de la tasa de ablandamiento de igual magnitud en los genotipos mutantes slggp1 y el genotipo silvestre, con respecto al tratamiento control (Fig. 3.13 y 3.15). El 1-MCP se une permanentemente a los receptores existentes en el momento en el que se realiza el tratamiento (Sisler y Serek, 1997). Cualquier retorno de la sensibilidad al etileno se debe a la síntesis de nuevos receptores y la 
Capítulo III: Efecto de la deficiencia en GDP-L-galactosa fosforilasa en la maduración en planta y postcosecha de frutos de tomate.

velocidad de síntesis de receptores (Blankenship y Dole, 2003). Por lo tanto, diferencias a nivel de expresión de receptores de etileno entre los genotipos mutantes slggp1 y el genotipo silvestre podría ser la razón de que el tratamiento con 1-MCP no haya tenido un efecto sobre estos mutantes diferente al genotipo silvestre. En el próximo capítulo se analizarán los niveles de expresión de receptores de etileno en frutos con distinto grado de madurez de los mutantes slggp1 y el genotipo silvestre, en vista de dilucidar posibles mecanismos intervinientes.

Además del ablandamiento y el cambio de color, durante la maduración de los frutos en general, ocurre un aumento del contenido de azúcares y un aumento del contenido de ácidos orgánicos (Yahia y Carrillo-Lopez, 2019). Esto fue observado tanto en los genotipos mutantes slggp1 como en el genotipo silvestre. Sin embargo, no se registraron diferencias en el contenido de ácidos orgánicos entre estos genotipos (Tabla 3.1). Contrariamente, el contenido de sólidos solubles totales registrado en los genotipos mutantes slggp1 en las etapas avanzadas de la maduración, fue más alto que en el genotipo silvestre. Esto fue observado tanto durante la maduración en planta como durante la maduración postcosecha (Tabla 3.1 y Fig. 3.17). Según las mediciones de azúcares totales y reductores realizadas a los frutos madurados en planta, se determinó que el mayor contenido de azúcares en los frutos $\mathrm{P}$ y $\mathrm{R}$ de los genotipos mutantes slggp1, está dado principalmente por una mayor concentración de azúcares no reductores (Fig. 3.12).

La sacarosa es el principal azúcar no reductor en tomates y su interconversión en glucosa y fructosa depende de las enzimas sacarosa sintasa, sacarosa fosfato sintasa e invertasa. En la acción de estas enzimas se basan los conceptos sobre los factores que determinan la fuerza de los destinos para la carga de fotoasimilados y la posterior regulación del metabolismo de los carbohidratos en el fruto del tomate (Sun y col., 1992; Wang y col., 1993). Estas enzimas participan en al menos cuatro ciclos "fútiles" que involucran el transporte de azúcares entre el citosol, la vacuola y el apoplasto y 
Capítulo III: Efecto de la deficiencia en GDP-L-galactosa fosforilasa en la maduración en planta y postcosecha de frutos de tomate.

que mediante el intercambio de sacarosa / hexosa gobiernan el contenido y la composición final de los azúcares en los frutos (Nguyen-Quoc y Foyer, 2001).

El mayor contenido de sólidos solubles observado en los frutos de los genotipos mutantes está representado presumiblemente por un mayor contenido de sacarosa. Esto sugiere que la mutación sobre la enzima GDP-L-galactosa fosforilasa tiene efectos sobre la acumulación de azúcares en los frutos, posiblemente como consecuencia de la desarticulación de la principal vía de síntesis de ascórbico. Serán necesarios más estudios para determinar el motivo de este desbalance en esta acumulación de azúcares. 


\section{CAPÍTULO IV}

Expresión de genes de enzimas

clave en la vía de síntesis de ácido

ascórbico y de receptores de etileno

en plantas deficientes en GDP-L-

galactosa fosforilasa 1 
Capítulo IV: Expresión de genes de enzimas clave en la vía de síntesis de ácido ascórbico y de receptores de etileno en plantas deficientes en GDP-L-Galactosa fosforilasa.

\subsection{Introducción}

Los frutos representan un órgano de acumulación de ácido ascórbico en las plantas y por lo tanto son fuentes importantes de esta vitamina en la dieta humana. En cuanto a su patrón de acumulación, los frutos pueden dividirse en dos tipos que se describen a continuación. Aquéllos en los que el contenido de ácido ascórbico aumenta mientras avanza la maduración, como el tomate, la uva y las frutillas (Cruz-Rus y col., 2010; 2011; Zhang y col., 2011), y otros en los que los niveles de ácido ascórbico disminuyen con el avance de la maduración como por ejemplo el kiwi, la acerola y el durazno (Badejo y col., 2009; Bulley y coll., 2009; Imai y col., 2009). Sin embargo, los detalles del mecanismo que regula esta acumulación o disminución de vitamina $C$ en frutas aún permanecen sin dilucidar completamente.

En experimentos en los que se realizaron aplicaciones exógenas de ácido ascórbico radiomarcado sobre hojas de plantas de tomate, se puso en evidencia la translocación de ácido ascórbico desde las hojas hacia los frutos (Badejo y col., 2012). Además, se observó que la administración exógena de L-galactosa a través del pedúnculo, condujo al aumento de los niveles de ácido ascórbico en frutos maduros e inmaduros de tomate. Estos resultados demostraron que el ácido ascórbico no sólo se transporta desde las hojas al fruto, sino también se produce la biosíntesis de ácido ascórbico en el fruto, a través de la vía de Smirnoff-Wheeler.

Otro mecanismo observado en frutos, es la síntesis de ácido ascórbico a partir del Dgalacturonato. Este monosacárido es liberado como consecuencia de la hidrólisis de pectinas durante el desmantelamiento de las paredes celulares que ocurre en el proceso de maduración de los frutos (Agius y col., 2003). En frutilla y uva, el nivel de expresión génica de la enzima D-galacturonato reductasa, se correlacionó con los niveles de ácido ascórbico durante la maduración de estos frutos (Agius y col., 2003; Cruz-Rus y col., 2010). Esta enzima cataliza la trasformación del D-galacturonato en L- 
Capítulo IV: Expresión de genes de enzimas clave en la vía de síntesis de ácido ascórbico y de receptores de etileno en plantas deficientes en GDP-L-Galactosa fosforilasa.

galactonato (Fig. 4.1), que luego se transforma en L-galactona-1,4-lactona, el último intermediario de la ruta de síntesis de ácido ascórbico de Smirnoff-Wheeler (Agius y col., 2003). En frutilla, el promotor del gen que codifica la D-galacturonato reductasa presentó altos niveles de expresión en frutos, pero no en hojas (Agius y col., 2005). Estos resultados sugieren que la vía del D-galacturonato es más activa en frutos que en hojas. Por otro lado, la aplicación exógena de D-galacturonato en tomate provocó un aumento de los niveles de ácido ascórbico en frutos maduros, pero no así en frutos inmaduros (Badejo y col., 2012). Además, las actividades enzimáticas de la Dgalacturonato reductasa también fueron mayores en frutos de tomate maduros que en inmaduros.

Estos antecedentes en conjunto sugieren que la vía de Smirnoff-Wheeler sintetiza ácido ascórbico durante todo el crecimiento y maduración de los frutos, mientras que la vía del D-galacturonato funciona sólo en la etapa de maduración. Como se mencionó en la introducción general, la vía del D-galacturonato parece constituir el mecanismo para el reciclado de los productos de degradación de las paredes celulares (Conklin, 2001; Davey y col., 2000).

Agius y col (2003) reportaron que la enzima encargada de la actividad D-galacturonato reductasa en frutillas, es la aldo-cetoreductasa 4B (FaAKR4B). En base a la similitud de secuencia con la enzima AKR4B de frutilla, se han propuesto posibles enzimas homologas en tomate. Ioannidi y col., (2009) reportaron tres isoenzimas posibles nombradas SIAKR1 (SGN-U323295), SIAKR2 (SGN-U316890), y SIAKR38 (SGNU315474) con un porcentaje de identidad con la isoenzima de frutilla de aproximadamente un $20 \%$. Por otro lado Zou y col., (2006) reportaron otra isoenzima AKR4b en tomate (SGN-U584148), esta enzima presentó un 39\% de identidad con la enzima AKR4b de frutilla. En otro trabajo más reciente, Suekawa y col., (2016) reportaron otra isoenzima AKR4B (XM_004235326) denominada SIAKR4B con un $49 \%$ de identidad con la AKR4B de frutilla. Estos autores realizaron alineamientos de 
Capítulo IV: Expresión de genes de enzimas clave en la vía de síntesis de ácido ascórbico y de receptores de etileno en plantas deficientes en GDP-L-Galactosa fosforilasa.

las secuencias proteicas de SIAKR4B con otras AKRs de tomate, frutilla y Arabidopsis y concluyeron que SIAKR4B contiene residuos de aminoácidos catalíticos conservados que son responsables de la actividad enzimática D-galacturonato reductasa. Además, en un árbol filogenético la secuencia de tomate $S I A K R 4 B$ y la de frutilla FaAKR4B4 se clasificaron en la misma rama, lo que indica una mayor similitud entre éstas con respecto a otras isoenzimas de tomate y Arabidopsis.

Por otro lado, los azúcares de 6 carbonos que son precursores de la síntesis de ascórbico en la ruta de Smirnoff-Wheeler, también son la materia prima utilizada en la síntesis de componentes de la pared celular. La GDP-D-manosa, contribuye a la síntesis de diferentes polisacáridos estructurales en las paredes celulares de las plantas (Fig. 1.4). Los polímeros de hemicelulosa como los glucomananos y galactomananos se sintetizan a partir de GDP-D-manosa (Bewley y col., 1997). Además la GDP-D-manosa es el sustrato para GDP-D-manosa-4,6-deshidratasa, una enzima que cataliza el primer paso en la biosíntesis de GDP-L-fucosa presente tanto en glicoproteínas como en la pared celular (Conklin y col., 1999). Esta enzima está codificada por el gen MUR1 de Arabidopsis (Bonin y col., 1997).

La GDP-D-manosa juega un papel importante en muchos procesos celulares esenciales diferentes. Los mutantes de Arabidopsis cyt1, que poseen una actividad nula de la enzima GDP-D-manosa pirofosforilasa, detienen su crecimiento embrionario en etapas muy tempranas debido a defectos en la $\mathrm{N}$-glicosilación de proteínas y la composición alterada de la pared celular. Los mutantes de Arabidopsis vtc1-1 y vtc1-2 también tienen una mutación que afecta la actividad de la enzima GDP-D-manosa pirofosforilasa y presentan un menor contenido de ascórbico que el genotipo control, no obstante esta mutación no es letal (Conklin y col., 1999).

La siguiente enzima de la ruta de Smirnoff-Wheeler es la GDP-D-manosa-3,5epimerasa y produce GDP-L-galactosa a partir de GDP-D-manosa y, por lo tanto, 
Capítulo IV: Expresión de genes de enzimas clave en la vía de síntesis de ácido ascórbico y de receptores de etileno en plantas deficientes en GDP-L-Galactosa fosforilasa.

representa una intersección entre la síntesis de ácido ascórbico y la biosíntesis de polisacáridos de la pared celular (Gilbert y col., 2009). Por otro lado, la GDP-D-manosa 3,5-epimerasa también genera GDP-L-gulosa, un precursor de la biosíntesis de ácido ascórbico en plantas en la vía alternativa de la L-gulosa (Wolucka y Van Montagu, 2003). Se ha reportado que el silenciamiento de la GDP-D-manosa-3,5-epimerasa, mediante ARN de interferencia, reduce el contenido de ácido ascórbico en plantas de tomate, lo que conduce a la acumulación de ROS, al blanqueamiento y defectos en el desarrollo asociados a alteraciones de la pared celular (Gilbert y col., 2009). Además se ha propuesto que esta enzima representa un paso regulador de la biosíntesis de ascórbico, ya que la adición in vitro de ácido ascórbico o L-galactona-1,4-lactona genera la regulación negativa de su actividad (Wolucka y Montagu 2003).

Como se mencionó anteriormente, a partir de la acción de la enzima GDP-D-manosa3,5-epimerasa, se forma GDP-L-galactosa. Este compuesto da lugar a la formación de L-galactosa, un componente minoritario de las paredes celulares de las plantas y además es el sustrato de la enzima GDP-L-galactosa fosforilasa (Wheeler y col., 1998). Tanto Arabidopsis como Tomate, poseen dos genes que codifican dos isoenzimas GDP-L-galactosa fosforilasa, vtc2/vtc5 en Arabidopsis y GGP1/GGP2 en Tomate (Baldet y col., 2013; Dowdle y col., 2007). Según los resultados de los niveles de ácido ascórbico registrados en los mutantes de inserción de ADN-T, vtc2 y vtc5, que fueron de aproximadamente $20 \%$ y $80 \%$ respectivamente, con respecto al genotipo silvestre, se concluyó que vtc2 predomina sobre vtc5 en la biosíntesis de ácido ascórbico en hojas de Arabidopsis (Dowdley col., 2007). Los mutantes dobles vtc2-vtc5 presentan una letalidad de sus embriones que sólo puede ser revertida mediante la aplicación de ácido ascórbico o L-galactosa, indicando que la reacción catalizada por GDP-L-galactosa fosforilasa es indispensable para la biosíntesis de ácido ascórbico (Dowdle y col., 2007). 
Capítulo IV: Expresión de genes de enzimas clave en la vía de síntesis de ácido ascórbico y de receptores de etileno en plantas deficientes en GDP-L-Galactosa fosforilasa.

La GDP-L-galactosa fosforilasa es considerada la primera enzima dedicada exclusivamente a la síntesis de vitamina C de la ruta de Smirnoff-Wheeler; a partir de este punto los metabolitos intermediarios de los próximos pasos enzimáticos son utilizados en la síntesis de ácido ascórbico. Es por este motivo que se considera un punto importante en la regulación de la biosíntesis de ácido ascórbico (Laing y col., 2015). Se ha determinado que los niveles de expresión de vtc2 y vtc5 correlacionan con el contenido de ascórbico en hojas de Arabidopsis (Dowdle y col., 2007). A partir de experimentos realizados en Arabidopsis, Laing y col. (2015) determinaron que las altas concentraciones de ascórbico regulan negativamente la expresión postranscripcional del gen que codifica la GDP-L-galactosa fosforilasa 1 (vtc 2). Estos autores encontraron un marco abierto de lectura ( ${ }_{u} \mathrm{ORF}$ del inglés upstrem Open Reading frame), en la región UTR 5' del $A R N_{m}$ del gen vtc2, que codifica un péptido inhibidor de la traducción de vtc2 (Laing y col 2015). Mediante la realización mutaciones estos autores generaron un codón de terminación temprana en el marco de lectura de este ${ }_{u} \mathrm{ORF}$. De esta manera lograron impedir la traducción de este péptido inhibidor y como consecuencia la desactivación de la regulación negativa sobre GGP1/vtc2 ante concentraciones altas de ácido ascórbico. Además se observó que este ${ }_{4} \mathrm{ORF}$ se encuentra ampliamente conservado desde musgos hasta angiospermas (Laing y col., 2015).

El último pasó para la síntesis de ascórbico en la ruta de Smirnoff-Wheeler es la oxidación de la L-galactona-1,4-lactona. Esta reacción ocurre en la mitocondria y es catalizada por la enzima L-galactona-1,4-lactona deshidrogenasa (Mapson y col., 1954). Esta enzima transfiere electrones al citocromo $c$ y está localizada en la membrana interna de la mitocondria con su sitio catalítico en el espacio intermembrana (Bartoli y col., 2000; Schimmeyeer y col., 2016). Además se ha demostrado que la L-galactona-1,4-lactona deshidrogenasa tiene una segunda función no enzimática, participando como factor de ensamble del complejo I de la cadena 
Capítulo IV: Expresión de genes de enzimas clave en la vía de síntesis de ácido ascórbico y de receptores de etileno en plantas deficientes en GDP-L-Galactosa fosforilasa.

transportadora de electrones mitocondrial (Schimmeyer y col., 2016). A lo largo de la maduración de frutos de tomate, se ha observado una disminución de la expresión de esta enzima (Mellidou y col., 2012).

Si bien la actividad de las enzimas antes mencionadas contribuye a los niveles y estado redox del pool de ácido ascórbico en los frutos, otro factor importante en este sentido es el reciclado de las formas oxidadas como el ácido monodehidroascórbico y el ácido dehidro ascórbico. Esto ocurre a través del denominado ciclo Foyer-HalliwellAsada (Asada, 1999; Foyer y Halliwell, 1976). Se ha reportado que durante la maduración de tomate, la elevada expresión de genes ortólogos que codifican la enzima monodehidro ascorbato reductasa se correlacionan con los niveles de ácido ascórbico finales del fruto (Mellidou y col., 2012).

El ácido dehidro ascórbico generado como consecuencia de la oxidación de la molécula puede sufrir una hidrólisis irreversible y transformarse en ácido 2,3-diceto glucónico o puede ser reciclado por acción de la enzima dehidro ascorbato reductasa. Se ha reportado que la sobreexpresión transciente en tomate de una dehidro ascorbato reductasa-1 de papa, genera un aumento de 1,9 veces del contenido de ácido ascórbico en los frutos (Li y col., 2012). Esto indica que el reciclado del ascórbico oxidado contribuye a mantener elevados los niveles de ascórbico en tomate sobre todo en las etapas finales de la maduración.

Además del aumento del contenido de ácido ascórbico, durante la maduración del tomate ocurren otros cambios, tanto en el color como contenido de azúcares y ácidos orgánicos. En conjunto estos cambios determinan las características organolépticas y nutricionales del fruto. Dado que el tomate es un fruto climatérico, todos estos procesos están coordinados por la producción y percepción del etileno (Cara y Giovannoni, 2008). 
Capítulo IV: Expresión de genes de enzimas clave en la vía de síntesis de ácido ascórbico y de receptores de etileno en plantas deficientes en GDP-L-Galactosa fosforilasa.

La percepción del etileno ocurre mediante la difusión de la molécula hasta las membranas retículo endoplasmático, donde se encuentran los receptores para esta hormona (Gallie, 2015). Cuando el etileno se une a estos receptores se desencadena la cascada de reacciones que constituyen la vía de transducción de señales activada por etileno (Klee, 2004). Los receptores de etileno pueden ser divididos en dos grupos en base a las regiones conservadas de sus residuos histidina-kinasa (Kevany y col., 2007). En tomate se han identificado 6 receptores de etileno diferentes, tres de ellos, SIETR1, SIETR2 y SIETR3 (Never Ripe; NR) se agrupan en la subfamilia I por tener similutud con residuos histidina-kinasa y los receptores SIETR4, SIETR5 y SIETR6 se agrupan en la subfamilia II por poseer similitud con residuos serina-kinsa (Klee y Tieman, 2002).

Toda la evidencia existente soporta el modelo por el cual los receptores de etileno actúan como reguladores negativos de la señal en ausencia de etileno (Gallie, 2015; Zhong y col., 2008). Este modelo predice una relación inversa entre los niveles de expresión de los receptores y la sensibilidad al etileno de un tejido (Klee y Tieman, 2002). Este modelo asume que hay un efecto umbral de etileno y por lo tanto es necesario que cierto número de receptores sean inactivados por la unión del etileno, para que el efecto de esta hormona se manifieste en los tejidos. Se requiere una mayor cantidad de etileno para inactivar un mayor número de receptores que para inactivar un menor número de receptores (Klee y Tieman, 2002). Plantas que sobreexpresan constitutivamente el gen que codifica el receptor ETR3/NR (SIETR3) son menos sensibles al etileno (Ciardi y col., 2000).

Según análisis comparativos de la expresión de los receptores de etileno en tomate, se observó que SIETR3 y SIETR4 son los principales receptores expresados durante la maduración (Kevany y col., 2007; Liu y col., 2015). La expresión de SIETR6 también es inducida durante las primeras fases de la maduración, mientras que los niveles de 
Capítulo IV: Expresión de genes de enzimas clave en la vía de síntesis de ácido ascórbico y de receptores de etileno en plantas deficientes en GDP-L-Galactosa fosforilasa.

expresión de los receptores SIETR1, SITER2 y SIETR5 se mantienen constantes (Kevany y col., 2007; Lashbrook y col., 1998).

En los mutantes deficientes en GDP-L-galactosa fosforilasa estudiados en esta tesis, se observó una mayor producción de etileno durante la maduración de los frutos en planta. Además durante el almacenamiento postcosecha se observó una maduración más acelerada de los frutos mutantes slggp1; de manera contraria a lo observado durante la maduración en planta. Por este motivo en este capítulo se analizará la expresión génica de los receptores de etileno. 
Capítulo IV: Expresión de genes de enzimas clave en la vía de síntesis de ácido ascórbico y de receptores de etileno en plantas deficientes en GDP-L-Galactosa fosforilasa.

\section{$\underline{4.2}$ Objetivos}

En este capítulo se abordó el objetivo específico 4 que consistió en Determinar el efecto de la mutación en el gen SIGGP1 sobre la expresión de genes involucrados en la síntesis del ácido ascórbico, de rutas asociados y de la señalización por etileno en hojas y frutos.

En función de este, se fijaron cuatro actividades a realizar:

4.2.1 Determinar la expresión de genes correspondientes a enzimas de la síntesis de ácido ascórbico en hojas y frutos.

4.2.2 Determinar la expresión de genes correspondientes a enzimas que participan en la síntesis y degradación de componentes de pared celular en hojas y frutos.

4.2.3 Determinar la expresión de enzimas que participan en el reciclado del ácido ascórbico a partir de sus formas oxidadas en hojas y frutos.

4.2.4 Determinar la expresión de genes correspondientes a receptores de etileno en hojas y frutos. 
Capítulo IV: Expresión de genes de enzimas clave en la vía de síntesis de ácido ascórbico y de receptores de etileno en plantas deficientes en GDP-L-Galactosa fosforilasa.

\section{$\underline{4.3 \quad \text { Materiales y métodos }}$}

\subsubsection{Extracción de RNA de hojas}

Hojas colectadas a partir de plantas en estado fenológico de antesis, fueron congeladas en nitrógeno líquido y conservadas a $-80^{\circ} \mathrm{C}$ hasta su uso. Posteriormente se molió la muestra en nitrógeno líquido utilizando mortero estéril y $100 \mathrm{mg}$ de tejido se homogeneizaron con $1 \mathrm{ml}$ de TRI Reagent $®$ (Sigma-Aldrich $\circledast$ ) para realizar la extracción de $\mathrm{ARNm}$. El homogenato reposó 5 min a temperatura ambiente y luego se centrifugó durante 15 min a 12000 x g y $4{ }^{\circ} \mathrm{C}$. El sobrenadante acuoso resultante se trasvasó a otro tubo y se mezcló mediante vortex vigorosamente durante 15 seg con $200 \mu \mathrm{l}$ de cloroformo por cada $\mathrm{ml}$ de TRI Reagent $\AA$ utilizado inicialmente. Luego de reposar la mezcla durante 5 min a temperatura ambiente, ésta se centrifugó durante $10 \min$ a 12000 x g y $4^{\circ} \mathrm{C}$. En este punto se observó la separación de la mezcla en dos fases, una inferior orgánica de color rojo y una superior acuosa e incolora. Se tomó la fase acuosa superior y se trasvasó a otro tubo en el que se mezcló suavemente por inversión con un volumen igual de isopropanol para favorecer la precipitación del ARN. Los tubos fueron incubados en un baño de agua-hielo durante 5 min y posteriormente se centrifugaron durante 15 min a $12000 \mathrm{x}$ $g$ y $4{ }^{\circ} \mathrm{C}$. Se descartó el líquido sobrenadante y el pellet se lavó con $500 \mu \mathrm{l}$ de $70 \%$ v/v etanol. Se centrifugó durante $10 \mathrm{~min}$ a 12000 x g y $4{ }^{\circ} \mathrm{C}$ y se descartó el etanol sobrenadante. El pellet se resuspendió con $90 \mu$ de agua destilada y luego se agregaron $10 \mu \mathrm{l}$ de $3 \mathrm{M}$ Acetato de sodio $\mathrm{pH} 5,2$ y $250 \mu \mathrm{l}$ de etanol puro, esta mezcla precipitó durante $1 \mathrm{~h}$ a $-20{ }^{\circ} \mathrm{C}$. Luego de la precipitación la mezcla se centrifugó durante $20 \mathrm{~min}$ a $12000 \mu \mathrm{l}$ y $4^{\circ} \mathrm{C}$, el pellet resultante se lavó con $500 \mu \mathrm{l}$ de $70 \% \mathrm{v} / \mathrm{v}$ etanol y luego de centrifugar a $12000 \times g$ y $4{ }^{\circ} \mathrm{C}$, se descartó el etanol y el pellet fue secado en flujo laminar durante 20 min. Por último el pellet se resuspendió en $30 \mu \mathrm{l}$ de agua mili $Q$ tratada con DEPC y se almacenó a $-80^{\circ} \mathrm{C}$ hasta su uso. 
Capítulo IV: Expresión de genes de enzimas clave en la vía de síntesis de ácido ascórbico y de receptores de etileno en plantas deficientes en GDP-L-Galactosa fosforilasa.

La cantidad y pureza del ARN en cada muestra se cuantificó mediante el uso de un lector de micro placas (CLRIOSTAR-plus BGM LABTECH). En una placa (LVisPLATE, BGM LABTECH) se colocó $1 \mu$ l por pocillo de una dilución 1:10 de la muestra de ARN y se midió la absorbancia a $\lambda=260$ y $280 \mathrm{~nm}$.

Para chequear la integridad del ARN extraído, cada muestra de ARN total se analizó mediante electroforesis en gel de $1 \% \mathrm{p} / \mathrm{v}$ agarosa. El gel se preparó disolviendo $1 \mathrm{~g}$ de Agarosa en $100 \mathrm{ml}$ de buffer TBE 1X (0,089 M Tris, 0,087 M ácido bórico M, 0,002 M EDTA). Se mezclaron $3 \mu \mathrm{L}$ de la muestra de ARN con $0,6 \mu l$ de solución de carga Orange G 6X (agua miliQ, $40 \% \mathrm{v} / \mathrm{v}$ glicerol, Orange $\mathrm{g} 1 \mathrm{mg} / \mathrm{ml}$ ). Finalmente, las muestras se sembraron en el gel de agarosa y se realizó la electroforesis a voltaje constante de $70 \mathrm{~V}$ usando como buffer TBE 0,5 X. Los geles fueron revelados utilizando bromuro de etidio $\left(0,3 \mu \mathrm{g} \mathrm{L}^{-1}\right)$, y se consideró la presencia de dos bandas bien definidas correspondientes a las dos subunidades del ARN ribosómico, como criterio de integridad de la muestra. Las muestras se almacenaron a $-80^{\circ} \mathrm{C}$ hasta el momento de su uso.

A las muestras se les aplicó un tratamiento para eliminar posibles contaminaciones con ADN genómico que consistió en una digestión con DNAsa. En un tubo Eppendorf de $0,2 \mathrm{ml}$ se dispusieron $8 \mu \mathrm{g}$ de RNA total, $2,5 \mu \mathrm{l}$ de buffer DNAse RQ $10 \times, 0,5 \mu \mathrm{lde}$ RNase free-DNase $R Q 1 U \mu l^{-1}$ Promega ${ }^{\circledR}$ por cada $\mu g$ de $A R N$ total y agua mili $Q$ tratada con DEPC hasta completar $25 \mu$ finales. La mezcla se incubó durante $1 \mathrm{~h}$ a 37 ${ }^{\circ} \mathrm{C}$. Posteriormente los tubos fueron dispuestos en hielo, se agregaron $75 \mu \mathrm{l}$ de agua miliQ, $100 \mu \mathrm{l}$ de una solución de cloroformo y octanol 24:1 y se mezcló vigorosamente con un vortex y luego se centrifugó durante $10 \min$ a 12000 x $g$ y $4^{\circ} \mathrm{C}$. El sobrenadante fue transferido a otro tubo, se agregaron $200 \mu \mathrm{l}$ de etanol puro frío y 20 $\mu \mathrm{l}$ de $3 \mathrm{M}$ acetato de sodio, y la mezcla precipitó durante $1 \mathrm{~h}$ a $-80^{\circ} \mathrm{C}$. Luego de la precipitación, la mezcla se centrifugó durante 20 min a 12000 x g y $4^{\circ} \mathrm{C}$, se descartó el sobrenadante y el pellet fue lavado con $1 \mathrm{ml}$ de $70 \% \mathrm{v} / \mathrm{v}$ etanol. Luego se centrifugó 
Capítulo IV: Expresión de genes de enzimas clave en la vía de síntesis de ácido ascórbico y de receptores de etileno en plantas deficientes en GDP-L-Galactosa fosforilasa.

durante 20 min a 12000 x g a $4^{\circ} \mathrm{C}$ y se descartó la totalidad del etanol sobrenadante. El pellet se secó en flujo laminar durante 15 min y luego se resuspendió en $20 \mu \mathrm{l}$ de agua mili $\mathrm{Q}$ tratada con DEPC. Las muestras se almacenaron a $-80{ }^{\circ} \mathrm{C}$ hasta el momento de su uso.

\subsubsection{Extracción de RNA de frutos}

Se emplearon frutos en el estadio de madurez verde maduro $(\mathrm{VM})$, pintón $(\mathrm{P})$ y rojo $(\mathrm{R})$, previamente congelados en nitrógeno líquido, y conservados a $-80^{\circ} \mathrm{C}$ hasta su uso. La muestra se molió en nitrógeno líquido utilizando mortero estéril y $200 \mathrm{mg}$ de tejido fueron colocados en un tubo Eppendorf de $2 \mathrm{ml}$ junto con 2 perlas de acero para realizar una segunda molienda del tejido utilizando un vortex para lograr una agitación vigorosa durante 10 seg y las muestras se conservaron en nitrógeno líquido hasta su uso. Posteriormente se añadió a cada tubo $1 \mathrm{ml}$ del reactivo TRI Reagent $囚$ (SigmaAldrich $\left.{ }^{\circledR}\right)$ y se homogeneizó vigorosamente empleando un vortex durante 15 seg para realizar la extracción de ARNm. Se retiraron las perlas de acero utilizando un magneto y se incubó el homogenato durante 5 min a temperatura ambiente. Luego se añadió $200 \mu \mathrm{l}$ de cloroformo puro, se mezcló vigorosamente utilizando un vortex durante 15 seg y se incubó la muestra durante 5 min más a temperatura ambiente. La mezcla se centrifugó durante $10 \mathrm{~min}$ a $12000 \times \mathrm{g}$ a $4{ }^{\circ} \mathrm{C}$, se trasvasó la fase acuosa a un tubo Eppendorf de $1,5 \mathrm{ml}$ y se volvieron a agregar $200 \mu \mathrm{l}$ de cloroformo puro; se mezcló vigorosamente utilizando vortex durante $15 \mathrm{seg}$ y se incubó la muestra durante 5 min a temperatura ambiente nuevamente. La mezcla se centrifugó durante 10 min a $12000 x$ g a $4{ }^{\circ} \mathrm{C}$. La fase acuosa se transfirió a otro tubo Eppendorf de $1,5 \mathrm{ml}$ y se agregó un volumen igual al recuperado de isopropanol puro, se realizó una mezcla por inversión y se incubó en un baño de agua hielo durante $5 \mathrm{~min}$. La mezcla se centrifugó durante 15 min a 12000 × g a $4^{\circ} \mathrm{C}$ y se descartó la totalidad del sobrenadante. Se disolvió el pellet en $100 \mu \mathrm{l}$ de agua mili $Q$ tratada con DEPC y se mezcló suavemente con $33 \mu \mathrm{l}$ de $8 \mathrm{M}$ cloruro de litio (1/3 del volumen de agua mili $\mathrm{Q}$ tratada con DEPC) utilizando 
Capítulo IV: Expresión de genes de enzimas clave en la vía de síntesis de ácido ascórbico y de receptores de etileno en plantas deficientes en GDP-L-Galactosa fosforilasa.

pipeta y punta con filtro. La mezcla precipitó durante una noche a $4{ }^{\circ} \mathrm{C}$ y posteriormente se centrifugó a $10000 \times g$ a $4{ }^{\circ} \mathrm{C}$. Se descartó el sobrenadante utilizando pipeta y punta con filtro, y se lavó el pellet con $500 \mu \mathrm{l}$ de $70 \%$ v/v etanol frío. Se centrifugó durante $10 \mathrm{~min}$ a $12000 \times \mathrm{g}$ y $4{ }^{\circ} \mathrm{C}$, se descartó la totalidad del etanol y el pellet se secó en flujo laminar durante $15 \mathrm{~min}$. El pellet se resuspendió suavemente en $88 \mu \mathrm{l}$ de agua mili $\mathrm{Q}$ tratada con DEPC y se mezcló con $10 \mu \mathrm{l}$ de buffer $10 \mathrm{X} R Q$ y $2 \mu \mathrm{l}$

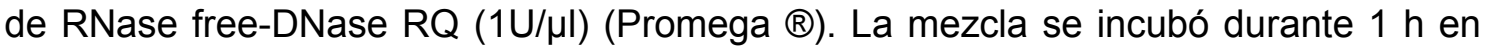
un baño a $37^{\circ} \mathrm{C}$. Luego se mezcló por inversión con $200 \mu \mathrm{l}$ de isopropanol puro y se centrifugó durante $10 \min \left(10000 \times g\right.$ y $\left.4^{\circ} \mathrm{C}\right)$. Se descartó el sobrenadante y se lavó el pellet con $500 \mu \mathrm{l}$ de $70 \% \mathrm{v} / \mathrm{v}$ etanol frio, se centrifugó durante $10 \mathrm{~min}\left(10000 \mathrm{xg}\right.$ y $4^{\circ}$ C), se descartó la totalidad del etanol y el pellet se secó en flujo laminar durante 15 min. Por último el pellet se resuspendió en $20 \mu \mathrm{l}$ de agua mili $Q$ tratada con DEPC. Las muestras se almacenaron a $-80{ }^{\circ} \mathrm{C}$ hasta el momento de su uso. La cuantificación del ARN total y el chequeo de la integridad del mismo se realizó como se describió previamente para el ARN extraído de hojas.

\subsubsection{Síntesis de ADNc}

Se obtuvo ADN complementario (ADNc) de los distintos extractos de ARN por medio de una reacción de transcripción reversa utilizando la enzima M-MLV (Moloneymurine leucemia virus reverse transcriptase, Promega, $\left.200 U \mu \mathrm{L}^{-1}\right)$. Se mezclaron el volumen necesario para alcanzar $2 \mu \mathrm{g}$ de ARN purificado con $1 \mu \mathrm{l}\left(50\right.$ pmoles $\left.\mu^{-1}\right)$ de oligodT (OligodT (15) Biodynamics ${ }^{\circledR}$ ) y agua mili $Q$ tratada con DEPC cantidad necesaria para alcanzar un volumen de $15 \mu \mathrm{l}$. La mezcla se incubó primero a $70{ }^{\circ} \mathrm{C}$ durante $5 \mathrm{~min}$, luego 5 min en hielo y se centrifugaron los tubos brevemente para colectar toda la mezcla en el fondo del tubo. Posteriormente, se agregaron $5 \mu \mathrm{L}$ de buffer de reacción M-MLV 5X, 1,5 $\mu \mathrm{l}$ de una mezcla de 10mM dNTPs (100mM dATP, 100mM dCTP, 100mM dGTP, 100 mM dTTP; PB-L Productos Bio-Logicos $\left.{ }^{\circledR}\right), 0,5 \mu l$ de inhibidor de ribonucleasas (Recombinant $\mathrm{RNasin}^{\circledR} 40 \mathrm{U} \mathrm{\mu l}^{-1}$ Promega), $1 \mu \mathrm{L}$ de enzima M-MLV y 
Capítulo IV: Expresión de genes de enzimas clave en la vía de síntesis de ácido ascórbico y de receptores de etileno en plantas deficientes en GDP-L-Galactosa fosforilasa.

la cantidad necesaria de agua mili $Q$ tratada con DEPC para alcanzar un volumen final de $25 \mu \mathrm{L}$. Luego la mezcla de reacción se incubó durante $1 \mathrm{~h}$ a $42^{\circ} \mathrm{C}$ para generar el ADNc. El ADNc generado se almacenó a $-20^{\circ} \mathrm{C}$ hasta el momento de su uso.

\subsubsection{Análisis de expresión de genes por RT-qPCR}

Se determinó la expresión relativa de genes codificantes para algunas enzimas de interés de la principal vía de síntesis de ascórbico como la GDP-Dmanosapirofosforilasa (SIGMP), GDP-D-manosa-3',5'-epimerasa (S/GME), GDP-Lgalactosa fosforilasa 1(S/GGP1), GDP-L-galactosa fosforilasa 2 (SIGGP2), Lgalactona-1,4-lactona deshidrogenasa (SIGALDH). También se determinó la expresión relativa de un gen que codifica para la enzima GDP-manosa-4,6-deshidratasa (SIGMD), que cataliza el primero de tres pasos en la vía de síntesis de fucosa a partir de GDP-D-manosa y de un gen que codifica la enzima aldo-ceto reductasa 4b (AKR) que cataliza la transformación de D-galacturonato en L-galactato en la vía de degradación de pectinas. También se analizó la expresión de genes que codifican enzimas responsables del reciclado del ácido ascórbico oxidado como la monodehidroascorbato reductasa 1 y 3 (SIMDHAR1 y $\quad$ SIMDHAR3) y la dehidroascorbato reductasa 3 (SIDHAR3). Además se analizó la expresión de genes codificantes para receptores de etileno SIETR2 y SIETR3 (Ethylene resistant 2 y 3 ).

En algunos casos los cebadores para el análisis de expresión relativa fueron extraídos de la bibliografía (Tabla 4.1). En otros casos las secuencias fueron buscadas en GenBank (http://www.ncbi.nlm.nih.gov/genbank/) y luego las secuencias ortólogas buscadas en el genoma de tomate disponible en la plataforma solgenomics (https://solgenomics.net/).

A partir de estas secuencias los cebadores fueron diseñados utilizando la herramienta online Primer3 (http://bioinfo.ut.ee/primer3/)teniendo en cuenta las siguientes condiciones: 
Capítulo IV: Expresión de genes de enzimas clave en la vía de síntesis de ácido ascórbico y de receptores de etileno en plantas deficientes en GDP-L-Galactosa fosforilasa.

- Tamaño del amplicón entre 85-150 pares de bases ( $\mathrm{pb})$;

- \%GC entre 40-60\%;

- Tamaño del cebador entre 18-25 pb

- Temperatura de melting entre $59-63^{\circ} \mathrm{C}$

- Extremo 3' con C o G preferentemente

- Se evitó la autocomplementariedad.

\subsubsection{Eficiencia de los cebadores}

Los cebadores liofilizados (Macrogen®) se resuspendieron en $250 \mu$ le agua mili $Q$ tratada con DEPC estéril y se obtuvieron concentraciones stock de $100 \mu \mathrm{M}$. A partir de estas diluciones stock se prepararon diluciones de trabajo de concentración $10 \mu \mathrm{M}$.

Se determinó la eficiencia de cada par de cebadores mediante la realización de una curva de calibración de molde variable y primer constante. Para esto se realizó una dilución en serie de una mezcla correspondiente a ADNc de muestras de hojas o de ADNc de muestras frutos verdes del genotipo silvestre en una relación 1:3 (1/3, 1/9, $1 / 27$ y $1 / 81)$

Se tomó $1 \mu \mathrm{l}$ de cada una de las diluciones y se agregó con una mezcla de reacción compuesta por $0,7 \mu \mathrm{l}$ del cebador directo (D) y $0,7 \mu \mathrm{l}$ del cebador reverso (R) (dilución de trabajo $10 \mathrm{mM}$ ), $5 \mu \mathrm{l}$ de SYBER Green Master (Rox), 2,6 $\mu$ le agua MiliQ para obtener un volumen final de reacción de $10 \mu$ l. Se realizó la cuantificación del nivel expresión de cada uno de los genes encada dilución de ADNc mediante reacciones de amplificación RT-qPCR. Las mismas se llevaron a cabo utilizando un equipo Step One Plus $^{\text {TM }}$ Real-Time PCR System (Applied Biosystems) y SYBR Green I cómo método de detección. Se siguieron las especificaciones del kit Fast Start Universal SYBR Green Master (Rox) para reacciones con un volumen final de $10 \mu \mathrm{l}$. Se consideró aceptable una eficiencia entre 0,80 y 1,05 y un $R^{2}>0,95$. 
Capítulo IV: Expresión de genes de enzimas clave en la vía de síntesis de ácido ascórbico y de receptores de etileno en plantas deficientes en GDP-L-Galactosa fosforilasa.

\subsubsection{Genes normalizadores}

Se determinó la eficiencia de los siguientes genes normalizadores: Factor de elongación a 1 (SIEfa1) según Badejo y col., (2012), Actina 2 (SIACT2) según Lovdal y Lillo, (2009) y Expressed sequence (Express) según González-Aguilera y col.,(2016). A partir de los resultados se optó por la utilización de SIEFa1 como gen normalizador en frutos por presentar la mejor eficiencia en este sistema y SIACT2 en hoja por presentar mejor eficiencia en este sistema que los demás genes normalizadores.

\subsubsection{Análisis de expresión relativa}

Se realizó una cuantificación relativa de la expresión de los genes a nivel de ARN mensajero mediante reacciones de amplificación en cadena por la ADN polimerasa en tiempo real (RT-qPCR). Las mismas se llevaron a cabo utilizando un equipo StepOne Plus $^{\text {TM }}$ Real-Time PCR System (AppliedBiosystems) y SYBR Green I cómo método de detección. Se siguieron las especificaciones del kit FastStart Universal SYBR Green Master (Rox) para reacciones con un volumen final de $10 \mu \mathrm{l}$. Se utilizaron $0,7 \mu \mathrm{l}$ de cada cebador (dilución de trabajo $10 \mathrm{mM}$ ), $5 \mu \mathrm{l}$ de SYBER Green Master (Rox), 2,6 $\mu \mathrm{l}$ de agua MiliQ y $1 \mu \mathrm{l}$ de ADNc (dilución 1:5). Se usó el siguiente programa de ciclado: $95^{\circ} \mathrm{C}$ durante $10 \mathrm{~min} ; 40$ ciclos de $95^{\circ} \mathrm{C}$ durante 15 seg y $60{ }^{\circ} \mathrm{C}$ durante $1 \mathrm{~min}$, con un paso de medición de fluorescencia al final de cada ciclo de $15 \mathrm{seg}$. Al final al programa de ciclado se le agregó la obtención de una curva de disociación para cada reacción, de modo tal de detectar posibles contaminaciones.

Se analizó la expresión de los genes mencionados anteriormente a partir de tres muestras biológicas de ADNc de hojas de los dos genotipos mutantes slggp1 y del genotipo silvestre. También se analizaron tres muestras biológicas de frutos en cada uno de los tres estadios de maduración mencionados anteriormente de los dos genotipos mutantes slggp1 y del genotipo silvestre. Todas las reacciones RT qPCR fueron realizadas por triplicado técnico para cada una de tres muestras biológicas y los 
Capítulo IV: Expresión de genes de enzimas clave en la vía de síntesis de ácido ascórbico y de receptores de etileno en plantas deficientes en GDP-L-Galactosa fosforilasa.

niveles de expresión fueron calculados utilizando el método $\Delta \Delta C T$ de la siguiente forma:

1. $\Delta \mathrm{CT}_{\text {mutante }}=\left(\mathrm{CT}_{\text {gen de interés, mutante }}-\mathrm{CT}\right.$ gen normalizador,mutante $)$ $\Delta \mathrm{CT}_{\text {silvestre }}=\left(\mathrm{CT}_{\text {gen de interés, silvestre }}-\mathrm{CT}\right.$ gen normalizador, silvestre $)$

2. $\Delta \Delta \mathrm{CT}=\left(\Delta \mathrm{CT}_{\text {mutante }}-\Delta \mathrm{CT}\right.$ silvetre $)$

3. $(2)^{\Delta \Delta \mathrm{CT}}=$ Expresión relativa

La expresión de los distintos genes analizados se relativizó a la expresión promedio de la serie de tres réplicas biológicas del genotipo silvestre $\left(\Delta C T_{\text {silvetre }}\right)$. En el caso del análisis de la expresión génica en frutos, la expresión de los genes analizados en los mutantes se relativizó a la serie de tres réplicas biológicas de los frutos verdes del genotipo silvestre. 
Capítulo IV: Expresión de genes de enzimas clave en la vía de síntesis de ácido ascórbico y de receptores de etileno en plantas deficientes en GDP-LGalactosa fosforilasa.

Tabla 4. 1-Cebadores utilizados en el análisis de expresión génica tanto en hoja como en fruto de tomate.

\begin{tabular}{|c|c|c|c|c|c|c|c|}
\hline Código & Nombre & $\begin{array}{c}\text { Código } \\
\text { solgenomics.net }\end{array}$ & Directo $\left(5^{\prime}-3^{\prime}\right)$ & Reverso (5'-3') & $\begin{array}{l}\text { Eficiencia } \\
\text { en hoja \% }\end{array}$ & $\begin{array}{l}\text { Eficiencia } \\
\text { en fruto } \%\end{array}$ & $\begin{array}{l}\text { Referencia bibliográfi } \\
\text { ca }\end{array}$ \\
\hline SIGMP & $\begin{array}{l}\text { GDP-D-manosa } \\
\text { pirofosforilasa }\end{array}$ & Solyc06g051270.3 & GGTCCTTCCTGGGTTTTTGG & ATGCCAGTTTTGGTGAAGACC & 87 & 103 & Badejo y col., 2012 \\
\hline SIME & $\begin{array}{l}\text { GDP-D-manosa }-3^{\prime}, 5^{\prime}- \\
\text { epimerasa }\end{array}$ & Solyc09g082990.3 & GAAGCTTCGGGTCTCTATTACAGG & GACATGTGCTCATTCTTCTTCCAG & 83 & 80 & Badejo y col., (2012 \\
\hline SIGGP 2 & $\begin{array}{l}\text { GDP-L-galactosa } \\
\text { fosforilasa } 2\end{array}$ & Solyc02g091510.3 & CAAGCTGTGGTCTTTGGCAG & GCAAGGAGGAGTCTCACCTG & 80 & 89 & Diseño \\
\hline SIGGP 1 & $\begin{array}{l}\text { GDP-L-galactosa } \\
\text { fosforilasa } 1\end{array}$ & Solyc06g073320.3 & GAAATCTGGTCTGTTCCTCTGTGA & TTCACACACCAACTCCACATTACA & 85 & 85 & Diseño \\
\hline SIGLDH & $\begin{array}{l}\text { L-galactona-1,4-lactona } \\
\text { deshidrogenasa }\end{array}$ & solyc10g079470.3 & CGAGTCAGTGGAGGAGCTTG & AATTCACCATCCCAGCTCG & 80 & 81 & Badejo y col.,(2012) \\
\hline SIETR2 & "Ethylene resistant 1" & Solyc07g056580.3 & ACCAGGAACCAGCAACTAAAAA & CGACACCTTCACTTTCAATCC & 100 & 96 & Diseño \\
\hline SIETR3 & $\begin{array}{l}\text { "Ethylene resistant 3/ } \\
\text { NeverRipe" }\end{array}$ & Solyc09g075440.3 & CCTTTGGCAAGGATGAGGAATA & GACAGTTCAGCCCAGTCATTAG & 92 & 84 & Diseño \\
\hline SIGMD & $\begin{array}{l}\text { GDP-manosa 4,6 } \\
\text { dehidratasa }\end{array}$ & Solyc03g118270.1 & AGAGGCATTTGGTTCTGTAGG & GCTCGAATCACCCTTGAGATTA & 85 & 88 & Diseño \\
\hline SIAKR & $\begin{array}{l}\text { Aldo-ceto reductasa } 4 b \\
\text { like }\end{array}$ & solyc09g011240.2 & CTATCAAGATGGGCTACCGGC & AGCTCTCGCCTCTTGACAAC & 83 & 94 & Diseño \\
\hline $\begin{array}{l}\text { SIMDHA } \\
\text { R1 }\end{array}$ & $\begin{array}{l}\text { Monodehidro ascorbato } \\
\text { reductasa } 1\end{array}$ & Solyc08g081530.3 & CAAGGGTTTCGGTTCCTTCT & CTGCATTTCCTCCTCCAACT & 88 & 90 & Mellidouy col., 2012 \\
\hline $\begin{array}{c}\text { SIMDHA } \\
\text { R3 }\end{array}$ & $\begin{array}{l}\text { Monodehidro ascorbato } \\
\text { reductasa } 3\end{array}$ & Solyc02g086710.3 & AGGAATGGAATGTGCTGCTT & GACCGTGCCTTTCACAAACT & 86 & 90 & Mellidou y col., 2012 \\
\hline SIDHAR1 & $\begin{array}{l}\text { Dehidro ascorbato } \\
\text { reductasa } 1\end{array}$ & Solyc05g054760.3 & AGGTGGCTCTTGGACACTTC & CTTCAGCCTTGGTTTTCTGG & 85 & 87 & Mellidou y col., 2012 \\
\hline SIEF1 $\alpha$ & Factor de elongación $\alpha 1$ & Solyc06g005060.3 & TGATCAAGCCTGGTATGGTTGT & CTGGGTCATCCTTGGAGTT & 86 & 92 & Badejo y col., 2012 \\
\hline SIExp & Expresse & Solyc07g025390.2.1 & GCTAAGAACGCTGGACCTAATG & TGGGTGTGCCTTTCTGAATG & 83 & 80 & $\begin{array}{l}\text { González-Aguilera y } \\
\text { col., (2016) }\end{array}$ \\
\hline SIACT 2 & Actina 2 & Solyc11g005330 & GAAATAGCATAAGATGGCAGACG & ATACCCACCATCACACCAGTAT & 102 & 80 & Lovdaly col., 2008 \\
\hline
\end{tabular}

Tesis Doctoral - Lic. Matias Leonel Alegre 
Capítulo IV: Expresión de genes de enzimas clave en la vía de síntesis de ácido ascórbico y de receptores de etileno en plantas deficientes en GDP-LGalactosa fosforilasa.

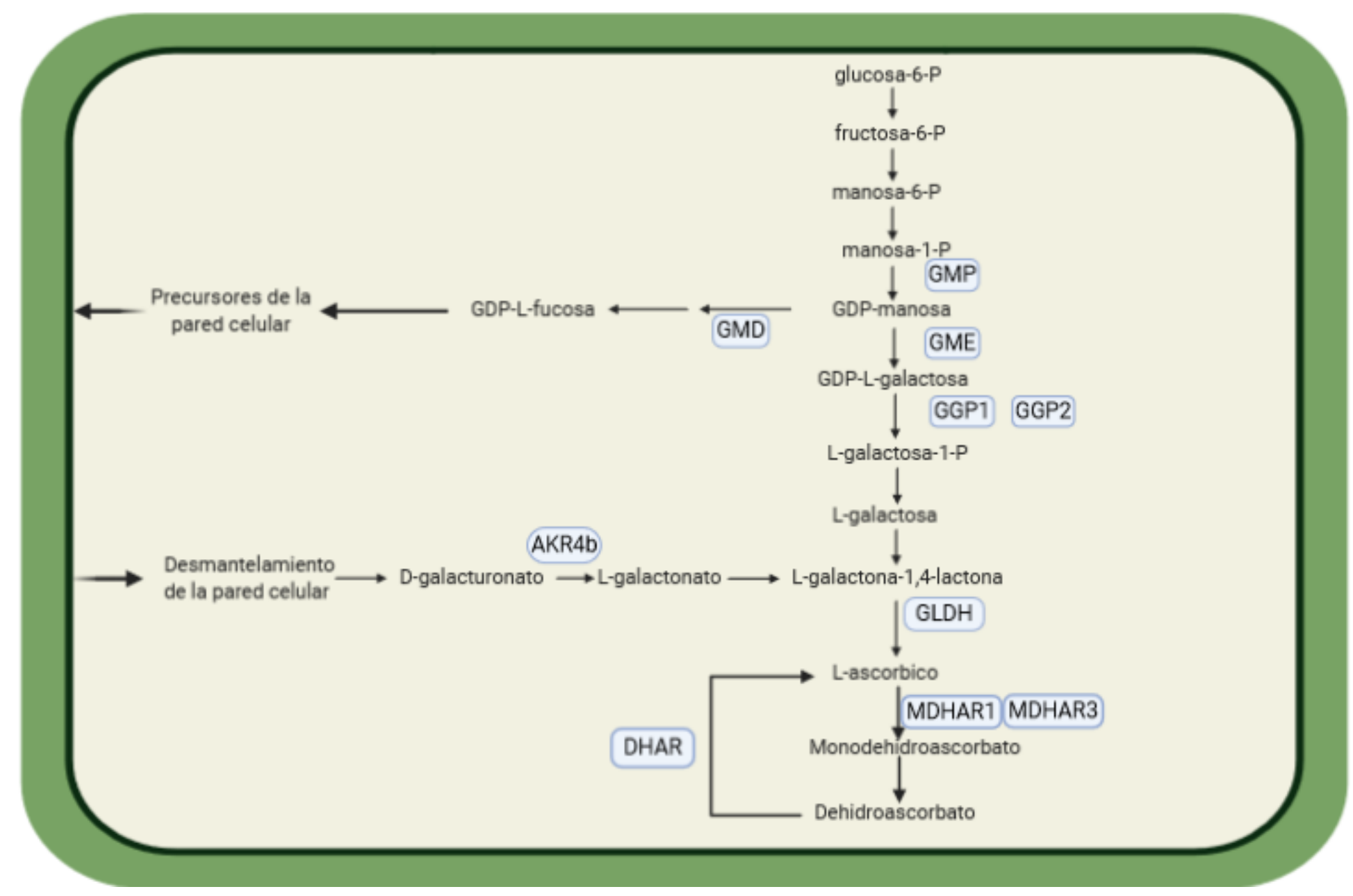

Figura 4. 1-Rutas metabólicas y enzimas evaluadas mediante expresión génica.

GDP-D-manosapirofosforilasa (GMP); GDP-D-manosa -3',5'-epimerasa (GME); GDP-L-galactosa fosforilasa 1 (GGP1); GDP-L-galactosa fosforilasa 2 (GGP2);L-galactona-1,4-lactona deshidrogenasa (GLDH); GDP-manosa 4,6 dehidratasa (GMD); Aldo-ceto reductasa 4b (AKR4b);Monodehidroascorbato reductasa 1 (MDHAR1); Monodehidroascorbato reductasa 3 (MDHAR3); Dehidroascorbato reductasa 1 (DHAR). 
Capítulo IV: Expresión de genes de enzimas clave en la vía de síntesis de ácido ascórbico y de receptores de etileno en plantas deficientes en GDP-L-Galactosa fosforilasa.

\section{$\underline{4.4 \quad \text { Resultados }}$}

\subsubsection{Expresión génica relativa en hojas}

\subsubsection{Expresión relativa de genes que codifican enzimas de la vía de síntesis de ascórbico en hoja.}

Se analizó la expresión de genes de enzimas de la ruta de Smirnoff-Wheeler, que se encuentran aguas arriba (GDP-D-manosapirofosforilasa y GDP-D-manosa-3',5'epimerasa) y aguas abajo (L-galactona-1,4-lactona deshidrogenasa) de la enzima GDP-L-galactosa fosforilasa 1 (Fig. 4.1).Los genes que codifican la enzima GDP-Dmanosapirofosforilasa (SIGMP) y la enzima GDP-D-manosa-3',5'-epimerasa (SIGME) presentaron una mayor expresión en los mutantes GGP-5261 yGGP-49C12 con respecto al genotipo silvestre (Fig. 4.2). Por otro lado el gen que codifica la enzima GDP-L-galactosa fosforilasa 1 (SIGGP1), enzima que se encuentra mutada en los genotipos GGP-49C12 y GGP-5261, presentó una drástica reducción (95 y 88 \% respectivamente) de su expresión con respecto al genotipo silvestre.

En cambio la expresión del gen que codifica la isoenzima GDP-L-galactosa fosforilasa 2 (SIGGP2) fue considerablemente mayor en los mutantes GGP-49C12 y GGP-5261 con respecto a su expresión en el genotipo silvestre (Fig. 4.2). Se analizó también la expresión del gen que codifica la enzima L-galactona-1,4-lactona deshidrogenasa (SLGLDH), pero no se observaron diferencias en la expresión de este gen en los genotipos mutantes slggp1 con respecto a la expresión observada en el genotipo silvestre (Fig. 4.2). 
Capítulo IV: Expresión de genes de enzimas clave en la vía de síntesis de ácido ascórbico y de receptores de etileno en plantas deficientes en GDP-L-Galactosa fosforilasa.

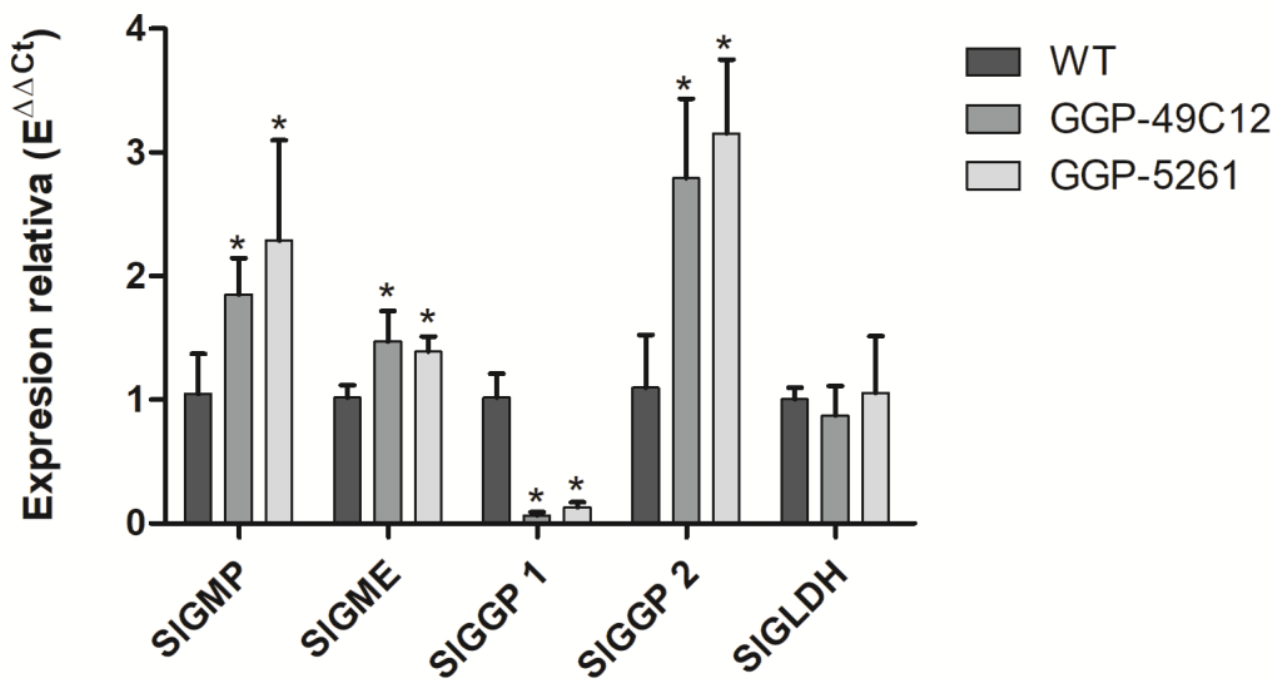

Figura 4. 2-Análisis de la expresión de los genes SIGMP, SIGME, SIGGP1, SIGGP2, SIGLDH. Genes que codifican las enzimas: GDP-D-manosapirofosforilasa (SIGMP), GDP-D-manosa 3',5'-epimerasa (SIGME), GDP-L-galactosa fosforilasa 1(SIGGP1), GDP-L-galactosa fosforilasa 2 (SIGGP2) y L-galactona-1,4-lactona deshidrogenasa (SIGLDH) en hojas de los mutantes GGP-49C12 y GGP-5261. La expresión en cada genotipo mutante slggp1 es relativa a la expresión observada en el genotipo silvestre (WT). Las medias \pm SD fueron analizadas mediante una Prueba $t$ de Student $(p<0,05)$. Los asteriscos indican diferencias significativas de la expresión de cada mutante con respecto al genotipo silvestre.

\subsubsection{Expresión relativa de genes que codifican enzimas de la vía de síntesis y degradación de componentes de pared celular en hoja.}

Se analizó la expresión del gen que codifica la enzima GDP-D-manosa-4,6 deshidratasa (SLGMD), la cual cataliza el primero de tres pasos en la vía de síntesis de fucosa a partir de GDP-D-manosa. Ambos mutantes slggp1 presentaron una mayor expresión de este gen en sus hojas con respecto al genotipo silvestre.

Se analizó la expresión del gen que codifica la enzima aldo-ceto reductasa 4B (SIAKR4). Esta enzima cataliza la transformación de D-galacturonato en L-galactonato en la vía de degradación de pectinas. No se observaron diferencias en la expresión relativa de este gen en hojas entre los mutantes slggp1 y el genotipo silvestre (Fig. 4.3). 
Capítulo IV: Expresión de genes de enzimas clave en la vía de síntesis de ácido ascórbico y de receptores de etileno en plantas deficientes en GDP-L-Galactosa fosforilasa.

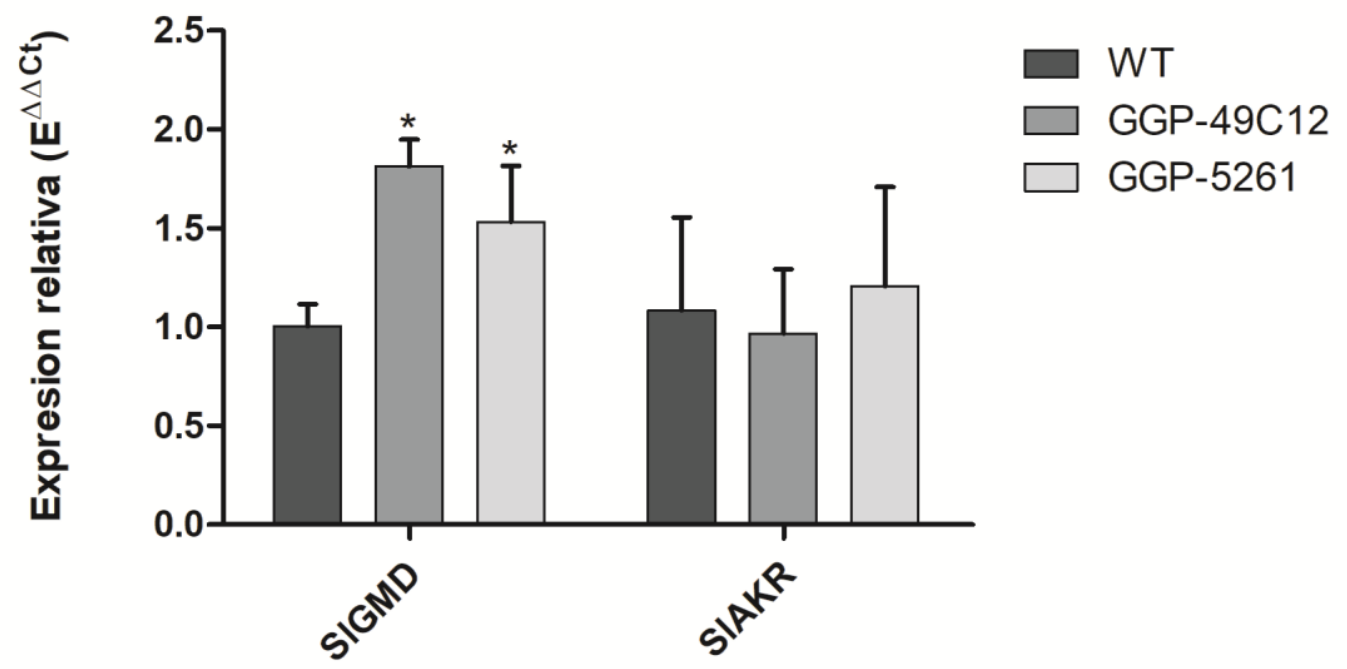

Figura 4. 3-Análisis de la expresión de los genes SIGMD, SIAKR.

Genes que codifican las enzimas: GDP-manosa 4,6 deshidratasa (SIGMD) y aldo-ceto reductasa 4B (SIAKR) en hojas de los mutantes GGP49C12 y GGP5261, relativa a la expresión en las hojas del genotipo silvestre (WT). Las medias \pm SD fueron analizadas mediante una Prueba $t$ de Student $(p<0,05)$.Los asteriscos indican diferencias significativas de la expresión de cada mutante con respecto al genotipo silvestre.

\subsubsection{Expresión relativa de genes que codifican enzimas de las rutas del reciclado del ácido ascórbico en hoja.}

La enzima monodehidro ascorbato reductasa (MDHAR) cataliza la regeneración del ácido ascórbico a partir de sus formas oxidadas utilizando electrones aportados por el NADPH en el ciclo ascorbato-glutatión (Foyer y Noctor, 2011). Se analizó la expresión de los genes que codifican dos isoenzimas de la MDHAR y se observó una mayor expresión del gen SIMDHAR1 en las hojas de los genotipos mutantes slggp1 con respecto a la expresión observada en las hojas del genotipo silvestre, mientras que el gen SIMDHAR3 no presentó una expresión diferencial entre los genotipos mutantes slggp1 y el genotipo silvestre (Fig. 4.4). 
Capítulo IV: Expresión de genes de enzimas clave en la vía de síntesis de ácido ascórbico y de receptores de etileno en plantas deficientes en GDP-L-Galactosa fosforilasa.

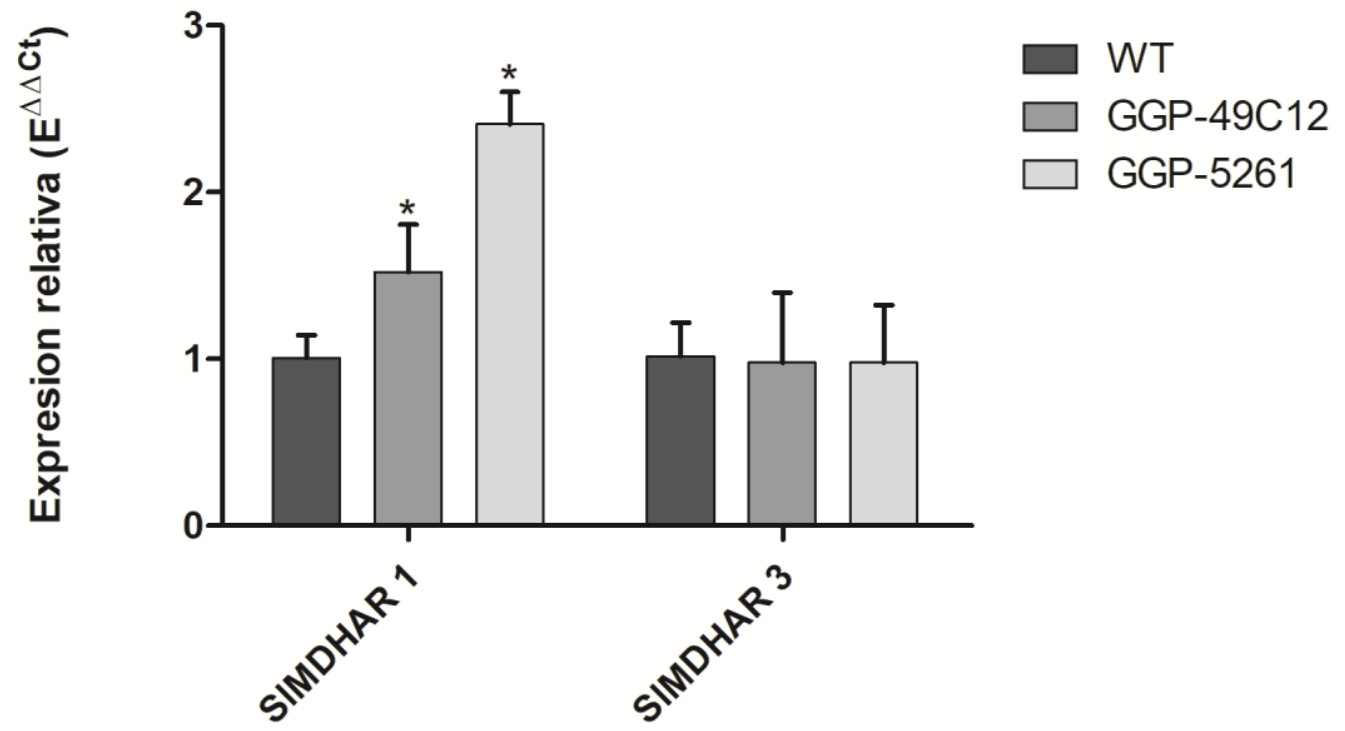

Figura 4. 4-Análisis de la expresión de los genes SIMDHAR1, SIMDHAR3.

Genes que codifican las enzimas: monodehidroascorbato reductasa 1 y 3 (SIMDHAR1, SIMDHAR3) en hojas de los mutantes GGP49C12 y GGP5261, relativa a la expresión en las hojas del genotipo silvestre (WT). Las medias \pm SD fueron analizadas mediante una Prueba $t$ de Student $(p<0,05)$. Los asteriscos indican diferencias significativas de la expresión de cada mutante con respecto al genotipo silvestre.

\subsubsection{Expresión relativa de genes que codifican receptores de etileno en} hoja.

Dada la importancia de esta hormona en los tejidos vegetales y considerando que los mutantes deficientes en GDP-L-galactosa fosforilasa 1 presentan una mayor producción de etileno en frutos, se midió la expresión de genes que codifican los receptores de etileno SIETR2 y SIETR3 en hojas de los mutantes slggp1 y el genotipo silvestre.

Se observó una mayor expresión del gen SIETR2 en las hojas del mutante GGP-5261 con respecto al genotipo silvestre, mientras que el mutante GGP-49C12 no presentó diferencias significativas en la expresión de este gen con respecto al genotipo silvestre (Fig. 4.5). Por otro lado ambos mutantes slggp1 presentaron en sus hojas una mayor expresión del gen SIETR3 con respecto a la expresión observada en las hojas del genotipo silvestre (Fig. 4.5). 
Capítulo IV: Expresión de genes de enzimas clave en la vía de síntesis de ácido ascórbico y de receptores de etileno en plantas deficientes en GDP-L-Galactosa fosforilasa.

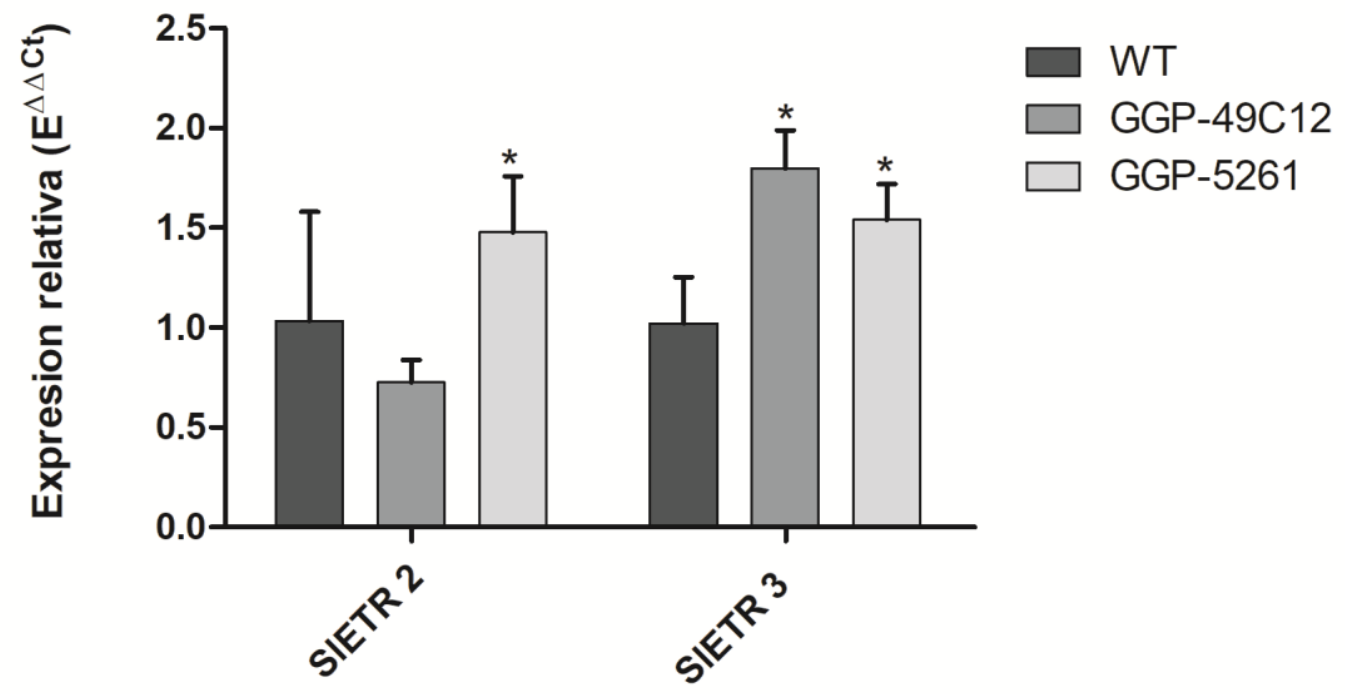

Figura 4. 5-Análisis de la expresión de los genes SIETR2 y SIETR3.

Genes que codifican los receptores de etileno SIETR2 y SIETR3 en hojas de los mutantes GGP-49C12 y GGP-5261, relativa a la expresión en las hojas del genotipo silvestre (WT). Las medias \pm SD fueron analizadas mediante una Prueba $t$ de Student $(p<0,05)$. Los asteriscos indican diferencias significativas de la expresión de cada mutante con respecto al genotipo silvestre.

\subsubsection{Expresión génica relativa en frutos}

El análisis de la expresión de genes en frutos se llevó a cabo en los estadios de maduración verde maduro $(\mathrm{VM})$ pintón $(\mathrm{P})$ y rojo $(\mathrm{R})$, en frutos de los dos genotipos mutantes slggp1 y en el genotipo silvestre. Los niveles de expresión a lo largo de la maduración y en los genotipos mutantes slggp1 fueron relativizados al nivel de expresión promedio de la serie de tres muestras biológicas correspondientes a los frutos del genotipo silvestre en estado de maduración VM.

\subsubsection{Expresión de genes que codifican enzimas de la vía de síntesis de ácido ascórbico en frutos.}

La expresión del gen que codifica la enzima GDP-D-manosa pirofosforilasa (SIGMP) presentó un aumento a la largo de la maduración de los frutos, tanto en el genotipo silvestre como en los genotipos mutantes slggp1. En el mutante GGP-49C12 se observa un gran aumento de la expresión en los frutos en estado pintón mientras que en el genotipo GGP-5261 el aumento de la expresión se observa más tardíamente, en 
Capítulo IV: Expresión de genes de enzimas clave en la vía de síntesis de ácido ascórbico y de receptores de etileno en plantas deficientes en GDP-L-Galactosa fosforilasa.

el estado de maduración rojo. Mientras que en el genotipo silvestre se observa un aumento de la expresión en el estadio pintón que se mantiene al mismo nivel en el estadio rojo. Al comparar estadísticamente los niveles de expresión de GDP-D-manosa pirofosforilasa en el estado de maduración verde maduro, no se observan diferencias entre los mutantes slggp1 y el genotipo silvestre. Sin embargo en el estado de maduración pintón el genotipo GGP-49C12 presenta una mayor expresión de GDP-Dmanosa pirofosforilasa que el genotipo silvestre y en el estado de maduración rojo ambos genotipos mutantes slggp1 presentan una mayor expresión de este gen que el genotipo silvestre (Fig. 4.6 a).

También se analizó la expresión del gen que codifica la enzima GDP-D-manosa-3',5'epimerasa (SIGME). En este caso se observaron tendencias distintas entre los mutantes slggp1 y el genotipo silvestre. En el genotipo silvestre la expresión de la GDP-D-manosa-3',5'-epimerasa disminuye a lo largo de la maduración. Sin embargo en los mutantes slggp1 los niveles de expresión presentaron un pico en el estadio pintón y luego una disminución de la expresión en el estadio rojo (Fig. 4.6 b). Al comparar estadísticamente los niveles de expresión del gen que codifica la enzima GDP-D-manosa-3',5'-epimerasa en el estado de maduración verde maduro se observó una menor expresión del gen en los genotipos mutantes slggp1 con respecto al genotipo silvestre. En cambio el genotipo mutante GGP-49C12 presenta un mayor nivel de expresión de este gen en el estado de maduración pintón que el genotipo silvestre, y el mutante GGP-5261 presenta una tendencia similar. Por último en el estado de maduración rojo el nivel de expresión de este gen es mayor en el mutante GGP-49C12, con respecto al genotipo silvestre, mientras que el mutante GGP-5261 no presentó diferencias significativas (Fig. 4.6 b). 
Capítulo IV: Expresión de genes de enzimas clave en la vía de síntesis de ácido ascórbico y de receptores de etileno en plantas deficientes en GDP-L-Galactosa fosforilasa.

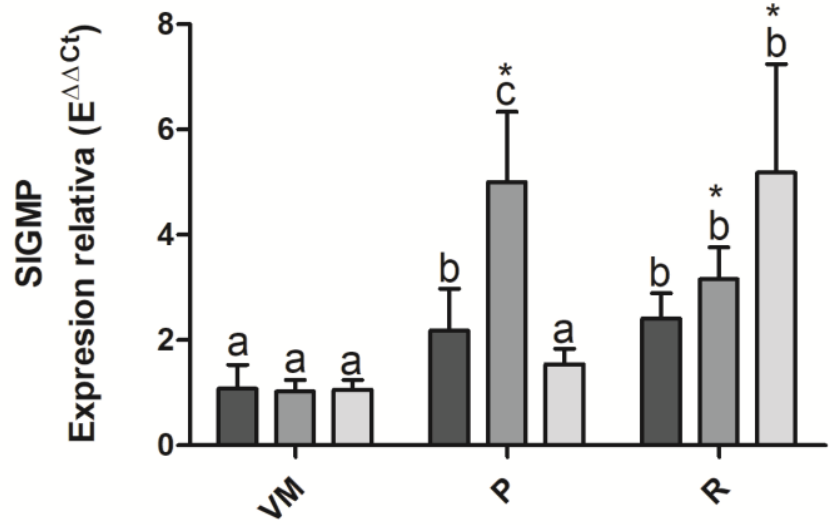

a

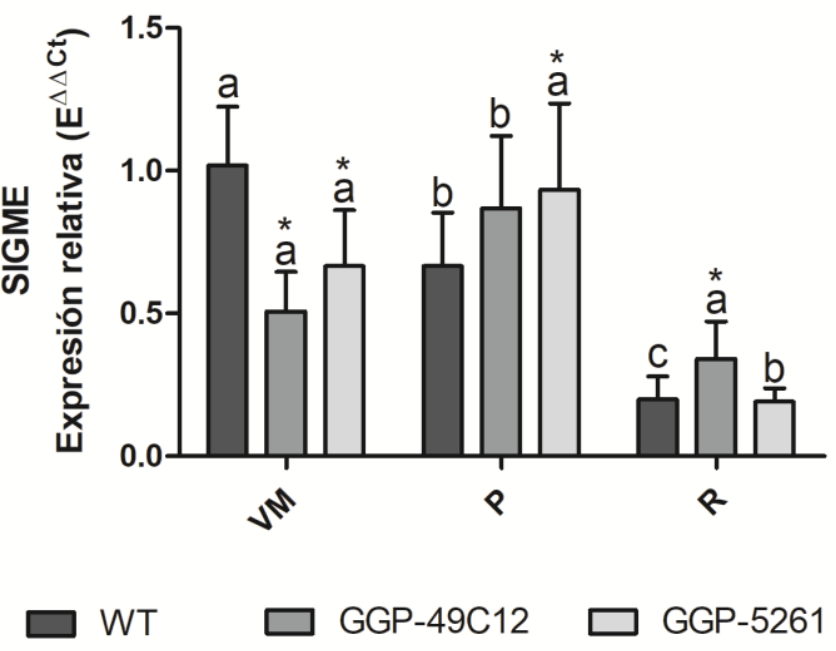

Figura 4. 6-Análisis de la expresión de los genes SIGMP, SIGME.

Genes que codifican las enzimas: a) GDP-D-manosa pirofosforilasa (SIGMP) y b) GDP-Dmanosa-3',5'-epimerasa ( $S / G M E)$, en frutos en estado de maduración verde maduro (VM), pintón $(\mathrm{P})$ y rojo $(\mathrm{R})$, de los mutantes GGP-49C12 y GGP-5261 y del genotipo silvestre. La expresión es relativa a la del genotipo silvestre en estado de maduración VM. Letras distintas indican diferencias significativas entre estados de maduración para cada genotipo (ANOVA, test de Tukey $p<0,05$ ). Los asteriscos indican diferencias significativas de la expresión de cada mutante con respecto al genotipo silvestre en el mismo estado de maduración (Prueba $t$ de Student; $p<0,05)$.

La expresión del gen (S/GGP1) presentó un menor nivel en los frutos de los genotipos mutantes slggp1 en todos los estados de maduración en comparación con el nivel de expresión del genotipo silvestre. A lo largo de la maduración, el nivel de expresión de este gen presentó un aumento en el estado de maduración pintón con respecto al estado de maduración verde maduro y el estado de maduración rojo. Esta tendencia fue observada en el genotipo mutante GGP-49C12 y el genotipo silvestre, sin embargo 
Capítulo IV: Expresión de genes de enzimas clave en la vía de síntesis de ácido ascórbico y de receptores de etileno en plantas deficientes en GDP-L-Galactosa fosforilasa.

el genotipo mutante GGP-5261 no presentó diferencias en la expresión del gen SIGGP1 a lo largo de la maduración (Fig. 4.7. a).

La expresión del gen SIGGP2 presentó una tendencia similar a la observada en la expresión del gen que codifica la enzima GDP-L-galactosa fosforilasa 1. En el estado de maduración verde maduro, el genotipo mutante GGP-5261 presentó un menor nivel de expresión del gen SIGGP2 que el genotipo silvestre, mientras que el genotipo GGP49C12 no presentó diferencias significativas en nivel de expresión de este gen con respecto al genotipo silvestre. Se observó un aumento del nivel de expresión en el estado de maduración pintón con respecto al estado de maduración verde maduro y una caída de la expresión en el estado de maduración rojo con respecto al estado de maduración pintón. En este estado de maduración los frutos del genotipo GGP-49C12 presentaron un mayor nivel de expresión de este gen que los frutos del genotipo silvestre. En los frutos en estado de maduración rojo, se observó un mayor nivel de expresión de este gen en los genotipos mutantes slggp1 con respecto al genotipo silvestre (Fig. 4.7 b).

Por último se analizó la expresión en los frutos del gen que codifica la enzima Lgalactona-1,4-lactona deshidrogenasa (S/GLDH). A lo largo de la maduración se observó una disminución de los niveles de expresión de SIGLDH, tanto en el genotipo mutante GGP-5261 como en el genotipo silvestre, mientras que el nivel de expresión de este gen se mantuvo constante a lo largo de la maduración de los frutos del genotipo mutante GGP-5261. El mutante GGP-49C12 presentó un mayor nivel de expresión de SIGLDH que el genotipo silvestre en los frutos rojos, pero no presentó diferencias en la expresión de este gen en los estadios verde maduro y pintón. El mutante GGP-5261 no presentó diferencias significativas en la expresión de SIGLDH con respecto al genotipo silvestre en ninguno de los estados de maduración (Fig. 4.7 c). 
Capítulo IV: Expresión de genes de enzimas clave en la vía de síntesis de ácido ascórbico y de receptores de etileno en plantas deficientes en GDP-L-Galactosa fosforilasa.

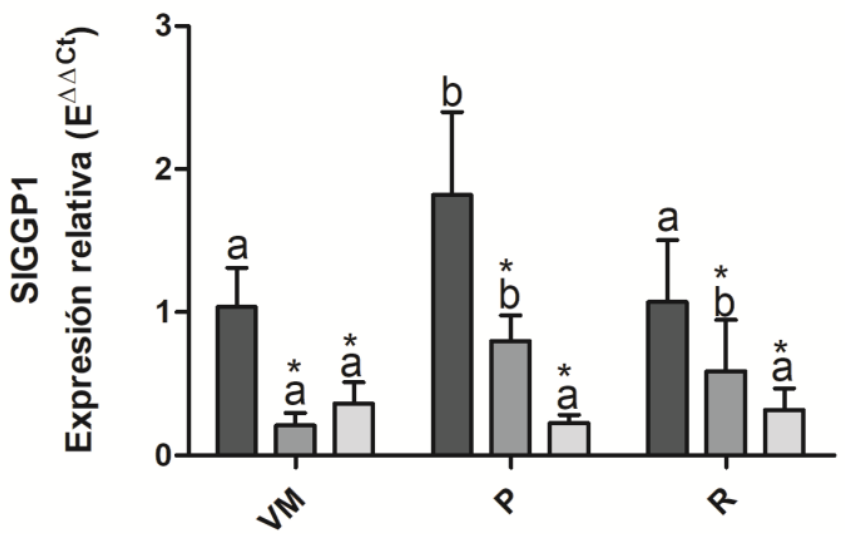

a

b
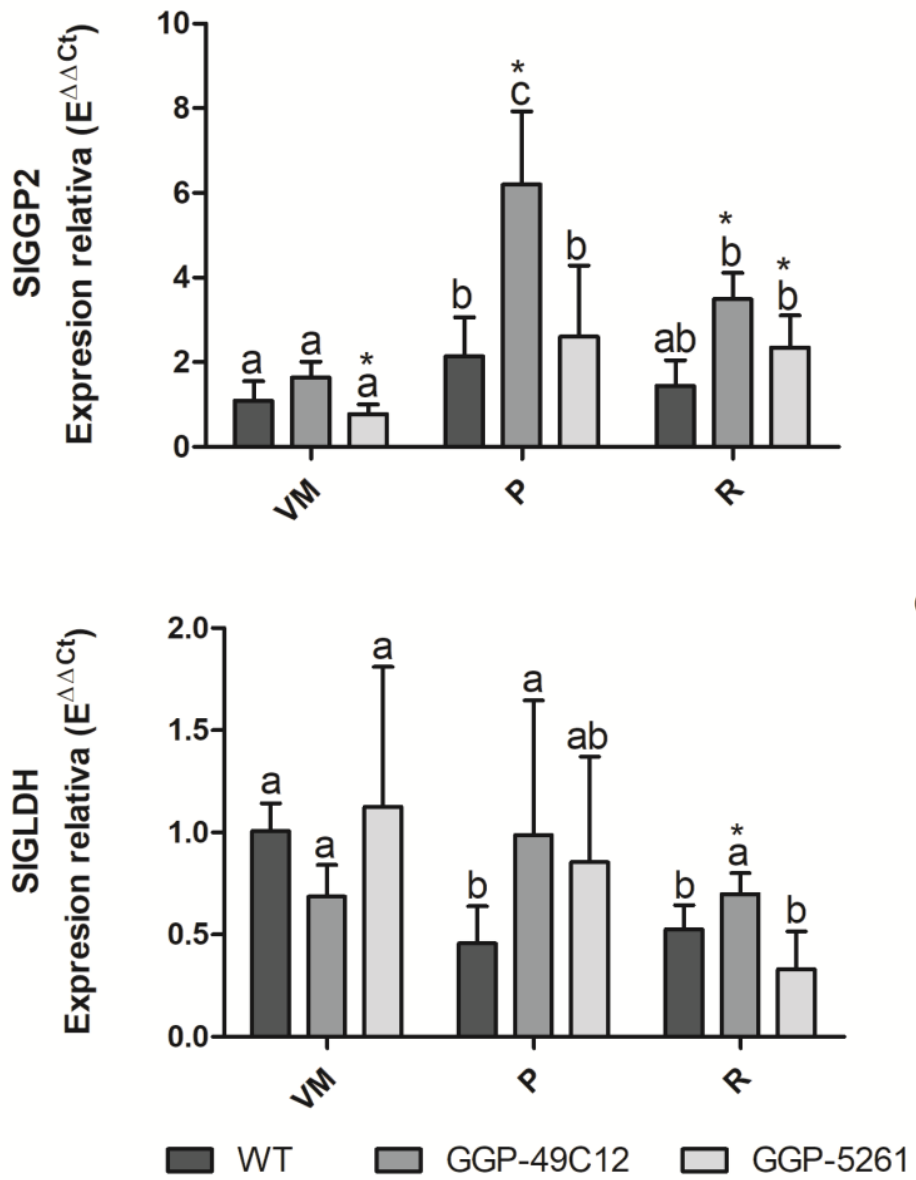

Figura 4. 7-Análisis de la expresión de los genes SIGGP1, SIGGP2, SIGLDH.

Genes que codifican las enzimas: a) GDP-L-galactosa fosforilasa 1 (S/GGP1) y b) GDP-Lgalactosa fosforilasa 2 (S/GGP2) y c) L-galactona-1,4-lactona deshidrogenasa (SIGLDH), en frutos en estado de maduración verde maduro $(V M)$, pintón $(P)$ y rojo $(R)$ de los mutantes GGP. 49C12 y GGP-5261 y del genotipo silvestre. La expresión es relativa a la del genotipo silvestre en estado de maduración VM. Letras distintas indican diferencias significativas entre estados de maduración para cada genotipo (ANOVA, test deTukey $p<0,05$ ). Los asteriscos indican diferencias significativas de la expresión de cada mutante con respecto al genotipo silvestre en el mismo estado de maduración (Prueba t de Student; $p<0,05$ ). 
Capítulo IV: Expresión de genes de enzimas clave en la vía de síntesis de ácido ascórbico y de receptores de etileno en plantas deficientes en GDP-L-Galactosa fosforilasa.

\subsubsection{Expresión de enzimas que participan en vías de síntesis y degradación de pectinas}

Se analizó la expresión en frutos del gen que codifica la enzima GDP-D-manosa-4,6dehidratasa $(S / G M D)$, la cual como se mencionó anteriormente cataliza el paso inicial en la conversión de GDP-D-manosa en GDP-L-fucosa, que es uno de los compuestos precursores en la síntesis de pectinas y hemicelulosa. Al observar la tendencia de la expresión de este gen a lo largo de la maduración se puede ver que en los mutantes slggp1 la expresión aumenta significativamente en el estado de maduración pintón y luego disminuye en el estado de maduración rojo. Por el contrario en el genotipo silvestre la expresión se mantiene constante entre el estado de maduración verde maduro y pintón y se observa una disminución en los niveles de expresión en el estado de maduración rojo. En el estado de maduración verde maduro el nivel de expresión de este gen es menor, en ambos genotipos mutantes slggp1, al observado en el genotipo silvestre. Sin embargo, en el estado de maduración pintón el nivel de expresión de SIGMD fue mayor en los genotipos mutantes slggp1 que en el genotipo silvestre. En el estado de maduración rojo no se observan diferencias en la expresión entre los genotipos mutantes y el genotipo silvestre. (Fig. 4.8. a).

La enzima aldo-ceto reductasa $4 \mathrm{~b}$ de tomate presenta homología de secuencia con la D-galacturononato reductasa de Arabidopsis, la cual participa de la reducción del Dgalacturonato, derivado de la degradación de pectinas, a D-galactonato que posteriormente es lactonizado y transformado enL-galactona-1,4-lactona. Este compuesto es finalmente transformado en ácido ascórbico por acción de la Lgalactona-1,4-lactona deshidrogenasa.

Se analizó la expresión del gen que codifica la enzima aldo-ceto reductasa en tomate $(S I A K R)$ y se observó que los genotipos mutantes slggp1 presentaron un mayor nivel de expresión de este gen en los frutos verde maduro. La expresión de este gen disminuye en estados más avanzados de maduración tanto en el genotipo silvestre 
Capítulo IV: Expresión de genes de enzimas clave en la vía de síntesis de ácido ascórbico y de receptores de etileno en plantas deficientes en GDP-L-Galactosa fosforilasa.

como en el genotipo mutante GGP-5261, el cual presenta un menor nivel de expresión que el genotipo silvestre en el estado de maduración rojo. En cambio en el mutante GGP-49C12 el nivel de expresión de este gen no cambia a lo largo de la maduración (Fig. 4.8 b).

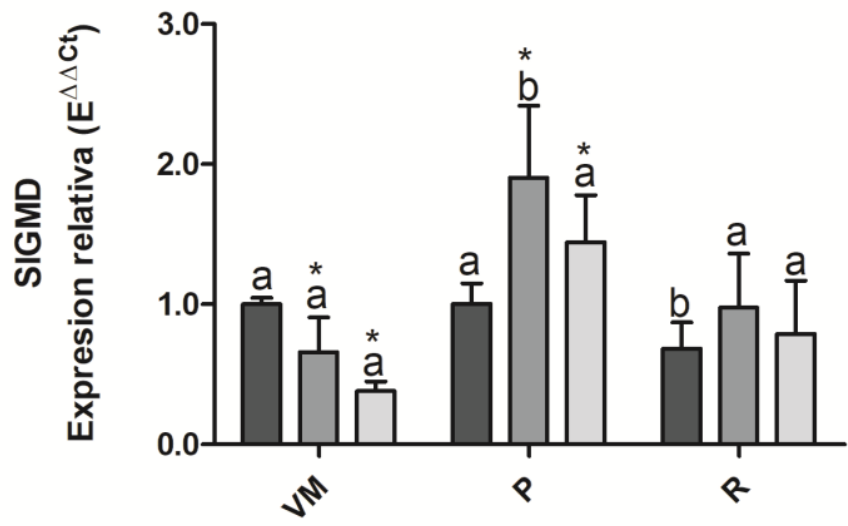

a

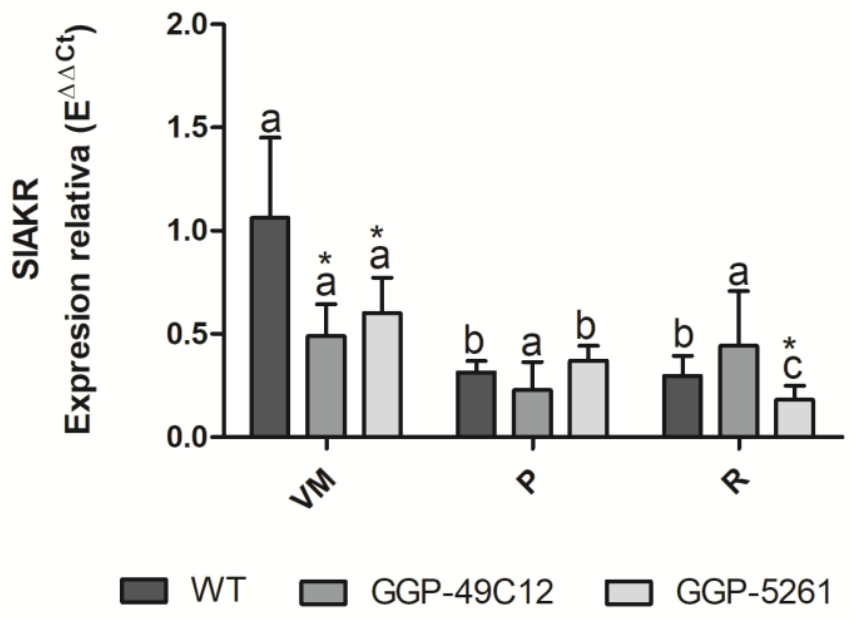

b

Figura 4. 8-Análisis de la expresión de los genes SIGMD, SIAKR.

Genes que codifican las enzimas: a) GDP-manosa 4,6 deshidratasa (SIGMD) y b) Aldo-ceto reductasa 4B (SIAKR) en frutos en estado de maduración verde maduro $(\mathrm{VM})$, pintón $(\mathrm{P})$ y rojo (R) de los mutantes GGP-49C12 y GGP-5261 y del genotipo silvestre. La expresión es relativa a la del genotipo silvestre en estado de maduración VM. Letras distintas indican diferencias significativas entre estados de maduración para cada genotipo (ANOVA, test deTukey $p<0,05$ ). Los asteriscos indican diferencias significativas de la expresión de cada mutante con respecto al genotipo silvestre en el mismo estado de maduración (Prueba t de Student; $p<0,05$ ). 
Capítulo IV: Expresión de genes de enzimas clave en la vía de síntesis de ácido ascórbico y de receptores de etileno en plantas deficientes en GDP-L-Galactosa fosforilasa.

\subsubsection{Expresión génica relativa de enzimas que participan del reciclado del ácido ascórbico}

Se analizó la expresión en frutos de tomate, de genes que codifican enzimas involucradas en el reciclado de las formas oxidadas del ácido ascórbico. La expresión de la monodehidro ascorbato reductasa 1 y 3 (SIMDHAR1 y SIMDHAR3) presentaron tendencias similares en la expresión a lo largo de la maduración de frutos de tomate. La expresión del gen SIMDHAR1 en el estado de maduración verde maduro fue menor en los mutantes que en el genotipo silvestre. En el estado de maduración pintón, la expresión de este gen fue mayor en el mutante GGP-49C12 con respecto al genotipo silvestre y en los frutos rojos la expresión de este gen fue mayor en ambos mutantes slggp1 que en los frutos rojos silvestres (Fig. 4.9 a).

La expresión del gen SIMDHAR3 en el estado de maduración verde maduro fue menor en el genotipo GGP-5261 con respecto a los frutos del genotipo silvestre. En los frutos pintones se observó un aumento de la expresión de este gen en todos los genotipos con respecto al estado de maduración verde maduro y se observó una mayor expresión del gen en el genotipo GGP-49C12 con respecto al genotipo silvestre. Finalmente en los frutos en estado de maduración rojo, se observó una disminución de los niveles de expresión tanto en el genotipo silvestre como en el mutante GGP. 49C12, mientras que el mutante GGP-5261 mantuvo niveles de expresión significativamente mayores al genotipo silvestre (Fig. 4.9. b)

Por último, también se analizó la expresión del gen que codifica la enzima dehidroascorbato reductasa-1 (SIDHAR1). Este gen se expresó a lo largo de la maduración de manera similar a las dos enzimas mencionadas previamente, presentando una tendencia al aumento de los niveles de expresión en el estado de maduración pintón y un descenso de la expresión en el estado de maduración rojo a niveles similares a los observados en los frutos verde maduro. El genotipo mutante GGP-49C12 presentó un mayor nivel de expresión que el genotipo silvestre en frutos pintones y rojos (Fig. 4.9. c). 
Capítulo IV: Expresión de genes de enzimas clave en la vía de síntesis de ácido ascórbico y de receptores de etileno en plantas deficientes en GDP-L-Galactosa fosforilasa.

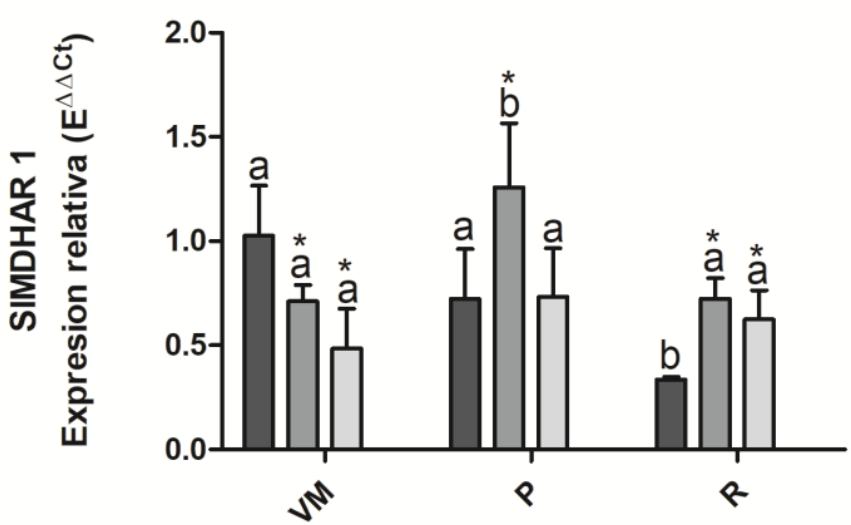

a

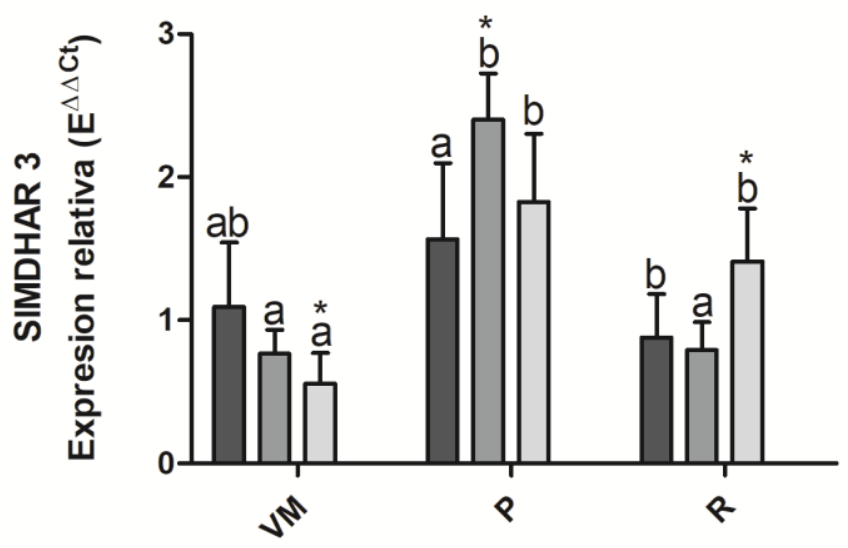

b

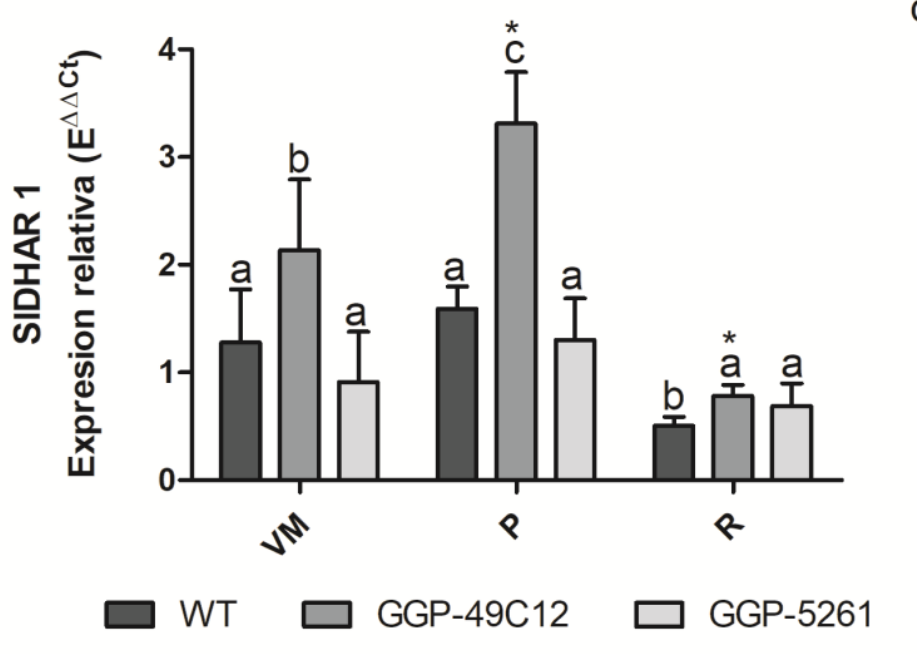

Figura 4. 9-Análisis de la expresión de los genes SIMDHAR1, SIMDHAR3 y SIDHAR1.

Genes que codifican las enzimas: a) Monodehidro ascorbato reductasa 1 (SIMDHAR1), b) Monodehidro ascorbato reductasa 3 (SIMDHAR3) y c) Dehidro ascorbato reductasa 1 (SIDHAR1) en frutos en estado de maduración verde maduro $(\mathrm{VM})$, pintón $(\mathrm{P})$ y rojo $(\mathrm{R})$ de los mutantes GGP-49C12 y GGP-5261 y del genotipo silvestre. La expresión es relativa a la del genotipo silvestre en estado de maduración verde maduro (VM). Letras distintas indican diferencias significativas entre estados de maduración para cada genotipo (ANOVA, test deTukey $\mathrm{p}<0,05)$. Los asteriscos indican diferencias significativas de la expresión de cada mutante con respecto al genotipo silvestre en el mismo estado de maduración (Prueba $t$ de Student; $p<0,05)$. 
Capítulo IV: Expresión de genes de enzimas clave en la vía de síntesis de ácido ascórbico y de receptores de etileno en plantas deficientes en GDP-L-Galactosa fosforilasa.

\subsubsection{Expresión génica relativa de receptores de etileno en frutos}

Se analizó la expresión de genes que codifican los receptores de etileno ETR2 y ETR3 dado que como se mencionó en el capítulo 3 los mutantes deficientes en GDP-Lgalactosa fosforilasa presentan un aumento en la producción de etileno. El nivel de expresión del gen SIETR2 en frutos presentó un aumento en estadios de maduración $\mathrm{P}$ y $\mathrm{R}$ con respecto a los frutos en estado de maduración verde maduro (Fig. 4.10. a). Esta tendencia se observó tanto en los genotipos mutantes slggp1 como en el genotipo silvestre. En el estadio de maduración P, el mutante GGP-49C12 presentó un nivel de expresión del gen SIETR2 significativamente mayor que el genotipo silvestre y se observó una tendencia similar en el mutante GGP-5261 (Fig. 4.10. a). En el estado de maduración $\mathrm{R}$ el mutante GGP-49C12 presentó niveles de expresión de SIETR2 significativamente mayores que el genotipo silvestre, mientras que el mutante GGP5261 no presentó diferencias (Fig. 4.10. a).

Los niveles de expresión del gen SIETR3 en tomates presentaron un aumento en estados de maduración $\mathrm{P}$ y $\mathrm{R}$ con respecto al estado de maduración verde maduro, de manera similar a la tendencia observada en la expresión de SIETR2 (Fig. 4.10 b). Sin embargo, los niveles de expresión de SIETR3 en los tomates de los genotipos mutantes en estado de maduración verde maduro, fueron significativamente menores a los niveles de expresión de este gen en el genotipo silvestre (Fig. 4.10 b). Por otro lado, en los frutos $P$ y $R$ del mutante GGP-49C12 el nivel de expresión de SIETR3 resultó significativamente mayor al nivel de expresión de este gen en el genotipo silvestre. Mientras que el mutante GGP-5261 presentó una tendencia similar a GGP49C12 en los frutos en estado $\mathrm{P}$ pero una reducción del nivel de expresión en el estado de maduración R (Fig. 4.10 b). 
Capítulo IV: Expresión de genes de enzimas clave en la vía de síntesis de ácido ascórbico y de receptores de etileno en plantas deficientes en GDP-L-Galactosa fosforilasa.

a

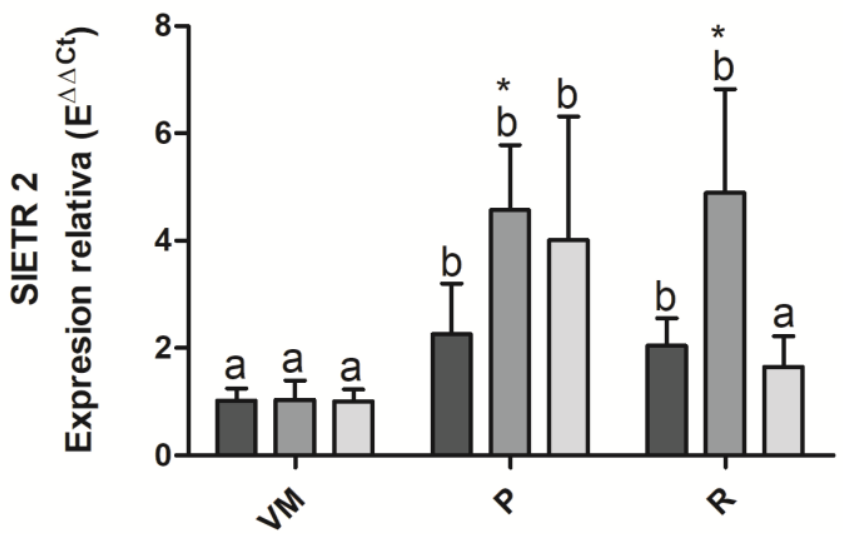

b

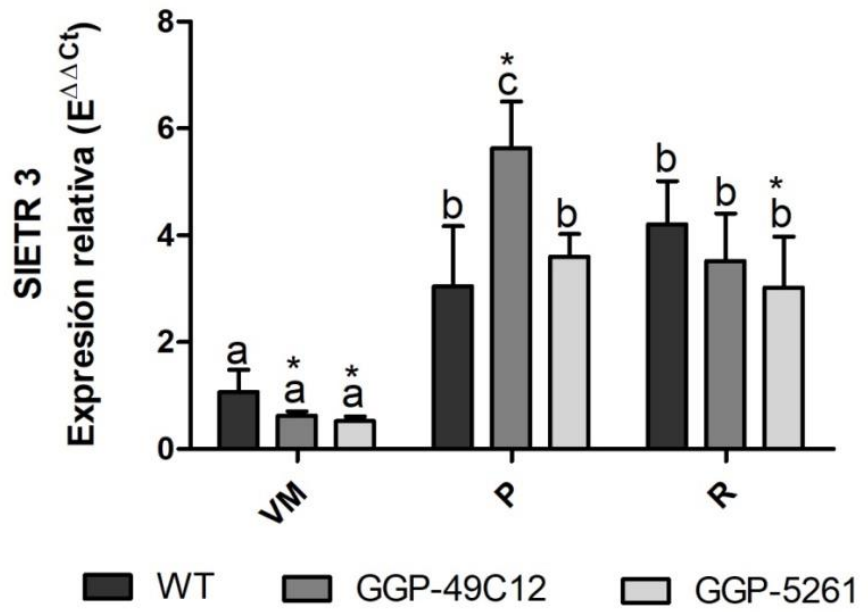

Figura 4. 10-Análisis de la expresión de los genes SIETR2, SIETR3.

Genes que codifican los receptores de etileno :a) SIETR2 ( Ethylene Resistant 2) y b) SIETR3 (Ethylene Resistant 3 ) en frutos en estado de maduración verde maduro (VM), pintón ( $P$ ) y rojo (R) de los mutantes GGP-49C12 y GGP-5261 y del genotipo silvestre. La expresión es relativa a la del genotipo silvestre en estado de maduración verde maduro (VM). Letras distintas indican diferencias significativas entre estados de maduración para cada genotipo (ANOVA, test deTukey $\mathrm{p}<0,05)$. Los asteriscos indican diferencias significativas de la expresión de cada mutante con respecto al genotipo silvestre en el mismo estado de maduración (Prueba t de Student; $p<0,05)$. 
Capítulo IV: Expresión de genes de enzimas clave en la vía de síntesis de ácido ascórbico y de receptores de etileno en plantas deficientes en GDP-L-Galactosa fosforilasa.

\section{$\underline{4.5 \quad \text { Discusión }}$}

Este capítulo se enfocó en estudiar el efecto de la deficiencia en GDP-L-galactosa fosforilasa, sobre los niveles de expresión de algunos genes en hojas completamente expandidas y frutos de tomate en distintos estadios de madurez. Se analizó la expresión de genes de la ruta principal de síntesis de ascórbico en plantas y de enzimas que participan en el reciclado del ácido ascórbico oxidado. También se analizaron los niveles de expresión de genes que codifican enzimas que participan en rutas de degradación o síntesis de compuestos de pared celular, ya que estas rutas comparten intermediarios con la ruta de síntesis de ácido ascórbico. Además se analizó la expresión de genes que codifican para la síntesis de receptores de etileno.

Los genotipos mutantes slggp1 presentaron una mayor expresión de los genes SIGMP y SIGME, tanto en las hojas como en los frutos en estadios pintón y rojo, con respecto al genotipo silvestre (Fig.4.2). De la misma manera en hojas de plantas de tomate transgénicas con un silenciamiento antisentido de la enzima GDP-L-galactosa fosforilasa, se observó una mayor expresión de SIGMP, SIGME y otros genes que codifican enzimas aguas arriba de la GDP-L-galactosa fosforilasa en la ruta de Smirnoff-Wheeler (Wang y col., 2013). Esto sugiere una acumulación de los metabolitos que están aguas arriba de la enzima mutada.

En coincidencia con ello, SIGMD también presentó un aumento de expresión. Este gen codifica la enzima GDP-D-manosa-4,6-deshidratasa, la cual cataliza el primer paso de la transformación de GDP-D-manosa en GDP-D-fucosa, un monosacárido que sirve como sustrato para la síntesis de glicoproteínas (Bonin y col., 1997; Conklin y col., 1999).

La GDP-D-manosa, además, es el monosacárido utilizado en la síntesis de polímeros de hemicelulosa (Bewley y col., 1997). Como se mencionó en la introducción de este capítulo, los mutantes cyt-1 de Arabidopsis, deficientes en GDP-D-manosa 
Capítulo IV: Expresión de genes de enzimas clave en la vía de síntesis de ácido ascórbico y de receptores de etileno en plantas deficientes en GDP-L-Galactosa fosforilasa.

pirofosforilasa (SIGMP), presentan alteraciones en la composición de la pared celular como consecuencia de la deficiencia de precursores para su síntesis (Lukowitz y col., 2001).

Por otro lado, en plantas de tomate transgénicas que presentan un silenciamiento de SIGME mediante ARN de interferencia $\left(A R N_{i}\right)$ se observó una disminución del contenido de ácido ascórbico pero también efectos sobre el crecimiento como una mayor fragilidad de las hojas y menor firmeza en los frutos (Gilbert y col., 2009). Estos autores analizaron la composición de paredes celulares de hojas y de frutos en desarrollo de las líneas transgénicas. Observaron principalmente una alteración del contenido de aquellos monosacáridos que son producto de la actividad enzimática de GDP-D-manosa-3',5'-epimerasa, como la D-manosa y la L-galactosa.

Estos antecedentes en conjunto, muestran que la deficiencia de enzimas que se encuentran aguas arriba de la enzima GDP-L-galactosa fosforilasa, afecta el contenido de ácido ascórbico y además produce alteraciones del desarrollo de la pared celular como consecuencia de una disminución de los metabolitos que son sustrato para sus síntesis.

Esto sugiere que la mayor expresión observada de SIGMP, SIGME y SIGMD en estos resultados, podría tener relación con la mayor firmeza que presentan los frutos de los mutantes slggp1 al final de la maduración en planta (Capítulo III, fig. 3.8). Futuros experimentos serán necesarios para confirmar estos resultados y cuantificar los diferentes componentes que se sintetizan a nivel de pared celular en estos mutantes.

Por otro lado, la enzima GDP-D-manosa-3',5'-epimerasa también cataliza la formación de GDP-L-gulosa a partir de GDP-D-manosa. Este es el primer intermediario de la ruta de la gulosa (Figura 2, Introducción general), una ruta de síntesis de ácido ascórbico alternativa a la ruta de Smirnoff-Wheleer (Wolucka y Van Montagu, 2003). Esto sugiere que los metabolitos como la GDP-D-manosa, acumulado aguas arriba de la enzima 
Capítulo IV: Expresión de genes de enzimas clave en la vía de síntesis de ácido ascórbico y de receptores de etileno en plantas deficientes en GDP-L-Galactosa fosforilasa.

mutada, pueden ser derivados a la ruta de la gulosa. Esta ruta alternativa podría contribuir al contenido de ascórbico final de los frutos y las hojas de los mutantes slggp1. Sin embargo los doble mutantes vtc2/vtc5 de Arabidopsis no son viables indicando que al menos en hojas esta contribución no sería relevante (Dowdle y col. 2007; Lim y col., 2016).

En estos mutantes la expresión de SIGGP1, fue significativamente menor con respecto el genotipo silvestre, tanto en hojas como en frutos en todos los estadios de maduración observados (Fig. 4.7 a). En el genotipo silvestre el nivel de expresión de este gen a lo largo de la maduración, presentó un aumento en el estadio de maduración pintón (Fig. 4.7 a). En estudios realizados por Badejo y col., (2012), se observó una leve disminución de la expresión de GDP-L-galactosa fosforilasa a lo largo de la maduración de frutos de tomate. Sin embargo, también se observó un aumento del contenido de ácido ascórbico ante la suplementación con L-galactosa exógena a través del pedúnculo de los frutos, indicando que la actividad de esta vía de síntesis se estimula en frutos de estadios avanzados de maduración (Badejo y col., 2012). Este resultado indicaría que la ruta de Smirnoff-Weeler está activa en el genotipo silvestre durante la maduración de los frutos y contribuye al contenido final de ascórbico en éstos. Además, la gran disminución de la expresión de SIGGP1 en los genotipos mutantes sugiere que los niveles de ácido ascórbico observados tanto en hojas como en los frutos se deben a la actividad de rutas de síntesis alternativas o a la expresión de SIGGP2.

Según los estudios realizados en Arabidopsis por Dowdle y col., (2007), la isoenzima GDP-L-galactosa fosforilasa 2 tiene menor afinidad por la GDP-L-galactosa y un nivel de expresión de 100 a 1000 veces más bajo en hojas que la isoenzima GDP-Lgalactosa fosforilasa 1. La mayor expresión de SIGGP2 en hojas y frutos de los genotipos mutantes slggp1 (Fig. 4.2 y 4.7 b) con respecto al genotipo silvestre, indica una compensación y aumento de la actividad de la isoenzima GDP-L-galactosa 
Capítulo IV: Expresión de genes de enzimas clave en la vía de síntesis de ácido ascórbico y de receptores de etileno en plantas deficientes en GDP-L-Galactosa fosforilasa.

fosforilasa 2 como consecuencia de la menor contribución de la isoenzima GDP-Lgalactosa fosforilasa 1. Esto indica que la actividad de esta isoenzima contribuye al nivel de ácido ascórbico observado en hojas y frutos de los mutantes slggp1.

En contraste con el mayor nivel de expresión observado en los genes SIGMP y SIGME, no se observó un efecto de la mutación sobre SLGGP1, en la expresión del gen que codifica la enzima L-galactona-1,4-lactona deshidrogenasa (SIGLDH) en hojas y frutos de los genotipos mutantes slggp1 con respecto al genotipo silvestre (Fig. 4.2 y 4.7 c). De la misma manera, en plantas transgénicas de tomate con un silenciamiento de la GDP-L-galactosa fosforilasa mediante $\mathrm{ARN}_{i}$, tampoco se observó una mayor expresión de SIGLDH (Wang y col., 2013). Esto indicaría que la deficiencia de GDP-Lgalactosa fosforilasa tiene como consecuencia una regulación distinta de los genes que codifican enzimas que actúan aguas arriba y aguas debajo de esta enzima mutada (Fig. 4.1).

A partir del silenciamiento en tomate del gen $S / G L D H$ mediante $A R N_{i}$ realizado por Alhagdow y col., (2007), no se observaron cambios en los niveles de ácido ascórbico indicando que esta enzima se encuentra en exceso y que niveles residuales de actividad son suficientes para mantener el pool de ascórbico inalterado. Como se mencionó en la introducción, esta enzima se encuentra en la membrana interna mitocondrial donde participa del ensamblaje del complejo 1 y del transporte electrónico en la cadena transportadora de electrones mitocondrial (Bartoli y col., 2000; Schimmeyer y col., 2016).

Por otro lado, se evaluó el nivel de expresión relativa del gen SIAKR que codifica la enzima D-galacturonato reductasa. La cual cataliza la conversión de D-galacturonato en L-galactonato, que luego se transforma en L-galactona-1,4-lactona, el último intermediario de la ruta principal de síntesis de ácido ascórbico en plantas. Suekawa y col. (2016) evaluaron la expresión de AKR en hojas de tomate y encontraron una mayor expresión en hojas senescentes que en hojas jóvenes. También evaluaron la 
Capítulo IV: Expresión de genes de enzimas clave en la vía de síntesis de ácido ascórbico y de receptores de etileno en plantas deficientes en GDP-L-Galactosa fosforilasa.

expresión de esta enzima en frutos de tomate en distintos estados de maduración y observaron una mayor expresión en frutos naranjas y rojos mientras que los frutos verde inmaduro no presentaron expresión de este gen.

Resultados similares fueron obtenidos por Badejo y col. (2012). Estos autores realizaron aplicaciones exógenas de D-galacturonato sobre pedúnculos de frutos en distintos estados de maduración y observaron una mayor actividad de la enzima Dgalacturonato reductasa (SIAKR) en tomates en estadio de maduración rojo.

En los experimentos realizados en esta tesis, la expresión de SIAKR no aumentó con el progreso de la maduración de los frutos en ninguno de los genotipos, esto sugiere que la actividad de esta vía alternativa no contribuye a los niveles de ascórbico observados al final de la maduración. En coincidencia con esto, no se observaron diferencias en el contenido de ácido ascórbico en frutos en distintos estadios de maduración en ningún genotipo (Fig. 1.9 d)

Por otro lado, la expresión de SIAKR en hojas y en frutos, no resultó diferente entre los genotipos mutantes slggp1 y el genotipo silvestre (Fig. 4.3). Estos resultados sugieren que la vía de síntesis de ácido ascórbico del D-galacturonato no aumenta su actividad en compensación, ante la desarticulación de la vía de Smirnoff-Wheeler como consecuencia de la mutación sobre GDP-L-galactosa fosforilasa.

Sin embargo, se ha reportado que la expresión de dos genes ortólogos que codifican las enzimas monodehidro ascorbato reductasa (MDHAR), presentan un aumento de su expresión durante la maduración de frutos de tomate, que se correlaciona positivamente con el contenido de ascórbico (Mellidou y col., 2012). Observaciones similares fueron realizadas por Eltelib y col. (2011) en frutos de acerola (Malpighia glabra). Estos autores observaron un aumento gradual de las actividades enzimáticas de MDHAR y DHAR hasta alcanzar estadios intermedios de maduración, y un descenso de la actividad de estas enzimas en estadios tardíos de madurez. Por otro 
Capítulo IV: Expresión de genes de enzimas clave en la vía de síntesis de ácido ascórbico y de receptores de etileno en plantas deficientes en GDP-L-Galactosa fosforilasa.

lado la sobreexpresión transciente en plantas de tabaco del gen SIMDHAR de acerola, generó un aumento del contenido de ácido ascórbico en estas plantas y una resistencia aumentada al estrés salino (Eltelib y col., 2011).

El análisis de la expresión de genes que codifican enzimas del reciclado de las formas oxidadas de ácido ascórbico mostró que los mutantes slggp1 presentan una mayor expresión de estas enzimas en hojas y frutos (Fig. 4.4 y 4.9). Esto sugiere una mayor contribución de estas enzimas en los mutantes slggp1 al contenido final de ácido ascórbico tanto en frutos como en hojas, moderando el impacto de la deficiencia de GDP-L-galactosa fosforilasa.

Además, del análisis de expresión de genes relacionados al metabolismo del ácido ascórbico y la pared celular, también se analizó la expresión de genes que codifican los receptores de etileno debido a la importancia que tiene esta hormona en la maduración de frutos climatéricos como el tomate.

Como se mencionó en la introducción a este capítulo, los receptores de etileno actúan como reguladores negativos de la respuesta a etileno (Hua y Meyerowitz, 1998). Por lo tanto, una reducción en la cantidad de receptores incrementa la sensibilidad al etileno en los tejidos (Tieman y col., 2000; Hall y col., 2000), mientras que un incremento en la cantidad de receptores tiene el efecto contrario (Ciardi y col., 2000). Durante el comienzo de la maduración el etileno juega un papel esencial, sobre todo en frutos climatéricos como el tomate, sin embargo en este momento se produce también un aumento de la expresión de los receptores de etileno.

Para resolver esta aparente contradicción, varios autores determinaron el nivel de proteína de receptores más importantes durante la maduración y lo correlacionaron con el nivel de $\mathrm{ARN}_{\mathrm{m}}$ durante la maduración de los frutos. Kevany y col. (2007) cuantificaron las proteínas de los receptores de etileno SIETR3 o NR, SIETR4 y SIETR6 utilizando anticuerpos y encontraron que los niveles de $A R N_{m}$ presentaban 
Capítulo IV: Expresión de genes de enzimas clave en la vía de síntesis de ácido ascórbico y de receptores de etileno en plantas deficientes en GDP-L-Galactosa fosforilasa.

una correlación negativa con los niveles de proteína cuantificados para cada receptor durante la maduración. Estos autores concluyeron que la unión del etileno a los receptores induce la degradación del receptor. Por lo tanto, aunque los genes que codifican los receptores se inducen transcripcionalmente durante la maduración, los niveles reales de proteínas receptoras disminuyen y permanecen bajos durante la maduración (Klee y Giovannoni, 2011).

De manera contraria, otros autores reportaron una correlación positiva entre los niveles de expresión de $\mathrm{ARN}_{\mathrm{m}}$ y proteínas de receptores de etileno, durante la maduración de los frutos (Kamiyoshihara y col., 2012; Chen y col., 2019; Mata y col., 2018). Además Kamiyoshihara y col. (2012) observaron que tratamientos con etileno no alteran el contenido de proteína del receptor SIETR4 en ningún estadio de maduración, lo que pone en duda la hipótesis que sostiene la degradación de los receptores ante la unión del etileno. No obstante, el tratamiento con etileno genera la disminución del nivel de fosforilación sobre los receptores SIETR4 y SIETR3, mientras que este efecto no es observado en tratamientos con 1-MCP, indicando que la respuesta al etileno es activada cuando el nivel de fosforilación de los receptores disminuye. Estos autores observaron que el nivel de fosforilación de los receptores disminuye a medida que progresa la maduración y presenta una correlación negativa con el nivel de expresión de estos receptores.

En conjunto, estos estudios (Kevany y col., 2007; Kamiyoshihara y col., 2012) sugieren que, durante la maduración de los frutos, la señalización del etileno se modula a nivel de las proteínas receptoras, ya sea cuantitativamente ajustando su cantidad o ajustando su estado de fosforilación (Liu y col., 2015).

Por otro lado, la expresión de los receptores de etileno podría ser inducida por los niveles endógenos de etileno. Se ha observado que la aplicación de etileno induce la expresión de ETR2 en plántulas de Arabidopsis etioladas (Binder y col., 2004). 
Capítulo IV: Expresión de genes de enzimas clave en la vía de síntesis de ácido ascórbico y de receptores de etileno en plantas deficientes en GDP-L-Galactosa fosforilasa.

También se observó una inducción positiva de la expresión de ETR3 mediante la aplicación de etileno en pétalos de rosas (Xue y col., 2008).

Los mutantes deficientes en GDP-L-galactosa fosforilasa 1 presentaron un aumento del nivel de expresión génica de los receptores ETR2 y ETR3, tanto en las hojas como en los frutos en estadio pintón y rojo, con respecto al genotipo silvestre (Fig. 4.5 y 4.10 a-b). Por otro lado, como se comentó en el capítulo III, la producción de etileno en los mutantes slggp1 es mayor en el estado de maduración pintón (Capítulo III, Fig. 3.9). Futuros experimentos serán necesarios para evaluar si la deficiencia en GDP-Lgalactosa fosforilasa y de ácido ascórbico afectan la actividad de enzimas de la vía de síntesis de etileno como la ACC sintasa y la ACC oxidasa durante la maduración de los frutos.

Dado que la expresión génica de los receptores de etileno es mayor en los frutos de los mutantes slggp1 en estadios de maduración pitón y rojo, es probable que éstos tengan una mayor cantidad de proteínas receptoras en las células de sus frutos en comparación con el genotipo silvestre. Esto sugiere que los frutos de los genotipos mutantes presentarían una menor sensibilidad al etileno durante la maduración de los frutos en planta ya que, a pesar de producir más etileno en el estadio P y R (Fig. 3.10), éstos tardan más en madurar (Fig. 1.11 b) y presentan una mayor firmeza en el estadio $\mathrm{R}$, con respecto al genotipo silvestre (Fig. 3.8).

En resumen, los resultados presentados en este capítulo muestran alteraciones en la expresión de genes del metabolismo de ácido ascórbico, el metabolismo de pared celular y de la percepción de etileno, como consecuencia de la deficiencia de GDP-Lgalactosa fosforilasa en las líneas mutantes slggp1 con respecto al genotipo silvestre. 
Capítulo V

Conclusiones generales y perspectivas a futuro 


\section{Conclusiones generales}

El objetivo general planteado en esta tesis es determinar el efecto de modificaciones en el contenido de ácido ascórbico sobre el proceso de maduración de frutos. Este objetivo se llevó a cabo mediante la utilización de dos líneas independientes de plantas de tomate de la variedad Micro-Tom, cada una de ellas con una mutación sobre la secuencia del gen que codifica la enzima GDP-L-galactosa fosforilasa 1, que provoca la inactividad de esta enzima y una reducción en el contenido de ácido ascórbico.

Como resultado del análisis de la fenología, parámetros de desarrollo, análisis a nivel metabólico y de expresión génica de las líneas mutantes slggp1 y la línea silvestre se concluyó que:

- La deficiencia de GDP-L-galactosa fosforilasa 1 no afecta por igual el contenido de ácido ascórbico en los distintos órganos de la planta. Se observó una reducción del $65 \%$ en hojas, $55 \%$ en frutos, $48 \%$ en raíz y $45 \%$ en flores. Por otro lado, se observó que no afecta el estado redox del contenido total de ácido ascórbico en ninguno de los órganos analizados.

- La deficiencia en GDP-L-galactosa fosforilasa 1 genera alteraciones morfológicas y fenológicas en el desarrollo, como el aumento de la longitud de entrenudos y un retraso en la floración de los mutantes con respecto al genotipo silvestre, posiblemente como consecuencia de alteraciones hormonales.

- La deficiencia en GDP-L-galactosa fosforilasa 1 genera una reducción en la asimilación de $\mathrm{CO} 2$ del $45 \%$ determinada en mayor medida por una menor conductancia estomática que tuvo también una significativa disminución (65\%). Las reducciones de la tasa de transporte fotosintética de electrones y la fotosíntesis medida como liberación de $\mathrm{O}_{2}$ en presencia de concentraciones saturantes de $\mathrm{CO}_{2}$ fueron del 10 al 19\%, respectivamente. Estos resultados ponen en evidencia que la reducción en la actividad fotosintética está asociada principalmente a una limitación estomática y secundariamente a otros aspectos del metabolismo no estudiados en esta tesis.

- Los experimentos fuente-destino muestran que no existe una limitación en la provisión de fotoasimilados para el crecimiento de los frutos en ninguno de los genotipos.

- La deficiencia en GDP-L-galactosa fosforilasa 1 genera un mayor crecimiento individual promedio de los frutos pero no alcanza a compensar la biomasa total de los mismos respecto al genotipo silvestre. Estos resultados indican que el número de frutos determina el rendimiento en plantas de tomate.

- El suministro exógeno de ácido ascórbico demuestra que la menor productividad de biomasa de frutos en los mutantes slggp1 está asociada a una reducción en el porcentaje de cuajado. 
- La deficiencia en GDP-L-galactosa fosforilasa 1 genera un retraso en la maduración en planta de los frutos con respecto al genotipo silvestre a pesar de la mayor producción de etileno, posiblemente como consecuencia de una menor sensibilidad a esta hormona dada por una mayor expresión génica de receptores de etileno.

- La deficiencia de GDP-L-Galactosa fosforilasa 1 genera una mayor firmeza de los frutos durante la maduración en planta. Los resultados muestran una regulación positiva de la expresión de genes que se encuentran aguas arriba de esta enzima que podría involucrar un aumento de la síntesis de metabolitos destinados a la formación de polisacáridos de la pared celular.

- La deficiencia de GDP-L-Galactosa fosforilasa 1 acelera el proceso de maduración durante el almacenamiento postcosecha de frutos de tomate. Estas alteraciones de la maduración en postcosecha no pueden explicarse por una mayor tasa de producción de etileno.

- La deficiencia de GDP-L-Galactosa fosforilasa 1 altera la regulación del metabolismo de hidratos de carbono en frutos tanto durante la maduración en planta como en almacenamiento postcosecha. Esto se pone en evidencia por un aumento del contenido de azúcares no reductores en los mutantes con respecto al genotipo silvestre.

- La deficiencia de GDP-L-Galactosa fosforilasa 1 genera mecanismos de compensación de los niveles de ascórbico tanto en hojas como en frutos de tomate. Esto ocurre mediante una regulación positiva de la expresión de genes que codifican enzimas que participan en el reciclado de las formas oxidadas de ácido ascórbico y de su síntesis, particularmente en enzimas aguas arriba de la GDP-L-galactosa fosforilasa y la isoenzima GDP-L-galactosa fosforilasa 2.

- $\quad$ El ácido ascórbico participa en la regulación del proceso de maduración de los frutos y en la regulación de los procesos reproductivos en plantas de tomate, posiblemente a través de alteraciones hormonales, puesto en evidencia por el aumento de etileno en frutos y la disminución de giberelinas en flores de ambos mutantes slggp1.

Esta tesis aporta los primeros resultados de una caracterización fenológica, morfológica, metabólica y molecular, de plantas de tomate que presentan una deficiencia en ácido ascórbico como producto de una mutación en GDP-L-galactosa fosforilasa 1, la cual representa un punto clave en la síntesis de este metabolito. 


\section{Perspectivas futuras}

- Determinar la participación del ácido ascórbico en procesos fisiológicos relacionados con el establecimiento o cuajado de los frutos. Particularmente en la germinación del grano de polen, velocidad de crecimiento del tubo polínico y los cambios hormonales asociados al establecimiento del fruto de tomate luego de la fecundación.

- Evaluar el efecto del restablecimiento del contenido de ácido ascórbico, mediante suplementación exógena, en la maduración de frutos de tomate slggp1 durante el almacenamiento postcosecha. Determinar en éstos el desmantelamiento de la pared celular a lo largo de la maduración postcosecha mediante el análisis del aumento de los productos de la degradación de polisacáridos y de las actividades de enzimas como pectatoliasas, $\beta$-galactosidasa o expansinas,.

- Evaluar la capacidad de síntesis de etileno del pericarpio de frutos mutantes deficientes en GDP-L-galactosa fosforilasa mediante la aplicación del ácido aminociclopropano carboxílico, precursor del etileno, así como también los niveles de proteína de receptores de etileno a lo largo de la maduración.

- Evaluar la expresión, a lo largo de la maduración de frutos mutantes deficientes en GDP-L-galactosa fosforilasa, de genes que codifican enzimas de la vía de síntesis de etileno como SIACS, SIACO y genes que codifican factores de transcripción, como SIEINs, SIEILs, y otros implicados en la cascada de respuesta al etileno. 
Capítulo V: Conclusiones generales y Perspectivas a futuro

\section{Referencias}

Agius, F., Amaya, I., Botella, M. A., \& Valpuesta, V. (2005). Functional analysis of homologous and heterologous promoters in strawberry fruits using transient expression. Journal of Experimental Botany, 56(409), 37-46.

https://doi.org/10.1093/jxb/eri004

Agius, F., González-Lamothe, R., Caballero, J. L., Muñoz-Blanco, J., Botella, M. A., \& Valpuesta, V. (2003). Engineering increased vitamin C levels in plants by overexpression of a D-galacturonic acid reductase. Nature Biotechnology, 21(2), 177-181. https://doi.org/10.1038/nbt777

Airianah, O. B., Vreeburg, R. A. M., \& Fry, S. C. (2016). Pectic polysaccharides are attacked by hydroxyl radicals in ripening fruit: Evidence from a fluorescent fingerprinting method. Annals of Botany, 117(3), 441-455. https://doi.org/10.1093/aob/mcv192

Alexandratos, N., \& Bruinsma, J. (2012). World Agruculture Towards 2030/2050. The 2012 revision. Food and Agriculture Organization of the United Nations, (june).

Alhagdow, M., Mounet, F., Gilbert, L., Nunes-Nesi, A., Garcia, V., Just, D., ... Baldet, P. (2007). Silencing of the mitochondrial ascorbate synthesizing enzyme Lgalactono-1,4-lactone dehydrogenase affects plant and fruit development in tomato. Plant Physiology, 145(4), 1408-1422.

https://doi.org/10.1104/pp.107.106500

Ali, A., Maqbool, M., Ramachandran, S., \& Alderson, P. G. (2010). Gum arabic as a novel edible coating for enhancing shelf-life and improving postharvest quality of tomato (Solanum lycopersicum L.) fruit. Postharvest Biology and Technology, 58(1), 42-47. https://doi.org/10.1016/j.postharvbio.2010.05.005

Arrigoni, O., Arrigoni-Liso, R., \& Calabrese, G. (1977). Ascorbic acid requirement for biosynthesis of hydroxyproline-containing proteins in plants. FEBS Letters, 82(1), 135-138. https://doi.org/10.1016/0014-5793(77)80903-4

Arrigoni, O., \& De Tullio, M. C. (2000). The role of ascorbic acid in cell metabolism: Between gene-directed functions and unpredictable chemical reactions. Journal of Plant Physiology, 157(5), 481-488. https://doi.org/10.1016/S0176-1617(00)801029

Artés, F., Gómez, P. A., \& Artés-hernández, F. (2006). Modified atmosphere packaging 
Capítulo V: Conclusiones generales y Perspectivas a futuro

of fruits and vegetables. Stewart Postharvest Review, 2(5), 1-13.

https://doi.org/10.2212/spr.2006.5.2

Asada, K. (1999). THE WATER-WATER CYCLE IN CHLOROPLASTS: Scavenging of Active Oxygens and Dissipation of Excess Photons. Annual Review of Plant Physiology and Plant Molecular Biology, 50(1), 601-639.

https://doi.org/10.1146/annurev.arplant.50.1.601

Badejo, Adebanjo A., Fujikawa, Y., \& Esaka, M. (2009). Gene expression of ascorbic acid biosynthesis related enzymes of the Smirnoff-Wheeler pathway in acerola (Malpighia glabra). Journal of Plant Physiology, 166(6), 652-660.

https://doi.org/10.1016/j.jplph.2008.09.004

Badejo, Adebanjo Ayobamidele, Wada, K., Gao, Y., Maruta, T., Sawa, Y., Shigeoka, S., \& Ishikawa, T. (2012). Translocation and the alternative D-galacturonate pathway contribute to increasing the ascorbate level in ripening tomato fruits together with the D-mannose/L-galactose pathway. Journal of Experimental Botany, 63(1), 229-239. https://doi.org/10.1093/jxb/err275

Baldet, P., Bres, C., Okabe, Y., Mauxion, J. P., Just, D., Bournonville, C., ... Rothan, C. (2013). Investigating the role of vitamin C in tomato through TILLING identification of ascorbate-deficient tomato mutants. Plant Biotechnology, 30(3), 309-314. https://doi.org/10.5511/plantbiotechnology.13.0622b

Bapat, V. A., Trivedi, P. K., Ghosh, A., Sane, V. A., Ganapathi, T. R., \& Nath, P. (2010). Ripening of fleshy fruit: Molecular insight and the role of ethylene. Biotechnology Advances, 28(1), 94-107. https://doi.org/10.1016/j.biotechadv.2009.10.002

Baron, J. H. (2009). Sailors' scurvy before and after James Lind - A reassessment. Nutrition Reviews, 67(6), 315-332. https://doi.org/10.1111/j.17534887.2009.00205.x

Barro-Trastoy, D., Carrera, E., Baños, J., Palau-Rodríguez, J., Ruiz-Rivero, O., Tornero, P., ... Pérez-Amador, M. A. (2020). Regulation of ovule initiation by gibberellins and brassinosteroids in tomato and Arabidopsis: two plant species, two molecular mechanisms. Plant Journal, 102(5), 1026-1041. https://doi.org/10.1111/tpj.14684

Barth, C., De Tullio, M., \& Conklin, P. L. (2006a). The role of ascorbic acid in the control of flowering time and the onset of senescence. Journal of Experimental 
Botany, 57(8), 1657-1665. https://doi.org/10.1093/jxb/erj198

Barth, C., De Tullio, M., \& Conklin, P. L. (2006b). The role of ascorbic acid in the control of flowering time and the onset of senescence. Journal of Experimental Botany, 57(8), 1657-1665. https://doi.org/10.1093/jxb/erj198

Bartoli, C. G., Gomez, F., Gergoff, G., Guiamét, J. J., \& Puntarulo, S. (2005). Upregulation of the mitochondrial alternative oxidase pathway enhances photosynthetic electron transport under drought conditions. Journal of Experimental Botany, 56(415), 1269-1276. https://doi.org/10.1093/jxb/eri111

Bartoli, C. G., Pastori, G. M., \& Foyer, C. H. (2000). Ascorbate biosynthesis in mitochondria is linked to the electron transport chain between complexes III and IV. Plant Physiology, 123(1), 335-343. https://doi.org/10.1104/pp.123.1.335

Bartoli, C. G., Tambussi, E. A., Diego, F., \& Foyer, C. H. (2009). Control of ascorbic acid synthesis and accumulation and glutathione by the incident light red/far red ratio in Phaseolus vulgaris leaves. FEBS Letters, 583(1), 118-122. https://doi.org/10.1016/j.febslet.2008.11.034

Bartoli, C. G., Yu, J., Gómez, F., Fernández, L., Mclntosh, L., \& Foyer, C. H. (2006). Inter-relationships between light and respiration in the control of ascorbic acid synthesis and accumulation in Arabidopsis thaliana leaves. Journal of Experimental Botany, 57(8), 1621-1631. https://doi.org/10.1093/jxb/erl005

Bewley, D. J., Burton, R. A., Morohashi, Y., \& Fincher, G. B. (1997). Molecular cloning of a cDNA encoding a $(1 \rightarrow 4)-\beta$-mannan endohydrolase from the seeds of germinated tomato (Lycopersicon esculentum). Planta, 203(4), 454-459. https://doi.org/10.1007/s004250050214

Biale, J. B. (1961). The Postharvest Biochemistry Of Tropical And Subtropical Fruits. Advances in Food Research, 10(C), 293-354. https://doi.org/10.1016/S00652628(08)60140-8

Bielski, B. H. J. (1982). Chemistry of Ascorbic Acid Radicals. Advances, 11973, 81100.

Binder, B. M., O’Malley, R. C., Wang, W., Moore, J. M., Parks, B. M., Spalding, E. P., \& Bleecker, A. B. (2004). Arabidopsis seedling growth response and recovery to ethylene. A kinetic analysis. Plant Physiology, 136(2), 2913-2920.

https://doi.org/10.1104/pp.104.050369 
Bishop, G. J., Harrison, K., \& Jones, J. D. G. (1996). The tomato Dwarf gene isolated by heterologous transposon tagging encodes the first member of a new cytochrome P450 family. Plant Cell, 8(6), 959-969. https://doi.org/10.1105/tpc.8.6.959

Bishop, G. J., Nomura, T., Yokota, T., Harrison, K., Noguchi, T., Fujioka, I., ... Kamiya, Y. (1999). The tomato DWARF enzyme catalyses C-6 oxidation in brassinosteroid biosynthesis. Proceedings of the National Academy of Sciences of the United States of America, 96(4), 1761-1766. https://doi.org/10.1073/pnas.96.4.1761

Blankenship, S. M., \& Dole, J. M. (2003). 1-Methylcyclopropene: A review. Postharvest Biology and Technology, 28(1), 1-25. https://doi.org/10.1016/S09255214(02)00246-6

Bombarely, A., Menda, N., Tecle, I. Y., Buels, R. M., Strickler, S., Fischer-York, T., ... Mueller, L. A. (2011). The sol genomics network (solgenomics.net): Growing tomatoes using Perl. Nucleic Acids Research, 39(SUPPL. 1), 1149-1155. https://doi.org/10.1093/nar/gkq866

Bonin, C. P., Potter, I., Vanzin, G. F., \& Reiter, W. D. (1997). The MUR1 gene of Arabidopsis thaliana encodes an isoform of GDP-D-mannose-4,6-dehydratase, catalyzing the first step in the de novo synthesis of GDP-L-fucose. Proceedings of the National Academy of Sciences of the United States of America, 94(5), 20852090. https://doi.org/10.1073/pnas.94.5.2085

Borguini, R. G., \& da Silva Torres, E. A. F. (2009). Tomatoes and tomato products as dietary sources of antioxidants. Food Reviews International, 25(4), 313-325. https://doi.org/10.1080/87559120903155859

Bouzayen, M., Latché, A., Nath, P., \& Pech, J. C. (2010). Mechanism of Fruit Ripening. Developmental Biology, 1. https://doi.org/http://dx.doi.org/10.1007/978-3-64202301-9 To

Brummell, D. A. (2006). Cell wall disassembly in ripening fruit. Functional Plant Biology, 33(2), 103-119. https://doi.org/10.1071/FP05234

Brummell, D. A., \& Harpster, M. H. (2001). Cell wall metabolism in fruit softening and quality and its manipulation in transgenic plants. Plant Molecular Biology, 47(1-2), 311-339. https://doi.org/10.1023/A:1010656104304

Bulley, S., \& Laing, W. (2016). The regulation of ascorbate biosynthesis. Current 
Capítulo V: Conclusiones generales y Perspectivas a futuro

Opinion in Plant Biology, 33(vitamin C), 15-22.

https://doi.org/10.1016/j.pbi.2016.04.010

Bulley, S. M., Rassam, M., Hoser, D., Otto, W., Schünemann, N., Wright, M., ... Laing, W. (2009). Gene expression studies in kiwifruit and gene over-expression in Arabidopsis indicates that GDP-L-galactose guanyltransferase is a major control point of vitamin C biosynthesis. Journal of Experimental Botany, 60(3), 765-778. https://doi.org/10.1093/jxb/ern327

Burg, P. S., \& Burg, A. E. (1965). Ethylene Action and the Ripening of Fruits. Science, 148(May), 1190-1196.

Burns, J. . (1957). Missing Step in MAn, Monkey and Guinea Pig required for the Biosynthesis of L-Ascorbic Acid, september(4585), 553.

Cano, A., Acosta, M., \& Arnao, M. B. (2003). Hydrophilic and lipophilic antioxidant activity changes during on-vine ripening of tomatoes (Lycopersicon esculentum Mill.). Postharvest Biology and Technology, 28(1), 59-65. https://doi.org/10.1016/S0925-5214(02)00141-2

Cara, B., \& Giovannoni, J. J. (2008). Molecular biology of ethylene during tomato fruit development and maturation. Plant Science, 175(1-2), 106-113. https://doi.org/10.1016/j.plantsci.2008.03.021

Carr, A. C., \& Maggini, S. (2017). Vitamin C and immune function. Nutrients, 9(11), 125. https://doi.org/10.3390/nu9111211

Caviglia, M., Mazorra Morales, L. M., Concellón, A., Gergoff Grozeff, G. E., Wilson, M., Foyer, C. H., \& Bartoli, C. G. (2018). Ethylene signaling triggered by low concentrations of ascorbic acid regulates biomass accumulation in Arabidopsis thaliana. Free Radical Biology and Medicine, 122(February), 130-136. https://doi.org/10.1016/j.freeradbiomed.2018.01.032

Chen, Y., Rofidal, V., Hem, S., Gil, J., Nosarzewska, J., Berger, N., ... Chervin, C. (2019). Targeted Proteomics Allows Quantification of Ethylene Receptors and Reveals SIETR3 Accumulation in Never-Ripe Tomatoes. Frontiers in Plant Science, 10(August), 1-10. https://doi.org/10.3389/fpls.2019.01054

Chen, Z., \& Gallie, D. R. (2004). The ascorbic acid redox state controls guard cell signaling and stomatal movement. Plant Cell, 16(5), 1143-1162.

https://doi.org/10.1105/tpc.021584 
Chen, Z., Young, T. E., Ling, J., Chang, S. C., \& Gallie, D. R. (2003). Increasing vitamin $\mathrm{C}$ content of plants through enhanced ascorbate recycling. Proceedings of the National Academy of Sciences of the United States of America, 100(6), 35253530. https://doi.org/10.1073/pnas.0635176100

Cheng, T. S., Floros, J. D., Shewfelt, R. L., \& Chang, C. J. (1988). The Effect of HighTemperature Stress on Ripening of Tomatoes (Lycopersicon esculentum). Journal of Plant Physiology, 132(4), 459-464. https://doi.org/10.1016/S01761617(88)80063-4

Chhun, T., Aya, K., Asano, K., Yamamoto, E., Morinaka, Y., Watanabe, M., ... Ueguchi-Tanaka, M. (2007). Gibberellin regulates pollen viability and pollen tube growth in rice. Plant Cell, 19(12), 3876-3888. https://doi.org/10.1105/tpc.107.054759

Ciardi, J. A., Tieman, D. M., Lund, S. T., Jones, J. B., Stall, R. E., Klee, H. J., \& Box, P. O. (2000). Response to Xanthomonas campestris pv . vesicatoria in Tomato Involves Regulation of Ethylene Receptor Gene Expression 1.

Conklin, P. L. (2001). Recent advances in the role and biosynthesis of ascorbic acid in plants. Plant, Cell and Environment, 24(4), 383-394. https://doi.org/10.1046/j.1365-3040.2001.00686.x

Conklin, P. L., \& Barth, C. (2004). Ascorbic acid, a familiar small molecule intertwined in the response of plants to ozone, pathogens, and the onset of senescence. Plant, Cell and Environment, 27(8), 959-970. https://doi.org/10.1111/j.13653040.2004.01203.x

Conklin, P. L., Saracco, S. A., Norris, S. R., \& Last, R. L. (2000). Identification of Ascorbic Acid-Deficient Arabidopsis thaliana Mutants. Genomics, 154(february), 847-856.

Conklin, Patricia L., Norris, S. R., Wheeler, G. L., Williams, E. H., Smirnoff, N., \& Last, R. L. (1999). Genetic evidence for the role of GDP-mannose in plant ascorbic acid (vitamin C) biosynthesis. Proceedings of the National Academy of Sciences of the United States of America, 96(7), 4198-4203. https://doi.org/10.1073/pnas.96.7.4198

Contreras-Magaña, E., Arroyo-Pozos, H., Ayala-Arreola, J., Sánchez-Del-Castillo, F., \& Del Carmen Moreno-Pérez, E. (2013). Caracterización morfológica de la diferenciación floral en tomate (Solanum lycopersicum L.). Revista Chapingo, 
Capítulo V: Conclusiones generales y Perspectivas a futuro

Serie Horticultura, 19(4 SPEC.), 59-70.

https://doi.org/10.5154/r.rchsh.2012.02.010

Crisosto, C. H., Ferguson, L., \& Rodriguez-Bermejo, J. (2015). Emerging postharvest technologies. Acta Horticulturae, 1079, 47-52.

https://doi.org/10.17660/ActaHortic.2015.1079.3

Cruz-Rus, E., Amaya, I., Sánchez-Sevilla, J. F., Botella, M. A., \& Valpuesta, V. (2011). Regulation of L-ascorbic acid content in strawberry fruits. Journal of Experimental Botany, 62(12), 4191-4201. https://doi.org/10.1093/jxb/err122

Cruz-Rus, E., Botella, M. A., Valpuesta, V., \& Gomez-Jimenez, M. C. (2010). Analysis of genes involved in l-ascorbic acid biosynthesis during growth and ripening of grape berries. Journal of Plant Physiology, 167(9), 739-748.

https://doi.org/10.1016/j.jplph.2009.12.017

Dan, Y., Fei, Z., \& Rothan, C. (2007). Genes, Genomes and Genomics MicroTom-A New Model System for Plant Genomics. Genes, Genomes, and Genomics, 1, 167-179. Retrieved from

http://www.globalsciencebooks.info/Online/GSBOnline/images/0712/GGG_1(2)/G GG_1(2)167-179o.pdf

Davey, M. W., Van Montagu, M., Inzé, D., Sanmartin, M., Kanellis, A., Smirnoff, N., ... Fletcher, J. (2000). Plant L-ascorbic acid: Chemistry, function, metabolism, bioavailability and effects of processing. Journal of the Science of Food and Agriculture, 80(7), 825-860. https://doi.org/10.1002/(SICI)10970010(20000515)80:7<825::AID-JSFA598>3.0.CO;2-6

De Simone, A., Hubbard, R., De La Torre, N. V., Velappan, Y., Wilson, M., Considine, M. J., ... Foyer, C. H. (2017). Redox Changes during the Cell Cycle in the Embryonic Root Meristem of Arabidopsis thaliana. Antioxidants and Redox Signaling, 27(18), 1505-1519. https://doi.org/10.1089/ars.2016.6959

De Tullio, M. C., Paciolla, C., Dalla Vecchia, F., Rascio, N., D’Emerico, S., De Gara, L., ... Arrigoni, O. (1999). Changes in onion root development induced by the inhibition of peptidyl-prolyl hydroxylase and influence of the ascorbate system on cell division and elongation. Planta, 209(4), 424-434.

https://doi.org/10.1007/s004250050745

De Vries, H. S. M., Harren, F. J. M., \& Reuss, J. (1995). In situ, real-time monitoring of wound-induced ethylene in cherry tomatoes by two infrared laser-driven systems. 
Capítulo V: Conclusiones generales y Perspectivas a futuro

Postharvest Biology and Technology, 6(3-4), 275-285.

https://doi.org/10.1016/0925-5214(95)00006-R

Demmig-Adams, B., \& Adams, W. W. (1996). The role of xanthophyll cycle carotenoids in the protection of photosynthesis. Trends in Plant Science, 1(1), 21-26. https://doi.org/10.1016/S1360-1385(96)80019-7

Dong, J. G., Fernandez-Maculet, J. C., \& Yang, S. F. (1992). Purification and characterization of 1-aminocyclopropane-1-carboxylate oxidase from apple fruit. Proceedings of the National Academy of Sciences of the United States of America, 89(20), 9789-9793. https://doi.org/10.1073/pnas.89.20.9789

Dowdle, J., Ishikawa, T., Gatzek, S., Rolinski, S., \& Smirnoff, N. (2007a). Two genes in Arabidopsis thaliana encoding GDP-L-galactose phosphorylase are required for ascorbate biosynthesis and seedling viability. Plant Journal, 52(4), 673-689. https://doi.org/10.1111/j.1365-313X.2007.03266.x

Dowdle, J., Ishikawa, T., Gatzek, S., Rolinski, S., \& Smirnoff, N. (2007b). Two genes in Arabidopsis thaliana encoding GDP-L-galactose phosphorylase are required for ascorbate biosynthesis and seedling viability. Plant Journal, 52(4), 673-689. https://doi.org/10.1111/j.1365-313X.2007.03266.x

Eltelib, H. A., Badejo, A. A., Fujikawa, Y., \& Esaka, M. (2011). Gene expression of monodehydroascorbate reductase and dehydroascorbate reductase during fruit ripening and in response to environmental stresses in acerola (Malpighia glabra). Journal of Plant Physiology, 168(6), 619-627. https://doi.org/10.1016/j.jplph.2010.09.003

Emmanuel, E., \& Levy, A. A. (2002). Tomato mutants as tools for functional genomics. Current Opinion in Plant Biology, 5(2), 112-117. https://doi.org/10.1016/S13695266(02)00237-6

Endres, S., \& Tenhaken, R. (2009). Myoinositol oxygenase controls the level of myoinositol in Arabidopsis, but does not increase ascorbic acid. Plant Physiology, 149(2), 1042-1049. https://doi.org/10.1104/pp.108.130948

Feller, C., Bleiholder, H., Buhr, L., Hack, H., Hess, M., Klose, R., ... Weber, E. (1995). Phanologische Entwicklungsstadien von Gemusepflanzen II. Fruchtgemuse und Hulsenfruchte. Nachrichtenblatt Des Deutschen Pflanzenschutzdienstes, 47(9), 217-232. 
Fernandez, A. I., Viron, N., Alhagdow, M., Karimi, M., Jones, M., Amsellem, Z., ... Hilson, P. (2009). Flexible tools for gene expression and silencing in tomato. Plant Physiology, 151(4), 1729-1740. https://doi.org/10.1104/pp.109.147546

Foyer, C. H., \& Halliwell, B. (1976). The presence of glutathione and glutathione reductase in chloroplasts: A proposed role in ascorbic acid metabolism. Planta, 133(1), 21-25. https://doi.org/10.1007/BF00386001

Foyer, C. H., \& Noctor, G. (2011). Ascorbate and glutathione: The heart of the redox hub. Plant Physiology, 155(1), 2-18. https://doi.org/10.1104/pp.110.167569

Foyer, C. H., \& Shigeoka, S. (2011). Understanding oxidative stress and antioxidant functions to enhance photosynthesis. Plant Physiology, 155(1), 93-100. https://doi.org/10.1104/pp.110.166181

Franceschi, V. R., \& Tarlyn, N. M. (2002). L-Ascorbic acid is accumulated in source leaf phloem and transported to sink tissues in plants. Plant Physiology, 130(2), 649656. https://doi.org/10.1104/pp.007062

Frusciante, L., Carli, P., Ercolano, M. R., Pernice, R., Di Matteo, A., Fogliano, V., \& Pellegrini, N. (2007). Antioxidant nutritional quality of tomato. Molecular Nutrition and Food Research, 51(5), 609-617. https://doi.org/10.1002/mnfr.200600158

Fry, S C. (1986). Cross-Linking of Matrix Polymers in the Growing Cell Walls of Angiosperms. Annual Review of Plant Physiology, 37(1), 165-186. https://doi.org/10.1146/annurev.pp.37.060186.001121

Fry, Stephen C. (2004). Primary cell wall metabolism: Tracking the careers of wall polymers in living plant cells. New Phytologist, 161(3), 641-675. https://doi.org/10.1111/j.1469-8137.2004.00980.x

Gallie, D. R. (2015). Ethylene receptors in plants - Why so much complexity? F1000Prime Reports, 7(April), 1-12. https://doi.org/10.12703/P7-39

Ganeva, D., Grozeva, S. Y., \& Pevicharova, G. T. (2019). Effect of reduced irrigation on flowering, fruit set and yield of indeterminate tomato. International Journal of Recent Technology and Engineering, 8(2 Special Issue 4), 932-936. https://doi.org/10.35940/ijrte.B1185.0782S419

Gao, Y., Nishikawa, H., Badejo, A. A., Shibata, H., Sawa, Y., Nakagawa, T., ... Ishikawa, T. (2011). Expression of aspartyl protease and C3HC4-type RING zinc 
Capítulo V: Conclusiones generales y Perspectivas a futuro

finger genes are responsive to ascorbic acid in Arabidopsis thaliana. Journal of Experimental Botany, 62(10), 3647-3657. https://doi.org/10.1093/jxb/err068

Genty, B., Briantais, J. M., \& Baker, N. R. (1989). The relationship between the quantum yield of photosynthetic electron transport and quenching of chlorophyll fluorescence. Biochimica et Biophysica Acta - General Subjects, 990(1), 87-92. https://doi.org/10.1016/S0304-4165(89)80016-9

Gergoff, G., Chaves, A., \& Bartoli, C. G. (2010). Ethylene regulates ascorbic acid content during dark-induced leaf senescence. Plant Science, 178(2), 207-212. https://doi.org/10.1016/j.plantsci.2009.12.003

Gest, N., Gautier, H., \& Stevens, R. (2013). Ascorbate as seen through plant evolution: the rise of a successful molecule. Journal of Experimental Botany, 63(2), 695709. https://doi.org/10.1093/jxb/err313

Gilbert, L., Alhagdow, M., Nunes-Nesi, A., Quemener, B., Guillon, F., Bouchet, B., ... Baldet, P. (2009). GDP-d-mannose 3,5-epimerase (GME) plays a key role at the intersection of ascorbate and non-cellulosic cell-wall biosynthesis in tomato. Plant Journal, 60(3), 499-508. https://doi.org/10.1111/j.1365-313X.2009.03972.x

Gillaspy, G., Ben-David, H., \& Gruissem, W. (1993). Fruits: A Developmental Perspective. The Plant Cell, 5(10), 1439. https://doi.org/10.2307/3869794

Giovannoni, J. J. (2007). Fruit ripening mutants yield insights into ripening control. Current Opinion in Plant Biology, 10(3), 283-289. https://doi.org/10.1016/j.pbi.2007.04.008

Giovannoni, J., Nguyen, C., Ampofo, B., Zhong, S., \& Fei, Z. (2017). The Epigenome and Transcriptional Dynamics of Fruit Ripening. Annual Review of Plant Biology, 68(1), 61-84. https://doi.org/10.1146/annurev-arplant-042916-040906

Gomez, M. D., Barro-Trastoy, D., Escoms, E., Saura-Sańchez, M., Sańchez, I., Briones-Moreno, A., ... Perez-Amador, M. A. (2018). Gibberellins negatively modulate ovule number in plants. Development (Cambridge), 145(13), 1-11. https://doi.org/10.1242/dev.163865

González-Aguilera, K. L., Saad, C. F., Chávez Montes, R. A., Alves-Ferreira, M., \& de Folter, S. (2016). Selection of reference genes for quantitative real-time RT-PCR studies in tomato fruit of the genotype MT-Rg1. Frontiers in Plant Science, 7(September), 1-8. https://doi.org/10.3389/fpls.2016.01386 
Capítulo V: Conclusiones generales y Perspectivas a futuro

Gorres, K. L., \& Raines, R. T. (2010). Prolyl 4-hydroxylase. Critical Reviews in Biochemistry and Molecular Biology (Vol. 45).

https://doi.org/10.3109/10409231003627991

Grantz, A. A., Brummell, D. A., \& Bennett, A. B. (1995). Ascorbate free radical reductase mRNA levels are induced by wounding. Plant Physiology, 108(1), 411418. https://doi.org/10.1104/pp.108.1.411

Grozeff, G. E. G., \& Bartoli, C. G. (2013). Participation of ascorbic acid in the dormancy establishment of poplar lateral branch buds. Journal of Forest Research, 19(2), 301-304. https://doi.org/10.1007/s10310-013-0410-5

Hall, A. E., \& Bleecker, A. B. (2003). Analysis of combinatorial loss-of-function mutants in the Arabidopsis ethylene receptors reveals that the ers 1 etr1 double mutant has severe developmental defects that are ein2 dependent. Plant Cell, 15(9), 20322041. https://doi.org/10.1105/tpc.013060

Harker, F. R., Redgwell, R. J., Hallett, I. C., Murray, S. H., \& Carter, G. (1997). Texture of Fresh Fruit. Horticultural Reviews (Vol. 20). https://doi.org/10.1002/9780470650646.ch2

Hemavathi, Upadhyaya, C. P., Young, K. E., Akula, N., Kim, H. soon, Heung, J. J., ... Park, S. W. (2009). Over-expression of strawberry d-galacturonic acid reductase in potato leads to accumulation of vitamin $C$ with enhanced abiotic stress tolerance. Plant Science, 177(6), 659-667. https://doi.org/10.1016/j.plantsci.2009.08.004

Heuvelink, E. (2018). TOMATOES 2nd Edition. CROP ANDRODUCTION SCIENCE IN HORTICULTURE.

Holst, A., \& Froelich, T. (1907). Experimental studies relating to ship beri beri and scurvy. Nutrition Reviews, 32(9), 273-275. https://doi.org/10.1111/j.17534887.1974.tb00973.x

Hossain, M. A., Munné-Bosch, S., Burritt, D. J., Diaz-Vivancos, P., Fijita, M., \& Lorence, A. (2017). Ascorbic Acid in Plant Growth, Development and Stress Tolerance. Ascorbic Acid in Plant Growth, Development and Stress Tolerance.

Hua, J., \& Meyerowitz, E. M. (1998). Ethylene responses are negatively regulated by a receptor gene family in Arabidopsis thaliana. Cell, 94(2), 261-271.

https://doi.org/10.1016/S0092-8674(00)81425-7 
Imai, T., Ban, Y., Terakami, S., Yamamoto, T., \& Moriguchi, T. (2009). L-Ascorbate biosynthesis in peach: Cloning of six I-galactose pathway-related genes and their expression during peach fruit development. Physiologia Plantarum, 136(2), 139149. https://doi.org/10.1111/j.1399-3054.2009.01213.x

Ioannidi, E., Kalamaki, M. S., Engineer, C., Pateraki, I., Alexandrou, D., Mellidou, I., ... Kanellis, A. K. (2009). Expression profiling of ascorbic acid-related genes during tomato fruit development and ripening and in response to stress conditions. Journal of Experimental Botany, 60(2), 663-678. https://doi.org/10.1093/jxb/ern322

Jain, A. K., \& Nessler, C. L. (2000). Metabolic engineering of an alternative pathway for ascorbic acid biosynthesis in plants. Molecular Breeding, 6(1), 73-78. https://doi.org/10.1023/A:1009680818138

Jiang, K., Meng, Y. L., \& Feldman, L. J. (2003). Quiescent center formation in maize roots is associated with an auxin- regulated oxidizing environment, 1429-1438. https://doi.org/10.1242/dev.00359

Jiménez, A., Gómez, J. M., Navarro, E., \& Sevilla, F. (2002). Changes in the antioxidative systems in mitochondria during ripening of pepper fruits. Plant Physiology and Biochemistry, 40(6-8), 515-520. https://doi.org/10.1016/S09819428(02)01424-9

Kamiyoshihara, Y., Tieman, D. M., Huber, D. J., \& Klee, H. J. (2012). Ligand-induced alterations in the phosphorylation state of ethylene receptors in tomato fruit. Plant Physiology, 160(1), 488-497. https://doi.org/10.1104/pp.112.202820

Kato, Y. (1995). Responses of Plant Cells to Gibberellin. Botanical Gazette, 117(1), 16-24.

Kerchev, P. I., Pellny, T. K., Vivancos, P. D., Kiddle, G., Hedden, P., Driscoll, S., ... Foyer, C. H. (2011). The transcription factor ABi4 Is required for the ascorbic aciddependent regulation of growth and regulation of jasmonate-dependent defense signaling pathways in arabidopsis. Plant Cell, 23(9), 3319-3334. https://doi.org/10.1105/tpc.111.090100

Kerk, N. M., \& Feldman, L. J. (1995). A biochemical model for the initiation and maintenance of the quiescent center: Implications for organization of root meristems. Development, 121(9), 2825-2833. 
Kevany, B. M., Tieman, D. M., Taylor, M. G., Cin, V. D., \& Klee, H. J. (2007). Ethylene receptor degradation controls the timing of ripening in tomato fruit. Plant Journal, 51(3), 458-467. https://doi.org/10.1111/j.1365-313X.2007.03170.x

Kka, N., Rookes, J., \& Cahill, D. (2018). The influence of ascorbic acid on root growth and the root apical meristem in Arabidopsis thaliana. Plant Physiology and Biochemistry, 129(February), 323-330.

https://doi.org/10.1016/j.plaphy.2018.05.031

Klee, H. J. (2004). Ethylene signal transduction. Moving beyond arabidopsis. Plant Physiology, 135(2), 660-667. https://doi.org/10.1104/pp.104.040998

Klee, H. J., \& Giovannoni, J. J. (2011). Genetics and control of tomato fruit ripening and quality attributes. Annual Review of Genetics, 45, 41-59. https://doi.org/10.1146/annurev-genet-110410-132507

Klee, H., \& Tieman, D. (2002). The tomato ethylene receptor gene family: Form and function. Physiologia Plantarum, 115(3), 336-341. https://doi.org/10.1034/j.13993054.2002.1150302.x

Kotchoni, S. O., Larrimore, K. E., Mukherjee, M., Kempinski, C. F., \& Barth, C. (2009). Alterations in the endogenous ascorbic acid content affect flowering time in Arabidopsis. Plant Physiology, 149(2), 803-815. https://doi.org/10.1104/pp.108.132324

Krebs, B. Y. H. A. (1954). Lind Bicentenary Symposium. Nutrition Reviews, 12(5), 160160. https://doi.org/10.1111/j.1753-4887.1954.tb03255.x

Laing, W. A., Martínez-Sánchez, M., Wright, M. A., Bulley, S. M., Brewster, D., Dare, A. P., ... Hellens, R. P. (2015a). An upstream open reading frame is essential for feedback regulation of ascorbate biosynthesis in arabidopsis. Plant Cell, 27(3), 772-786. https://doi.org/10.1105/tpc.114.133777

Laing, W. A., Martínez-Sánchez, M., Wright, M. A., Bulley, S. M., Brewster, D., Dare, A. P., ... Hellens, R. P. (2015b). An upstream open reading frame is essential for feedback regulation of ascorbate biosynthesis in arabidopsis. Plant Cell, 27(3), 772-786. https://doi.org/10.1105/tpc.114.133777

Laing, W. A., Wright, M. A., Cooney, J., \& Bulley, S. M. (2007). The missing step of the L-galactose pathway of ascorbate biosynthesis in plants, an L-galactose guanyltransferase, increases leaf ascorbate content. Proceedings of the National 
Capítulo V: Conclusiones generales y Perspectivas a futuro

Academy of Sciences of the United States of America, 104(22), 9534-9539. https://doi.org/10.1073/pnas.0701625104

Lashbrook, C. C., Tieman, D. M., \& Klee, H. J. (1998). Differential regulation of the tomato ETR gene family throughout plant development. Plant Journal, 15(2), 243252. https://doi.org/10.1046/j.1365-313X.1998.00202.x

Lee, S. K., \& Kader, A. A. (2000). Preharvest and postharvest factors influencing vitamin C content of horticultural crops. Postharvest Biology and Technology, 20(3), 207-220. https://doi.org/10.1016/S0925-5214(00)00133-2

Leggett, J. E., \& Frere, M. H. (1971). Growth and Nutrient Uptake by Soybean Plants in Nutrient Solutions of Graded Concentrations. Plant Physiology, 48(4), 457-460. https://doi.org/10.1104/pp.48.4.457

Li, M., Ma, F., Shang, P., Zhang, M., Hou, C., \& Liang, D. (2009). Influence of light on ascorbate formation and metabolism in apple fruits. Planta, 230(1), 39-51. https://doi.org/10.1007/s00425-009-0925-3

Li, Q., Li, Y., Li, C., \& Yu, X. (2012). Enhanced ascorbic acid accumulation through overexpression of dehydroascorbate reductase confers tolerance to methyl viologen and salt stresses in tomato. Czech Journal of Genetics and Plant Breeding, 48(2), 74-86. https://doi.org/10.17221/100/2011-cjgpb

Li, T., Yang, X., Yu, Y., Si, X., Zhai, X., Zhang, H., .. Xu, C. (2018). Domestication of wild tomato is accelerated by genome editing. Nature Biotechnology, 36(12), 1160-1163. https://doi.org/10.1038/nbt.4273

Lim, B., Smirnoff, N., Cobbett, C. S., \& Golz, J. F. (2016). Ascorbate-deficient VTC2 mutants in arabidopsis do not exhibit decreased growth. Frontiers in Plant Science, 7(2016JULY), 1-9. https://doi.org/10.3389/fpls.2016.01025

Lim, M. Y., Jeong, B. R., Jung, M., \& Harn, C. H. (2016). Transgenic tomato plants expressing strawberry d-galacturonic acid reductase gene display enhanced tolerance to abiotic stresses. Plant Biotechnology Reports, 10(2), 105-116. https://doi.org/10.1007/s11816-016-0392-9

LISO, R., INNOCENTI, A. M., BITONTI, M. B., \& ARRIGONI, O. (1988). Ascorbic acidinduced progression of quiescent centre cells from $\mathrm{G} 1$ to $\mathrm{S}$ phase. New Phytologist, 110(4), 469-471. https://doi.org/10.1111/j.1469-8137.1988.tb00284.x 
Liso, R., Tullio, M. C. De, Ciraci, S., Balestrini, R., Rocca, N. La, Bruno, L., ... Ecologia, D. (2004). Localization of ascorbic acid, ascorbic acid oxidase, and glutathione in roots of Cucurbita maxima L ., 55(408), 2589-2597.

https://doi.org/10.1093/jxb/erh262

Liu, M., Pirrello, J., Chervin, C., Roustan, J. P., \& Bouzayen, M. (2015). Ethylene control of fruit ripening: Revisiting the complex network of transcriptional regulation. Plant Physiology, 169(4), 2380-2390.

https://doi.org/10.1104/pp.15.01361

Lorence, A., Chevone, B. I., Mendes, P., \& Nessler, C. L. (2004). myo-Inositol Oxygenase Offers a Possible Entry Point into Plant Ascorbate Biosynthesis. English, 134(April), 1-338. https://doi.org/10.1104/pp.103.033936.sapiens

Lovdal, T., \& Lillo, C. (2009). Reference gene selection for quantitative real-time PCR normalization in tomato subjected to nitrogen, cold, and light stress. Analytical Biochemistry, 387(2), 238-242. https://doi.org/10.1016/j.ab.2009.01.024

Mapson, L. W., Isherwood, F. A., \& Chen, Y. T. (1954). Biological synthesis of Lascorbic acid: the conversion of L-galactono-gamma-lactone into L-ascorbic acid by plant mitochondria. The Biochemical Journal, 56(1), 21-28. https://doi.org/10.1042/bj0560021

Martí, E., Gisbert, C., Bishop, G. J., Dixon, M. S., \& García-Martínez, J. L. (2006). Genetic and physiological characterization of tomato cv. Micro-Tom. Journal of Experimental Botany, 57(9), 2037-2047. https://doi.org/10.1093/jxb/erj154

Martinez-madrid, M. C., Serrano, M., Riquelme, F., \& Romojaro, F. (1996). POLYAMINES , ABSCISIC ACID AND ETHYLENE PRODUCTION IN TOMATO FRUIT, 43(2), 6-9.

Masciarelli, O., Llanes, A., \& Luna, V. (2014). A new PGPR co-inoculated with Bradyrhizobium japonicum enhances soybean nodulation. Microbiological Research, 169(7-8), 609-615. https://doi.org/10.1016/j.micres.2013.10.001

Mata, C. I., Van de Poel, B., Hertog, M. L. A. T. M., Tran, D., \& Nicolai, B. M. (2018). Transcription analysis of the ethylene receptor and CTR genes in tomato: The effects of on and off-vine ripening and 1-MCP. Postharvest Biology and Technology, 140(December 2017), 67-75.

https://doi.org/10.1016/j.postharvbio.2018.02.014 
Matsukura, C., Aoki, K., Fukuda, N., Mizoguchi, T., Asamizu, E., Saito, T., ... Ezura, H. (2008). Comprehensive Resources for Tomato Functional Genomics Based on the Miniature Model Tomato Micro-Tom. Current Genomics, 9(7), 436-443. https://doi.org/10.2174/138920208786241225

Mazorra Morales, L. M., Senn, M. E., Grozeff, G. E. G., Fanello, D. D., Carrión, C. A., Núñez, M., ... Bartoli, C. G. (2014). Impact of brassinosteroids and ethylene on ascorbic acid accumulation in tomato leaves. Plant Physiology and Biochemistry, 74, 315-322. https://doi.org/10.1016/j.plaphy.2013.11.021

McMurchie, E. J., McGlasson, W. B., \& Eaks, I. L. (1972). Treatment of Fruit with Propylene gives Information about the biogenesis of Ethylene. Nature New Biology, 237(May), 235-237.

Meier, U. (2001). Estadios de las plantas mono-y dicotyledóneas. CFIBAS (Centro Federal de Investigaciones Biologicas Para Agricultura y Silvicultura), (2), 149.

Meissner, R., Jacobson, Y., Melamed, S., Levyatuv, S., Shalev, G., Ashri, A., ... Levy, A. (1997). A new model system for tomato genetics. The Plant Journal.

Melino, V. J., Soole, K. L., \& Ford, C. M. (2009). Ascorbate metabolism and the developmental demand for tartaric and oxalic acids in ripening grape berries. BMC Plant Biology, 9, 1-14. https://doi.org/10.1186/1471-2229-9-145

Mellidou, I., Keulemans, J., Kanellis, A. K., \& Davey, M. W. (2012). Regulation of fruit ascorbic acid concentrations during ripening in high and low vitamin $\mathrm{C}$ tomato cultivars. BMC Plant Biology, 12(1), 1. https://doi.org/10.1186/1471-2229-12-239

Mignolli, F., Vidoz, M. L., Picciarelli, P., \& Mariotti, L. (2019). Gibberellins modulate auxin responses during tomato (Solanum lycopersicum L.) fruit development. Physiologia Plantarum, 165(4), 768-779. https://doi.org/10.1111/ppl.12770

Mounet-Gilbert, L., Dumont, M., Ferrand, C., Bournonville, C., Monier, A., Jorly, J., ... Baldet, P. (2016). Two tomato GDP-D-mannose epimerase isoforms involved in ascorbate biosynthesis play specific roles in cell wall biosynthesis and development. Journal of Experimental Botany, 67(15), 4767-4777. https://doi.org/10.1093/jxb/erw260

Müller-Moulé, P., Conklin, P. L., \& Niyogi, K. K. (2002). Ascorbate deficiency can limit violaxanthin de-epoxidase activity in vivo. Plant Physiology, 128(3), 970-977. https://doi.org/10.1104/pp.010924 
Nakatsuka, A., Shiomi, S., Kubo, Y., \& Inaba, A. (1997). Expression and internal feedback regulation of ACC synthase and ACC oxidase genes in ripening tomato fruit. Plant and Cell Physiology, 38(10), 1103-1110. https://doi.org/10.1093/oxfordjournals.pcp.a029094

Nguyen-Quoc, B., \& Foyer, C. H. (2001). A role for "futile cycles" involving invertase and sucrose synthase in sucrose metabolism of tomato fruit. Journal of Experimental Botany, 52(358), 881-889. https://doi.org/10.1093/jexbot/52.358.881

Niki, E. (1991). Action of ascorbic acid as scavenger of active and stable oxigen radicals. American Society for Clinical Nutrition, 54(May), 1119S-24S.

Nishikimi, M., Fukuyama, R., Minoshima, S., Shimizu, N., \& Yagi, K. (1994). Cloning and chromosomal mapping of the human nonfunctional gene for L- gulono- $Y$ lactone oxidase, the enzyme for L-ascorbic acid biosynthesis missing in man. Journal of Biological Chemistry, 269(18), 13685-13688.

Noctor, G. (2006). Metabolic signalling in defence and stress: The central roles of soluble redox couples. Plant, Cell and Environment, 29(3), 409-425. https://doi.org/10.1111/j.1365-3040.2005.01476.x

Noctor, G., \& Foyer, C. H. (1998). Ascorbate and Glutathione: Keeping Active Oxygen under Control. Annual Review of Plant Biology, 49, 249-279. https://doi.org/10.1146/annurev.arplant.49.1.249

Osorio, S., Alba, R., Damasceno, C. M. B., Lopez-Casado, G., Lohse, M., Zanor, M. I., ... Fernie, A. R. (2011). Systems biology of tomato fruit development: Combined transcript, protein, and metabolite analysis of tomato transcription factor (nor, rin) and ethylene receptor $(\mathrm{Nr})$ mutants reveals novel regulatory interactions. Plant Physiology, 157(1), 405-425. https://doi.org/10.1104/pp.111.175463

Padh, H. (1990). Cellular functions of ascorbic acid. Biochemistry and Cell Biology, 68(10), 1166-1173. https://doi.org/10.1139/o90-173

Pastori, G. M., Kiddle, G., Antoniw, J., Bernard, S., Veljovic-Jovanovic, S., Verrier, P. J., ... Foyer, C. H. (2003). Leaf vitamin C contents modulate plant defense transcripts and regulate genes that control development through hormone signaling. Plant Cell, 15(4), 939-951. https://doi.org/10.1105/tpc.010538

Pavet, V., Olmos, E., Kiddle, G., Mowla, S., Kumar, S., Antoniw, J., ... Foyer, C. H. (2005). Ascorbic acid deficiency activates cell death and disease resistance 
Capítulo V: Conclusiones generales y Perspectivas a futuro

responses in Arabidopsis. Plant Physiology, 139(3), 1291-1303.

https://doi.org/10.1104/pp.105.067686

Plumb, W., Townsend, A. J., Rasool, B., Alomrani, S., Razak, N., Karpinska, B., ... Foyer, C. H. (2018). Ascorbate-mediated regulation of growth, photoprotection, and photoinhibition in Arabidopsis thaliana. Journal of Experimental Botany, 69(11), 2823-2835. https://doi.org/10.1093/jxb/ery170

Pnueli, L., Carmel-Goren, L., Hareven, D., Gutfinger, T., Alvarez, J., Ganal, M., ... Lifschitz, E. (1998). The SELF-PRUNING gene of tomato regulates vegetative to reproductive switching of sympodial meristems and is the ortholog of CEN and TFL1. Development, 125(11), 1979-1989.

Potters, G., Horemans, N., Caubergs, R. J., \& Asard, H. (2020). Ascorbate and Dehydroascorbate Influence Cell Cycle Progression in a Tobacco Cell Suspension 1.

Radzio, J. A., Lorence, A., Chevone, B. I., \& Nessler, C. L. (2003). L-Gulono-1,4lactone oxidase expression rescues vitamin C-deficient Arabidopsis (vtc) mutants. Plant Molecular Biology, 53(6), 837-844. https://doi.org/10.1023/B:PLAN.0000023671.99451.1d

Rick, C. M. (1991). Tomato paste: A concentrated review of genetic highlights from the beginnings to the advent of molecular genetics. Genetics, 128(1), 1-5.

Rose, J., Catalá, C., Gonzalez-Carranza, Z. H., \& Roberts, J. A. (2003). Cell Wall Disassembly. Annual Plant Reviews online (Vol. 8). https://doi.org/10.1002/9781119312994.apr0075

Ruan, Y. L., Patrick, J. W., Bouzayen, M., Osorio, S., \& Fernie, A. R. (2012). Molecular regulation of seed and fruit set. Trends in Plant Science, 17(11), 656-665. https://doi.org/10.1016/j.tplants.2012.06.005

Saladié, M., Matas, A. J., Isaacson, T., Jenks, M. A., Goodwin, S. M., Niklas, K. J., ... Rose, J. K. C. (2007). A reevaluation of the key factors that influence tomato fruit softening and integrity. Plant Physiology, 144(2), 1012-1028. https://doi.org/10.1104/pp.107.097477

Sato, S., Peet, M. M., \& Gardner, R. G. (2004). Altered flower retention and developmental patterns in nine tomato cultivars under elevated temperature. Scientia Horticulturae, 101(1-2), 95-101. 
Capítulo V: Conclusiones generales y Perspectivas a futuro

https://doi.org/10.1016/j.scienta.2003.10.008

Schimmeyer, J., Bock, R., \& Meyer, E. H. (2016). I-Galactono-1,4-lactone dehydrogenase is an assembly factor of the membrane arm of mitochondrial complex I in Arabidopsis. Plant Molecular Biology, 90(1-2), 117-126. https://doi.org/10.1007/s11103-015-0400-4

Senn, M. E., Gergoff Grozeff, G. E., Alegre, M. L., Barrile, F., De Tullio, M. C., \& Bartoli, C. G. (2016). Effect of mitochondrial ascorbic acid synthesis on photosynthesis. Plant Physiology and Biochemistry, 104, 29-35. https://doi.org/10.1016/j.plaphy.2016.03.012

Serrani, J. C., Fos, M., \& Atares, A. (2007). Effect of gibberellin and auxin on parthenocarpic fruit growth induction in the cv Micro-Tom of tomato. Journal of Plant Growth Regulation, 26(3), 211-221. https://doi.org/10.1007/s00344-0079014-7

Serrani, J. C., Sanjuán, R., Ruiz-Rivero, O., Fos, M., \& García-Martínez, J. L. (2007). Gibberellin regulation of fruit set and growth in tomato. Plant Physiology, 145(1), 246-257. https://doi.org/10.1104/pp.107.098335

Seymour, G. B., Ostergaard, L., Chapman, N. H., Knapp, S., \& Martin, C. (2013). Fruit development and ripening. Annual Review of Plant Biology, 64, 219-241. https://doi.org/10.1146/annurev-arplant-050312-120057

Sharma, M. K., \& Buettner, G. R. (1993). Interaction of vitamin C and vitamin E during free radical stress in plasma: An ESR study. Free Radical Biology and Medicine, 14(6), 649-653. https://doi.org/10.1016/0891-5849(93)90146-L

Shinozaki, Y., Hao, S., Kojima, M., Sakakibara, H., Ozeki-lida, Y., Zheng, Y., ... Ariizumi, T. (2015). Ethylene suppresses tomato (Solanum lycopersicum) fruit set through modification of gibberellin metabolism. Plant Journal, 83(2), 237-251. https://doi.org/10.1111/tpj.12882

Shoulders, M. D., \& Raines, R. T. (2009). Collagen structure and stability. Annual Review of Biochemistry, 78, 929-958.

https://doi.org/10.1146/annurev.biochem.77.032207.120833

Singh, D. P., Jermakow, A. M., \& Swain, S. M. (2002). Gibberellins are required for seed development and pollen tube growth in Arabidopsis. Plant Cell, 14(12), 3133-3147. https://doi.org/10.1105/tpc.003046 
Sisler, E. C., \& Serek, M. (1997). Inhibitors of ethylene responses in plants at the receptor level: Recent developments. Physiologia Plantarum, 100(3), 577-582. https://doi.org/10.1034/j.1399-3054.1997.1000320.x

Smirnoff, N. (1996). The function and metabolism of ascorbic acid in plants. Annals of Botany, 78(6), 661-669. https://doi.org/10.1006/anbo.1996.0175

Smirnoff, N. (2000). Ascorbic acid: metabolism and functions of a multi-facetted molecule. Physiology and Metabolism, 3(3), 229-235. https://doi.org/10.1016/s1369-5266(00)80070-9

Smirnoff, N. (2018). Ascorbic acid metabolism and functions: A comparison of plants and mammals. Free Radical Biology and Medicine, 122(March), 116-129. https://doi.org/10.1016/j.freeradbiomed.2018.03.033

Smirnoff, N., \& Wheeler, G. L. (2000). Ascorbic acid in plants: Biosynthesis and function. Critical Reviews in Plant Sciences, 19(4), 267-290. https://doi.org/10.1080/07352680091139231

Sommer-Knudsen, J., Clarke, A. E., \& Bacic, A. (1997). Proline- and hydroxyprolinerich gene products in the sexual tissues of flowers. Sexual Plant Reproduction, 10(5), 253-260. https://doi.org/10.1007/s004970050095

Stasolla, C., Lam, M. S. W., \& Yeung, E. C. (2006). Exogenous applications of ascorbic acid enhance shoot apical meristem growth and induce shoot organogenesis in germinating white spruce (Picea glauca) somatic embryos. International Journal of Plant Sciences, 167(3), 429-436. https://doi.org/10.1086/501506

Steelheart, C., Alegre, M. L., Vera Bahima, J., Senn, M. E., Simontacchi, M., Bartoli, C. G., \& Gergoff Grozeff, G. E. (2019). Nitric oxide improves the effect of 1methylcyclopropene extending the tomato (Lycopersicum esculentum L.)fruit postharvest life. Scientia Horticulturae, 255(March), 193-201. https://doi.org/10.1016/j.scienta.2019.04.035

Sturgeon, B. E., Sipe, H. J., Barr, D. P., Corbett, J. T., Martinez, J. G., \& Mason, R. P. (1998). The fate of the oxidizing tyrosyl radical in the presence of glutathione and ascorbate: Implications for the radical sink hypothesis. Journal of Biological Chemistry, 273(46), 30116-30121. https://doi.org/10.1074/jbc.273.46.30116

Suekawa, M., Fujikawa, Y., Inada, S., Murano, A., \& Esaka, M. (2016a). Gene expression and promoter analysis of a novel tomato aldo-keto reductase in 
Capítulo V: Conclusiones generales y Perspectivas a futuro

response to environmental stresses. Journal of Plant Physiology, 200, 35-44. https://doi.org/10.1016/j.jplph.2016.05.015

Suekawa, M., Fujikawa, Y., Inada, S., Murano, A., \& Esaka, M. (2016b). Gene expression and promoter analysis of a novel tomato aldo-keto reductase in response to environmental stresses. Journal of Plant Physiology, 200, 35-44. https://doi.org/10.1016/j.jplph.2016.05.015

Sun, J., Loboda, T., Sung, S. J. S., \& Black, C. C. (1992). Sucrose synthase in wild tomato, lycopersicon chmielewskii, and tomato fruit sink strength. Plant Physiology, 98(3), 1163-1169. https://doi.org/10.1104/pp.98.3.1163

Svirbely, J. L., \& Szent-Gyorgyi, A. (1932). The chemical nature of vitamin C. Science, 75(1944), 357-359. https://doi.org/10.1126/science.75.1944.357-a

Szent-Györgyi, A. (1928). Observations on the function of peroxidase systems and the chemistry of the adrenal cortex. Biochemical Journal, 22(6), 1387-1409. https://doi.org/10.1042/bj0221387

Tabata, K., Ôba, K., Suzuki, K., \& Esaka, M. (2001). Generation and properties of ascorbic acid-deficient transgenic tobacco cells expressing antisense RNA for Lgalactono-1,4-lactone dehydrogenase. The Plant Journal, 27(2), 139-148. https://doi.org/10.1046/j.1365-313X.2001.01074.x

Taiz, L., Zeiguer, E., Moller, I. M., \& Murphy, A. (2015). Plant Physiology and Development, 6th editio, 761. https://doi.org/10.2307/4115602

Tanaka, A., \& Fujita, K. (1974). Nutrio-physiological studies on the tomato plant IV. Source-sink relationship and structure of the source-sink unit. Soil Science and Plant Nutrition, 20(3), 305-315. https://doi.org/10.1080/00380768.1974.10433252

Tang, N., Deng, W., Hu, G., Hu, N., \& Li, Z. (2015). Transcriptome profiling reveals the regulatory mechanism underlying pollination dependent and parthenocarpic fruit set mainly mediated by auxin and gibberellin. PLOS ONE, 10(4), 1-22. https://doi.org/10.1371/journal.pone.0125355

The Tomato Genome Consortium. (2012). The tomato genome sequence provides insights into fleshy fruit evolution. Nature, 485(7400), 635-641. https://doi.org/10.1038/nature11119

Tieman, D. M., Taylor, M. G., Ciardi, J. A., \& Klee, H. J. (2000). The tomato ethylene 
receptors NR and LeETR4 are negative regulators of ethylene response and exhibit functional compensation within a multigene family. Proceedings of the National Academy of Sciences of the United States of America, 97(10), 56635668. https://doi.org/10.1073/pnas.090550597

Traber, M. G., \& Stevens, J. F. (2011). Vitamins C and E: Beneficial effects from a mechanistic perspective. Free Radical Biology and Medicine, 51(5), 1000-1013. https://doi.org/10.1016/j.freeradbiomed.2011.05.017

Tsuchiya, M., Sakaki, H., \& Yoshino, J. (1985). Room temperature observation of differential negative resistance in an alas/gaas/alas resonant tunneling diode. Japanese Journal of Applied Physics, 24(6 A), L466-L468.

https://doi.org/10.1143/JJAP.24.L466

Walker, D. (1997). The Use of the Oxygen Electrode and Fluorescence Probes in Simple Measurements of Photosynthesis. University of Sheffield, 72(1), 101.

Wang, F., Sanz, A., Brenner, M. L., \& Smith, A. (1993). Sucrose synthase, starch accumulation, and tomato fruit sink strength. Plant Physiology, 101(1), 321-327. https://doi.org/10.1104/pp.101.1.321

Wang, K., Shao, X., Gong, Y., Zhu, Y., Wang, H., Zhang, X., .. Lu, H. (2013). The metabolism of soluble carbohydrates related to chilling injury in peach fruit exposed to cold stress. Postharvest Biology and Technology, 86, 53-61. https://doi.org/10.1016/j.postharvbio.2013.06.020

Wang, L. Y., Li, D., Deng, Y. S., Lv, W., \& Meng, Q. W. (2013). Antisense-mediated depletion of tomato GDP-l-galactose phosphorylase increases susceptibility to chilling stress. Journal of Plant Physiology, 170(3), 303-314. https://doi.org/10.1016/j.jplph.2012.10.015

Watada, A. E., Herner, R. C., Kader, A. A., Roman, R. J., \& Staby, G. L. (1984). Terminology for the description of developmental stages of horticultural crops. HortScience, 19(February), 1-2. Retrieved from http://agris.fao.org/agrissearch/search.do?recordID=US19850003056

Welty, N., Radovich, C., Meulia, T., \& Van Der Knaap, E. (2007). Inflorescence development in two tomato species. Canadian Journal of Botany, 85(1), 111-118. https://doi.org/10.1139/B06-154

Wheeler, G. L., Jones, M. A., \& Smirnoff, N. (1998). The biosynthetic pathway of 
Capítulo V: Conclusiones generales y Perspectivas a futuro

vitamin C in higher plants. Nature, 393(6683), 365-369.

https://doi.org/10.1038/30728

Wolucka, B. A., \& Van Montagu, M. (2003). GDP-Mannose 3',5'-Epimerase Forms GDP-L-gulose, a Putative Intermediate for the de Novo Biosynthesis of Vitamin C in Plants. Journal of Biological Chemistry, 278(48), 47483-47490.

https://doi.org/10.1074/jbc.M309135200

Wudiri, B. B., \& Henderson, D. W. (1985). Effects of water stress on flowering and fruit set in processing-tomatoes. Scientia Horticulturae, 27(3-4), 189-198. https://doi.org/10.1016/0304-4238(85)90022-6

Xue, J., Li, Y., Tan, H., Yang, F., Ma, N., \& Gao, J. (2008). Expression of ethylene biosynthetic and receptor genes in rose floral tissues during ethylene-enhanced flower opening. Journal of Experimental Botany, 59(8), 2161-2169. https://doi.org/10.1093/jxb/ern078

Yahia, E. M., \& Carrillo-Lopez, A. (2019). Postharvest Physiology and Biochemistry of Fruits and Vegetables. Elsevier.

Yang, D. Y., Li, M., Ma, N. N., Yang, X. H., \& Meng, Q. W. (2017). Tomato SIGGPLIKE gene participates in plant responses to chilling stress and pathogenic infection. Plant Physiology and Biochemistry, 112, 218-226. https://doi.org/10.1016/j.plaphy.2017.01.006

Yoshimura, K., \& Ishikawa, T. (2018). Chemistry and metabolism of ascorbic acid in plants. Ascorbic Acid in Plant Growth, Development and Stress Tolerance, (July), 1-23. https://doi.org/10.1007/978-3-319-74057-7_1

Zhang, C., Liu, J., Zhang, Y., Cai, X., Gong, P., Zhang, J., ... Ye, Z. (2011). Overexpression of SIGMEs leads to ascorbate accumulation with enhanced oxidative stress, cold, and salt tolerance in tomato. Plant Cell Reports, 30(3), 389398. https://doi.org/10.1007/s00299-010-0939-0

Zhang, Y. (2013). Ascorbic Acid in Plants biosynthesis, regulation and Enhancement. Springer. https://doi.org/10.1007/978-1-4614-4127-4

Zhong, S., Lin, Z., \& Grierson, D. (2008). Tomato ethylene receptor-CTR interactions: Visualization of NEVER-RIPE interactions with multiple CTRs at the endoplasmic reticulum. Journal of Experimental Botany, 59(4), 965-972.

https://doi.org/10.1093/jxb/ern021 
Capítulo V: Conclusiones generales y Perspectivas a futuro

Zou, L., Li, H., Ouyang, B., Zhang, J., \& Ye, Z. (2006). Cloning and mapping of genes involved in tomato ascorbic acid biosynthesis and metabolism. Plant Science, 170(1), 120-127. https://doi.org/10.1016/j.plantsci.2005.08.009 